\title{
Environmental regulation and low-carbon development
}

Citation for published version (APA):

Blohmke, J. (2016). Environmental regulation and low-carbon development: a study into regulatory determinants, innovation systems and economic outcomes. [Doctoral Thesis, Maastricht University]. Datawyse / Universitaire Pers Maastricht. https://doi.org/10.26481/dis.20160422jb

Document status and date:

Published: 01/01/2016

DOI:

10.26481/dis.20160422jb

Document Version:

Publisher's PDF, also known as Version of record

\section{Please check the document version of this publication:}

- A submitted manuscript is the version of the article upon submission and before peer-review. There can be important differences between the submitted version and the official published version of record.

People interested in the research are advised to contact the author for the final version of the publication, or visit the DOI to the publisher's website.

- The final author version and the galley proof are versions of the publication after peer review.

- The final published version features the final layout of the paper including the volume, issue and page numbers.

Link to publication

\footnotetext{
General rights rights.

- You may freely distribute the URL identifying the publication in the public portal. please follow below link for the End User Agreement:

www.umlib.nl/taverne-license

Take down policy

If you believe that this document breaches copyright please contact us at:

repository@maastrichtuniversity.nl

providing details and we will investigate your claim.
}

Copyright and moral rights for the publications made accessible in the public portal are retained by the authors and/or other copyright owners and it is a condition of accessing publications that users recognise and abide by the legal requirements associated with these

- Users may download and print one copy of any publication from the public portal for the purpose of private study or research.

- You may not further distribute the material or use it for any profit-making activity or commercial gain

If the publication is distributed under the terms of Article $25 \mathrm{fa}$ of the Dutch Copyright Act, indicated by the "Taverne" license above, 


\section{Environmental regulation and low-carbon development}

A study into regulatory determinants, innovation systems and economic outcomes

Julian Blohmke 
Copyright Julian Blohmke, Maastricht 2016

Production print Datawyse | Universitaire Pers Maastricht ISBN 9789461595577

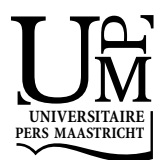




\title{
Environmental regulation and low-carbon development
}

\section{A study into regulatory determinants, innovation systems and economic outcomes}

\author{
DISSERTATION \\ to obtain the degree of Doctor at Maastricht University, \\ on the authority of the Rector Magnificus Prof. Dr. L.L.G. Soete, \\ in accordance with the decision of the Board of Deans, \\ to be defended in public on Friday 22 April 2016 at 14:45 hours
}

by

Julian Blohmke 


\section{Supervisor}

Prof. Dr. R.P.M. Kemp

\section{Co-promoter}

Prof. Dr. Manfred Wiebelt (University of Kiel)

\section{Assessment Committee}

Prof. Dr. Pierre Mohnen (chairman)

Dr. Tilman Altenburg (German Development Institute)

Prof. Dr. Georgeta Vidican (University of Erlangen-Nuremberg)

Dr. Thomas Ziesemer 


\section{Table of Contents}

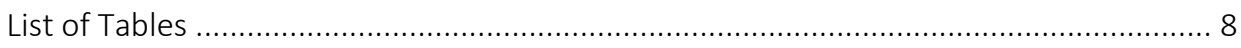

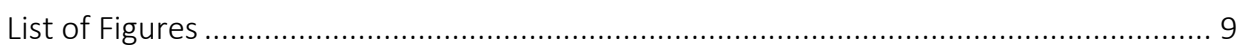

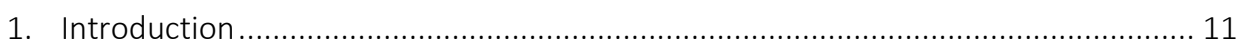

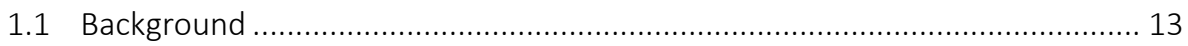

1.2 Objective and relevance of the research.................................................... 15

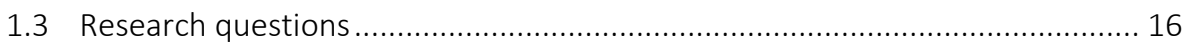

1.4 Fields of research, methodology and outline ................................................ 18

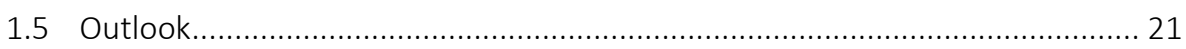

2. Disentangling the causal structure behind environmental regulation ...................... 25

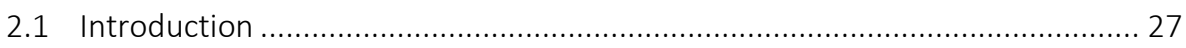

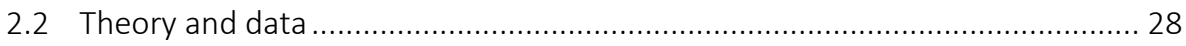

2.2.1 Political-institutional framework conditions ....................................... 31

2.2.2 Cognitive-informational framework conditions................................. 32

2.2.3 Dependent variables: National environmental policy output and international environmental governance ......................................... 34

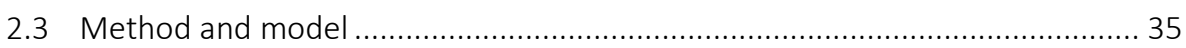

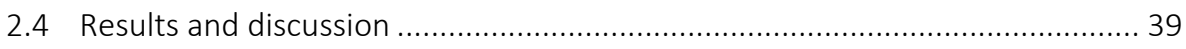

2.4.1 Reflective measurement model ..................................................... 39

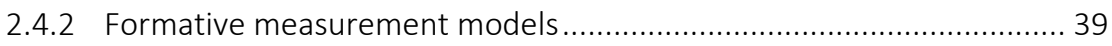

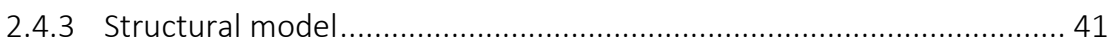

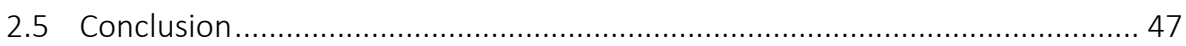

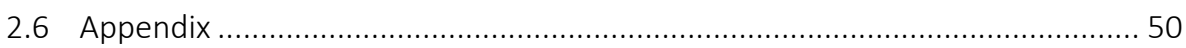

3. Technology complexity, technology transfer mechanisms and sustainable development.

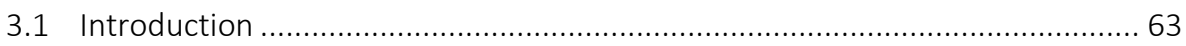

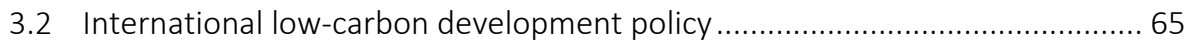

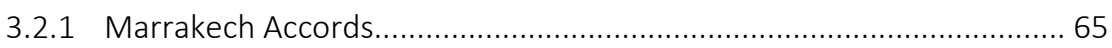

3.2.2 The Clean Development Mechanism .............................................. 66

3.2.3 Nationally Appropriate Mitigation Actions .............................................6 66

3.3 Theory: innovation, technology transfer and technology complexity ..............69

3.4 Technology complexity and economic development potential ....................... 72

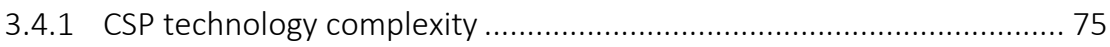

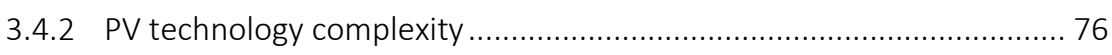

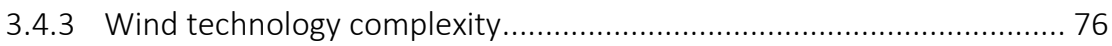

3.5 Implication for technology-specific climate policy design ............................... 77

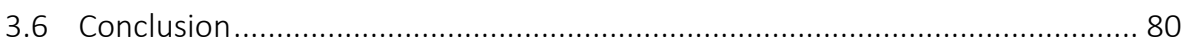


4. Renewable energy technology adoption in developing countries and how technology suppliers can strengthen fragmented innovation systems. 85

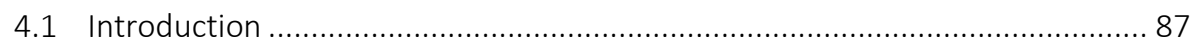

4.2 The innovation system approach - structures and functions ......................... 89

4.3 Analysis of the RET innovation system functions in Kenya ............................. 92

4.3.1 Entrepreneurial activity and knowledge development ...................... 92

4.3.2 Knowledge diffusion and networks..................................................... 95

4.3.3 Market formation and resource mobilisation..................................... 97

4.4 The way forward: Barriers and the strengthening of a fragmented

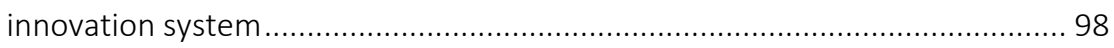

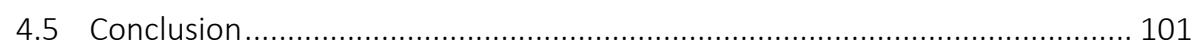

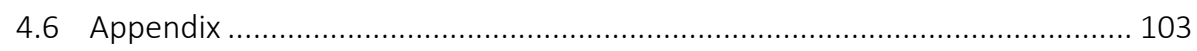

5. The adoption of energy efficiency measures by firms in Africa: case studies of cassava processing in Nigeria and maize milling in Kenya ................................... 105

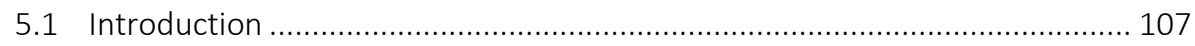

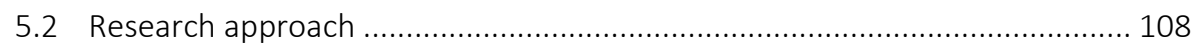

5.3 The conceptual framework for studying the adoption of energy efficiency measures in the context of agro-industrial sectors in sub-Saharan Africa ..... 108

5.4 Cassava processing in Nigeria and maize milling in Kenya ............................ 110

5.4.1 Cassava processing in Nigeria ................................................... 110

5.4.2 Maize milling in Kenya.......................................................... 110

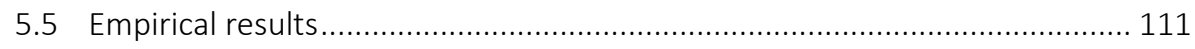

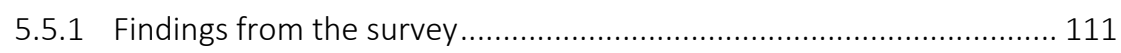

5.5.2 Case study illustrations............................................................ 119

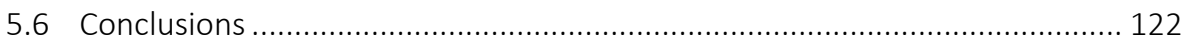

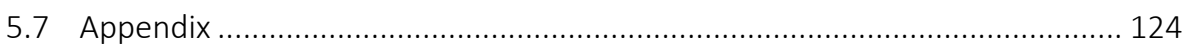

6. Regional and sectoral economic impacts of an integrated renewable energy transition across the Mediterranean in Europe, the Middle East and North

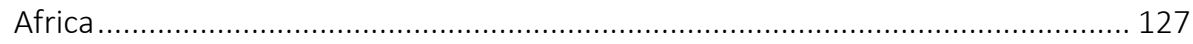

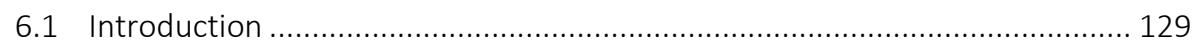

6.2 An EUMENA renewable energy vision towards 2050 ................................... 131

6.3 Assumptions and quantitative model...................................................... 136

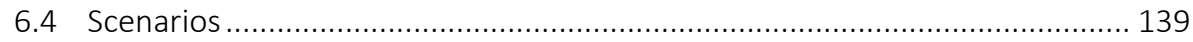

6.5 Results: Economic impacts of renewable energy transition ........................... 140

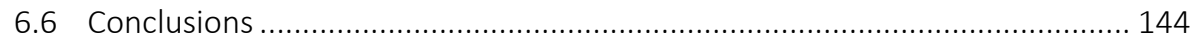

6.7 Appendix: The renewable energy version of the DART model ..................... 145 
7. Harnessing the sun and wind for economic development? An economy-wide assessment for Egypt

7.1 Introduction

7.1.1 Energy sector status quo

7.1.2 Potential for renewables

7.1.3 Egypt's Renewable Energy Strategy

7.2 Methods: Modelling the economy-wide effects of investing in renewable energy

7.2.1 The database: A renewable-energy-focused Social Accounting Matrix155

7.2.2 The model: A Dynamic Computable General Equilibrium Model........ 158

7.3 Results and discussion: Potential impacts of investing in renewable energy projects

7.3.1 Renewables in the economy-wide context.................................... 161

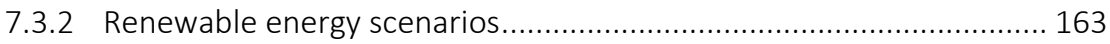

7.3.3 Impacts on economic growth and employment................................ 163

7.3.4 Impacts on household incomes and poverty ................................... 172

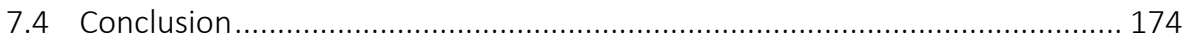

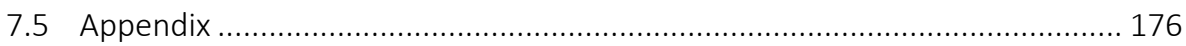

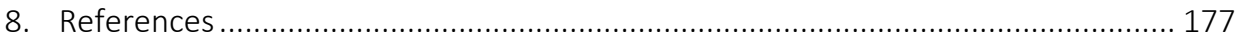

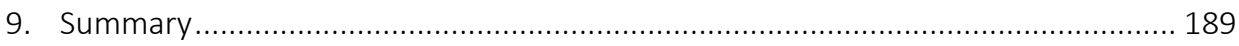

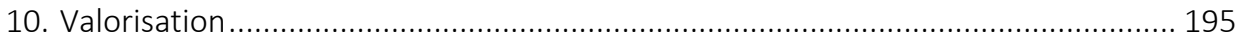

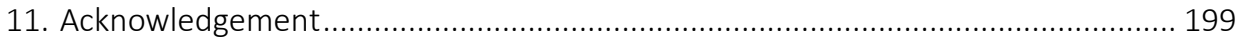

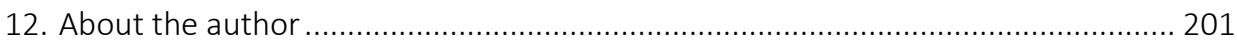




\section{List of Tables}

Table 1: Formative measurement model results.......................................................... 40

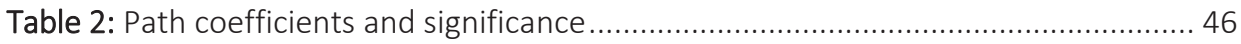

Table 3: Collinearity assessment of constructs.......................................................... 46

Table 4: Effect size, and predictive relevance of constructs ........................................ 47

Table 5: Political-institutional framework conditions.................................................. 50

Table 6: Cognitive-informational framework conditions......................................... 51

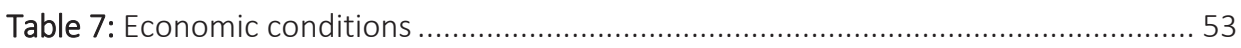

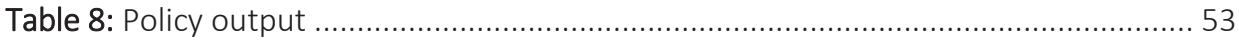

Table 9: Table of countries used in main model........................................................... 54

Table 10: Complexity of Technology Component and Value Share of Investment......... 84

Table 11: Development of technology sourcing ........................................................ 93

Table 12: Commitment by technology providers to improve RET .................................. 94

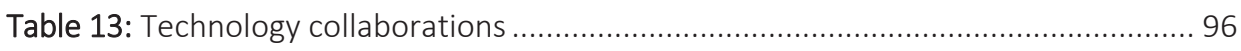

Table 14: Provision of technical support and training ................................................. 96

Table 15: Provision of financial support to clients....................................................... 98

Table 16: Barriers to RETs adoption according to suppliers/distributors/marketers .... 100

Table 17: Sources and components of energy efficiency packages ............................ 114

Table 18: Importance of consultancy /external advisors for energy efficiency project success .......................................................................... 116

Table 19: Factors affecting the adoption of energy efficiency measures ...................... 118

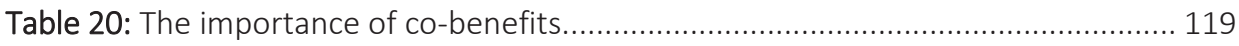

Table 21: Basic characteristics of the respondent firms.............................................. 124

Table 22: Regional, sectoral and factoral aggregation in DART .................................. 147

Table 23: Production cost estimates for renewable equipment manufacturing

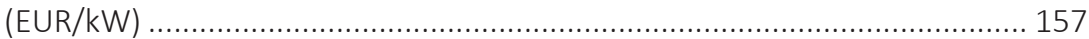

Table 24: Production cost estimates for renewable electricity generation $(\mathrm{EUR} / \mathrm{kW})$

Table 25: Benchmark cost shares for renewable equipment manufacturing, all other manufacturing, and electricity generation...................................... 157

Table 26: Structure of Egypt's economy, 2008........................................................ 162

Table 27: Scenarios for Renewable Energy development in Egypt by 2020 .................. 163

Table 28: Core macroeconomic assumptions and results, 2008-2020 ........................ 164

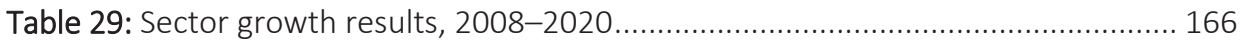

Table 30: Employment results, 2008-2020 .......................................................... 170

Table 31: Household per capita equivalent variation results, 2008-2020 .................... 172

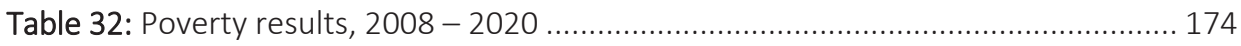

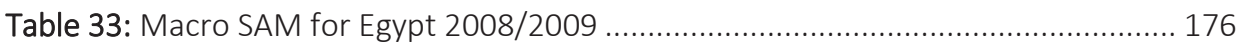




\section{List of Figures}

Figure 1: Measurement model and structural model .................................................. 37

Figure 2: Determinants of environmental policy conditions .................................... 38

Figure 3: Path coefficient of the main model ........................................................... 43

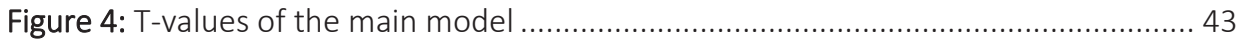

Figure 5: Path coefficients for model variant A ...................................................... 55

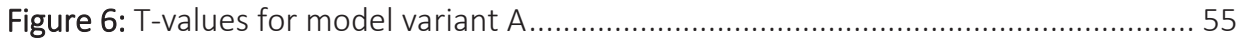

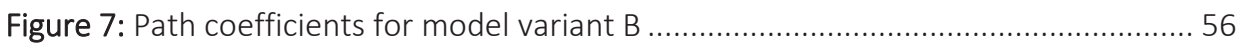

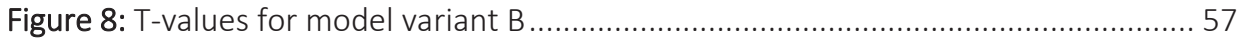

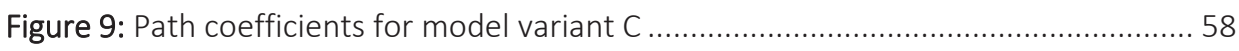

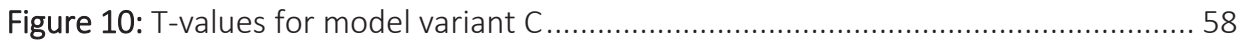

Figure 11: Path coefficients for model variant D .................................................... 59

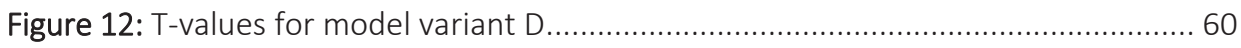

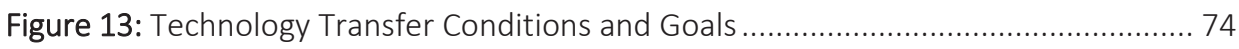

Figure 14: Technologies and component complexity................................................ 79

Figure 15: CSP Technology Complexity and Value of Investment .................................. 82

Figure 16: PV Technology Complexity and Value of Investment.................................... 83

Figure 17: Wind Technology Complexity and Value of Investment .............................. 84

Figure 18: Sample of RET suppliers/distributors/marketers surveyed in Kenya ............ 103

Figure 19: Overview of energy efficiency measures adopted .................................... 112

Figure 20: Origin of energy efficiency technologies ............................................ 113

Figure 21: Organisations involved in successful energy efficiency projects ................. 116

Figure 22: Learning about energy efficiency measures through visits of previous

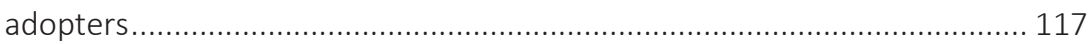

Figure 23: Electricity production, installed capacity and investment in solar and

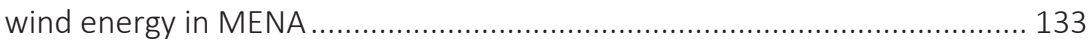

Figure 24: Electricity production, installed capacity and investment in solar and

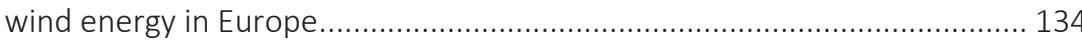

Figure 25: Range of LCOE for different technologies in MENA and Europe

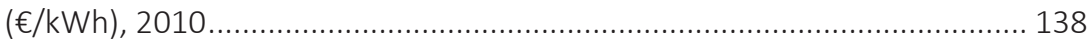

Figure 26: Schematic representation of the policy scenarios and reference ................. 139

Figure 27: Changes in real income under a current policy background (percentage change with respect to the current policy scenario)

Figure 28: Total subsidies in solar and wind electricity production (share of GDP) ...... 142

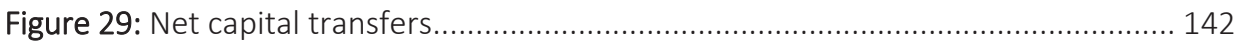

Figure 30: Changes in real income under a climate policy background (percentage change with respect to the climate policy scenario)

Figure 31: Change in per capita equivalent variation from baseline scenario by quintile, $2010-2020$ 

CHAPTER 1

Introduction 



\subsection{Background}

The consequences of anthropogenic climate change are among the greatest challenges of the future of humankind. Climate change potentially has devastating impacts on human health and on the natural environment. Every world region will be hit by the consequences of rising atmospheric temperature, particularly the least-developed countries, which often have are least able to adapt to the impacts of climate change, and thus will be affected the most severely.

Human behaviour and its consequences on the climate, the effects on humans, and potential benefits of avoiding climate change, have been given high priority in national and global politics and recognised as important areas of inquiry in the academic literature. In order to change policies and unlock countries from high carbon infrastructure pathways, it is important to develop arguments in support of a shift towards low-carbon growth pathways. Thoroughly studying the economic benefits of a transition towards more climate friendly economies, detecting drivers in the environmental policymaking process, and unravelling specific facilitating factors for the diffusion of climate mitigation technology will help to highlight the enabling circumstances for low-carbon growth pathways.

Such a low-carbon transition envisions a global shift to the use of low carbon technologies. Low-carbon development has been on the international political agenda since the 1970s, with increasing emphasis in the late 1990s when the UN climate policy process gained momentum (Urban \& Nordensvard, 2013). Economic development on a low-carbon intensity pathway is a sub-set of the field of sustainable development, which means to "meet the needs of the past without compromising the ability of future generations to meet their own needs" (World Commission on Environment and Development, 1987). Its goal is sustainable development, but its focus is on climate change and not broader environmental sustainability. On the other hand, green growth is the broader definition of environmentally sustainable growth (OECD, 2011a). It comprises fostering economic growth, while ensuring that the natural environment can continue to provide the resources and services required for human well-being. Yet, low-carbon development is not only about low-carbon economic growth, but also about equitable, socially-friendly growth, beyond mere economic growth in the classical sense.

This dissertation is concerned with climate friendly economic growth, while society and actors are also emphasised. Thus, low-carbon development is the preferred analytical perspective guiding the subsequent research. In the low-carbon development debate, special attention is given to energy and its contribution to climate change. The environmental imperative to reduce $\mathrm{CO}_{2}$ emissions from the energy sector requires a large-scale transformation of the sector in favour of renewable energy and energy efficiency technologies (OECD, 2011b). Population and economic growth, especially in emerging economies, lead to a rapid increase in global energy demand. The energy system relies heavily on fossil fuels, with the combustion of fossil fuels contributing 
more than $60 \%$ of global greenhouse gas emissions in 2010 (IPCC, 2014). Thus, there is a strong justification to inquire into the factors which facilitate a climate friendly energy systems transformation.

It is widely recognised that technology, and especially energy technology, will play a major role in the challenge of mitigating climate change (Stern, 2006; IPCC, 2007). Industrialised countries have developed around high carbon intensive infrastructure, yet it remains to be seen whether developing countries will move in the same direction. Low-carbon development has been pursued by many developed countries and huge efforts have been made to mitigate $\mathrm{CO}_{2}$ emissions. Yet, low-carbon development is also an option for lower-income countries to provide access to modern energy services and to foster industrialization. Their successful energy system transformation towards renewable energy technologies (RET), such as solar photovoltaic or wind technology, plays a crucial role in the global endeavour to mitigate climate change. Therefore, how developing countries manage to acquire and handle those low-carbon technologies is another important aspect of the debate on mitigation of global climate change. The point in time is decisive, since energy technologies are highly capital intensive and are characterised by a long investment cycle and lifetime. The risk for a developing country of being trapped in a high-carbon development pathway over years is thus even greater, taking into account constrained public budgets and risk-sensitive financial sources from the commercial sector.

The deployment of RET and their adherent potential economic benefits in developing countries still need to be better understood. This PhD research aims at contributing to the analysis of economic benefits of renewable energy deployment and its drivers and barriers, by using various methodological and theoretical research approaches. Put simply, the enabling environment for mitigation action is analysed, by using different conceptual frameworks to study different aspects of climate mitigation technology rollout, while in a first step the drivers for environmental regulation, the starting point for climate mitigation technology deployment, are assessed.

The core of the research asks what the different facilitating factors for climate change mitigation action are, starting from regulation that promotes the environmental cause, via diffusion and actual deployment of technologies down to the potential postdeployment economic benefits. The facilitation of a low-carbon growth pathway starts off with environmentally-friendly regulation. Since low carbon growth takes part to a large extent in developing countries, technology transfer and technology adoption drivers are assessed and followed by an ex-post economic benefit quantification, which justifies the investments into climate mitigation technologies from a macroeconomic standpoint. Those potential facilitation factors can be divided into two distinct groups, namely the ex-ante and ex-post circumstances of climate action: i) the enabling environment, incorporating regulation and institutional systems; and ii) the potential benefits of transitions towards sustainable, climate friendly systems, which would justify investment in climate mitigation technology infrastructure. 
With regard to the ex-ante view from an institutional perspective, the drivers for environmentally friendly regulation have not yet been systematically analysed; especially the interdependencies between the drivers itself and influencing factors in the policymaking process. Also, the enabling factors and barriers of climate mitigation technology diffusion faced by actors in the field of technology deployment need to be better understood in developing countries. Further, academic research has not exhaustively analysed, in a comprehensive economic sense, as to what way developing countries benefit from deploying RET.

\subsection{Objective and relevance of the research}

Low-carbon development inherits the challenge of how to develop and manage economic development, without compromising the state of the environment, and at the same time undertaking considerable shifts in the energy systems and land use (Lockwood, 2013). It is the area where climate change mitigation and economic development overlap. Many developing countries fail to manage a stable economic growth process. Others make promising progress in transforming their economies and bringing them onto a low-carbon growth pathway. The low-carbon development pathway per se does not start from a given point of departure but is embedded in a development trajectory, formed by political processes. Thus, it is of great interest to policymakers how pathdependency can be changed, through regulation, and what the economic consequences of breaking this path-dependency are. Conventional thinking, and resistance to systemic change in favour of low-carbon technology, is pervasive. Hence, determining the means by which powerful forces, and positive narratives for low carbon development pathways, can be unleashed is at the core of success or failure of global climate change mitigation.

The aim of this PhD research is to discuss various aspects around i) environmental regulation, ii) drivers and barriers of renewable energy and energy efficiency technology diffusion, and iii) economic benefits of implementing RET in developing countries. More precisely, the research focuses on the forces in the environmental regulation design process in general, conditions, drivers and barriers to renewable energy and energy efficiency technology diffusion, and, on the other side, on the economic benefits of RET deployment in developing countries. It can be claimed that low carbon development is either driven by environmental concerns about climate change, or that it can be shaped by economic interests. The discussion of those various aspects of drivers and barriers, by using different approaches, condenses insights on the factors that could be strengthened to increase the diffusion of climate mitigation technologies.

This thesis comprises an analysis of renewable energy and energy efficiency technology deployment and its drivers and benefits by using cross-country approaches and also offering country-specific assessments. Weighing the economic benefits analysis in this PhD thesis in favour of developing countries is justified, since economic develop- 
ment requires energy, especially in the earlier stages, and balancing the rising demand for energy with a need to limit $\mathrm{CO}_{2}$ emissions is one of the key climate change mitigation challenges (Chow et al., 2003; Jakob et al., 2012). Together with the increase of energy efficiency, which has huge potential to mitigate carbon emissions, the rapid diffusion of RET is considered the second most important mitigation option (GEA, 2012).

The field of research ranges from political economy to quantitative economic models. It comprises political science theory on environmental regulation and renewable energy and energy efficiency technology deployment. The approaches range from econometric analysis to empirical case studies. Quantitative economic models are used for the assessment of economic benefits induced by RET deployment in developing countries.

The findings of the research could be relevant to policymakers in several ways. First, results illustrate the driving forces for environmental regulation on national levels. The findings try to prove political economy theory by applying an econometric analysis. Second, studying renewable technology transfer mechanisms reveals insights into the challenges of fostering low-carbon development induced by RET transfer. This is complemented by case studies on the barriers and drivers of renewable energy and energy efficiency technology adoption, using insights from surveys with technology adopters, which are reliable, first-hand information. Third, quantitative analyses of economic benefits of country-wide RET deployment indicates the magnitude of economic benefits in developing countries in a comparative scenario analysis, as well as in a country case study, by testing specific governmental technology pathways.

The work tries to render insights for policymakers about the barriers in national environmental policymaking and interconnections of actors in that policymaking process, in the area of renewable energy and energy efficiency technology deployment functions and actors, and about potential economic benefits induced by a shift towards RET.

\subsection{Research questions}

Effective and efficient regulations are required in the field of low-carbon growth, since climate change comes with inherent market failures. Beyond regulation, the role of a well-designed technology transfer to developing countries has to be considered in order to unleash the growth potential of climate change mitigation in developing countries. On the other hand, the barriers faced by practitioners in the field of technology deployment need to be minimised. Technological change is associated with economic benefits. Therefore, the economic impact assessment is crucial for the success and justification of a low-carbon development transition. Following the chronology of low carbon technology implementation from environmental regulation, via technology transfer and domestic technology adoption in developing countries, to the economic outcomes of the implementation of climate mitigation technologies, the thesis will 
address explicit questions within each sequence of low carbon growth in order to identify its causes (in terms of regulation) or outcomes (of mitigation technology implementation). The objective of this $\mathrm{PhD}$ research can be defined along the following six broad research questions, dealt with in six separate chapters, which discuss general concepts and broader aspects as well as case study examples:

Question 1: What are the drivers behind environmental regulation?

The central introductory question in this thesis deals with environmental regulation as the core of mitigating environmental pressure. To answer this question I investigate how environmental regulation is being shaped and especially what the domestic drivers for strong national environmental regulation are, as this is the starting point for climate mitigation technology deployment.

Question 2: How could technology transfer mechanisms, acknowledging economic development goals in developing countries, incorporate inherent technology properties?

In order to mitigate climate change and deploy RET in developing countries, the transfer of technology from developed to developing countries needs to be facilitated. The technology transfer mechanisms should therefore support the uptake of new technologies in developing countries by acknowledging the properties of technologies itself. It is being challenged how the transfer of technology to developing countries could serve the dual purpose of climate change mitigation and sustainable development, by not only considering climate mitigation and economic development potentials, but also assessing technology properties within a technology transfer environment. Technology complexity assessments are proposed, which allow for the acknowledgement of technology properties.

Question 3: What are the barriers to adoption of renewable energy technologies (RET) in Kenya?

The uptake of renewable energy technologies in developing countries depends on several factors, which are assessed in a case study on RET adoption in Kenya. Going beyond theoretical considerations, I will inquire empirically how RET deployment can be facilitated by applying a functional analysis with a focus on industry practitioners.

Question 4: What drives the implementation of energy efficiency measures in Kenya and Nigeria?

The implementation of energy efficiency measures can be crucial and an effective step towards low-carbon development driven by the private sector. In two country-specific case studies, the drivers and motives for investments into energy efficiency technology will be analysed. 
Question 5: What are the macroeconomic benefits of a transition to renewable energy technologies (RET) in developing counties?

The potential to realise economic benefits can give developing countries a strong motivation to shift towards renewable energy technologies. The potential macroeconomic benefits of a transition to RET are studied in the Middle East and North Africa (MENA). Based on the idea of comparative advantage, the production of electricity from solar and wind resources could take place in geographical locations which favour solar and wind technology build-up. Further, electricity as a product could be exported to geographical locations with high demand. Whether economic benefits from large investments into the renewable energy sectors can be reaped for the economy as a whole is assessed quantitatively.

Question 6: How can harvesting solar and wind resources contribute to economic development?

In order to study not only the macroeconomic benefits but also the potential poverty alleviation aspects of a clean energy transition on a country level, I conduct a quantitative case study into the domestic renewable energy strategy announced by the government of Egypt.

\subsection{Fields of research, methodology and outline}

Since the goal of the research is to address different stages of the clean technology diffusion process, from regulation, over technology transfer, barriers and drivers to its economic benefits, it is not aimed at defining one unified theoretical or analytical framework. Consequently, different analytical frameworks are chosen to grasp the different dimensions of the broader subject of detecting facilitation factors in favour of low carbon growth.

The research work is located in different research fields and comprises several different methodological approaches. It utilises empirical case studies in order to combine theory with real world observations and to derive implications. Further, quantitative modelling approaches are used to explore interdependencies between drivers for environmental regulation and the magnitude of economic benefits induced by a clean energy transition.

A transition to low-carbon development touches on a restructuring of the economy as a whole and therefore challenges the vested interests of actors and the allocation of powers. The chapter on drivers of environmental regulation locates the research in the field of political economy, through analysis of the interplay between political and economic actors (Oates \& Portney, 2003; Cohen 2014, p. 138; Kern, 2014). Low-carbon political economy research investigates the connection between interests, represented by various groups of actors, and institutions (Lockwood, 2013), which is done by quanti- 
tatively measuring the interdependencies between interest groups, institutions and environmental regulation.

The present research also analyses the circumstances and institutional contexts of a low-carbon transition, which is typical for sustainability transition research (Kern, 2014). Various relationships between societies, micro-level networks of actors, macroeconomic circumstances and socio-technical regimes constitute the socio-technical transition environment (see for further overview Smith et al., 2010; Baker, et al., 2014). Sustainability transition research points to the multi-level relationship between economic, social, technological and political factors (Meadowcroft, 2011) and how socio-technical systems can be changed in favour of more sustainable arrangements (Kern, 2014). In transition research, changes at several different levels are often analysed, reaching from institutions, to skills and production practices (Kemp, 2001, p. 157).

Acknowledging the political element in sustainable transition processes (Kemp \& Loorbach, 2003; Meadowcroft, 2011) means that the political economy of sustainability transition research process is a topic worthy of investigation. The state-society nexus needs to be emphasised in transition research, because transition processes are also influenced by individuals, rather than solely by states (Kern, 2014, p. 10). The present research on low-carbon transition investigates state and actor relations and approaches the issue of system change, thus touching on the fields of political economy and sustainability transition research.

Broad and concrete country-specific analyses are applied. Analysing the causal structure on environmental regulation drivers is a conceptual, introductory part of the thesis. Using a quantitative approach with cross-country data provides the basis for the highest degree of objectivity possible. For the questions on how to facilitate the adoption of renewable energy and energy efficiency technology in developing countries, a conceptual discussion and also concrete case studies are provided. Using qualitative case studies provides insights from individual actors about the pragmatic side of technology adoption. It offers a view from the opposite angle of environmental regulation. Similarly, with regard to the inquiry on economic benefits, a broad, region-wide empirical analysis as well as a country analysis is conducted in order to grasp potential future economic benefits in numbers.

Chapter 2 is a general assessment of the drivers for environmentally friendly regulation. The chapter tries to disentangle the causal structure behind environmental regulation processes. The work relates to the area of political economy of environmental regulation and capacity for environmental policy (Jaenicke, 2005). A political economy approach is suited to study environmental regulation aspects, as it puts particular emphasis on the nexus between political and economic actors. The different actors and institutions in the environmental policymaking process are described. Further, the dynamic interactions between the different institutions in the policymaking process of environmental regulation are assessed with the aid of an econometric, structural equa- 
tion model. The calculation of different path coefficients between institutions and actors allows the exploration of theory by using empirical, cross-country data.

Chapter 3 comprises an analysis of technology transfer mechanisms of RET by locating the research in the field of innovation systems in developing countries (see Lundvall et al., 2009). It investigates the degree to which degree technology transfer mechanisms have acknowledged climate technology specific properties in its current frameworks and how those fit together with innovation systems in developing countries. The field of climate policy research is combined with detailed technology complexity aspects, which are the core of the technology transfer and innovation systems discussion in this chapter. Climate policy usually emphasises the different actors and mechanisms, while the subject matter (or hardware characteristics), in this case the RET concentrated solar power (CSP), solar photovoltaics (PV) and wind, are viewed through the lens of innovation systems and a climate governance discussion. It is crucial to consider technology characteristics in order to design effective technology transfer mechanisms which simultaneously serve sustainable development requirements of international climate policy. Incorporating those requirements in the technology transfer process would help facilitate low carbon technology diffusion.

Chapter 4 offers a case study on the drivers and barriers of the diffusion of renewable energy technologies in Kenya, which introduced a feed-in tariff in 2008. The field of research is embedded in technology diffusion theory in an innovation systems approach, which considers policy frameworks and user preferences (see Lema \& Lema, 2012), and is applied in context with concrete examples of RET adoption in Kenya. A detailed country survey has been conducted among RET importers and end users in order to detect the barriers and drivers for RET adoption in the country. The focus of the stakeholder survey is the supply and uptake of small-scale solar PV, wind and bioenergy technology. The chapter gives insights into the roles of different stakeholders in the technology adoption process in Kenya, and highlights the barriers to technology adoption. As a result, the existing technology diffusion theory is enriched by experiences from survey participants, which give insights on how domestic participants in the technology adoption process circumvent obstacles to the technology deployment in the country. The chapter concludes with findings on how weak innovation systems institutions can be substituted or bridged by national actors.

Chapter 5 presents an investigation of the uptake of energy efficiency measures in agro-industrial sectors in sub-Saharan Nigeria and Kenya. The case studies conducted in the cassava and maize processing industries provide deeper insights into the analytical approach of innovation systems with regard to energy efficiency technologies. They reveal the role of economic reasoning with regard to cost-efficiency and give special attention to the meaning of informal mechanisms of learning and to the transfer of foreign technologies and collaborative relationships in an environment of weak innovation systems (Altenburg \& Pegels, 2012). 
Chapter 6 provides a quantitative, economic development analysis of the transition to renewable energy technologies in the MENA region and the export of electricity from solar and wind power across the Mediterranean to Europe. It applies a quantitative economic modelling framework in order to detect the major macroeconomic developments induced by RET deployment. A computational general equilibrium (CGE) model for the whole world is used, with a special focus on the MENA region, and adjusted for RET. This analysis is innovative due to its disaggregated assessment of various RET in the model, such as CSP, PV, and wind as well as the exchange of large amounts of electricity between geographical regions. Also, as input with regard to the renewable energy deployment trajectories, exogenous, renewable energy potential data are utilised, based on spatial and hourly renewable energy potential analysis for the MENA region (other studies use only annual data, see Fragkos et al., 2012, Haller et al., 2012). The modelling time horizon is 2050. Different climate policy scenarios are compared with a baseline, business as usual scenario in order to discuss relative changes in levels of economic development over time. Findings of this analysis provide insights on the relative economic benefits for the MENA region if it embarks on a low-carbon growth pathway and facilitates the exchange of electricity across the Mediterranean.

Chapter 7 examines the economic benefits and distribution effects of a renewable energy transition in Egypt. While Chapter 6 gives an overview of potential macroeconomic development trajectories in the MENA region until the year 2050, Chapter 7 provides a detailed economic development assessment of Egypt, based on Egypt's RET pathways. An Egypt-specific CGE model is used and expanded by CSP, PV and wind technology. With regard to income distribution changes and poverty alleviation potentials of RET diffusion until the year 2020, this chapter provides insights into the economic aspects of renewable energy deployment. The CGE model used in this chapter differentiates five types of households and tests different technology build-up trajectories. The economic effects of the realisation of the domestically announced renewable energy targets are calculated and compared with a business as usual scenario.

\subsection{Outlook}

The goal of the thesis is to investigate the facilitation factors for low-carbon growth pathways. It sheds light on the causal structures behind environmental regulation, and on understanding the mechanisms, drivers and barriers triggering low-carbon technology transfer and deployment, as well as assessing potential economic benefits stemming from RET deployment. The ultimate objective is to contribute to the discussion on drivers and benefits of low-carbon development in times when government budgets are constrained and the weakened global economic situation is not particularly favourable for leaving conventional technology pathways behind and promoting technologies requiring relatively high upfront investments compared to conventional technologies. 
Firstly, this research contributes to understanding the dynamics of environmental policy-making on national levels, by quantitatively disentangling the different influencing factors in the environmental policy-making process. Further, the concept of technology complexity and the potential to contribute to economic development is discussed in an integrated technology transfer assessment framework. Then, in a countrylevel case study approach, the drivers and obstacles to energy efficiency and RET deployment are analysed empirically. Finally, the potential economic benefits of a shift in the direction to a low-carbon growth pathway are modelled quantitatively on regional and country levels. Those findings can help develop arguments for low-carbon, renewable energy and energy efficiency technology based development.

In the context of environmental policymaking, future research should include international dynamics and measurable factors of the international environmental policy arena in the assessment of national policymaking processes. However, the availability of data on actors and dynamics in the international environmental policy arena is limited. Empirical data across a large set of countries is sometimes only obtainable with regard to specific environmental policy domains, such as air pollution control or waste management regulation, which makes linking international drivers and national environmental policymaking even more difficult.

The work on technology complexity and economic development potential on a technology component level could be further specified in a next step by combining the loose ends of evaluating and quantifying the technology production or innovation capacity in a specific country against the complexity of a certain technology component under investigation. An evaluation framework for technology- and component-specific domestic innovation capacities could be developed.

The case studies on technology deployment barriers with regard to energy efficiency and RET focus on few sub-Saharan African countries. Even though the empirical survey results of the present work are very informative, they are biased towards a small set of countries. Rigorous empirical diagnostics are necessary to inform policymakers which could be replicated in other countries where weak innovation systems are also prevalent. Comparative studies on innovation system weaknesses are desirable in order to develop the research field on innovation systems and technology transfer further.

In this work, economic benefits analyses focus on a regional-level approach covering North Africa and the Middle East as well as on one country, namely Egypt. Those regions are interesting for studying low-carbon, renewable energy based transitions for two reasons: firstly because the level of energy infrastructure and economic development is low; secondly because the regions are endowed with huge potential in solar and wind energy which can be harvested, if appropriate technologies are deployed across the region. With regard to the modelling of economic benefits, additional countries could be studied in more detail, going beyond developing countries. Adding bioenergy and hydropower to the energy sector in the CGE model could be advisable, though those technologies are not meaningful for the MENA region, as biomass feedstock and 
water resources are scarce in those regions. Future economy-wide research taking into account power systems and economic systems could also try to fill research gaps in: i) modelling electricity transmission infrastructure; and ii) detailing the implications of storage infrastructure investments induced by renewable energy sector expansion. 



\section{Disentangling the causal structure behind environmental regulation ${ }^{1}$}

\footnotetext{
${ }^{1}$ This chapter is based on the paper Blohmke, J., Kemp, R., Türkeli, S. (2016). Disentangling the causal structure behind environmental regulation. Technology Forecasting and Social Change (2016) 103, 174-190. It has been co-authored by Julian Blohmke (Maastricht University), René Kemp (Maastricht University, UNU-MERIT) and Serdar Türkeli (UNU-MERIT). In this chapter, my contribution consists of designing the research approach, choosing the empirical method, conducting the data collection and applying partial least square analysis to calculate various structural equation models with the software smartPLS. René Kemp and Serdar Türkeli gave significant feedback with regard to the modelling framework and checked the empirical results, while both coauthors contributed to editing the paper.
} 



\subsection{Introduction}

Environmental regulation provides the basis for low-carbon technology deployment and is therefore an important aspect in the discussion around factors to facilitate lowcarbon growth pathways. Thus, this chapter discusses the drivers and interdependencies of factors in the process of developing environmental regulation.

Compared to the literature on the effects of environmental policy, the literature on determinants of environmental policy is relatively small. The literature falls into two categories: qualitative studies and quantitative studies of political-institutional and structural economic determinants. Among the qualitative studies, the study of Vogel (1986) of environmental policy styles in the United States and Great Britain stands out as a landmark study. It uncovered a number of important differences in environmental policy styles: whereas the United States opted for a (conflict-ridden) command-andcontrol approach, Great Britain established a system of negotiated individual standards. It was found that the stricter system in the United States did not lead to better environmental outcomes, because enforcement proved difficult. A second important contribution to the topic of environmental policy output is the study of Jaenicke (1997), based on the notion of the political system's capacity for environmental policy.

Most quantitative studies on national determinants of environmental policy have been undertaken as part of the lead-laggard debate of countries (Liefferink et al., 2009) or assessed the role of the green industry (Jacob \& Volkey, 2006).

Avoiding the adjustment costs of international regulation, strengthening economic advantages and competition of domestic industries, as well as gaining a stronger leadership role in future international environmental policy dialogue, are considered strategic motivations for environmental policymaking. However, the interaction of those factors awaits further analysis.

This chapter is an attempt to disentangle the causal structure and structural, country-specific determinants of environmental policy, with the help of a rigorous analysis in the form of structural equation modelling. More specifically, the chapter seeks to disentangle the influence of proximate factors such as governance capacity and demand for environmental regulations (from green business and green activists) from background factors such as democracy, environmental knowledge and social cohesion. ${ }^{2}$ Because the causal structure is complex and various causal chains are conceivable, we will investigate different causal structures, based on the framework of Jaenicke (2005), which is considered a suitable framework as it incorporates political advocacy in the analysis, economic circumstances, structural political-institutional factors and structural cognitive-informational factors. Missing from the framework are situational factors and culture, as these are difficult to include both technically (structural equation modelling

\footnotetext{
${ }^{2}$ The background factors are called "ultimate" variables in the socio-economic development literature (Rodrik, 2003, and Szirmai, 2015).
} 
does not allow for the inclusion of dummy variables such as protestant ethos) and analytically (both variables comprise many events and phenomena).

The determinants of environmental policy are investigated with the help of a structural equation model incorporating manifest and latent variables. Special attention is given to the interaction effects of the causal variables. All variables are structural variables and are measured at a high level of aggregation. The analysis is restricted to an analysis of the systemic conditions for policymaking action (Jaenicke, 1992). Our approach does not allow us to analyse the choice of policy instruments (policy) nor does it enable us to analyse the policymaking process (the wheeling and dealing between politically active parties involved in environmental policymaking). The analysis investigates the normative and particular organisational aspects of policy mechanisms (polity) as the basis for the choice of instruments and national decision making (Jaenicke, 1992).

Our analysis differs from other studies by: i) incorporating more countries (47) and more environmental policy determinants in the analysis (including structural factors); ii) by examining the interaction effects of factors in a structural equation model; and iii) by building latent variables. In comparison, Jacob \& Volkery (2006) run regressions with no more than 30 observations (countries) and focus on the analysis of carbon emission and renewable energy policy. Liefferink et al. (2006) run multivariate regressions without forming groups of influencing factors. We study the influence of the determinants for the quality of environmental policy as an aggregate variable (across environmental issues) in a nation.

The structure of the chapter is as follows: In the second part, the environmental policymaking process and the concept of capacity for environmental policymaking are explained. The data of the quantitative analysis is also discussed. The third section describes the method we apply in our empirical analysis. The fourth section discusses the results of the factors that influence the stringency of environmental regulation (47 countries). The last section concludes.

\subsection{Theory and data}

A fully-fledged theory of environmental policymaking does not exist but useful approaches to build one have been developed.

According to Jaenicke (1997) capacity for environmental policy depends on administrative capacities but also on societal forces working through the political process. He states that the ability of government to formulate and enforce environmental policy is an important element of the environmental policymaking process, alongside knowledge creation, green enterprises, degree of corporatism, public awareness and wellfunctioning communication.

In a later publication Jaenicke (Jaenicke, 2005) contends that the following countryspecific factors are determinants of whether a country will be a pioneer country or laggard in environmental policy: 
- $\quad$ strength of environmentally friendly advocacy groups;

- economic factors;

- $\quad$ structural political-institutional factors;

- $\quad$ structural cognitive-informational factors.

The political-institutional factors refer to the capacity of policymaking and capability for dialogue. Cognitive-informational factors refer to the capability to generate and transfer environmental knowledge. Economic factors describe the degree of economic development and constitute general administrative as well as scientific capacities.

In much of the literature which has been undertaken in the footsteps of Vogel and Jaenicke, the focus of attention is on structural determinants such as the openness of an economy, the presence of a protestant ethos, the political economy institutional structure (statist, liberal pluralist, neo-corporatist), EU membership (Liefferink et al.,2009), corruption, the degree of democracy (Pellegrini \& Gerlagh, 2006) and political instability (Fredriksson \& Svensson, 2003). The influence of situational factors and issuespecific factors has been ignored in those studies, as they are difficult to measure and operationalise in an objective way.

Liefferink et al., 2009 argue that countries with advanced environmental policies tend to exert the pressure of competition on states lagging behind in their environmental policy implementation. They found that EU membership played the strongest role, as it facilitates the communication and technology transfer between countries. Other positive predictors for being an environmental leader are: a neo-corporatist institutional structure, environmental pressure (proxied by $\mathrm{CO}_{2}$ intensity of the industry), as well as a high level of economic development. Culture (religion) and trade openness turned out to be not significant determinants of environmental policy leadership. The findings of this study are informative, yet they do not tell us how the factors potentially interact with each other. Missing from the analysis is the influence of a clean technology industry in the policymaking process. Industry's role in environmental policy is captured by the dummy variable neo-corporatism as an institutional structure variable (next to liberal-pluralist and statist structures), but this variable captures many things.

The influence of green industry is examined in the study of Jacob \& Volkery (2006) together with the influence of 26 other variables. Green industry is positively associated with environmental policy, together with neo-corporatism, governance effectiveness, and strength of environmental non-governmental organisation (NGO) activity. In this study, the role of religion and cultural factors is not investigated. The results are not fully comparable, as the study of Liefferink et al. examines environmental policy gaps (as the dependent variable) whereas the dependent variable of Jacob and Volkery is based on climate and energy related policies in the form of $\mathrm{CO}_{2}$ reduction targets, $\mathrm{CO}_{2}$ / energy taxes, and quotas for renewable and energy feed-in tariffs.

Studies analysed corruption, democratisation, trade openness or political instability as factors influencing environmental policymaking (see for an overview Pellegrini \& Gerlagh, 2006; Liefferink et al., 2009). Yet, scholars assess factors in an isolated manner 
or concentrate on the analysis of only a few potential determinants, which leave their models underspecified and neglect the potential interdependencies between the influencing factors. One relevant scheme is the framework of environmental policy diffusion created by Tews and others (Tews, 2005). In this framework a distinction is made between horizontal diffusion of environmental policy and vertical policy diffusion. Horizontal policy diffusion occurs when environmental policy is transferred from lead countries to other countries. Vertical diffusion of environmental policy takes place when international organisations set policies which are being implemented by countries. The different factors in this approach are grouped into two categories (Tews, 2005): i) dynamics of the international system and ii) national factors.

Giving the sovereignty of nation states, national factors influence the various designs of environmental policies across countries (see further Kern, Jörgens, \& Jaenicke, 2001). Whether governments want to adopt an environmental policy agenda depends on their institutional capacity (the functioning of institutions of a government) and that capacity sets the limits to policy innovation. Distinct country characteristics as well as the structural framework of a country can influence national environmental policy (Tews, 2005). The size of a country, market volume, and contextual reputation of a country are relevant country characteristics (Tews, 2005) but they are not determinants of it.

The exposure of a country to regulatory competition has been discussed as another potential determinant of environmental regulation (Holzinger et al., 2008; Jaenicke 2005; Vogel, 1997). It has been hypothesised that global economic competitiveness, expressed by trade openness, leads to a mutual adjustment and convergence of regulations, including with regard to environmental regulation. Yet exposure to regulatory competition has only been studied for a small sample size (EU countries) and quantitative results have not necessarily been satisfying (Liefferink et al., 2009).

Structural determinants of environmental policy are: environmental policy capacity; green advocacy coalitions; knowledge about environmental problems; active or passive support for regulations by the wider public; and acceptance of regulations by business which is directly affected by it (Jaenicke, 2005). Put differently, environmental policy capacity refers to "a society's ability to identify and solve environmental problems" (OECD, 1994, p. 8).

Environmental policy theory has been based on interest groups and constitutional structures (summarised in Oates \& Portney, 2003) but offered a rather crude description of interactions and failed to consider wider structural conditions and distal factors, such as the role of environmental knowledge creation within a country. We opt for a different approach, building on the work of Martin Jaenicke and other scholars, which is based on political-institutional framework conditions and cognitive-informational framework conditions (Jaenicke, 1997, p. 11; Mason, 1999).

The political-institutional framework conditions describe more structural conditions as requirements in the policy cycle, ranging from sensing a problem, agenda setting, 
target formulation, to decision and implementation (Jaenicke, Kunig, \& Stitzel, 1999). An important element of political-institutional structural conditions is "green" advocacy coalitions of private and public actors (Sabatier, 1999).

The cognitive-informational framework conditions are systemic preconditions that relate to individuals' values and knowledge and the communication channels through which they learn and express themselves.

In the following, we discuss each of the types of conditions, starting with the political-institutional framework conditions which directly influence the environmental policymaking process (as proximate factors). A detailed explanation for each variable used to represent the conditions explained here is given in the appendix (Table 5 to Table 8). It shall be highlighted that due to the requirement of using homogenous data across countries, it was necessary to use data from one source for each variable. The Environmental Sustainability Index (ESI) provides a compilation of variables to represent the conditions described in this section. The set of variables has been used in the discussion about environmental regulatory stringency in a set of simple regression analyses, without building on a construct of latent variables and its dependencies (Esty \& Porter, 2005). The ESI data appear suitable for the purpose of comparing a large set of countrylevel variables due to the fact that they are relatively homogenous, even though many of them date back to the year 2005 .

\subsubsection{Political-institutional framework conditions}

How the policy process is structured with regards to openness of input structure influences the opportunity to include citizens' environmental interests in the policymaking process (Jaenicke, 1997, p. 12). This participative capacity shows to be decisive for the influence of environmental movements on policymaking. Also, the capacity for cooperation between environmental policy institutions and non-state actors describes environmental capacity (Jaenicke, 1997, p. 13). The interaction of interest groups in society and business with the government influences the policymaking (Vogel, 1986, p. 273-275).

If interest groups and sub-societies participate in policy consultation, then these interest groups can heavily influence policymaking while governments still can choose to whom they grant consultative status and access to policy consultations.

In our analysis, the variable "green advocacy" is used to account for the actions and support for environmental policy of civil society actors and private industry. Such actions and support are conceptualised as civil society and private sector politicalinstitutional framework conditions for (more) environmental policy. We chose local, community-level and private sector environmental activism of civil society, and green industry activity as green advocacy drivers in the political-institutional framework. Our variables of green advocacy are: 


\begin{tabular}{ll}
\hline Civil society and private sector political-institutional framework conditions: Green advocacy \\
\hline Environmental Activism & $\begin{array}{l}\text { Degree to which civil society on a local level cooperates with the } \\
\text { local government to create a sustainable future. }\end{array}$ \\
Competitiveness of Green Industry & Environmental competitiveness refers to the innovative activities of \\
& companies in the environmental domain and environmental \\
& management systems. It contributes to solutions within industry to \\
& environmental problems and increases the power of these sectors \\
& in the policymaking process by connecting to the government.
\end{tabular}

Note: see appendix for further description.

On the other hand, the effectiveness of government actors and strength of government administration has a direct influence on environmental policymaking as well. The governance capacity, i.e. the ability of government bodies to formulate environmental regulation, can be understood as the public sector political-institutional framework conditions $^{3}$ :

\begin{tabular}{ll}
\hline Public sector political-institutional framework conditions: Governance Capacity \\
\hline Government Effectiveness & The government effectiveness describes the competence of civil \\
& servants and quality of bureaucracy which enhances the ability of \\
& society to effectively translate environmental concerns into \\
& regulation.
\end{tabular}

Note: see appendix for further description.

The hypothesis is that environmental activism of civil society as well as the strength of the green industry has a positive influence on the quality of environmental regulation. Further, the effectiveness of the government and competence of civil servants is believed to be indispensable for effective formulation of regulation, and this also applies to high-quality environmental regulation.

\subsubsection{Cognitive-informational framework conditions}

Environmental knowledge and environmental awareness of citizens are associated with cognitive-information framework conditions which are hypothesised to be positively linked to environmental policy (Jaenicke, 1997, p. 11-12; OECD, 1994). They can be considered a necessary element and positive predictor for environmental policy. Awareness is influenced by culture while knowledge gets influenced by information generation and distribution. Thus, the knowledge base has to be produced, transferred and adopted by the public sphere (Jaenicke, 2005). All those factors are equally important in the policy innovation process and grouped under the term cognitiveinformational framework conditions.

\footnotetext{
${ }^{3}$ Other variables like Regulatory Quality are dropped from the analysis as they are highly correlated with Government Effectiveness.
} 
In this category we not only group awareness infrastructure and awareness institutions, but also include environmental knowledge, the access to this knowledge and sharing and distribution of knowledge.

Also, societal cultural values and the attitude towards the environment are seen to be the key factors in determining capacity in environment (OECD, 1994, p. 12). Cultural heritage determines how problems are solved, whereas the willingness and ability to change is also embedded in culture. Social awareness, creation of effective linkages among organisations and a strengthened role for the private sector and NGOs does contribute positively to the abilities of a society to identify environmental problems and solve them. The influence of social cohesion and trust have been discussed in the literature in the context of economic performance (Knack \& Keefer, 1997) and environmental performance (Bouma, Bulte, and van Soest, 2008). They are based on informal societal attributes that influence human interaction, by lowering transaction costs in the interaction among citizens, which comprise norms, values and attitudes (Foa, 2008).

Cognitive-informational framework conditions (which we cluster as the latent variable awareness) are pre-conditions for green advocacy and governmental institutions to act towards formulation of environmental interests and design of environmental regulation. They are the basis for the flow of information, which is necessary for politicalinstitutional framework conditions to unfold. Awareness enables advocacy for a specific cause. In this context, awareness is not to be understood as popular awareness-raising campaigning but the infrastructure of creating and raising awareness.

\begin{tabular}{|c|c|}
\hline \multicolumn{2}{|c|}{ Cognitive-informational framework conditions: Awareness } \\
\hline Democratisation & $\begin{array}{l}\text { In democracies citizens are better informed and can express their } \\
\text { concerns about environmental problems more transparently. Thus, } \\
\text { democratic structures support the flow of information. }\end{array}$ \\
\hline Internet Access & $\begin{array}{l}\text { Access to internet enables the quick and inexpensive access to } \\
\text { information on environmental issues. It is crucial for efficient } \\
\text { knowledge sharing. }\end{array}$ \\
\hline Environmental Knowledge & $\begin{array}{l}\text { Creation and publication of knowledge especially in the field of } \\
\text { environmental processes promotes decision-making based on } \\
\text { sound information and data. It is an indicator for the sophistication } \\
\text { of environmental knowledge in a country. }\end{array}$ \\
\hline Interpersonal Safety and Trust & $\begin{array}{l}\text { Trust between individuals which influences social cohesion and } \\
\text { safety. This increases the creation of effective linkages among } \\
\text { individuals and lowers transaction costs of information sharing and } \\
\text { trust in information and reliability. }\end{array}$ \\
\hline
\end{tabular}

Note: see appendix for further description.

We hypothesise that on the one hand environmental knowledge creation by scientists is important for the sensing of environmental problems by the wider public, and that on the other hand, democratisation, use of the internet, and trust between individuals 
facilitates the sharing, distribution and application of such knowledge towards raising environmental awareness and policymaking.

It is important to note that economic factors can also influence the policy output. The level of national income and individual disposable income increases the availability of financial and technical resources and can improve the capabilities of a system to solve environmental problems (Jaenicke, 2005). The influence of this has been tested for post hoc (in the structural equation model analysis and in a separate linear regression analysis). GDP was found not to have a significant influence, which is why we have not incorporated it into the structural model. ${ }^{4}$

\subsubsection{Dependent variables: National environmental policy output and international environmental governance}

The environmental policy capacity, reflected in political-institutional and cognitiveinformational framework conditions, is assumed to influence the policymaking process and the final policy output. We use Environmental Governance as a measure for the quality of national environmental policy output. An indicator of the stringency of environmental regulation, which was constructed by the World Economic Forum (WEF, 2014) in a survey among CEOs, is highly correlated with the Environmental Governance measure (WEFGOV) which we use $\left(R^{2}\right.$ 0.93). The stringency indicator asks how CEOs perceive the stringency of environmental regulation. In our research we opt for the broader Environmental Governance measure. All WEF indicators are subjective in nature, yet there are no other indicators available on the subject matter with that large sample size (see also Haščič et al., 2009). Further, the participation of countries' administrations in international environmental agreements is a policy output which we call International Environmental Governance. International Environmental Governance influences national environmental policy as well, according to the environmental policy diffusion theory, which acknowledges the influence of international policy institutions influencing national government's administrations (Tews, 2005). We hypothesise that participation in international environmental agreements is an output of national Environmental Governance capacity, while International Environmental Governance also influences national environmental policy.

\footnotetext{
${ }^{4}$ We discuss the model findings with GDP as an explanatory variable.
} 
Environmental policy output: Environmental regulation, international environmental governance

Environmental Governance

Environmental governance is a policy output indicator which comprises clarity and stability of regulations, flexibility of regulations, environmental regulatory innovation, leadership in environmental policy, consistency of regulation enforcement, environmental regulatory stringency, toxic waste disposal regulations, and water pollution regulations.

Participation in International Participation in international environmental efforts is a result of the Environmental Agreements work of national environmental government institutions to contribute to solving environmental problems. Furthermore, it also gives an indication of the degree of exchange on the international policy arena and communication of policy issues across countries.

Note: see appendix for further description.

\subsection{Method and model}

Our quantitative analysis is based on theory, in the form of a conceptual model consisting of three types of conditions for environmental policy: green advocacy, governance capacity and awareness. The precise interplay between the conditions is something which we do not want to specify beforehand but investigate empirically. Specifically, we are interested if the influence of green advocacy on environmental policy is partially through governance capacity and whether awareness works directly on governance capacity or works also via advocacy. Ordinary Least Squares is not well suited for studying such complex causal relations between explanatory variables ( $A$ having an influence on $D$ directly and via $B$, in combination with variable $C$ which has an influence on $A$ and $B$ ), which is why we opted for the use of Structural Equation Modelling (SEM). SEM is a multivariate data analysis, which is based on a theoretical model involving unobservable latent variables and a measurement model (Haenlein \& Kaplan, 2004). SEM allows the researcher to investigate different model structures. SEM usually includes two types of sub-models: the inner and the outer model (Wong, 2013). SEM allows researchers to include unobservable variables, which are measured indirectly by indicator variables (Hair et al., 2014). The inner model describes the relationship between independent and dependent latent variables (Figure 1, left and right hand side of inner model). Latent variables cannot be observed directly. ${ }^{5}$ The outer model, also known as the measurement model, specifies the relationship between observed indicators ${ }^{6}$ and latent variables.

SEM analysis entails two models. The measurement model specifies how latent variables are measured in the measurement model (Hair, et al., 2014). The measurement model consists of a formative measurement part (which describes assumed causal, predictive, relationship of the indicator variables) with an explanatory construct (left

\footnotetext{
${ }^{5}$ They are also known as constructs or factors.

${ }^{6}$ Indicators are also called items or manifest variables.
} 
hand side measurement model in Figure 1) and a reflective part which is about the measurement of the dependent latent variable (right hand side measurement model in Figure 1). ${ }^{7}$

The structural model consists of the relations of the theoretical variables with each other (inner model in Figure 1). The theoretical variables consist of exogenous (explanatory) variables and endogenous (dependent) variables. The theoretical model is thus the model of the latent (non-observable) exogenous and endogenous variables. It consists of the constructs and path relationships between them. It is about how the exogenous constructs, or independent latent variables, influence the endogenous constructs, or dependent latent variables (sequence from left to right in the structural model, Figure 1). Together, the structural model and measurement model form the structural equation model.

There are two approaches to estimate the parameters of a SEM, the variance-based approach and the covariance-based approach.

Partial Least Square (PLS), as a variance-based approach, uses the available data to estimate the path relationships, or coefficients, that maximise the $\mathrm{R}^{2}$ values of the (target) constructs by reproducing the measurement values as linear combination (Hair, et al., 2014). Compared to that is the co-variance (CB) based approach (Weiber \& Mühlhaus, 2010). The CB approach, similarly to factor analysis, tries to "explain" the measurement variables through the latent variable and attempts to minimise the difference between the sample covariance and that predicted by the theoretical model. In the structural model the CB method focuses on the factor variance while the error variance is excluded. Thus, this approach is similar to factor analysis.

SEM, based on PLS analysis, can be useful when the following situation is encountered (Wong, 2013): i) sample size is small, ii) little available theory on application, iii) predictive accuracy is important, and iv) model specification cannot be ensured.

The PLS approach firstly estimates the values of constructs for each latent variable (outer model or measurement model, Figure 1). PLS estimates coefficients that maximise the $\mathrm{R}^{2}$ of the constructs. In the second step those values of constructs are used to estimate the structural model, the relationships between latent variables, in a subsequent regression approach (inner model or structural model). PLS is the preferred method when the theory, which is underlying to the structural model, is not well established (Hair, et al., 2014). The CB based approach aims at testing the overall validity of variable interactions by optimising the overall interaction of all variables (Weiber \& Mühlhaus, 2010). It is to be applied when the goal is theory testing or validation and when a global goodness-of-fit criterion is critical (Hair et al., 2014). Additional advantages of PLS over CB based modelling are that small sample sizes can be used and

\footnotetext{
${ }^{7}$ Reflective indicators are different way of measuring the latent variable; formative indicators are not measurements of a latent variable but variables which affect it (either positively or negatively) (for an insightful discussion and empirical examples, see Haenlein and Kaplan, 2004).
} 
that no special assumptions are needed concerning the data distribution (Hair et al., 2014). Differing from normal multivariate regression, its use is not restricted by the following limitations: a) the postulation of a simple model structure, b) the assumption that all variables can be considered as observable, and c) the conjecture that all variables are measured without error (Haenlein and Kaplan, 2004 p. 284). SEM-PLS helps to study causal structures in the form of path relations, something OLS-based multivariate regression is not capable of doing as it is based on a linear model. PLS should be used when key "drivers" shall be predicted within a structural model and when the theory is to be explored rather than confirmed (Hair et al., 2014).

In this chapter, we occupy a middle ground between testing theory and exploring theory. Relevant variables for use are identified (on the basis of proto-theory and the empirical literature) but the exact relations between various items and its power in the overall construct is to be identified. Thus, PLS is a suitable theoretical modelling approach.

Figure 1: Measurement model and structural model

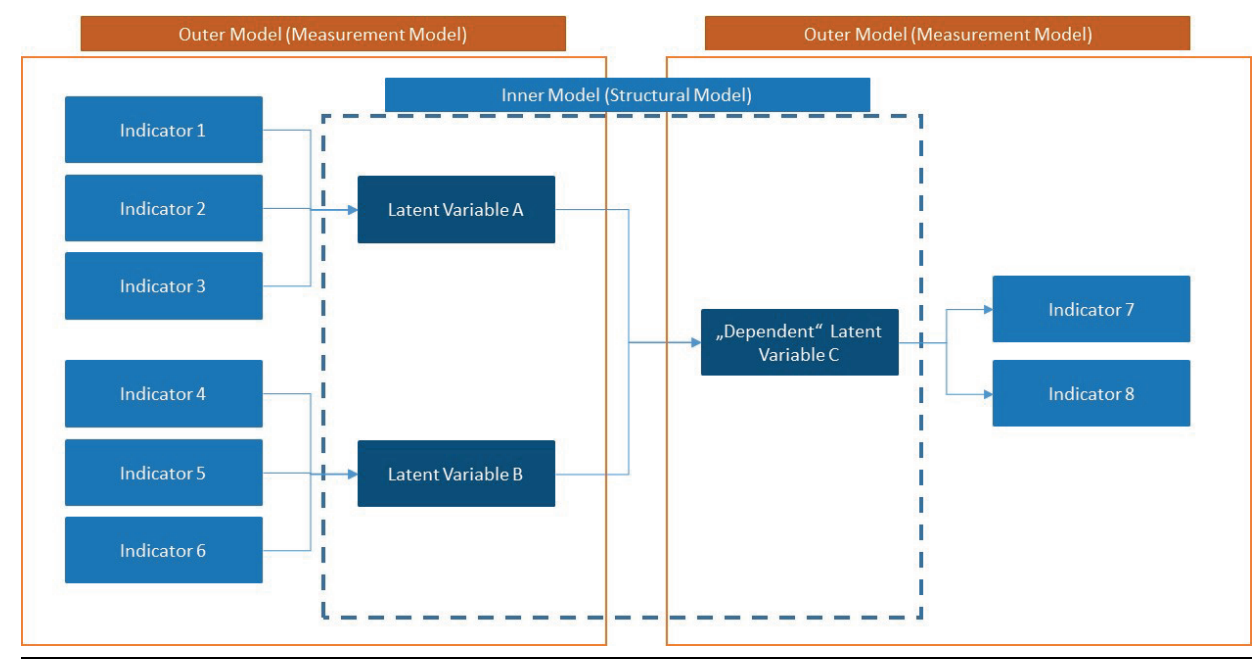

Source: based on Wong, 2013.

The structural model consists of the constructs Green Advocacy, Awareness and Governance Capacity as independent latent variables, constituting "environmental policy capacity" which influences the dependent latent variable Environmental Policy (Figure 2). All manifest variables directly or indirectly constitute the national drivers (stimuli) for Environmental Policy. We hypothesise that Green Advocacy, and Governance Capacity, represent the political-institutional conditions of the polity. Awareness represents the construct for cognitive-informational conditions. The construct International Environmental Governance interacts with national Environmental Policy. The direction of causality in this link (see Figure 2, option 1 or 2 ) is discussed below. 
We postulate that cognitive-informational framework conditions, the capacity to generate knowledge, and effectively distribute knowledge, influence the politicalinstitutional framework conditions. However, we hypothesise that Awareness does not directly influence the policy output. Policy output is believed to stem from the interactions of green advocacy actors with the administration and political actors. The influence of Awareness is hypothesised to occur via Green Advocacy, while in our path analysis we will also consider its influence via the direct route to Environmental Policy.

The influence of institutional structure of a country (neo-corporatism, liberalpluralism) and culture (dominant religion) is not being examined as done by Liefferink et al. (2009) because structural equation modelling is not suitable for the inclusion of binary dummy variables.

Figure 2: Determinants of environmental policy conditions

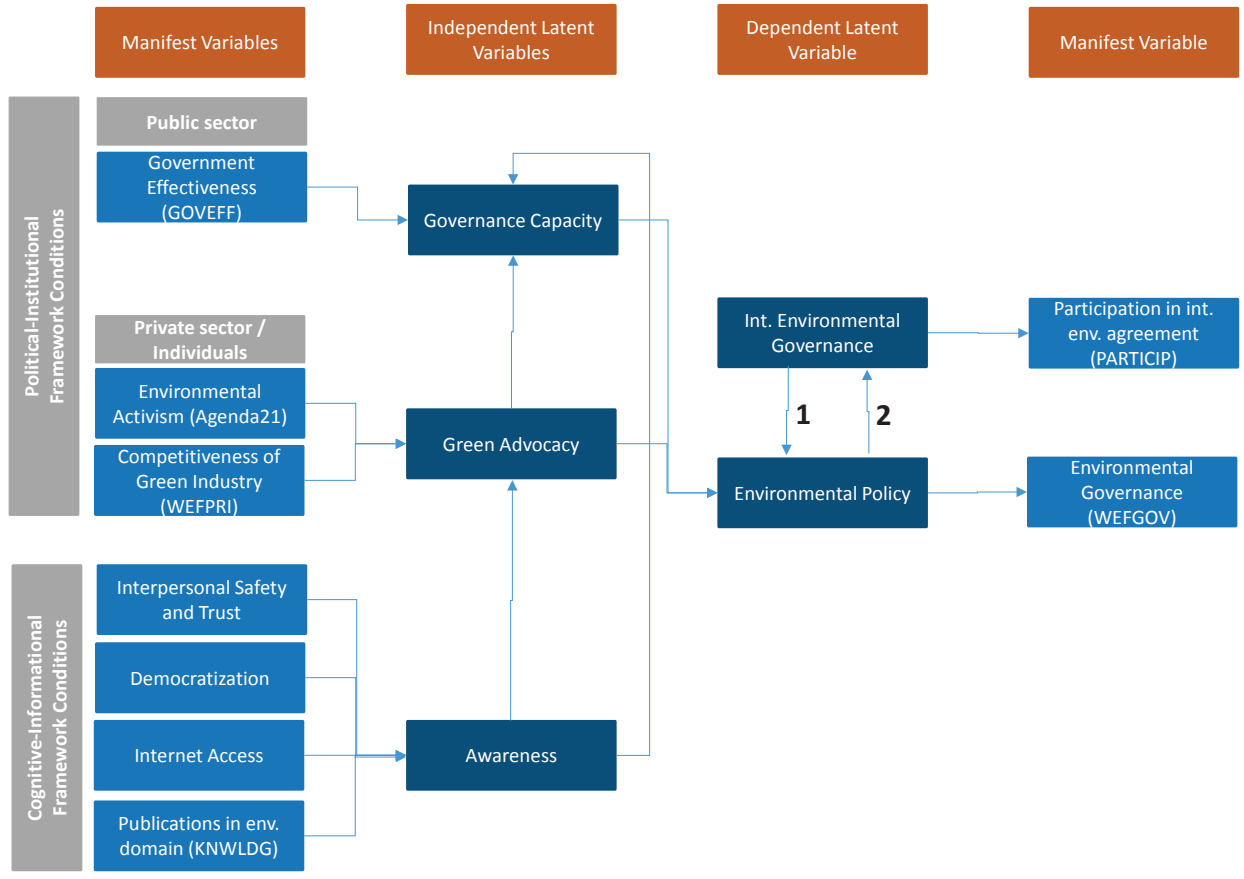

Source: own illustration, related to Jaenicke (2005).

We adjusted the data set by carrying out a missing value analysis to ensure validity of our analysis. Since, for example, for the variable Knowledge more than 5\% of the data cases are missing (Hair et al., 2014, p. 51), we chose not to revert to mean replacement algorithms but apply case-wise replacement of missing values, which means that cases with missing variables are dropped (Ringle et al., 2010). This reduces our set of observations from 71 countries to 47 country data sets (see appendix Table 9). 


\subsection{Results and discussion}

We calculated the basic structural model in order to detect the influential power of the different constructs towards Environmental Policy by using the software SmartPLS (Ringle et al., 2005). Alternative specifications of the structural model are also investigated, and results of those will be given too, but we start with the results for the model described in Figure 2.

The assessment of the PLS model results is conducted in two steps (see Weiber \& Mühlhaus, 2010). First the outer models (measurement models) are being assessed. In the next step the inner model (structural model) is examined.

\subsubsection{Reflective measurement model}

First, we discuss the reflective models with regard to the latent variable "Environmental Policy" and "International Environmental Governance". We need to examine the estimates for the relationships between the latent variables and the indicators (the outer loadings), which is WEFGOV and PARICIP respectively. The outer loadings of the latent variables on WEFGOV of 1.0 and PARTICIP of 1.0 are above the threshold value of $0.7^{8}$, because they are single item constructs (Figure 3 ). ${ }^{9}$ Thus, the reflective constructs (Environmental Policy, International Environmental Governance) are acceptable for the analysis.

\subsubsection{Formative measurement models}

The validity of formative constructs is examined by assessing the size of weights. If weights are close to 1 or -1 the dependency between manifest variable and latent variable is high. If weights are closer to 0 , the dependency between manifest variable and latent variable is weak (see results in (Figure 3).

The constructs Advocacy, Awareness and Governance Capacity all include some indicators with high weights (Table 1). Internet Access, and Strength of Green Industry (WEFPRI) have the strongest influences on the composite constructs (Figure 3). ${ }^{10}$ The indicator AGENDA21 has low weights. Strength of Green Industry (WEFPRI) is weakly correlated with the world trade share of potential environmental goods of OECD countries ( $R^{2}$ at 0.13 ) (Legler et al., 2007, export share in total world export for 24 countries

\footnotetext{
${ }^{8}$ Weiber \& Mühlhaus, 2010, p. 262. Hair et al., 2014, p. 109 suggest a threshold value of 0.7.

${ }^{9}$ In the single-item constructs "Environmental Policy" and "International Environmental Governance" factors are not represented by a multi-item measurement model. Thus, the criteria for reflexive measurement model analysis do not apply and it is left to the structural model examination whether the factors are representative (Hair et al., 2014, p. 99).

${ }^{10}$ If we add the $\mathrm{CO}_{2}$ intensity per GDP to the construct Advocacy as an instrument for the strength of polluting industry, the sign is negative (negative influence of high $\mathrm{CO}_{2}$ intensity per GDP on Advocacy, as expected). Yet the influence is insignificant in our model (coefficient -0.16, t-value at 1.94). We use the average value between 1998-2003 of the $\mathrm{CO}_{2}$ emission per GDP (2005 USD) from the World Bank World Development Indicators.
} 
only) with the United States, Germany and Japan being outliers in relative export strength. Thus, WEFPRI, which is available for a larger sample size, is utilised to capture the strength of green industry.

Democratisation, Knowledge and Interpersonal Safety and Trust have no meaningful influence within the construct Awareness. Internet Access has the highest loading on Awareness.

Technically, the correlation (i.e. multicollinearity) between manifest variables of a construct should be low. If manifest variables correlate, the construct is over-specified (Weiber \& Mühlhaus, 2010, p. 207). For all formative models the variance inflation factor (VIF), indicating multicollinearity, is below the threshold level of 5, except within the construct Governance Capacity. Governance Effectiveness and Regulatory Quality are correlated at an $\mathrm{R}^{2}$ of 0.88 (VIF 8.33). Thus, we drop Regulatory Quality from the construct Governance Capacity and use Governance Effectiveness as single-item construct. ${ }^{11}$ All other variables can be used for the measurement models.

The quality of formative measurement models can also be investigated by testing for the significance of the outer weights. The bootstrapping methodology can be used to calculate t-values which indicate whether a weight is significant (Nitzl, 2010, p 29; Hair et al., 2014, p 157). In three cases (Democracy, Interpersonal Trust, and Knowledge) the value is below 1.9, indicating that significance of the weight does not meet the 5\% significance level, while Knowledge meets the 10\% level (see Figure 4, Hair et al., 2014, p. 171).

Knowledge (KNWLDG) as an indicator for richness of knowledge in the domain of environmental issues within a society, does not contribute to the construct of Awareness in a significant way and it is understood as a cognitive-institutional framework condition. Shifting the indicator Knowledge into the construct of Advocacy does not yield any better results.

Table 1: Formative measurement model results

\begin{tabular}{lllll}
\hline Formative Constructs & Formative Indicators & Weight & T-Statistics & VIF \\
\hline Awareness & Democratisation & -0.044 & 0.686 & 1.18 \\
& Internet & $0.993^{* * *}$ & 9.423 & 1.87 \\
& Interpersonal Trust & 0.067 & 0.499 & 1.70 \\
& Knowledge & $0.146^{*}$ & 1.672 & 1.21 \\
Advocacy & Agenda21 & $0.243^{* * *}$ & 2.897 & 1.18 \\
& WEFPRI & $0.864^{* * *}$ & 17.145 & 1.18 \\
Governance Capacity & GovEff & $1.000^{* * *}$ & 0.000 & $/$ \\
\hline
\end{tabular}

\footnotetext{
${ }^{11}$ Adding a corruption index into the construct Governance Capacity is not sensible, since corruption (measured by the variable GRAFT, see appendix) is highly correlated with Governance Effectiveness ( $R^{2}$ at 0.95$)$.
} 
Source: own calculation using SmartPLS. VIF is calculated in SPSS. Note: the critical t-values for significance levels of $1 \%\left({ }^{* *}\right), 5 \%\left({ }^{* *}\right)$ and $10 \%\left({ }^{*}\right)$ probability of error are $2.57,1.96$, and 1.65 respectively. Bootstrapping calculation uses 47 cases (since we have 47 countries in the dataset) and 5000 samples.

\subsubsection{Structural model}

Several aspects are important for the assessment of the structural model (relations between latent variables). If path coefficients are above 0.2 the relation between latent variables is meaningful (Weiber \& Mühlhaus, 2010, p. 255). Further, the bootstrapping methodology can be used to determine the significance level of path coefficients. If the t-value is above 1.96 the path coefficient is significant at a $5 \%$ level.

There is no meaningful direct impact of the construct Awareness on Environmental Policy. ${ }^{12}$ As discussed above, Awareness works through Advocacy and Governance Capacity (Figure 3, see an overview of values also in Table 2).

If the construct Awareness is dropped from the overall structural model, the effect of Governance Capacity as well as Advocacy towards Environmental Policy does not change much. Yet the path coefficient from Awareness towards Advocacy is 0.83 (Figure 3), which is a rather strong effect which is also significant (Figure 3).

The effect of Advocacy on Environmental Policy is as similarly as strong as the effect of Governance Capacity on Environmental Policy. With a coefficient of 0.70 , the impact of Awareness on Governance Capacity is slightly weaker than the impact of Awareness on Advocacy, with a coefficient of 0.83 .

Government Effectiveness, the manifest variable in the construct Governance Capacity, is positively correlated with the policy output manifest variable WEFGOV. ${ }^{13}$ This is as expected, as general Governance Capacity does obviously influence the quality of policy output, also in specific policy areas like Environmental Policy.

Private sector advocacy does influence the general Governance Capacity slightly. ${ }^{14}$ Furthermore, private sector green advocacy has a direct influence on Environmental Policy. A limitation of our model and dataset is that there are no numbers on "environmental" or "green" aspects of Governance Capacity available for our sample size (since we use data for 47 countries). Yet, it cannot be ruled out, and empirically it shows to be reasonable according to our model results, that green Advocacy of the private sector has an influence on the Governance Capacity.

If Democratisation and Interpersonal Safety and Trust are put in a separate construct, apart from Awareness, their direct influence on Environmental Policy is not

\footnotetext{
${ }^{12}$ Calculating the path between Awareness and Environmental Policy would yield a coefficient of 0.13 and a tvalue of 1.05 , thus this path is not significant.

${ }^{13}$ The R2 of WEFGOV and GOVEFF is 0.88 .

${ }^{14}$ There is some influence of Advocacy on Governance Capacity. If a path between both constructs is added in the structural model, it yields a coefficient of 0.25 and a t-value of 2.53 . All other paths do not change if this influence is dropped.
} 
meaningful. This indicates that those variables are well placed in the construct Awareness (see appendix, Figure 5 - Figure 6).

When we add an economic factor (GDP per capita) as another independent variable to influence Environmental Policy (Jaenicke, 2005), the results do not change significantly. ${ }^{15}$ GDP per capita correlates positively with WEFGOV with an $R^{2}$ of 0.72 . This shows that rising GDP per capita may have a positive influence on the stringency of environmental regulation, yet in the structural model this influence is not systematically captured. The fact that an economic factor as another construct does not change the significance of the other variables reaffirms our structural model and lends credibility to the causal structure of polity drivers.

We also investigated the influence of economic conditions as a separate construct, such as trade openness and dependency on international financial inflows, measured as Foreign Direct Investment (FDI). The results do not change and the influence of those economic conditions on environmental policy is not significant (Figure 11, Figure 12, see data description in Table 7), or at least it cannot be captured in our model, since the relationship of interdependencies could be non-linear. This exemplifies that our core model, based on structural conditions regarding the institutions and actors is robust to alternative specifications. ${ }^{16}$ Countries with weaker environmental regulation do not per se receive higher amounts of FDI as postulated by the pollution haven hypothesis.

We use relative strength of environmental industry within a country (Competitiveness of Green Industry, WEFPRI) as a proxy for strength of advocacy of the environmental industry, which is in favour of environmental regulatory stringency. Also, causality in the other direction could be prevalent but reverse causality cannot be tested in structural equation modelling based on partial least squares (Henseler \& Fassott, 2010). There could, though, potentially be reverse causality between strong environmental industry (WEFPRI) and environmental policy (WEFGOV). In fact, Environmental Governance (WEFGOV) and Competitiveness of Green Industry (WEFPRI) are significantly and positively correlated ${ }^{17}$. The inability of reverse causality testing in partial least square analysis is a limitation in our methodological approach. If we change the structural model in the way that Environmental Policy influences the strength of environmental industry (WEFPRI) and environmental activism (AGENDA21) the $\mathrm{R}^{2}$ of Environmental Policy decreases to 0.84 (Figure 7, Figure 8). We thus conclude that Advocacy at least has the potential to influence Environmental Policy.

\footnotetext{
${ }^{15}$ The path coefficient of GDP per capita as a single item construct (independent latent variable) on Environmental Policy is at -0.036 .

${ }^{16}$ If we include a latent variable construct with only FDI as a reflexive instrument, which is influenced by Environmental Policy, the small positive relationship between quality of environmental regulation and FDI is insignificant. It could have been expected that stronger environmental regulation leads to fewer FDI inflows, according to the pollution haven hypothesis (Kalamova \& Johnstone, 2011).

${ }^{17} R^{2}$ of 0.82 .
} 
Figure 3: Path coefficient of the main model

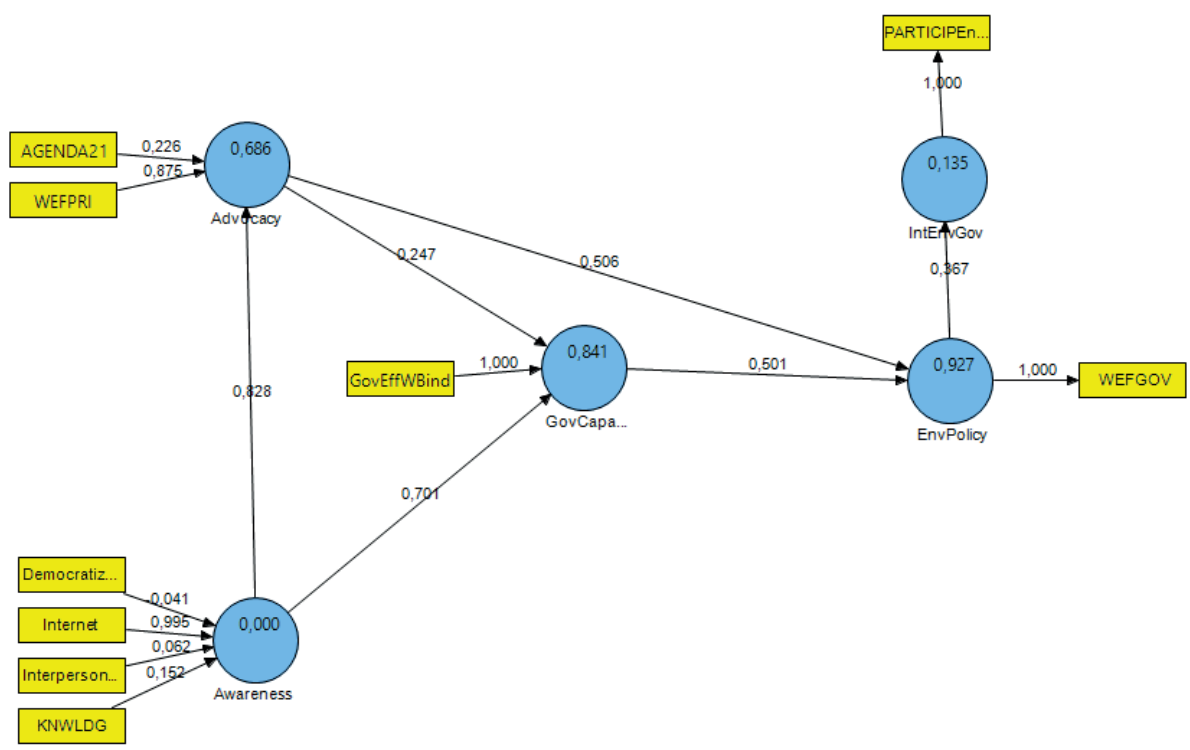

Source: based on own calculation using SmartPLS. Threshold values for coefficients is 0.2. The outer loading is always 1.0 in single item constructs. Coefficients in measurement models are always between -1.0 and 1.0. The closer the number is to -1.0 or 1.0 the larger is the effect of the item. Value in circle shows $R^{2}$.

Figure 4: T-values of the main model

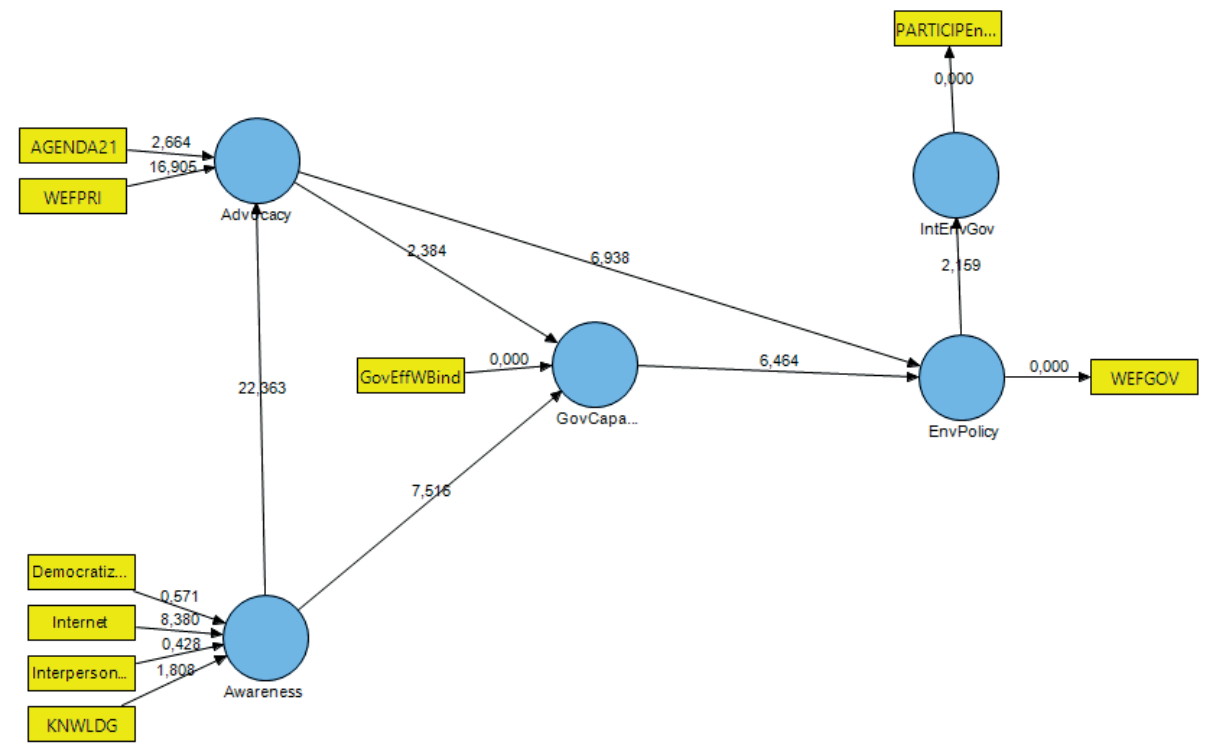

Source: based on own calculation using SmartPLS. Threshold values for significance of $1 \%, 5 \%$ and $10 \%$ probability of error are $2.57,1.96$, and 1.65 respectively. Singe item constructs do not have a significance level. 
As for the relationship between International Environmental Governance and Environmental Policy, the path analysis indicates that the causality runs from Environmental Policy to International Environmental Governance much more than in the other way. The coefficient for the influence of national Environmental Policy towards International Environmental Policy is larger than the coefficient for the reverse influence. ${ }^{18}$ A deeper (case-based) analysis is needed to investigate the question of causality, for example the identification of critical conditions for a policy to become adopted (which may have something to do with individuals and/or changes in government). ${ }^{19}$ Also, the $\mathrm{R}^{2}$ of the construct International Environmental Governance is very low at 0.13. This indicates that other factors do influence International Environmental Governance beyond national Environmental Policymaking capacity.

Advocacy and Governance Capacity have no direct, meaningful effect on International Environmental Governance, but via national Environmental Policy. ${ }^{20}$ This does not necessarily mean that e.g. Governance Capacity does not have a positive influence on International Environmental Governance, but that in this structural model it does not yield meaningful results. This could be an indication that international environmental policymaking follows very different dynamics than national environmental policymaking. ${ }^{21}$

Of the directly measured variables, Jacob \& Volkery (2006) detected a strong and positive influence of governance effectiveness, green industry strength as well as green NGO activity on environmental policy, which we can also confirm according to our results. Internet Access is positively associated with environmental policy, which has not been treated in other quantitative studies. It is found that the influence of Internet Access (as a cognitive-informational framework condition) is through Advocacy and Governance Capacity. Differing from Pellegrini \& Gerlagh (2006), the influence of the degree of democratisation does not turn out to be significant. Democratisation might influence environmental regulation, yet its direct influence cannot be measured in our model. In line with our results, Jacob \& Volkery (2006) find no significant dependency between environmental knowledge creation and environmental policy pioneer behaviour.

The analysis is subject to some further limitations. First, the effect of international environmental governance on countries is not appropriately measurable with the proxy participation in environmental agreements (PATICIP). For this construct, further indicators or time series (which we do not have) are required to explore the international environmental policymaking dynamics as well as situational factors like economic growth cycles, or electoral turnout, in greater detail. This would allow a better under-

\footnotetext{
${ }^{18}$ Path coefficient from national Environmental Policy to International Environmental Policy is 0.36 , whereas the coefficient in the other direction is -0.013 . The $R^{2}$ of the construct Environmental Policy does not change.

${ }^{19}$ Case studies are an important source of information for theory building but less suited for testing theories.

${ }^{20}$ If paths between Advocacy and International Environmental Agreements as well as Governance Capacity and International Environmental Agreements are tested, it yields the following results: coefficient values are at 0.006 and 0.680 , t-values are at 0.014 and 2.311 .

${ }^{21}$ Correlation between WEFGOV and PARTICIP is very low, with an $\mathrm{R}^{2}$ at 0.17 .
} 
standing of the interaction between national and international environmental governance and an investigation of the influence of international policy pressures. Jacob \& Volkery (2006) find a significant positive relationship between participation in international policymaking and national environmental policymaking. Second, only the influence of structural determinants is being analysed. In doing so, we do not want to deny the influence of strategic action in the form of wheeling and dealing and the role of media. Our approach does not allow us to analyse such factors. Third, the influence of resistance from polluters as a negative factor could not be analysed because there are no statistics or any good proxies for countervailing advocacy forces. Fourth, reverse causality could not be tested simultaneously in our structural equation model. This is a clear limitation of the analysis. The mechanism of simultaneous interaction deserves further investigation, which we could not conduct in our analysis. Fifth, we use an aggregate measure for policy output, which does not differentiate between, for example, emission policies and waste policies. It would also be interesting to do the analysis for different domains of environmental policy: climate policy, waste policy and clean air policy. Unfortunately information at lower levels of aggregation is not available for our country sample. A last limitation, holding true for all quantitative analysis, is that all variables are subject to measurement problems. The use of different manifest variables helps to go around this problem somewhat. Of the various measures we consider the construct for Governance Capacity as the weakest measured variable. This is caused by the absence of information on the size and quality of environmental protection agencies or representation of green interest in parliament in the countries of investigation. For GOVEFF and WEFPRI, subjective measures are used from the World Economic Forum. We would have liked to have used objective measures, if only to compare the robustness of the findings against more objective measures, but such measures are not available for the sample of investigation.

Despite several limitations, the results appear rather plausible. They fit quite well with the empirical grounded propositions from Jaenicke (2005) and Jacob \& Volkery (2006), in particular that national green industry competitiveness and cooperation with the government has a strong, positive link with environmental policy output. But also access to the internet and information distribution, via the political-institutional framework, positively contribute to environmental policymaking.

The $\mathrm{R}^{2}$ of the dependent latent variable (Environmental Policy) is an important measure for the quality of the overall structural model. An $R^{2}$ above 0.5 can already indicate a good fit of the inner, structural model. The $R^{2}$ is at 0.92 for the construct Environmental Policy. This shows that the four constructs explain 92\% of the variance of the endogenous latent construct Environmental Policy.

Statistically, 92\% of the variance of environmental policy output could be explained, which is very high for a model incorporating only structural factors.

If the construct International Environmental Policy is dropped, the $\mathrm{R}^{2}$ and coefficient values of the Environmental Policy model do not change. The construct International 
Environmental Governance is underrepresented, which is indicated by $R^{2}$ of 0.13 . Thus, as stated previously, International Environmental Governance follows a more complex structure which is beyond the scope and capability of our model to capture.

Table 2: Path coefficients and significance

\begin{tabular}{lllc}
\hline Path & Path Coefficient & Standard Deviation & T Statistics \\
\hline Advocacy -> EnvPolicy & $0.5021^{* * *}$ & 0.0462 & 10.8711 \\
Avcocacy -> GovCapacity & $0.2593^{* *}$ & 0.1039 & 2.4956 \\
Awareness -> Advocacy & $0.8296^{* * *}$ & 0.0236 & 35.0885 \\
Awareness -> GovCapacity & $0.9061^{* * *}$ & 0.0144 & 63.0199 \\
EnvPolicy -> IntEnvGov & $0.3669 * * *$ & 0.1109 & 3.3088 \\
GovCapacity -> EnvPolicy & $0.5038^{* * *}$ & 0.0492 & 10.2378 \\
\hline
\end{tabular}

Source: own calculation using SmartPLS. Note: the critical values for significance levels of $1 \%(* * *), 5 \%(* *)$ and $10 \%\left(^{*}\right)$ probability of error are $2.57,1.96$, and 1.65 respectively. Bootstrapping calculation uses 47 cases and 5000 samples.

We check the structural model (Table 3) for collinearity issues by extracting the latent variable scores from each predictor construct (Hair et al., 2014, p. 188). For two sets of predictors on dependent variables the bilateral possibility of collinearity is tested: Awareness and Advocacy on Governance Capacity, and Advocacy and Governance Capacity on Environmental Policy. Results show that the tolerance VIF for the latent variable values is slightly above the threshold value of 5 in three cases, which indicates that we encounter small collinearity among the predictor constructs and respective dependent latent variables (Table 3).

Table 3: Collinearity assessment of constructs

\begin{tabular}{llll}
\hline Set 1 & \multicolumn{2}{l}{ Set 2} \\
(independent latent variable Governance Capacity) & (dependent latent variable Environmental Policy) \\
\cline { 2 - 4 } Construct & VIF & Construct & VIF \\
\hline Awareness & 5.61 & Advocacy & 6.57 \\
Advocacy & 3.18 & Governance Capacity & 6.53 \\
\hline
\end{tabular}

Source: own calculation using SPSS.

In addition to the evaluation of the $\mathrm{R}^{2}$ of the endogenous construct Environmental Policy, it can be insightful to assess whether omitting a construct can have a substantive impact on the endogenous construct. This can be measured for each construct with the $f^{2}$ effect size (Hair et al., 2014, p 177). The $f^{2}$ effect size measures the change in the $\mathrm{R}^{2}$ value when a specified exogenous construct is omitted from the overall structural model. It is used to evaluate whether the omitted predictor construct has a substantive impact on the $\mathrm{R}^{2}$ values of the endogenous construct (Governance Capacity and Environmental Policy). It represents the contribution to dependent construct $R^{2}$ of an exog- 
enous construct. Threshold values are 0.02, 0.15 and 0.35, representing small, medium, and large effects of the exogenous latent variable to the endogenous latent variable's $\mathrm{R}^{2}$ value.

Predictive relevance postulates, besides the evaluation of the magnitude of the $R^{2}$ independent construct accuracy, that the model must be able to provide a prediction of the endogenous latent variable's indicators (Henseler et al., 2009). If the StoneGeisser's $Q^{2}$-values are above zero, they give evidence that the observed values are well reconstructed and that the model has predictive relevance. Cross-validated redundancy measures $\left(Q^{2}\right)$ are all well above 0 in our model (see further Hair et al., 2014, p. 186).

Also, similar to $\mathrm{R}^{2}$ and the respective effect size $f^{2}$, the relative impact of predictive relevance can be compared by means of the $q^{2}$ effect size. As a relative measure of predictive relevance $q^{2}$, values of $0.02,0.15$ and 0.35 respectively indicate that an exogenous construct has a small, medium, or large predictive relevance for a certain endogenous construct. Both, Advocacy and Governance Capacity have strong predictive relevance with regard to the endogenous construct Environmental Policy (Table 4). Similarly, the dependent construct Governance Capacity, is predicted by Awareness and Advocacy in a relevant way.

Table 4: Effect size, and predictive relevance of constructs

\begin{tabular}{|c|c|c|c|c|c|c|}
\hline \multirow[b]{2}{*}{ Construct } & \multicolumn{3}{|c|}{ Environmental Policy } & \multicolumn{3}{|c|}{ Governance Capacity } \\
\hline & $Q^{2}$ & $q^{2}$ & $f^{2}$ & $\mathrm{Q}^{2}$ & $q^{2}$ & $f^{2}$ \\
\hline & 0.85 & & & & & \\
\hline Advocacy & & 0.40 & 0.93 & & & \\
\hline \multirow[t]{2}{*}{ Governance Capacity } & & 0.50 & 1.08 & & & \\
\hline & & & & 0.83 & & \\
\hline Awareness & & & & & 0.95 & 1.04 \\
\hline Advocacy & & & & & 0.65 & 0.04 \\
\hline
\end{tabular}

Note: calculations based on SmartPLS and own calculations. We use an omission distance in the blindfolding procedure of 7 (it should be between 5 and 10 according to Hair et al., 2014). Only direct links in the structural model between exogenous and endogenous latent variables have been assessed.

The structural model is valid and the constructs have predictive relevance for the endogenous latent variable Environmental Policy and Governance Capacity.

\subsection{Conclusion}

In environmental policymaking many actors are involved in a direct and/or indirect way: citizens and citizen organisations, business organisations, politicians and policy officials. Business is known to exercise an important influence on environmental policy through lobbying activities. Business, however, is not a single actor. Those companies who will gain from new or stricter regulation (the suppliers of environmental technologies) can 
be expected to actively support such measures, whereas those that are affected negatively (the polluters) will lobby against new regulations. The success of business in attempting to influence policy will depend on the quality of environmental knowledge (whether or not this can be contested) and values in society. An important actor for the creation of environmental policy is the environmental protection administration, the cabinet-level agency responsible for protecting and conserving the natural environment. According to Jaenicke (2005), a high domestic capacity for environmental policymaking is a necessary condition for becoming a pioneer country in environmental policy. Environmental policymaking is also known to be affected by international environmental policy agenda setting and is interlinked with the policymaking of other countries (Tews, 2005). Macroeconomic factors are also hypothesised to play a role. Kalamova \& Johnstone (2011) have found that environmental policy stringency is positively associated with foreign direct investment inflow. Trade openness is seen by Holzinger et al. (2008) as a driver for environmental policy competition which leads to environmental policy convergence.

In this chapter, the influence of several variables is investigated through structural equation modelling which is based on three non-observable constructs (Environmental Awareness, Green Advocacy and Governance Capacity) on the basis of formative indicators for which measures exist. This is an innovative methodological approach as other studies (especially Liefferink et al., 2009; Jacob \& Volkery, 2006) have only used multivariate analyses so far, without analysing the interaction among the influencing factors itself. Of the three constructs representing the independent latent variables, Green Advocacy and Governance Capacity are most strongly associated with Environmental Policy. The most important factor behind Green Advocacy, according to the modelling results, is Competitiveness of Green Industry (WEFPRI), which suggests that demand from green business for Environmental Policy is potentially more important than environmental activism (AGENDA21). This is an important insight, which fits with what Jaenicke (2005) has written and Jacob \& Volkery (2006) showed empirically. Also, access to internet plays a relatively strong role in the construct Awareness. The overall modelling results indicate that Advocacy has a similarly strong effect on Environmental Policy as Governance Capacity, according to the path coefficients. This is an interesting finding, since Advocacy incorporates environmental-specific aspects, while Governance Capacity does not constitute explicit administrative capacity in the environmental area. The drivers towards environmental regulation are green industries and environmental knowledge creation, as well as knowledge sharing mechanisms (measured as publications in the environmental domain and internet access).

A particular area for further investigation is the direction of causality between national environmental policy and international environmental policymaking. Our methodology has also not captured the influence of lobbying work by the industry per se or the role of the media. Here, case analysis is particularly useful as it allows many variables to be integrated into the analysis, including the role of key individuals acting as 
policy entrepreneurs and the influence of empirically identified circumstances. ${ }^{22}$ There is also no coherent data available on the strength of environmental administration (which would be part of Governance Capacity) beyond the countries of the European Union. It would be a good deal of work to set standards for the measurement of environmental administration quality across countries.

The high positive and direct influence of the proximate variables Advocacy and Governance Effectiveness is a robust finding across different causal structures. Even though different structural models were investigated for different sets of data, we haven't exhausted all possible causal possibilities and the analysis is limited to variables that could be measured. The exact causal structure and true causal values have not been found, yet the analysis of causality presented in this chapter goes far deeper than what is possible with multivariate linear regression based on a simple model structure that does not permit the researcher to determine causal pathways of influence variables and build a theory. Structural equation modelling constitutes an important avenue for building a theory of environmental policymaking and testing hypotheses. We propose that it is used more in political science and political economy analysis to detect potential structural interdependencies between factors.

\footnotetext{
${ }^{22}$ An example of this is Lois Gibbs who, in the Love Canal case, was instrumental in bringing about change in U.S. environmental policy (Layzer, 2002) quoted in Crow (2010) who offers more examples of policy entrepreneurs and a discussion of the ways in which they were able to exercise influence.
} 


\subsection{Appendix}

\section{A. Detailed data explanation}

Table 5: Political-institutional framework conditions

\begin{tabular}{|c|c|c|c|c|}
\hline Environmental & Abbreviation: & Unit: & Source: & Year: \\
\hline Activism & AGENDA21 & $\begin{array}{l}\text { Number of Local Agenda } \\
21 \text { initiatives per million } \\
\text { people }\end{array}$ & ESI, 2005 & 2001 \\
\hline
\end{tabular}

\begin{tabular}{|c|c|c|c|c|c|}
\hline & 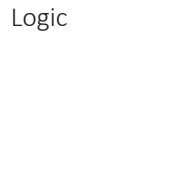 & \multicolumn{4}{|c|}{$\begin{array}{l}\text { Local Agenda } 21 \text { (LA21) is an international sustainability planning process } \\
\text { that provides an opportunity for local governments to work with their } \\
\text { communities to create a sustainable future. The number of Local Agenda } \\
21 \text { initiatives in a country measures the degree to which civil society is } \\
\text { engaged in environmental governance. }\end{array}$} \\
\hline & Methodology & \multicolumn{4}{|c|}{$\begin{array}{l}\text { For each country, the number of existing Local Agenda } 21 \text { initiatives was } \\
\text { counted and divided by the total country population. }\end{array}$} \\
\hline $\begin{array}{l}\text { Competitiveness of } \\
\text { Green Industry }\end{array}$ & & $\begin{array}{l}\text { Abbreviation: } \\
\text { WEFPRI }\end{array}$ & $\begin{array}{l}\text { Unit: } \\
\text { Min.: } 7.2 \\
\text { Max.: } 15.09=\text { high } \\
\text { World Economic Forum } \\
\text { Survey on private sector } \\
\text { environmental } \\
\text { innovation }\end{array}$ & $\begin{array}{l}\text { Source: } \\
\text { ESI, } 2005\end{array}$ & $\begin{array}{l}\text { Year: } \\
\text { 2003/4 }\end{array}$ \\
\hline
\end{tabular}

Logic Private sector innovation contributes to solutions to environmental problems.

Methodology This represents principal components of survey questions addressing several aspects of private sector environmental innovation: environmental competitiveness, prevalence of environmental management systems, and private sector cooperation with government.

\begin{tabular}{lllll}
\hline $\begin{array}{l}\text { Government } \\
\text { effectiveness }\end{array}$ & Abbreviation: & Unit: & Source: & Year: \\
& GOVEFF & Indexed between 0 and & World Bank, & Average \\
& & $\begin{array}{l}\text { 1=high levels of } \\
\text { effectiveness }\end{array}$ & Worldwide & 2000-2002 \\
& & & Governance \\
& & & Indicators \\
\hline
\end{tabular}

Logic Governmental effectiveness is defined in this data set as "quality of public service provision, the quality of the bureaucracy, the competence of civil servants, the independence of the civil service from political pressures, and the credibility of the government's commitment to policies." It is relevant for environmental sustainability because basic governmental competence enhances a society's ability to monitor and respond to environmental issues.

Methodology Government effectiveness captures perceptions of the quality of public services, the quality of the civil service and the degree of its independence from political pressures, the quality of policy formulation and implementation, and the credibility of the government's commitment to such policies. 


\begin{tabular}{llll}
\hline Regulatory Quality & $\begin{array}{l}\text { Abbreviation: } \\
\text { REGQUAL }\end{array}$ & $\begin{array}{l}\text { Unit: } \\
\text { Indexed between 0 and World Bank, } \\
\text { 1=high levels of quality }\end{array}$ & $\begin{array}{l}\text { Yorldwide } \\
\text { Average } \\
\text { Governance } \\
\text { Indicators }\end{array}$ \\
\hline Logic & $\begin{array}{l}\text { Regulatory quality captures perceptions of the ability of the government } \\
\text { to formulate and implement sound policies and regulations that permit } \\
\text { and promote private sector development. }\end{array}$ \\
\hline
\end{tabular}

Note: this variable is not being used in the final structural model.

Table 6: Cognitive-informational framework conditions

\begin{tabular}{|c|c|c|c|c|c|}
\hline Democratisation & & $\begin{array}{l}\text { Abbreviation: } \\
\text { Democratisation }\end{array}$ & $\begin{array}{l}\text { Unit: } \\
\text { Trend-adjusted 10-year } \\
\text { average score with high } \\
\text { values corresponding to } \\
\text { high levels of } \\
\text { democratic institutions }\end{array}$ & $\begin{array}{l}\text { Source: } \\
\text { Polity IV (ESI, } \\
\text { 2005) }\end{array}$ & $\begin{array}{l}\text { Year: } \\
\text { Average } \\
\text { 1993-2002 }\end{array}$ \\
\hline & Logic & \multicolumn{4}{|c|}{$\begin{array}{l}\text { The presence of democratic institutions increases the likelihood that } \\
\text { important environmental issues will be debated, that alternative views will } \\
\text { be aired, and that decision-making and implementation will be carried out } \\
\text { in an open manner. These factors improve the quality of environmental } \\
\text { governance. }\end{array}$} \\
\hline & Methodology & \multicolumn{4}{|c|}{$\begin{array}{l}\text { Average of the Polity IV scores for } 10 \text { years } 1993-2002 \text { adjusted for trend: } \\
\text { if the trend was positive, the average was increased by } 1 \text {, if the trend was } \\
\text { negative, the average was reduced by } 1 \text {. The purpose of the adjustment } \\
\text { was to reward improvement. }\end{array}$} \\
\hline \multirow[t]{3}{*}{ Internet Access } & & $\begin{array}{l}\text { Abbreviation: } \\
\text { Internet Access }\end{array}$ & $\begin{array}{l}\text { Unit: } \\
\text { Internet users (with } \\
\text { internet access) per } 100 \\
\text { people }\end{array}$ & $\begin{array}{l}\text { Source: } \\
\text { World Bank, } \\
\text { World } \\
\text { Development } \\
\text { Indicators }\end{array}$ & $\begin{array}{l}\text { Year: } \\
\text { Average } \\
\text { 2000-2002 }\end{array}$ \\
\hline & \multicolumn{5}{|l|}{ Logic } \\
\hline & \multicolumn{5}{|c|}{ Methodology Internet access, internet users (with internet access) per 100 people } \\
\hline
\end{tabular}




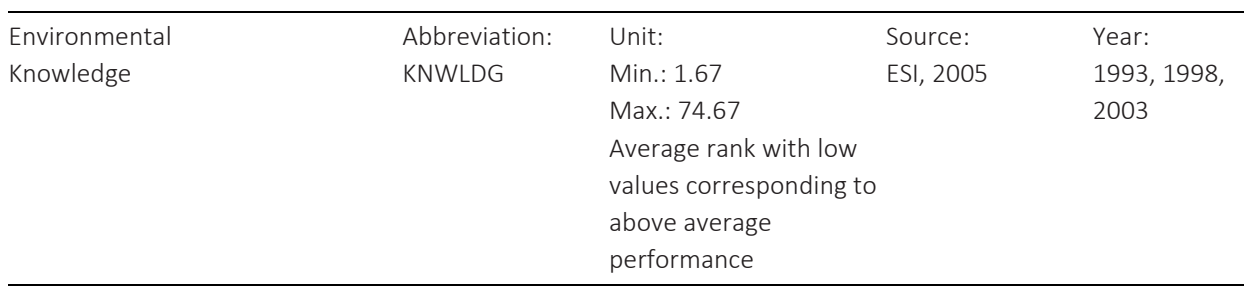

\begin{tabular}{|c|c|c|c|c|c|}
\hline & Logic & \multicolumn{4}{|c|}{$\begin{array}{l}\text { Creation and dissemination of knowledge about, inter alia, environmental, } \\
\text { ecological, and socio-economic processes is important for achieving } \\
\text { environmental sustainability for several reasons: i) it promotes decision- } \\
\text { making on the basis of sound information and data, ii) it facilitates } \\
\text { knowledge exchange and propagation between producers and users, iii) it } \\
\text { allows adoption of new knowledge and technologies in other regions and } \\
\text { sectors ("leapfrogging"). }\end{array}$} \\
\hline & Methodology & \multicolumn{4}{|c|}{$\begin{array}{l}\text { Count of publication of scientific knowledge in the top-rated peer- } \\
\text { reviewed journals in the fields of environmental science, technology, and } \\
\text { policy. ESI collected data on the primary author's institutional affiliation } \\
\text { and the location where the research was carried out for } 9 \text { highly ranked } \\
\text { peer-reviewed journals for each paper published during 1993, 1998, and } \\
\text { 2003. The } 9 \text { journals are: Ecology, Conservation Biology, Environmental } \\
\text { Science and Technology, Biological Conservation, Global Change Biology } \\
\text { (founded in 1995), Environmental Health Perspectives, Water Resources } \\
\text { Research, Environmental Toxicology and Chemistry, and Global } \\
\text { Biogeochemical Cycles. Three regressions were carried out: Publications } \\
\text { per author per million population Researchers per million population + } \\
\text { R\&D spending as \% of GDP + Publications per area and population; } \\
\text { Publications about foreign countries log(GDP) + Publications per area; } \\
\text { Publications per area } ~ \text { Publications per author + Population. The residuals } \\
\text { of each regression were ranked and aggregated to form an average rank } \\
\text { score. }\end{array}$} \\
\hline \multirow[t]{4}{*}{$\begin{array}{l}\text { Interpersonal } \\
\text { Safety and Trust }\end{array}$} & & $\begin{array}{l}\text { Abbreviation: } \\
\text { Interpersonal }\end{array}$ & $\begin{array}{l}\text { Unit: } \\
\text { Between } 0 \text { and } 1\end{array}$ & $\begin{array}{l}\text { Source: ISS, } \\
2011\end{array}$ & $\begin{array}{l}\text { Year: } \\
2000\end{array}$ \\
\hline & Logic & \multicolumn{4}{|c|}{$\begin{array}{l}\text { Studies have shown that societies with norms of trust and trustworthiness } \\
\text { experience faster economic growth, have denser civic and associational } \\
\text { life, and more effective public institutions, whereas in societies where } \\
\text { people must fear violation of their personal and property rights, there are } \\
\text { lower rates of new enterprise creation, engagement in associational life, } \\
\text { and compliance with public authorities (ISS, 2011). }\end{array}$} \\
\hline & Methodology & \multicolumn{4}{|c|}{$\begin{array}{l}\text { Focusing on perceptions and incidences of crime and personal } \\
\text { transgressions (scale, } 1=\text { low degree of crime). It ranges from small } \\
\text { criminality (theft, burglary, fraud) to serious crime (assault, murder). }\end{array}$} \\
\hline & & \multicolumn{4}{|c|}{$\begin{array}{l}\text { ISS measured personal security and trust by using data on general social } \\
\text { trust from a wide variety of surveys, indicators of trustworthiness such as } \\
\text { reported levels of crime victimisation, survey responses on feelings of } \\
\text { safety and security in one's neighbourhood, data on the incidence of } \\
\text { homicide, and risk reports on the likelihood of physical attack, extortion, or } \\
\text { robbery. }\end{array}$} \\
\hline
\end{tabular}


Table 7: Economic conditions

\begin{tabular}{|c|c|c|c|c|c|}
\hline \multirow[t]{3}{*}{ Investment } & & Abbreviation: FDI & $\begin{array}{l}\text { Unit: } \\
0=\text { low, 1=high }\end{array}$ & $\begin{array}{l}\text { Source: } \\
\text { World Bank, } \\
\text { World } \\
\text { Development } \\
\text { Indicators }\end{array}$ & $\begin{array}{l}\text { Year: } \\
\text { Average } \\
\text { 1998-2003 }\end{array}$ \\
\hline & Logic & \multicolumn{4}{|c|}{$\begin{array}{l}\text { The dependency on FDI could be an indicator how strongly a country is } \\
\text { exposed to manipulation concerning global policy diffusion. }\end{array}$} \\
\hline & Methodology & \multicolumn{4}{|c|}{ Foreign direct investment, net inflows (\% of GDP). } \\
\hline \multirow[t]{5}{*}{ Trade Openness } & & Abbreviation: & Unit: & Source: & Year: \\
\hline & & TRADEOPEN & Min.: 0.92 & World Bank, & Average \\
\hline & & & & $\begin{array}{l}\text { Development } \\
\text { Indicators }\end{array}$ & \\
\hline & Logic & \multicolumn{4}{|c|}{$\begin{array}{l}\text { The trade openness could be an indicator whether a country is prone to } \\
\text { regulatory competition due to its trade (economic) interconnectedness. }\end{array}$} \\
\hline & Methodology & \multicolumn{4}{|l|}{ Trade (\% of GDP). } \\
\hline
\end{tabular}

Table 8: Policy output

\begin{tabular}{lllll}
\hline World Economic & Abbreviation: & Unit: & Source: & Year: \\
Forum Survey on & WEFGOV & Min.: 0 & ESI, 2005 & 2003/2004 \\
$\begin{array}{l}\text { Environmental } \\
\text { Governance }\end{array}$ & & Max.: 1 & & \\
\hline
\end{tabular}

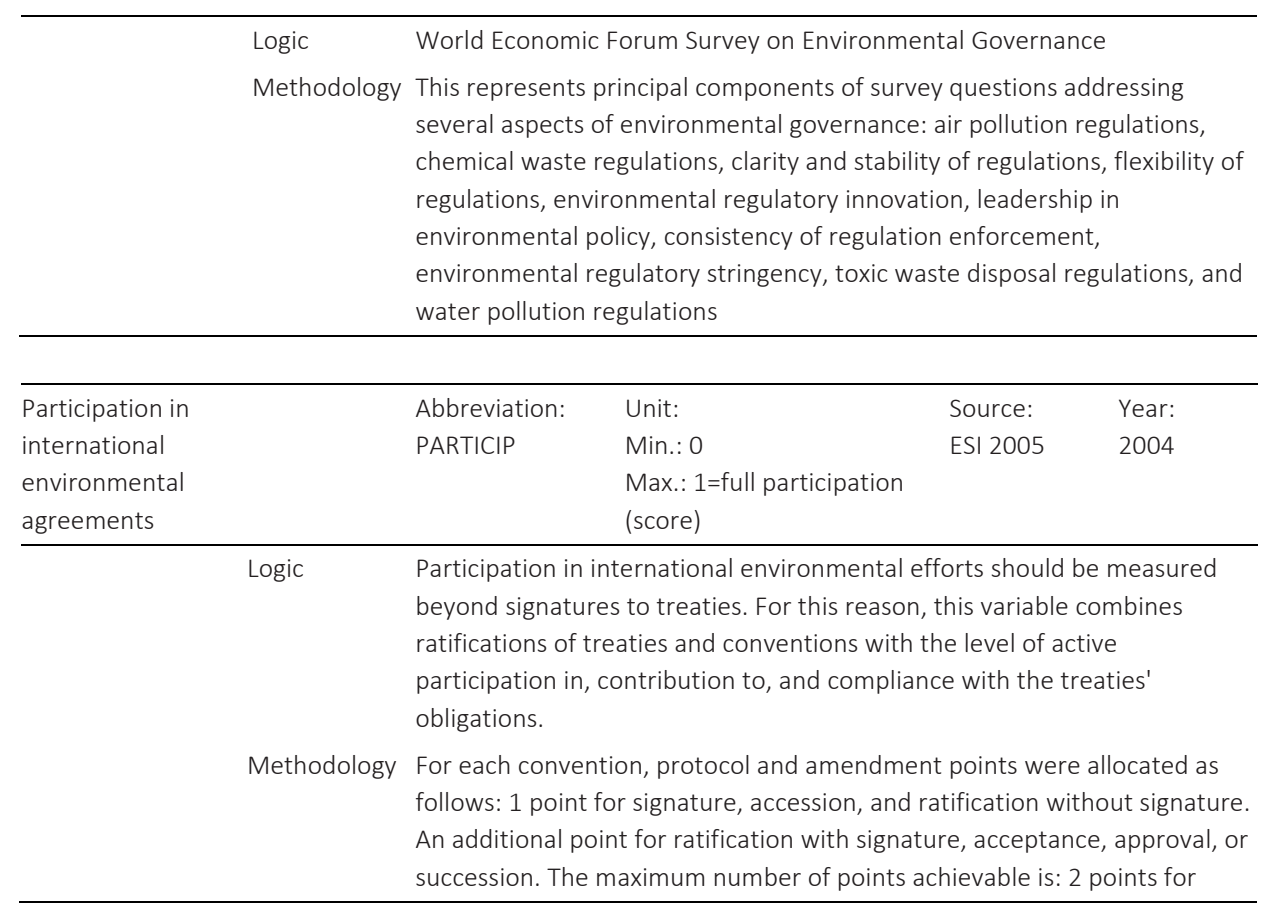




\begin{tabular}{|c|c|c|c|c|}
\hline $\begin{array}{l}\text { Participation in } \\
\text { international } \\
\text { environmental } \\
\text { agreements }\end{array}$ & $\begin{array}{l}\text { Abbreviation: } \\
\text { PARTICIP }\end{array}$ & $\begin{array}{l}\text { Unit: } \\
\text { Min.: } 0 \\
\text { Max.: 1=full participation } \\
\text { (score) }\end{array}$ & $\begin{array}{l}\text { Source: } \\
\text { ESI } 2005\end{array}$ & $\begin{array}{l}\text { Year: } \\
2004\end{array}$ \\
\hline
\end{tabular}

UNCCD, 12 points for Vienna Convention, Montreal Protocol, and its Amendments, 2 points for CITES, 4 points for UNFCCC and the Kyoto Protocol, 2 points for the Basel convention, 4 points for UNCBD, and 4 points for the Ramsar convention and the Cartagena Protocol. Due to the varying allocation of points, the observed value for each convention/protocol was re-scaled from 0-1 by dividing the observed points by the maximum number of points achievable. The re-scaled values were then aggregated using equal weights of $1 / 7$ each. Countries or territories not listed under the list of parties to a convention/protocol/amendment were assigned 0 points for the respective convention/protocol/amendment.

Table 9: Table of countries used in main model

\begin{tabular}{llll}
\hline Argentina & Ecuador & Jordan & Romania \\
Australia & Estonia & Latvia & Singapore \\
Austria & Finland & Lithuania & Slovenia \\
Belgium & France & Malaysia & Spain \\
Bolivia & Germany & Mexico & Sri Lanka \\
Brazil & Greece & Netherlands & Sweden \\
Bulgaria & Hungary & New Zealand & Switzerland \\
Canada & India & Nicaragua & Thailand \\
Chile & Ireland & Norway & Ukraine \\
China & Israel & Peru & United Kingdom \\
Colombia & Italy & Poland & United States \\
Denmark & Japan & Portugal & \\
\hline
\end{tabular}

\section{B. Different model structure}

Here we offer the results of alternative model structures. The influence of a separate construct consisting of Democratisation and Interpersonal Safety and Trust on Environmental Policy is shown to have no causal influence (Figure 5, Figure 6). The influence of Democracy and Interpersonal Safety and Trust (shown in Figure 7 and 8) cannot be viewed as separable from Knowledge and Internet (see Figure 3, Figure 4). 
Figure 5: Path coefficients for model variant A

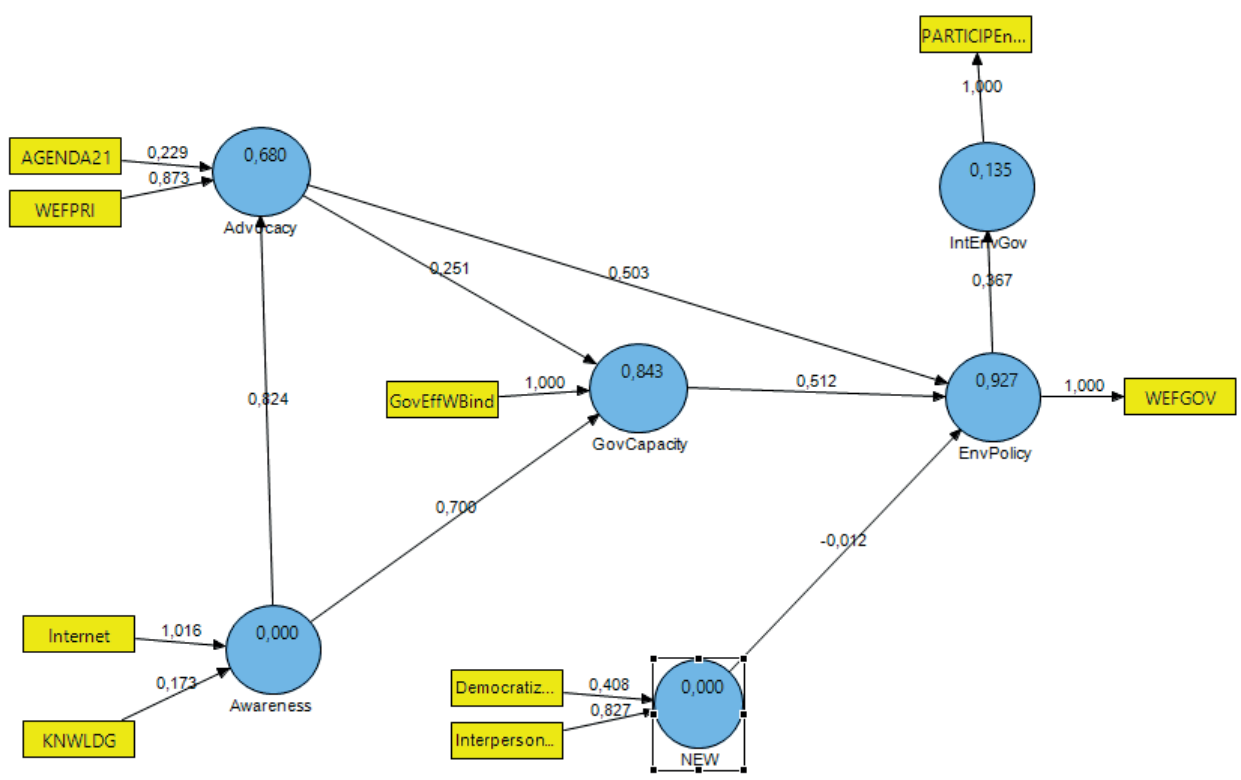

Source: based on own calculation using SmartPLS. Threshold values for coefficients is 0.2 . The outer loading is always 1.0 in single item constructs. Coefficients in measurement models are always between -1.0 and 1.0. The closer the number is to -1.0 or 1.0 the larger is the effect of the item. Value in circle shows $R^{2}$.

Figure 6: T-values for model variant A

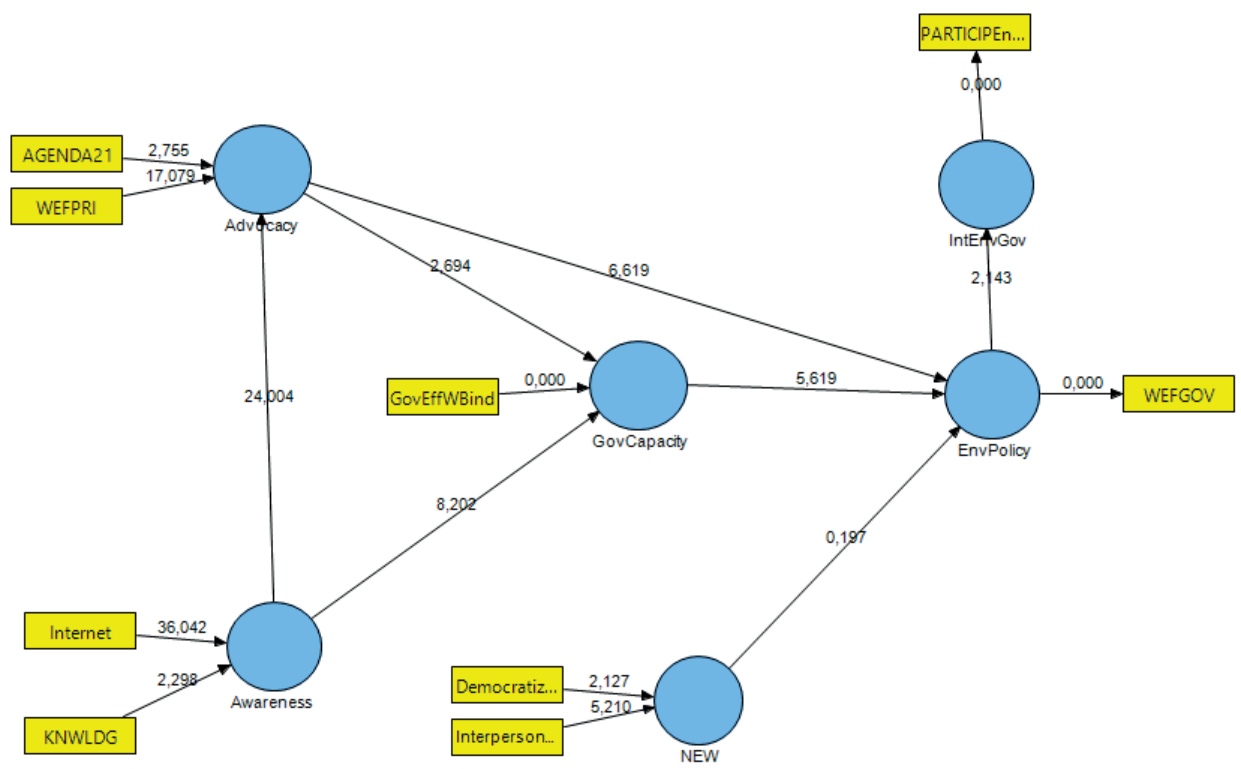

Source: Based on own calculation using SmartPLS. Threshold values for significance of $1 \%$, $5 \%$ and $10 \%$ probability of error are $2.57,1.96$, and 1.65 respectively. Singe item constructs do not have a significance level. 
If we reverse the causality between Environmental Policy and Advocacy (major strengths of green industry) the $\mathrm{R}^{2}$ decreases from 0.96 to 0.84 for the construct Environmental Policy (Figure 7). Thus, for the purpose to analyse environmental policy capacity we propose to understand the causality in the direction from strength of green industry (WEFPRI) to Environmental Policy.

Figure 7: Path coefficients for model variant B

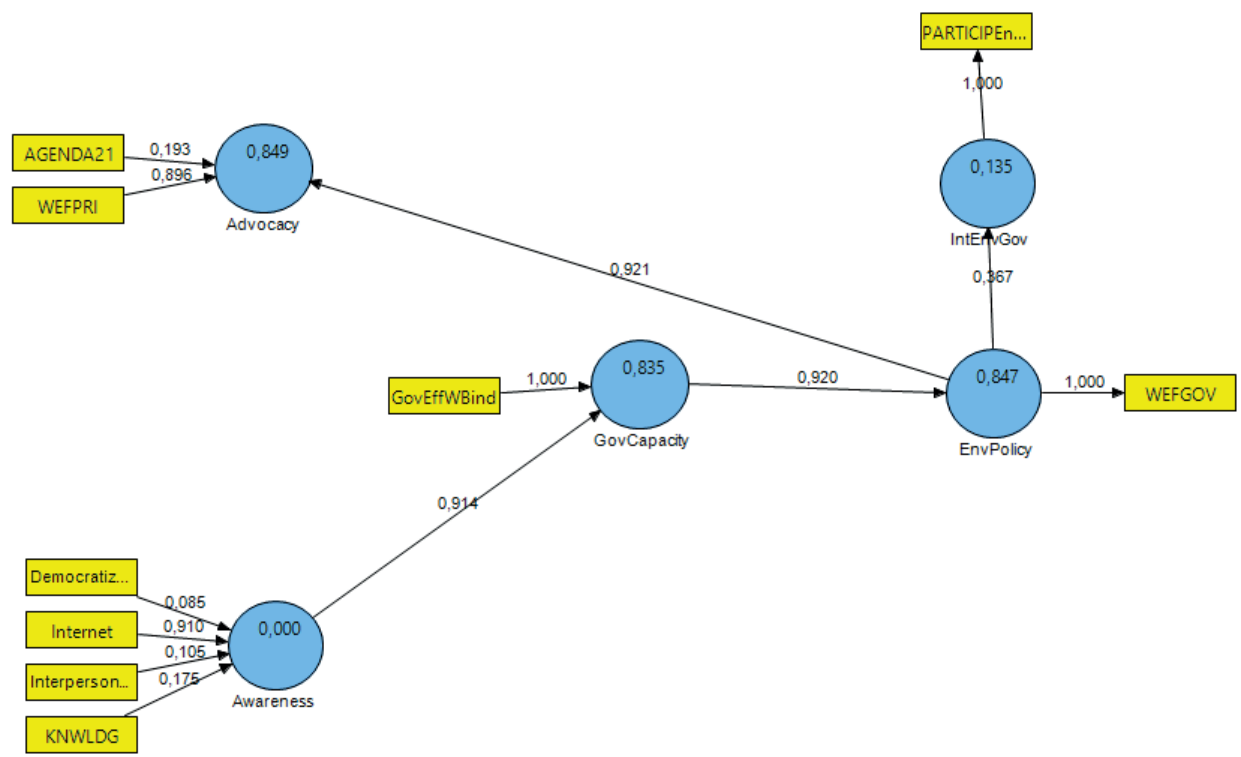

Source: Based on own calculation using SmartPLS. Threshold values for coefficients is 0.2 . The outer loading is always 1.0 in single item constructs. Coefficients in measurement models are always between -1.0 and 1.0. The closer the number is to -1.0 or 1.0 the larger is the effect of the item. Value in circle shows $R^{2}$. 
Figure 8: T-values for model variant B

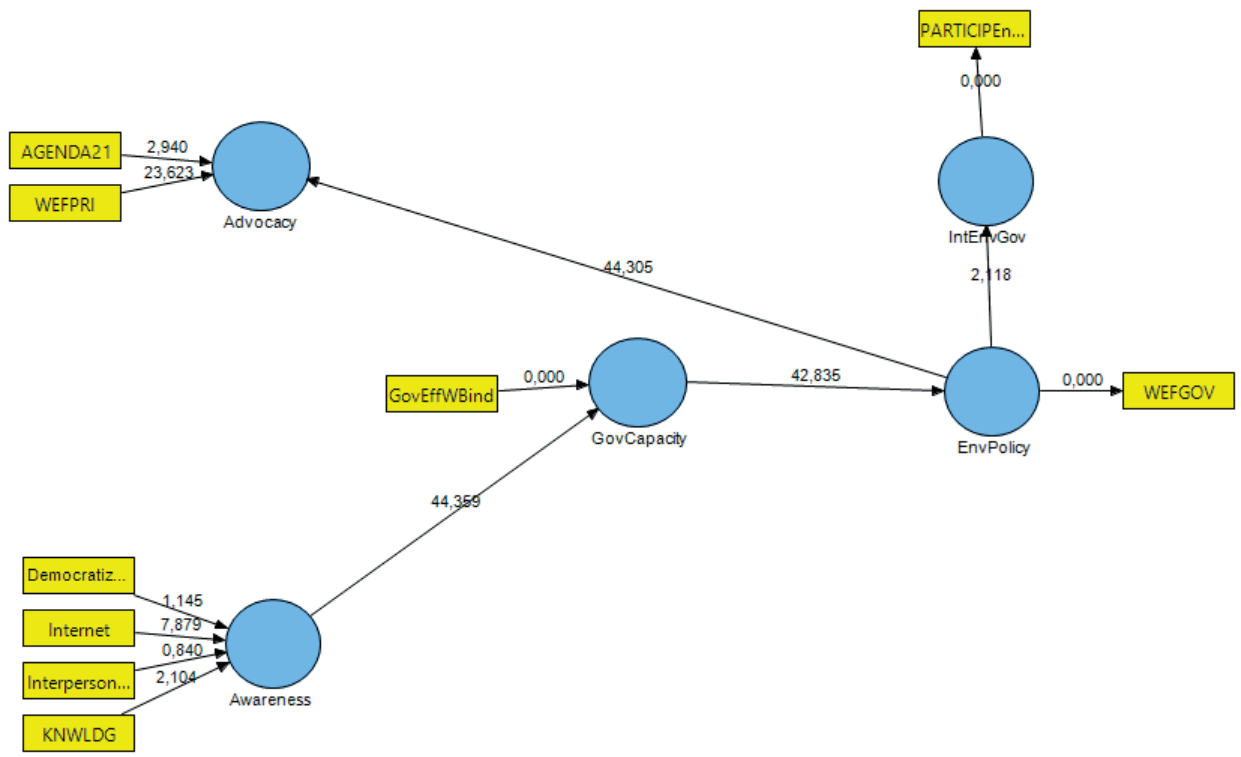

Source: Based on own calculation using SmartPLS. Threshold values for significance of $1 \%, 5 \%$ and $10 \%$ probability of error are $2.57,1.96$, and 1.65 respectively. Singe item constructs do not have a significance level.

Inserting Democratisation into the political-institutional framework conditions does not yield a better result (Figure 9, Figure 10). Thus, it can be assumed that Democratisation is part of the cognitive-informational framework conditions, which facilitate the exchange of information and knowledge. 
Figure 9: Path coefficients for model variant C

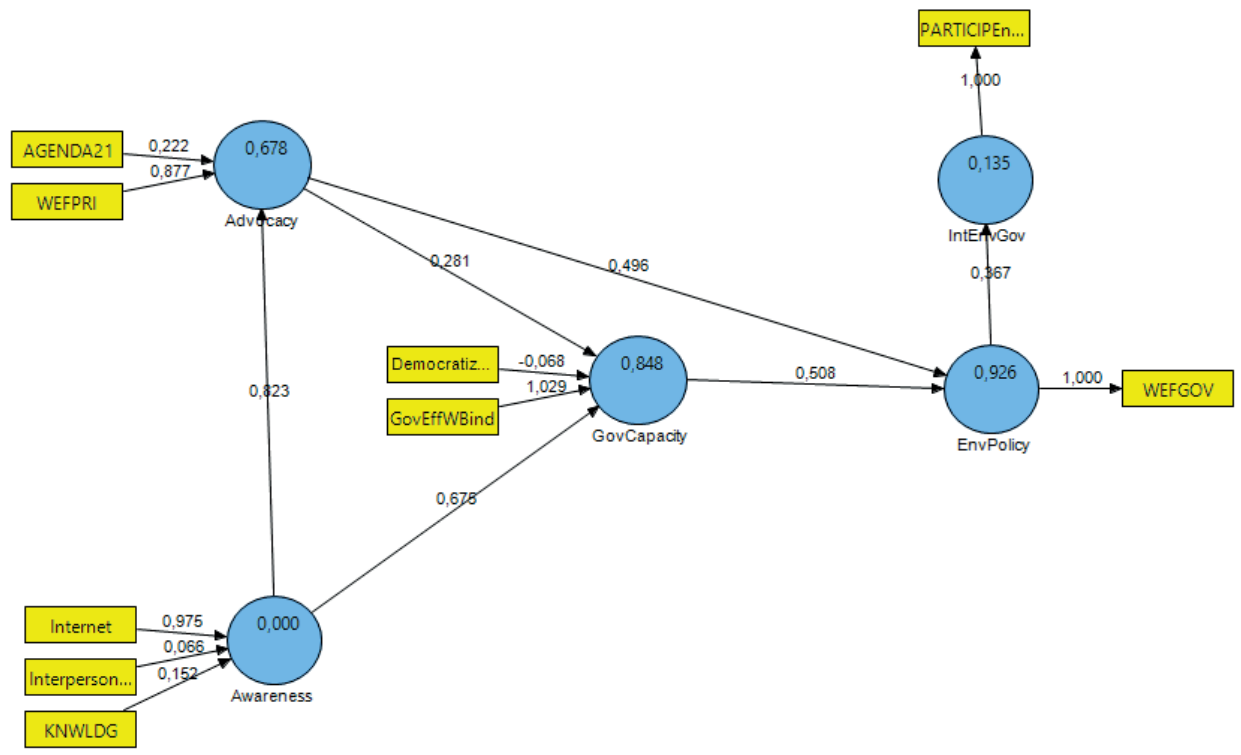

Source: Based on own calculation using SmartPLS. Threshold values for coefficients is 0.2 . The outer loading is always 1.0 in single item constructs. Coefficients in measurement models are always between -1.0 and 1.0. The closer the number is to -1.0 or 1.0 the larger is the effect of the item. Value in circle shows $\mathrm{R}^{2}$.

Figure 10: T-values for model variant C

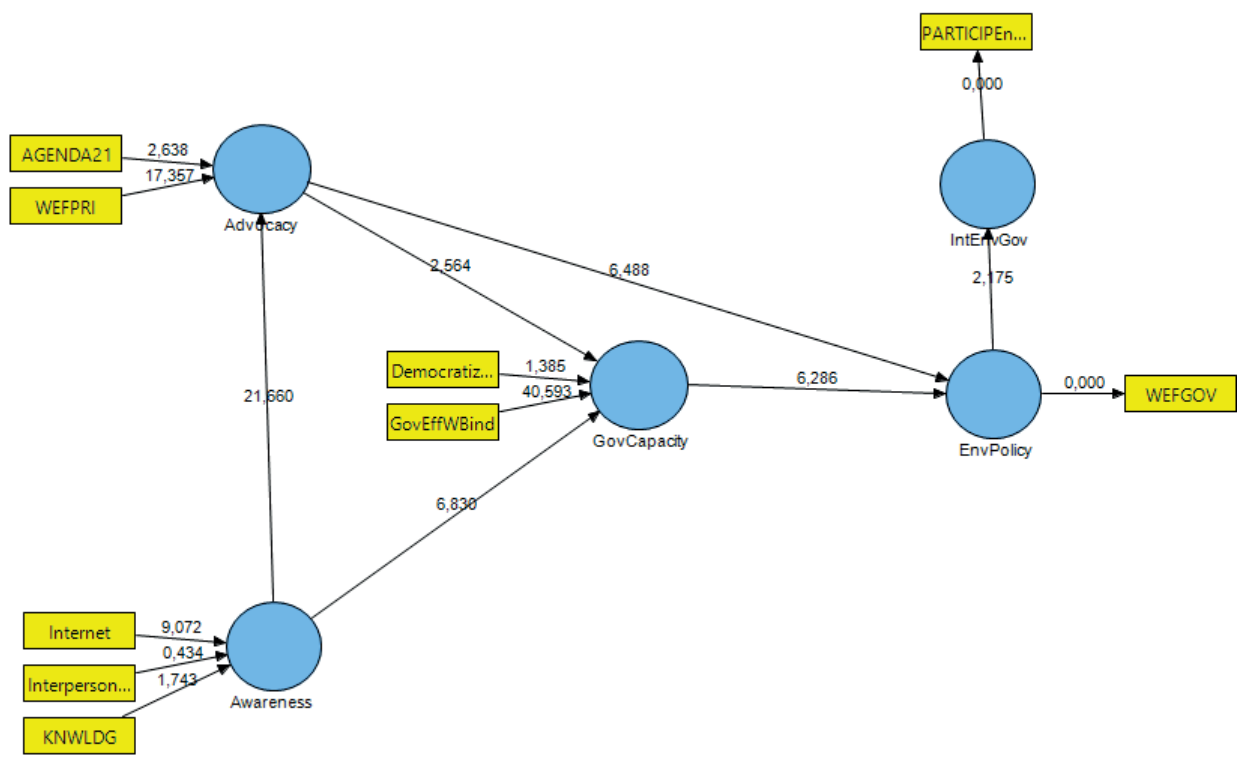

Source: Based on own calculation using SmartPLS. Threshold values for significance of $1 \%, 5 \%$ and $10 \%$ probability of error are $2.57,1.96$, and 1.65 respectively. Singe item constructs do not have a significance level. 
We also investigated the influence of economic conditions such as trade openness or dependency on international financial inflows, measured as Foreign Direct Investment (FDI). If we add a latent variable representing economic conditions in our model, the results do not change and the influence of those economic conditions on environmental policy is not significant (Figure 11, Figure 12, variables are described in Table 7). This exemplifies that our core model, based on structural conditions regarding the institutions and actors, is robust to alternative specifications.

Figure 11: Path coefficients for model variant D

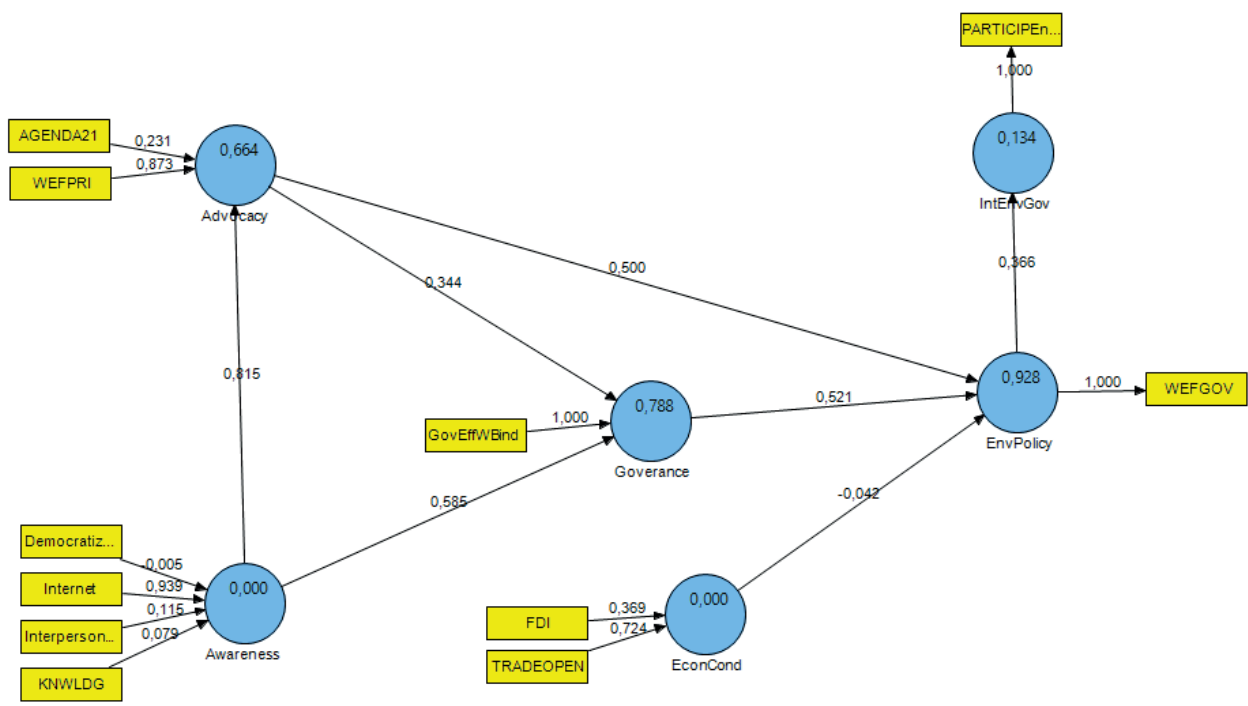

Source: Based on own calculation using SmartPLS. Threshold values for coefficients is 0.2 . The outer loading is always 1.0 in single item constructs. Coefficients in measurement models are always between -1.0 and 1.0. The closer the number is to -1.0 or 1.0 the larger is the effect of the item. Value in circle shows $R^{2}$. 
Figure 12: T-values for model variant D

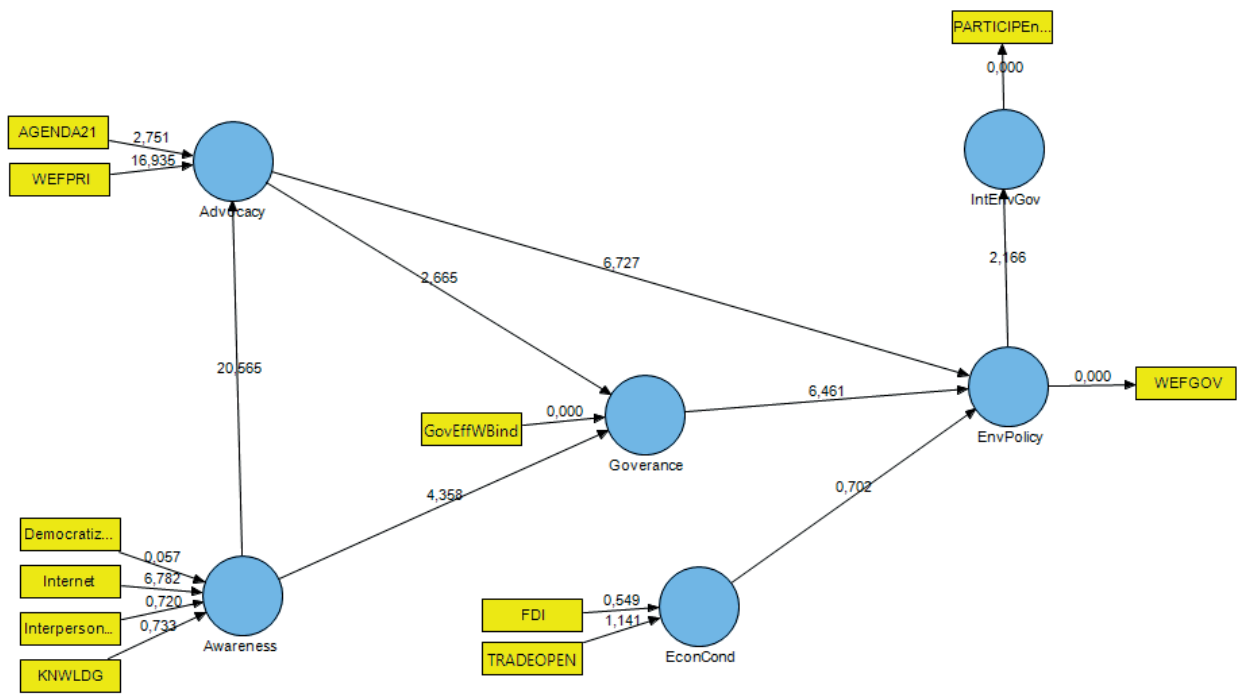

Source: Based on own calculation using SmartPLS. Threshold values for significance of $1 \%, 5 \%$ and $10 \%$ probability of error are $2.57,1.96$, and 1.65 respectively. Singe item constructs do not have a significance level. 


\section{CHAPTER 3}

\section{Technology complexity, technology transfer mechanisms and sustainable development ${ }^{23}$}

\footnotetext{
${ }^{23}$ This chapter is based on the paper Blohmke, J. (2014). Technology complexity, technology transfer mechanisms and sustainable development. Energy for Sustainable Development, 23 (2014) 237-246.
} 



\subsection{Introduction}

This chapter acknowledges the fact that in aiming for effective global climate change mitigation, mitigation technologies need to be deployed worldwide. Between environmental regulation, which was discussed in the previous chapter, and barriers to mitigation technology adoption from the viewpoint of a technology supplier, the technology transfer mechanisms and potential barriers to technology transfer, rooted in the technology itself, are discussed in this chapter. Technology transfer is crucial for the broad diffusion of renewable energy technology (RET). It is elaborated how climate mitigation technology transfer takes place from a technology adopting country's perspective by focusing on technology hardware properties and countries' technology absorption capacities.

In recent years, merging climate change mitigation with economic development has been prioritised on the international political agenda, which has been confirmed at the Rio+20 Conference and by multilateral international organisations (UNEP, 2011; Stern \& Noble, 2008). Developing countries ${ }^{24}$ have to take over a much stronger role in climate mitigation action in order to secure effective and global action against climate change (Kanie et al., 2010).

According to the OECD, the world faces two major challenges: unleashing economic growth opportunities with a constantly growing global population, and addressing environmental pressures which could undermine the chance to seize these growth opportunities (OECD, 2011a). The combustion of fossil fuels generated $60 \%$ of global greenhouse gas emissions in 2010 (IPCC, 2014). A transformation of the energy system, alongside agriculture and land use change, is at the heart of the low-carbon economic development discussion. The private sector is argued to have great potential to contribute to climate change mitigation and the removal of fossil fuel subsidies and marketbased instruments to promote the diffusion of low-carbon technologies, are seen as indispensable (Metz et al., 2000).

Following the definition of the OECD, sustainable development means fostering economic growth and development by ensuring that natural environmental assets continue to provide the natural resources and services which are the basis of our well-being (OECD, 2011a). Globally existing and available production technologies and current consumer behaviour can only be expected to produce positive outcomes up to a certain point, as environmental assets are limited or can be stressed only to a certain degree of intensity (OECD, 2011a). Innovation can help to decouple economic growth from the pollution of environmental assets, especially in the energy sector. Exploiting technology and innovation is crucial to achieve increasing returns on capital (Reinert, 2007; Cimoli

\footnotetext{
${ }^{24}$ The term „developing countries" is used for ease to refer to both developing and emerging economies. It is not meant to obscure the differences between, for example, BRICS countries and countries of Sub-Saharan Africa.
} 
et al., 2009). Access to technology in the form of technology ownership is a key determinant of the level of economic development. It increases the likelihood of self-reliant development and poverty alleviation by offering the possibility of moving up the value chain and diversifying, as well as to substitute for products originally imported by developing countries (Bell, 1997). Increasing competitive advantage and the development of new products is associated with growing employment and tax income (Lall, 1998). Acquiring new technologies, innovating, and broadening the manufacturing base, is a core objective of developing countries aiming to foster economic development. The transformation towards sustainable development pathways can also open up opportunities for new institutional practices and change (Deuten, 2003). If technological change is to unleash its potential to systemic change and produce positive impacts on the environment, then it is important to comprehensively understand the properties of technology. Embedding that knowledge into policy frameworks and global governance architecture is important for avoiding detrimental outcomes (Byrne et al., 2011).

The right to economic development, anchored in the current global climate negotiations, is a key principle of sustainable development in developing countries (UNFCCC, 2010b). Major concerns of developing countries are the costs of mitigation action and that emission reduction targets could be countervailing to their economic development and poverty alleviation goals (Dubash et al., 2013; Wlokas et al., 2012). Access to technology is critical for economic development and by joining the United Nations Framework Convention on Climate Change (UNFCCC), developing countries see the chance to strengthen their ownership of technology and reducing their technological dependency on developed countries (Roberts \&Parks, 2007). Vulnerability to negative environmental impacts is also a reason for developing countries to pursue innovation in environmentally friendly technologies (Olsen, 2013). Countries have different technology needs. Domestic energy technology needs are based on geography, domestic industries, demand patterns, and resource potential. However, taking a general view on RET per se, it is necessary to assess its complexity if the technology manufacturing capacity in developing countries is to be addressed in order to stimulate industrial development and thus economic development. The domestic low-carbon policymaking process ought to consider which RET and parts of the value chain can contribute to economic development and thus ought to be manufactured domestically (Vidican, 2012; see also in Huenteler \& Schmidt, 2013).

Besides efficient financing mechanisms, which are definitely one of the key determinants of successful RET diffusion in developing countries, this chapter will put the technology-specific properties in context with climate mitigation and domestic economic development potentials within a technology transfer environment.

This research will assess how technology complexity assessment, and the potential to add domestic economic value through technology deployment, can be integrated into decision making processes for certain RET pathways in addition to already established technology needs assessments frameworks. Economic development potential 
and national technology deployment strategies should be assessed simultaneously, while the research tries to enrich national as well as international policymaking processes.

The above mentioned concerns of developing countries have been expressed through the right to sustainable development in the context of clean technology innovation. They need to be integrated in a holistic technology innovation and technology transfer approach, which takes into account climate change mitigation and national sustainable development planning as well as the hardware specifics of technology.

The structure of the chapter is as follows. In the second section, I discuss the international low-carbon development policy landscape. The third section deals with the theory of innovation, technology transfer and technology complexity. In the fourth section, I describe how technology complexity and economic development potential can be assessed. The fifth section highlights implications for a technology-specific climate policy design. The sixth section concludes.

\subsection{International low-carbon development policy}

The international low-carbon development policy debate has evolved dynamically. It has attempted to merge technology transfer and sustainable development goals. National sustainable development goals are an important policy measure in developing countries taking action to mitigate greenhouse gas emissions (Olsen, 2013). From a developing country's standpoint, mitigation action must be mainstreamed into sustainable development frameworks to achieve emission reduction and concurrently meet national development priorities. Developing countries could choose low-carbon technologies instead of running into lock-in in high carbon technology pathways (Sauter \& Watson, 2008). Thus, it has been acknowledged by the global community that lowcarbon technology transfer is indispensable for the design of low-carbon growth trajectories (UNFCCC, Articles 4.3 and 4.5). Several existing mitigation technology diffusion policy frameworks use low-carbon technology transfer as a tool for sustainable development. In the following, I describe the most prominent frameworks, which are rooted in the global UNFCCC climate policy framework.

\subsubsection{Marrakech Accords}

In the Marrakech Accords of 2001, a technology transfer requirement was added to the Kyoto Protocol. When technological capacity is not available in the host country, technical and financial support is part of the diffusion of clean technology in non-Annex 1 countries, leading to technology transfer. This transfer includes technical equipment and know-how (Seres, 2007; Dechezleprêtre et al., 2008; Schneider et al., 2008). These rules are intended to help with implementation of the Kyoto Protocol. 


\subsubsection{The Clean Development Mechanism}

According to the Clean Development Mechanism of the Kyoto Protocol (CDM), industrialised countries, which have set emission reduction targets under the Protocol can develop greenhouse gas mitigation projects in other countries in exchange for emission reduction credits (World Bank, 2013). The CDM approach is a market-based instrument which is driven by private companies, and has a focus on projects (Wang-Helmreich et al., 2011). It has mainly been applied in countries where framework conditions were most promising. CDM projects have been criticised for instance, because they appeared to be ill-suited to multifaceted projects involving public policy actions and capacity building (World Bank, 2013). Also, high transaction costs, due to sophisticated evaluation and monitoring procedures in greenhouse gas abatement and technology diffusion, also undermine its potential. The CDM has not proven to foster sustainable development, since projects have been heavily skewed towards larger emerging economies, while at the same time, effective reduction of mitigation cost has been shown (Olsen, 2007; Sutter \& Parreno, 2007).

\subsubsection{Nationally Appropriate Mitigation Actions}

According to the Bali Action Plan (BAP) (UNFCCC, 2008), developing countries should take nationally appropriate mitigation actions (NAMAs) in order to foster sustainable development and reduce greenhouse gas emissions relative to business as usual emissions levels. The BAP provisions consider that developing countries undertake mitigation action in a nationally appropriate manner. This means that actions are tailored to particular national circumstances and aligned with the UNFCCC's principles of common but differentiated climate mitigation responsibilities. The mitigation measures are to be embedded in broader sustainable development strategies. The first step towards NAMAs are technology needs assessments (TNAs) with the goal of prioritising sectors and technologies for climate change mitigation and identify barriers for technology deployment in developing countries (UNFCCC 2010a).

NAMAs are voluntary actions seeking support by a developing country in the area of finance, technology and capacity-building transfer from an industrialized country. One reason for the creation of NAMAs is to ensure that developing countries also benefit from relatively low-cost emission reductions in developing countries compared to abatement in developed countries (CCAP, 2011). Moreover, the nature of NAMAs is to target the national mitigation efforts in developing countries. The extent to which developing countries will effectively implement their commitment will depend on financial resources and transfer of technology from developed to developing countries. Furthermore, NAMAs take into account aspects of economic and social development, leading to poverty eradication in developing countries (Wang-Helmreich, et al., 2011). Since NAMAs are to be designed in the context of sustainable development, which is not 
further defined in the policy framework (UNFCCC, 2008), the impacts on sustainable development should at least not be adverse and promote economic development.

The Global Environment Facility (GEF), acting as an entity entrusted with the financial mechanism of UNFCCC, has the mandate to scale up investment through grants and concessional funds for environmentally friendly technologies ${ }^{25}$. It has been deficient in effectively promoting technology transfer (Verbeken, 2012). Only after the Bali Conference in 2007 it integrated the notion that technology transfer would be part of the market transformation approach (GEF, 2010, p 86). Specifically, the reporting and knowledge management on technology transfer activities has been lacking (GEF, 2008, $\mathrm{p}$ 8). It becomes clear from past experiences in the GEF framework that technology transfer mechanisms have not been effective and that private companies keep technology proprietary (Verbeken, 2012). So far, efforts to increase the uptake of low-carbon technology have not necessarily improved the socio-economic situation of poor populations (Byrne et al., 2012; Mallett, 2013). For example, many CDM projects targeted large-scale, centralised energy projects. Initially, it can be concluded that the embedding of technology transfer in global climate policy has to be improved.

With the signing of the Cancun Agreements, efforts have been made to establish a new institutional technology transfer architecture under the Technology Mechanism (Hedger, 2012). It facilitates the implementation of action on development and transfer of adaptation and mitigation technology (UNFCCC, 2010b). This includes that "technology needs must be nationally determined, based on national circumstances and priorities" (UNFCCC, 2010b). Action should be taken "at different stages of the technology cycle, including research and development, demonstration, deployment, diffusion and transfer of technology" (UNFCCC, 2010b). The Technology Mechanism provides instruments to facilitate the technology transfer as requested in NAMAs. It is worth underlining that the Technology Mechanism envisions not only the technology transfer, but also the technology development and manufacturing in the technology recipient country. It consists of the following components:

- A Technology Executive Committee (TEC) with the following functions:

o provide technological needs and analysis of policy and technical issues which are related to the development and transfer of adaptation and mitigation technologies;

o seek cooperation with relevant international stakeholders;

o recommend actions to promote technology development and transfer, and measures to remove barriers respectively;

o promote collaboration on the development and transfer of technologies;

o catalyse the development and use of technology road maps and action plans.

- A Climate Technology Centre and Network (CTC\&N), with the following functions:

\footnotetext{
${ }^{25}$ http://www.thegef.org/gef/whatisgef (accessed 26 March 2016).
} 
o facilitate the advice on technology needs, and provide information and training and development of technologies;

o stimulate bilateral and multilateral technology cooperation;

o facilitate a network of technology centres, networks and initiatives on national, regional and sectoral levels.

The features of the Technology Mechanism go beyond the envisioned technology transfer aspects of the CDM policy framework, which essentially focuses on technology transfer by hardware import (ICTSD, 2011; Lema and Lema, 2013). The CDM mechanism has been seen as a "climate first" approach where the key problem is the challenge of reducing greenhouse gas emissions, and sustainable development outcomes are cobenefits of mitigation activity (Olsen, 2013). The NAMA policy approach is rather a bottom-up, dual approach, which aims to complement the goals of mitigating greenhouse gas emissions and promote sustainable development, emphasising technology transfer, which is institutionalized in the Technology Mechanism (UNFCCC ${ }^{26}$ ).

The detailed roles and instruments of the two arms of the Technology Mechanism, being developed under the auspices of UNFCCC, are still not yet fully designed and established. However, so far it is clear that the Technology Mechanism will go beyond technology needs assessments (TNAs), which concentrate on assessing mitigation potentials and costs (UNFCCC, 2010a). The TNA approach mentions the need for transfer of technology, and how deployment barriers can be overcome, but it does not institutionalize a bottom-up approach with regard to technology properties and their potential influence on economic development. The Technology Mechanism will account for technology development, value creation along the value chain of technologies and sustainable, integrated, development prospects.

In this context, the question arises as to whether it is reasonable for a low-income country to develop technology manufacturing capacities domestically, or, whether they should import the technology on a competitive and potentially cheaper basis from more industrialized countries. The competitiveness of domestic production of manufactured renewable energy components depends on cost structures and the availability of resources in the intermediate input sectors. As the UNFCCC Technology Mechanism goes beyond importing RET hardware, by also targeting capacity building and technology manufacturing-related value creation, this research deals with technology transfer policy interventions which target manufacturing activity. As stated above, for some countries it might not be cost-efficient to manufacture renewable energy components domestically, yet the dimension of cost-competitive sourcing of components is a highly political question, which can be addressed vis-à-vis the quest to follow a certain industrial development agenda. Finding the right balance of cost and benefit between im-

\footnotetext{
${ }^{26}$ http://unfccc.int/focus/technology/items/7000.php (accessed 4 February 2014).
} 
porting technology from abroad and sourcing domestically is important, yet not part of the immediate research question.

This research does not provide a comprehensive, fully fledged decision tool for sustainable development policymakers to decide which technology to deploy, acknowledging technology needs considerations and economic development potentials. It rather addresses the question whether a certain technology pathway, based on a technology needs assessment, can be synchronised with a country's aspiration to also develop its industry and deepen value added in the upstream RET value chain.

After having discussed recent developments in the global climate policy landscape with regard to technology transfer, in the next section, I describe relevant aspects for policymaking processes, which technology transfer policy should integrate in order to ensure sustainable development is induced by technology transfer.

\subsection{Theory: innovation, technology transfer and technology complexity}

Core conceptual issues regarding capacity to adopt and adapt new technologies, and why technology transfer is closely linked to the subject of innovation studies, are laid out. This shall make clear why it can be difficult to transfer low-carbon technology from developed countries to developing countries.

So far technology has been understood as a capital good and as codified information in the form of patents and hardware (World Bank, 2010). With regard to the transfer of technologies to developing countries, subsidies for new technologies, removal of trade barriers, foreign direct investment (FDI), improving intellectual property rights systems, and technology and know-how import are common solutions to closing the technology gap (OECD, 2011c). When assessing technology transfer in more detail, it becomes clear that the transfer mechanism is more complex than just transferring a capital good (Bell \& Pavitt, 1996, p. 73). Technology transfer can be grouped into three categories (Bell, 1990; Ockwell et al., 2010):

A. Capital goods: technology equipment manufacturing facilities, design and engineering services, existing product designs and specifications that may be purchased or licensed.

B. Know-how and skills necessary for operating manufacturing facilities and for maintenance activities with regard to new technologies.

C. Skills and knowledge for adapting and further developing the initially acquired technology.

The first two categories increase the technology production and technology operation capacity of a country, while the latter increases the technology innovative capability of a country. Technology innovation activity is not only influenced by intellectual property rights, licensing and technology imports, but also depends on capabilities to improve technologies (Lundvall et al., 2009; Lundvall, 2011), networks between producer, sup- 
plier and users, as well as the research institutions that are required to enable continuous technological learning and adaptation (Bell \& Figueiredo, 2012).

Tacit knowledge and firm capabilities are key factors for technology transfer and diffusion (Bell \& Pavitt, 1996). Technological knowledge within firms and by individuals is produced through technological learning (Cohen \& Levinthal, 1989). It is not sufficient to train individuals how to use new imported technologies (Ockwell \& Mallett, 2013). Also, knowing why and how a certain technology works, is fundamental to increasing technological learning. Technology transfer is thus a knowledge accumulation process that requires absorptive capacities (Doranova et al., 2011). The capacity to accumulate technological knowledge is closely linked to innovation capability (Bell, 2012).

Host country characteristics have been shown to be crucial in the technology transfer process of CDM projects (Schmid, 2012). Trade barriers, tariffs on environmental products, and administrative burdens are the most prominent factors inhibiting technology transfer. According to a study on CDM projects (Doranova et al., 2011), the acquisition of technological knowledge in technology transfer projects depends on prior knowledge, i.e. a level of technological capability upon which to build. Higher technological capabilities promote transfer of technology from developed to developing countries, because skills to use the technology are given, even though local availability of technology also potentially increases (Dechezleprêtre et al., 2008). On the other hand, it has also been argued that a larger knowledge base in clean technologies leads to higher rates of local technology sourcing (Doranova et al., 2009). In those studies the properties of the technology itself were not explicitly assessed. Yet, energy technologies are more complex compared to those in the agriculture sector, where higher levels of technological capabilities do not necessarily lead to higher technology transfer but more domestic technology sourcing. Thus, it could be reasonable to take into account also the technology specifics itself. In any case, host country technology knowledge and capability are highly necessary for the transfer of clean energy technology.

Differentiating between various types of innovation is important when discussing innovation capacity. It has been argued that radical or breakthrough innovations will be pivotal in order to address climate change (Bell, 2012; Slocum and Rubin, 2008). These take place in advanced economies and are determined by national policy priorities. In contrast to this are incremental and adaptive innovations (Ockwell \& Mallett, 2013). Rather than radically developing a technology, which is new to the world, developing countries often gradually improve hardware, the production process and design, enhancing the performance of the technology. This is called incremental innovation. Also, adaptive innovation can be observed in developing countries when technologies are adapted to new physical, social, or market contexts.

Unlike radical innovations, which entail creative innovation and most often emerge in developed or emerging economies, adaptive innovations are rather passive and based on replicative diffusion of technology, leading to only marginal improvements of the technology (Bell, 2012). If technology transfer is to lead to the absorption of techno- 
logical knowledge, then at least incremental and adaptive innovation capabilities are a minimum requirement in technology recipient countries. Incremental and adaptive innovation capabilities are perhaps more important than radical innovation capabilities (Ockwell \& Mallett, 2013, p 125) and the success of technology transfer depends on domestic absorptive capacity (Fisher-Vanden et al., 2006), going beyond market mechanisms (Byrne et al., 2012).

The role of innovation systems has been emphasised in international climate policy (UNFCCC, 2011) and been extensively discussed by academic scholars (Brewer, 2008; Marechal \& Lazaric, 2010; Lema \& Lema, 2013). Innovation systems are a set of institutions such as government, private sector and research institutions which enable the acquisition of new knowledge on technologies, the hardware itself and drive innovation in the sense of adapting and further developing new technologies. The socio-technical fit is also an important aspect as it determines the success of technology transfer (Rip \& Kemp, 1998; Geels, 2002; Smith et al., 2010; Byrne et al., 2012): different social and cultural spaces can facilitate technological transition, or inhibit it by maintaining rigid institutional norms and social practices.

When comparing studies on the context-specific needs and socio-technical aspects of different actors in different places, it becomes clear that it is necessary to differentiate the type of technology under investigation as well as the degree of complexity of the technology. The above-mentioned considerations regarding technology transfer and innovation deal with the "enabling environment" in both the developed and the developing country sides of the technology transfer process (Mallett, 2013).

The characteristics and complexity of technology have been insufficiently contextualised with technology transfer, yet complexity of technology has been discussed in the context of technological learning and incremental innovation (McNerney \& Farmer, 2011; Huenteler \& Schmidt, 2013). Another area where technology complexity has been mentioned but not assessed in detail, is the discussion of intellectual property rights (IPR) in the context of transfer of low-carbon technology (DECC, 2009). IPR related to complex technologies can create obstacles to adoption of technologies if the transfer of IPR is not accompanied by transferring the tacit knowledge inherent to the technology. Nevertheless, in global climate policy design, the complexity of technology has not been thoroughly examined in the context of innovation systems, technology transfer and economic development, triggered by enhanced manufacturing industry activity. For example, Huenteler \& Schmidt (2013) assess technology complexity in the context of technology transfer by focusing on product design and the manufacturing process. They discuss technological learning processes with regard to the product design and product manufacturing phase and showcase why those two dimensions of complexity assessment are worth being acknowledged in the technology transfer policy formulation process.

The approach presented in this chapter goes beyond the direct, hardware design and manufacturing-related technical complexity by adding other "enabling" conditions 
around the technology design and manufacturing process on a component level, which is unique.

I propose that technology properties need to be assessed in terms of technology complexity in combination with economic development potential as discussed in the next section, which is then embedded into the technology transfer and international climate policy design. Besides technology complexity, also the potential of technology transfer and potential technology manufacturing to contribute to economic development can be raised, as sustainable development is the second pillar in global climate policy. The potential economic impact of technology deployment is mentioned across the climate policy landscape, though the need for an integrated assessment approach alongside technology complexity has not been raised.

In the next section, I discuss how technology-specific properties could be integrated into technology transfer mechanisms geared towards economic development strategies that target climate change mitigation. I also raise the issue of economic development potential assessment within technology transfer frameworks.

\subsection{Technology complexity and economic development potential}

The complexity of technology has many different dimensions when considered in the context of innovation systems. To differentiate only between complex products and mass-produced products might be sufficient on a firm level (Magnusson et al., 2005) but not in the context of climate policy and economic development issues (see also Huenteler \& Schmidt, 2013). In the following, the term complexity will be used with regard to the technology production process (technical), the outcome of the production process (quality) and the enabling environment of the technology production process (financial), which will be further explained below.

Technology is highly integrated when it cannot be divided into technological subsystems (Ockwell et al., 2008). Technology which can be acquired in separate, subdivided parts from various equipment suppliers provides more opportunities for knowledge sharing amongst international suppliers and domestic firms in developing countries. It is a mixture of vertical technology transfer, where knowledge is shared from R\&D to commercialisation along the value chain, and horizontal technology transfer, where knowledge flows take place across geographical borders. RET can be divided into subsystems on a technology component level.

The assessment of complexity can be understood as a framework for potential profit- and technology-sharing agreements between developing countries on the one hand and high-income, technology exporting countries on the other hand. From this, technology strategies can be derived, also on a component level. They range from sole hardware transfer to low-income countries, in the case of highly complex components, to the build-up of innovation capacity, like knowledge and know-how, as well as manufacturing capacities, if components are less complex. Splitting up technologies on a 
component level and assessing their complexity allows for an estimate of the extent to which value added industrial activity could occur in the technology adopting economy.

I assess the following renewable energy technologies: concentrated solar power (CSP), solar photovoltaic (PV), and wind technology, on a component sub-system level. These three technologies are regarded as relatively mature, less so CSP, and possess the potential to drastically mitigate global greenhouse gases. In the following, I concentrate on the upstream part of the technology value chain, especially the manufacturing of the technology components. Successful technology transfer in developing countries faces barriers throughout the entire value chain, from the financing of the technology manufacturing to the operation and maintenance of the technology during the technology's lifetime. Thus, financial barriers to domestic manufacturing and quality considerations also need to be taken into account in the policy design of technology transfer mechanisms. This study assumes that financing mechanisms are in place and functioning in order that the discussion can focus on the technology's properties.

In the context of economic development, an analysis of technology should also take into account the potential economic benefits resulting from induced domestic demand for components in developing countries. ${ }^{27}$ Such economic benefits are especially job creation, economic value added, and government tax income. The extent of domestic economic benefits due to investment in new technologies depends on several factors. It is not necessarily true that the higher the investment in a certain domestic sector the higher the economic effects in the country. The nature of sectoral integration in a country (i.e. the interdependencies between national sectors) shapes the economic benefits of investments into one specific sector (see for example Lofgren et al., 2002). Furthermore, also the trade dependency, which describes the intensity of import dependency of domestic sectors, determines the volume of the investment flow which can be diverted to foreign markets to source complex technology or single components from abroad when they are not domestically available.

It becomes clear that economic development potential, determined by investment into a certain technology which induce demand for domestically produced goods, depends on specific structural characteristics of an economy. Economic development potential is discussed in an abstract way. Only the monetary value of the technology investment and the potential to induce domestic demand for technology goods and services is assessed. By doing this I neglect country-specific economic structures, which definitely shape the influence on economic development, as explained above.

The technology transfer conditions which lead to climate change mitigation and sustainable development in developing countries can be divided into two groups: enabling conditions and technology conditions. Enabling conditions can be further broken down into the necessary innovation systems, as discussed already, and access to finan-

\footnotetext{
${ }^{27}$ It is important to also mention that also downstream, during construction and operation of the technologies, economic activity is considerable (Barua et al., 2012).
} 
cial sources. The latter is equally important in encouraging actors to invest in new technologies (UNFCCC ${ }^{28}$ ) (Figure 13, left hand side). Developing countries require access to predictable, sustainable channels of finance for mitigation technologies. Alongside the technology transfer environment, the properties of technology are a critical factor in designing an effective international institutional technology transfer architecture (Figure 13 , right hand side). The technology conditions describe properties inherent to a specific technology and include the complexity of the technology and its subcomponents, as well as their potential to impact on the economic development. Technology conditions, as well as enabling conditions, are important for achieving the goals of climate change mitigation and sustainable development.

Figure 13: Technology Transfer Conditions and Goals

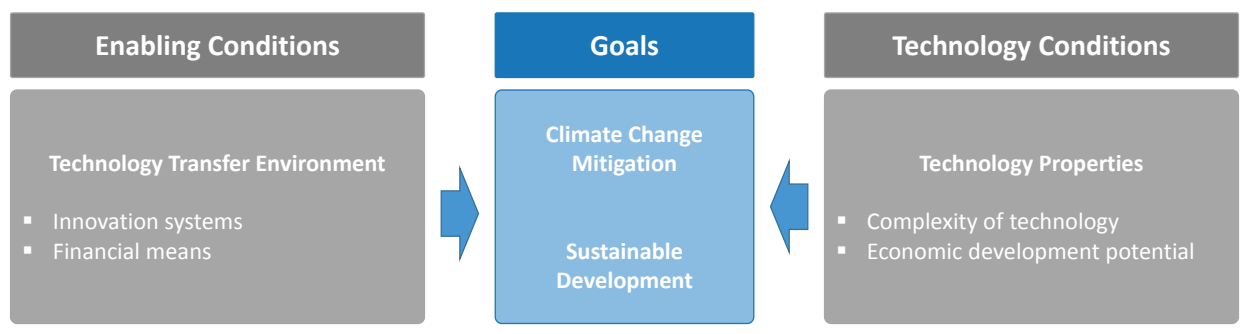

Source: Own illustration.

In order to evaluate the complexity of technology and its components, several dimensions of complexity are evaluated (based on World Bank, 2011):

- Technical complexity refers to the manufacturing of components in terms of process steps during manufacturing, specification of machinery and tools needed during manufacturing and whether the manufacturing technique is new to the market.

- Quality complexity refers to the quality requirements for each component and whether the reliability of components in the overall system is important.

- Financial complexity refers to the requirements of investment into expensive machinery for the manufacturing of components and the risk of investment into production facilities for specific components.

All these types of complexity can be used in combination to assess the overall complexity of the respective technology. In the following, I assess CSP, PV, and wind technology as examples to showcase the possible degree of component disaggregation and the detail in which technology complexity can be assessed.

In addition to the complexity assessment, I illustrate the disaggregated share of investment of the overall capital expenditure for each of the three technologies (see the

\footnotetext{
${ }^{28}$ http://unfccc.int/focus/finance/items/7001.php (accessed on 3 February 2014).
} 
appendix for an overview of results on complexity assessment and value added). ${ }^{29}$ This helps derive the potential economic development impact of each component, assuming that those investments could be translated into demand for domestic technology goods in developing countries.

\subsubsection{CSP technology complexity}

The complexity of CSP technology has been assessed in the context of technology deployment and manufacturing opportunities across the Middle East and North Africa (MENA) region (see for CSP technology complexity World Bank, 2011). Here we focus our analysis on parabolic trough technology, acknowledging that other CSP technologies also exist. $^{30}$

Receivers and the turbine for a CSP plant present high barriers to local manufacturing, since they are the most high-technology driven subsystems of the entire power plant. As such, they require substantial investment in specific manufacturing equipment, highly skilled personnel and know-how transfer from the handful of global players that currently dominate the world market.

The generator, at the heart of the plant, is less complex, mainly because of lower technical barriers. However, the dimensions of such a generator cannot be compared to those currently being produced in MENA, which are small- to medium-sized. Technical barriers to local manufacturing thus remain.

For mirrors the technical production barrier is low to medium, though the process of bending and coating the mirrors has not yet been adopted locally.

Pipes/heat exchangers and the synthetic heat transfer fluid (HTF) are two components that primarily feature low to medium technical and financial barriers, since experienced industries in MENA already exist, particularly in fossil fuel exporting countries. Manufacturing these components requires a large amount of manual labour, which is readily available. Standard tools with low capital cost can be employed.

Electronics/controls are produced at licensed assembly plants which is associated with lower risk. When focusing on the labour-intensive, manual assembly of electronic components, little investment in tools or training is required.

The mounting structure manufacturing process requires manual labour and the use of inexpensive standard tools. Metal plants serving the regional building sector are well integrated in the local industry landscape. Except for the investment in furnaces, no barriers would impede a rapid expansion of this sector, especially since cutting, drilling, and coating are labour intensive but require little to no additional training. The overall complexity of this component is low.

\footnotetext{
${ }^{29}$ Value added refers to the share of component investment in relation to overall investment into a certain technology.

${ }^{30}$ Besides the parabolic trough technology, power technology, linear fresnel and dish stirling technology exist.
} 
Cables are an example of a technically simple product that have been produced in MENA and exported to Europe for many years, therefore barriers are low.

\subsubsection{PV technology complexity}

The assessment of PV technology complexity is based on technology assessments undertaken in Morocco (see for PV technology complexity GIZ, 2012). The complexity analysis is on polysilicon based PV. ${ }^{31}$

The production of silicon and wafers/cells face significant barriers due to strict quality requirements and capital-intensive manufacturing plants. The production processes advance very quickly and require highly skilled personnel.

Solar glass production barriers are not substantial, as float glass production knowhow exists in the MENA region.

The inverter and other electronic components can be produced with a substantial level of manual labour, which lowers the financial barriers, while the technical manufacturing sophistication is of medium complexity.

The aluminium component ${ }^{32}$ manufacturing has neither high technical nor particular quality requirements, and thus the overall barrier of this component is low, particularly as there are alternative markets available, such as the construction industry.

The mounting structure and cables are ranked with low complexity, as in the CSP section.

\subsubsection{Wind technology complexity}

The wind technology complexity assessment is mainly based on a study of the wind technology sector in Egypt (see for wind technology complexity Vidican, 2012; Hau, 2008). We assess wind technology which uses a gearbox. ${ }^{33}$

Wind gearbox/bearings and top control ${ }^{34}$ are two groups of components that can be produced on a versatile manufacturing line (for example, machinery and automotive mechanical system production lines). Thus, financial and market barriers are at a medium level, since alternative markets can also be supplied. Cables are ranked with low complexity.

Blades are typically made from fibre-reinforced polymers and, due to the size of the structure, production generally involves a high share of manual labour, thereby lowering financial barriers. The production process is well understood and some companies in

\footnotetext{
${ }^{31}$ Other proven PV technologies like thin film and concentrating photovoltaic technology exist.

${ }^{32}$ Aluminium components are used for the PV module frame and other parts like clamps.

${ }^{33}$ Direct drive wind technology does not use a gearbox, is more capital intensive and has lower maintenance intervals.

${ }^{34}$ The cost block "Top control" also contains all expenses for electronic components (e.g. control system and inverter).
} 
MENA operate large-scale composite factories. Technical barriers are therefore assessed as medium.

The generators for wind technology are smaller and less powerful than the ones used in a CSP power plant cycle. The existing experience in MENA in the field of small generator manufacturing therefore further lowers the overall complexity of wind generators.

Towers are most often made of tubular steel sections (like a vertical pipeline). Technical barriers are rather low and the experience in MENA in the areas of structural steel design and pipeline construction sets the overall barrier very low. The rating of cables refers to the CSP section.

Wind technology and PV technology are less complex than CSP technology when components are assessed. In combination with the potential domestic demand volume for technology goods, this provides insights into whether a certain technology has the potential to contribute to economic development, if the technology goods are manufactured in developing countries. Of course, this simplification neglects the fact that the mere demand for specific sector goods such as metals or electronic equipment within an economy does not necessarily induce economic development. As discussed above, integration between sectors, trade dependency of sectors, and other factors such as savings rates, all influence economic development outcomes on a country level.

\subsection{Implication for technology-specific climate policy design}

In international climate policy, the acquisition of low-carbon technology is fostered via two vehicles. Technology needs assessments (TNAs) on a country level are funded via the technology needs assessment instrument. The consequence of TNAs is the design of regulation and capacity building through NAMAs. The Technology Mechanism, more dynamic than the simple assessment of technology needs in a TNA, is meant to secure the technology transfer needed for sustainable development anchored in NAMAs. While CDM and NAMA are voluntary mechanisms to support mitigation and sustainable development, the Technology Mechanism has the explicit goal of fostering technology transfer. The Technology Mechanism acknowledges that absorptive capacity in recipient countries needs to be strengthened. However, it does not specifically mention the necessity of a "technology assessment" towards eligibility to deliver on sustainable development. Nor does it require a fit with the absorptive capacities in technology recipient countries. The contextualisation between technology properties and country characteristics is not explicitly made.

Assuming that absorptive capacity does not change, then the more complex a component, or a whole technology system is, the more difficult it is to adopt the technology in developing countries. The assessment of technology complexity gives insights into how difficult a technology transfer can be, in terms of an aim to eventually manufacture 
components in the technology adopting country, and demonstrates that a high level of absorptive capacity will be required in the recipient country.

Therefore, I suggest that technology properties, which in this context are the complexity of technology components and economic development potential, need to be integrated into the technology transfer policymaking process in order to foster economic development. The two aspects, complexity of technology and economic development potential, should be integrated into national climate policymaking.

The construction of a multi-dimensional complexity index for technologies and technology sub-systems and components requires detailed information on those technology components. It must include the complexity, as well as the investment intensity, which influences domestic industry relative to the overall investment and GHG mitigation potential. Demand for technology components can induce expansion of domestic industry sectors, generating economic development.

The potential domestic demand for technology goods should be viewed in relation to the cost of mitigation of a certain amount of greenhouse gases ${ }^{35}$. This allows for a comparison of mitigation technologies with dual goals of achieving climate change mitigation and sustainable development. The complexity and potential domestic demand volume for technology components can be mapped or ranked on a component basis (Figure 14). Let us assume that, for example, technology 1 and technology 3 cost the same (same mitigation effect per Euro invested) ${ }^{36}$, but the various components (e.g. wind blades, wind tower, PV solar glass, metal mounting structure of PV modules) have different technology complexity properties across the respective technology system (see also the appendix for a detailed rating of the technology components for CSP, PV and wind technology). Then, the technology with a higher amount of components (each bubble in Figure 14 represents one component) ranked with lower complexity, in monetary terms (represented by the size of the bubble) bears a higher economic development potential. The reason is that components with lower complexity but high economic demand impact could potentially induce domestic demand for technology goods and be sourced domestically. The sum of the solid bubbles, representing the investment of technology 1 , is the same as the sum of the striped bubbles, making up the investment of technology 3 (Figure 14) - each of the technologies summing up to 1 on the x-axis. Because the individual components of the technology 1 are ranked with lower complexity (below the complexity value of 2 on the y-axis), it is assumed that the domestic demand for technology goods could turn out to be higher. The reason for this is that it is more likely that components with lower complexity can be manufactured by domestic industries in developing countries. The potential domestic demand effect of technology 1 is higher than that of technology 3. Overall, technology 2 is more costly per mitigated

\footnotetext{
${ }^{35}$ Economic development potential per unit of mitigation describes the monetary demand of a technology, scaled to the mitigation effect.

${ }^{36}$ E.g. both technologies mitigate 1 tonne of $\mathrm{CO}_{2}$ and cost EUR 1,000.
} 
unit of GHG. Thus, the sum of the striped bubbles is larger than the sum of the solid or dotted bubbles (2 instead of 1 ).

Figure 14: Technologies and component complexity

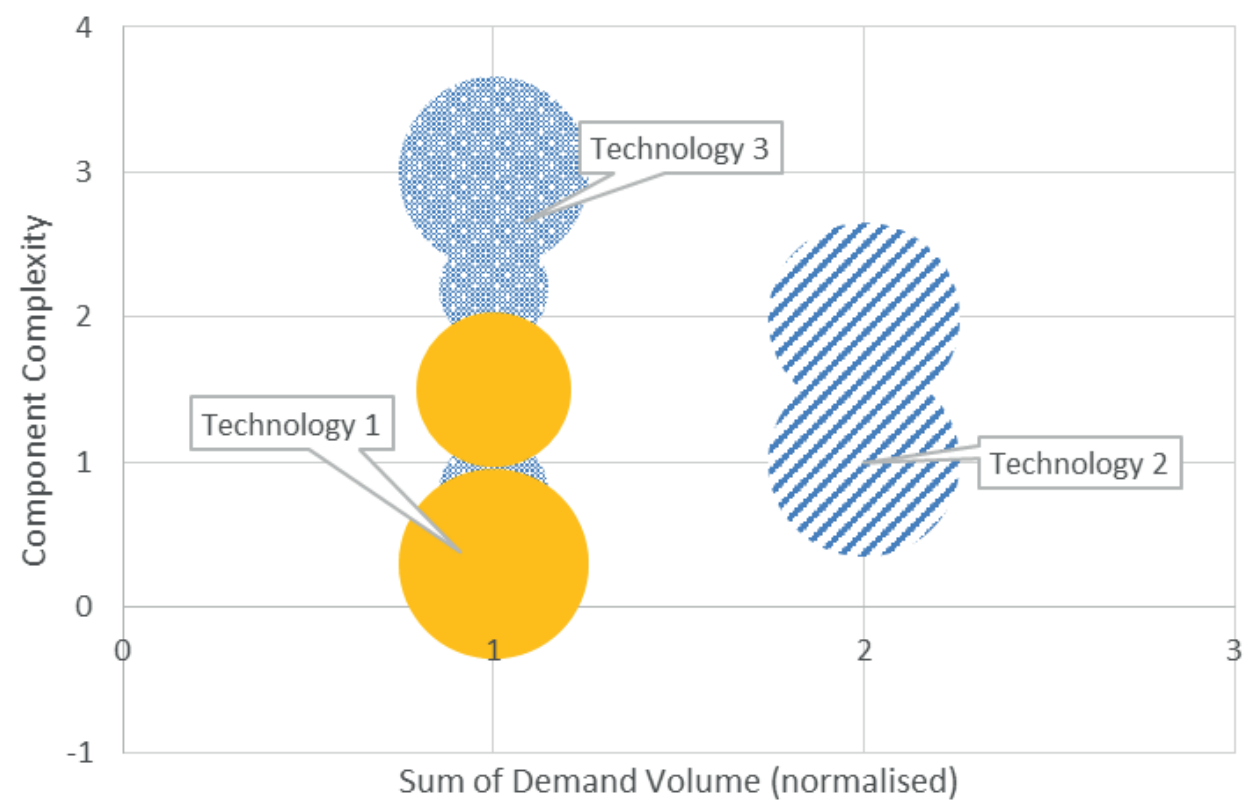

Source: Own illustration. Note: Each bubble represents one technology component.

Outcomes of such an analysis, where complexity and economic development potential are aggregated, could give policymakers relevant information for the formulation of national mitigation action plans that incorporate economic development through increased manufacturing industry activity. It can be assessed whether the chosen technology and its components have the potential of being adopted by the domestic industry, whether capabilities of domestic industries to adopt the technology are adequate, and what economic demand and development potential adhere to each technology component and to the overall choice of a certain technology.

Countries with lower degrees of domestic technology absorptive capacity should not necessarily concentrate on fostering the transfer of technology, or components, which are characterised by lower complexity relative to the mitigation cost adjusted for economic development potential. It is more important from a mitigation cost effectiveness perspective, to consider whether favourable solar or wind potential in a country prevails or whether the chosen technology is adequate in an overall context, i.e. in fitting domestic hourly electricity demand patterns, as determined in technology needs assessments. ${ }^{37}$ Yet the described approach of assessing complexity and economic develop-

\footnotetext{
${ }^{37}$ If an economy has high electricity demand during the day (due to air conditioning activity in warm geo-
} 
ment potential gives insights into the technology characteristics, which could be highly relevant for the design of global technology transfer mechanisms. Such a technology evaluation scheme should not conflict with building up domestic and endogenous innovation capacities which target more sophisticated, complex technologies. Rather it ought to be a guiding and awareness-raising tool for policymakers, in order that they are able to realistically assess technologies they want to promote for technology transfer and increasing domestic economic development.

The combination of the market share, which is indicated as the share of components' value of a specific technology, and complexity, which measures the chance of manufacturing the component in a developing country, could be used to identify a suitable technology strategy. The complexity assessment, as part of a national technology strategy, can be executed on a component level, rendering the possibility of creating win-win technology-sharing agreements between industrialized, component exporting countries, and developing, technology system importing countries.

To summarise, technologies which allow for a higher domestic share in local manufacturing, and are less complex, should render more economic benefits.

\subsection{Conclusion}

The global climate policy architecture, which supports technology transfer to developing countries has been under review and is about to change. The need to integrate sustainable development objectives into climate change mitigation practices by fostering technology transfer to developing countries, beyond mere hardware exports, has been acknowledged and put on the political agenda. The technology adoption capacity of developing countries has been focused upon until now and been reflected in the innovation systems debate. However, the extent to which a complex low-carbon technology can contribute to sustainable development from an economic perspective needs to be sufficiently analysed and addressed in policy plans. Technology-specific countrylevel capacity to innovate, adopt and translate technology deployment into economic development should be emphasised in the formulation of national mitigation action plans and capacity building programmes by UNFCCC, UNEP, UNDP, and other international institutions, as well as by national governmental agencies.

A component-level approach could help to identify technologies with the greatest potential to contribute additional economic value in the technology recipient country and promote potential win-win solutions for industrialized countries and RET adopting developing countries. As some RET components are versatile in terms of use and can be manufactured by relatively unspecific machinery, as it is the case for example with steel mounting structures, it is not necessary that the domestic renewable energy sector is a

graphical areas) then for example wind technology might not be appropriate, if wind mainly blows in the evening and night. 
high-growth market in order to foster targeted, domestic component manufacturing. As soon as components have the potential to be manufactured domestically, and on a competitive basis, domestic production could contribute to economic development. Thus, it is necessary to integrate the assessment of technology properties in the Technology Mechanism framework, going beyond the above discussed technology adoption capacities in technology receiving countries. This holds true only if it is economically feasible to source components domestically, and, if the stimulation of the domestic manufacturing industries leads to economic benefits.

In the process of choosing the right technology, technology transfer policy instruments should be more transparent in carefully inspecting the economic development potential of mitigation technologies. Technology properties, with respect to technology complexity, should be addressed and linked with domestic, technology recipient country's technology adoption capacities.

In a more detailed way, and accounting for a more diverse and comprehensive set of technology component complexity aspects as compared to Huenteler \& Schmidt (2013), I propose that climate change policy design should take into account technology complexity. In my view, technology complexity is best considered in combination with the economic development potential of technology components, so that economic development in the technology transfer process can be maximised on a technology component level. A technology transfer policy design needs to take into account technology complexity in combination with potential domestic economic value added on a technology component level. In this chapter, the role of technology knowledge, research and education policy as well as an entrepreneurial enabling environment is not discussed, yet strengthening those is crucial for the uptake of new technologies as they form the technology absorption capacities of a country. This approach can be used to inform policymakers with regard to climate friendly technological priorities for the design of national sustainable development pathways. 


\subsection{Appendix}

Figure 15: CSP Technology Complexity and Value of Investment

CSP Technology

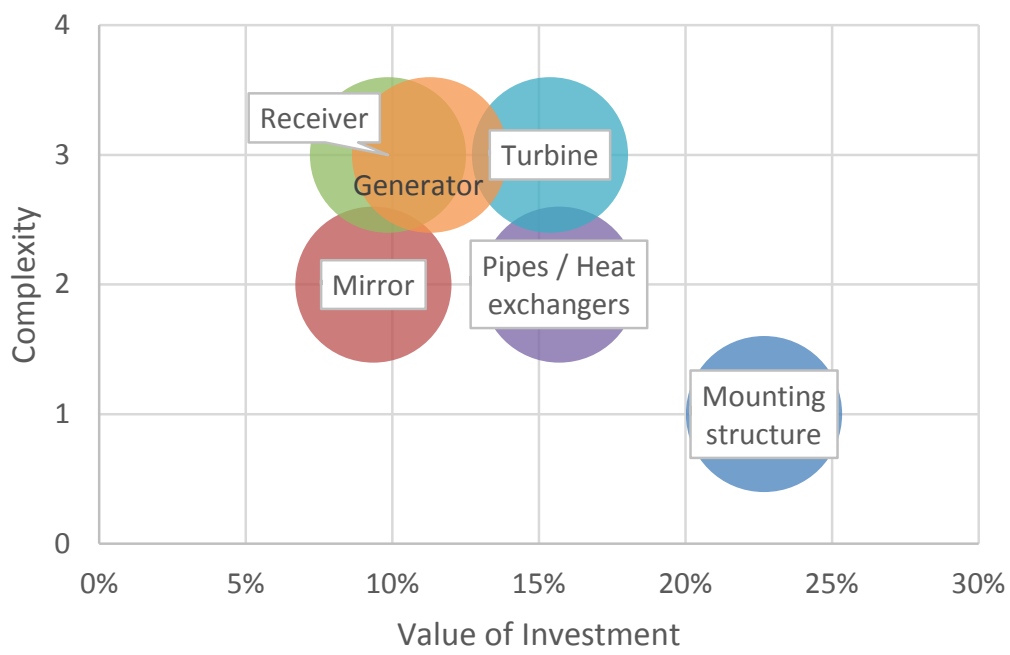

Source: Own illustration, data (see above). Volume of investment as share of overall investment. 
Figure 16: PV Technology Complexity and Value of Investment

\section{PV Technology}

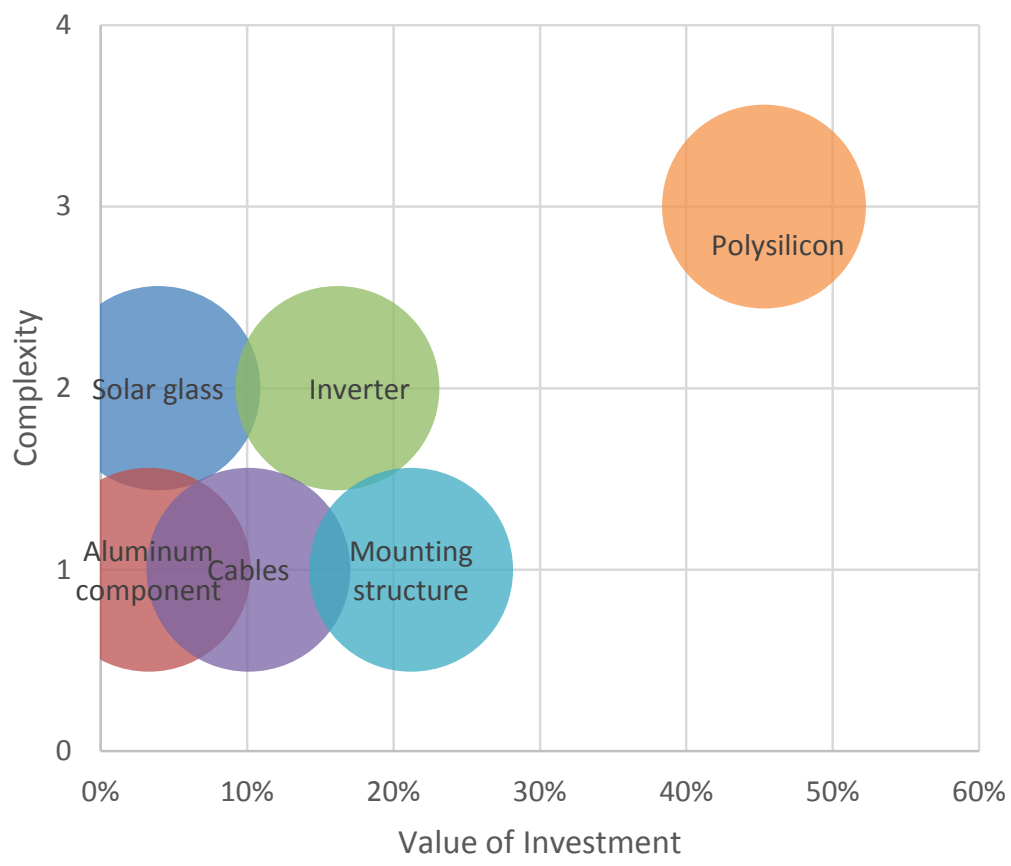

Source: Own illustration, data (see above). Volume of investment as share of overall investment. 
Figure 17: Wind Technology Complexity and Value of Investment

\section{Wind Technology}

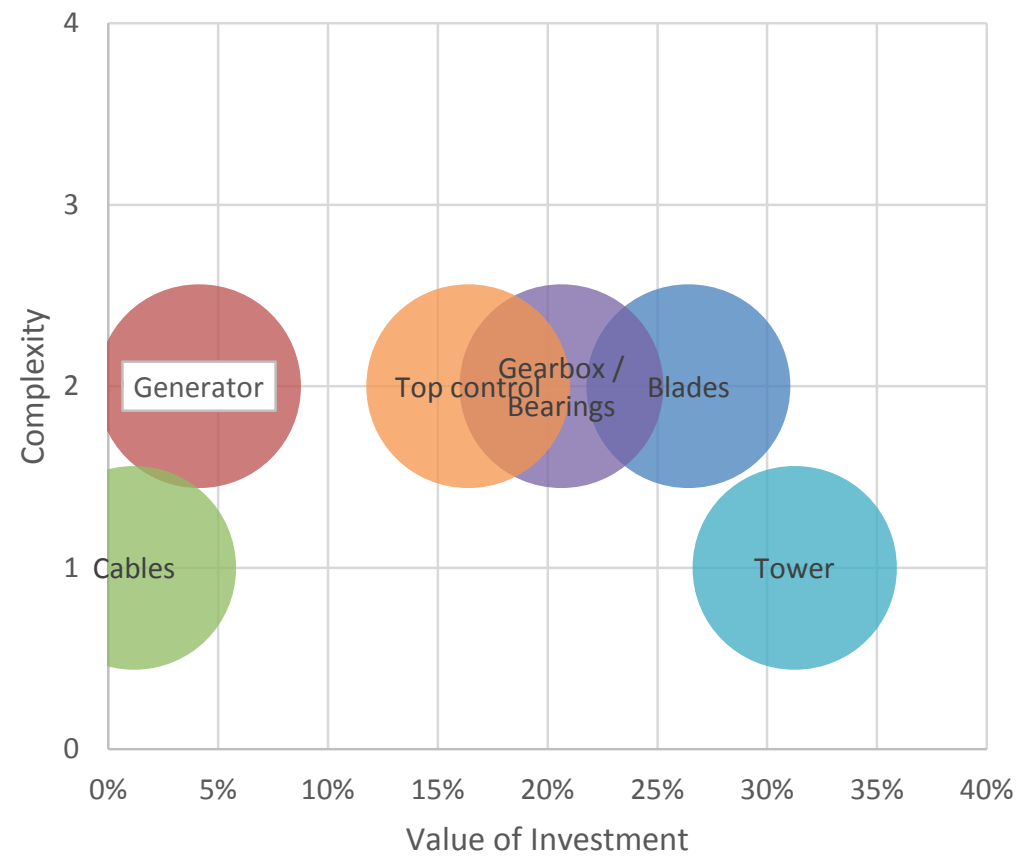

Source: Own illustration, data (see above). Volume of investment as share of overall investment.

Table 10: Complexity of Technology Component and Value Share of Investment

\begin{tabular}{|c|c|c|c|c|c|c|c|c|}
\hline \multicolumn{3}{|c|}{ CSP technology } & \multicolumn{3}{|c|}{ PV technology } & \multicolumn{3}{|c|}{ Wind technology } \\
\hline Component & $\begin{array}{l}\text { Component } \\
\text { complexity }\end{array}$ & $\begin{array}{l}\text { Value } \\
\text { share }\end{array}$ & Component & $\begin{array}{l}\text { Component } \\
\text { complexity }\end{array}$ & $\begin{array}{l}\text { Value } \\
\text { share }\end{array}$ & Component & $\begin{array}{l}\text { Component } \\
\text { complexity }\end{array}$ & $\begin{array}{l}\text { Value } \\
\text { share }\end{array}$ \\
\hline Cables & Low & $1 \%$ & Cables & Low & $10 \%$ & Cables & Low & $1 \%$ \\
\hline $\begin{array}{l}\text { Mounting } \\
\text { structure }\end{array}$ & Low & $23 \%$ & $\begin{array}{l}\text { Aluminium } \\
\text { component }\end{array}$ & Low & $3 \%$ & Tower & Low & $31 \%$ \\
\hline $\begin{array}{l}\text { Pipes/ Heat } \\
\text { exchanger }\end{array}$ & Medium & $16 \%$ & $\begin{array}{l}\text { Mounting } \\
\text { structure }\end{array}$ & Low & $21 \%$ & Generator & Medium & $4 \%$ \\
\hline $\begin{array}{l}\text { Electronics, } \\
\text { Controls }\end{array}$ & Medium & $15 \%$ & Inverter & Medium & $16 \%$ & Blades & Medium & $26 \%$ \\
\hline Generator & High & $11 \%$ & Solar glass & Medium & $4 \%$ & $\begin{array}{l}\text { Gearbox / } \\
\text { Bearings }\end{array}$ & Medium & $21 \%$ \\
\hline Mirror & Medium & $9 \%$ & $\begin{array}{l}\text { Polysilicon / } \\
\text { Wafer/ Cell }\end{array}$ & High & $45 \%$ & Top control & Medium & $16 \%$ \\
\hline Receiver & High & $10 \%$ & & & & & & \\
\hline Turbine & High & $15 \%$ & & & & & & \\
\hline
\end{tabular}

Source: See above (in the text). 


\section{Renewable energy technology adoption in developing countries and how technology suppliers can strengthen fragmented innovation systems ${ }^{38}$}

\footnotetext{
${ }^{38}$ This chapter is based on Blohmke, J., Ndichu, J., Kemp, R., Adeoti, J. O., and Obayelu, A. E. (2013). Renewable energy technology adoption in developing countries and how technology suppliers can strengthen fragmented innovation systems, Économie Appliquée 66(4): 167-193. It has been co-authored by Julian Blohmke (Maastricht University), Jacinta Ndichu (UNU-MERIT), René Kemp (UNU-MERIT), John Adeoti (NISER), Abiodun Elijah Obayelu (FUNAAB). It is based on research work for the UNIDO project "Diffusion Strategies of Green Technology and Green Industry in Africa. A Study of Renewable Energy Technology Market, and Energy Efficiency Adoption in Cassava and Maize Processing Industries in Kenya and Nigeria" funded by KEEl. My contribution in this chapter was the writing of the original paper, while the country surveys about renewable energy technology suppliers were conducted in the field by the UNU-MERIT team and other co-authors (project participants listed above). Extensive editorial work has been provided by René Kemp.
} 



\subsection{Introduction}

The following chapter takes a closer look at barriers to adoption of renewable energy technology (RET) from a technology supplier viewpoint, after country-level technology transfer frameworks have been elaborated in context with concrete technology specifics in the previous chapter.

Access to modern energy services is critical for human development. Its impact on the livelihoods of poor people and on economic potential is evident. Sometimes it is argued that increasing energy access and low-carbon economic development contradict each other. Conventional energy options are occasionally perceived as cheaper modes of electricity generation and thus less burdensome for household budgets in developing countries.

Nevertheless, it has been proved that renewable energy technologies can be competitive with conventional power generation in certain circumstances (REN21, 2013a) ${ }^{39}$. Solar and wind resource potentials, input for bioenergy from the agricultural sector and the absence of electricity distribution lines, can allow off-grid RET to be competitive with conventional power generation technologies. Furthermore, in rural areas where access to electricity distribution lines is likely to be weak, off-grid renewable energy supply can be the only solution for providing electricity.

Africa's economic growth has driven energy intensity, while it decreased in other world regions in recent years (IEA, 2012, pp. 273). Meanwhile, RET deployment is projected by the IEA to be moderate over the next decades, until 2035 on the African continent. However, governments in many developing countries recognise the synergies between RET and economic development and facilitate the diffusion of RET in their countries with strong efforts and international engagement.

A good example is Kenya, which introduced a feed-in tariff for various RET in 2008. The Vision $2030^{40}$, Kenya's blueprint for economic development, aims at transforming Kenya into a newly industrialising, middle-income country which provides a high quality of life for its citizens by 2030. This requires a steady increase in electricity demand over the decades to come. At the same time, the National Climate Change Response Strategy (NCCRS) discusses the serious threat of climate change to economic growth and development. One central aspect of the NCCRS is to further extend power generation with RET playing an increasing role.

Kenya's electricity is currently generated from: hydro 50\%; diesel $30 \%$; geothermal $13 \%$; gas $4 \%$; while cogeneration and wind constitute the remaining $3 \%{ }^{41}$. This translates into a $66 \%$ renewable energy share of Kenya's electricity mix, with significant potential to maintain this share in the future even as generation capacity expands. Overall

\footnotetext{
${ }^{39}$ REN21 compares levelised cost of electricity (LCOE) for different technologies and regions.

${ }^{40}$ Government of Kenya (2007). Kenya Vision 2030. The Government of Kenya.

${ }^{41}$ Kenya Power (2012).
} 
electricity connectivity has expanded in recent years and now stands at 23\%, though that of rural areas is at a paltry 4\% (Kiplagat et al., 2011). The main problem in the power sector is the mismatch between existing capacity and demand, especially in years when hydrological conditions are unfavourable. Roughly 40 watt per capita exist in Kenya - compared to 800 watt per capita in South Africa (ECA, 2012). This exemplifies that rapid expansion in power capacity is highly necessary to ensure economic growth and livelihood.

The country receives good solar irradiation all year round, estimated at 4-6 $\mathrm{kWh} / \mathrm{m}^{2} /$ day (Oludhe, 2013; Kiplagat et al., 2011). The wind energy potential is also good, as many areas have wind speeds above $6.0 \mathrm{~m} / \mathrm{s}$. Bioenergy in the form of biogas, which is a cleaner alternative to wood fuel, has great potential in Kenya, as does geothermal energy. Small scale, off-grid solar systems and bioenergy appliances, like biodigesters, are particularly suited for poor rural areas in sub-Saharan Africa because of their low cost and the availability of biomass energy resources from forests, woodlands, bush lands and farm lands, plantation and agricultural residues which are plentiful (Rogers et al., 2011, Kiplagat et al., 2012). Nevertheless many of the programmes driven by public initiatives to introduce and diffuse small scale RET appliances have not managed to establish a sustainable market in the long run (Rogers, et al. 2011). The problem is believed to lie partly with the support programmes being used. Initiatives failed to grow from a product-based approach towards widespread market-oriented programs (Nes \& Nhete, 2007).

The key objective of this chapter is to analyse the obstacles for RET deployment in developing countries by assessing RET suppliers in Kenya. We do not intend to analyse the effectiveness of RET policies in Kenya, such as feed-in tariffs, but look deeper into the practices of industry actors and analyse their experiences. The findings of the functional analysis approach are based on interviews with RET suppliers, who act as the link between technology manufacturers and end users.

The specific way in which the RET diffusion is studied is by investigating the knowledge sources, product offerings (in particular the "bundling of services"), and the mechanisms of learning and support, with special attention paid to the actors involved and the institutional context in which RETs are promoted and deployed.

Previous work on RET diffusion in a developing country context has concentrated on countries like China and India, where government policies, market structure and user preferences have been analysed (examples are Walz \& Delgado, 2012; Lema \& Lema, 2012). Our research differs from those of others by examining technology supply offerings, industry practices and market barriers to RET in sub-Saharan Africa with the help of original data collection.

The analysis is based on original data collection in Kenya about the technology, markets sales, facilitating and constraining factors of RET in solar, wind and biomass energy. Primary data are of two forms. The first is survey data obtained from interviews with RET suppliers/distributors/marketers using a semi-structured questionnaire. The second 
is interviews with key informants and case study analysis of selected suppliers/distributors and adopters of RET. This is supported by secondary data and information through the review of existing documents from relevant international and national sources/agencies. The sample of firms included in the survey analysis consist of 40 RET suppliers/distributors/marketers of RET in Kenya. Most of the solar technology suppliers examined in Kenya were established after the year 2000. Some of them have existed since the 1980's. Bioenergy technology supply companies are even younger. Almost all have been established since the year 2000 with three exemptions which started business in the late 1990s. Wind technology providers are the youngest in the market, having only set up business in the last few years.

The chapter is organised as follows. In section 2 we describe the innovation systems approach which is used as an analytical framework. Section 3 offers the findings of the functional analysis of the RET innovation system in Kenya based on empirical firm-level data derived from questionnaire-based interviews. Section 4 discusses the ways forward and how gaps in the RET innovation system can be overcome. Section 5 states the conclusions.

The research method is based on an industry survey focusing on Kenyan RET supplier firms. An empirical case study from a vertically integrated actor in the tea industry in Kenya is also added to demonstrate ways of overcoming weaknesses in the Kenyan RET innovation system.

\subsection{The innovation system approach - structures and functions}

The research on innovation in developing countries falls into two categories: those focusing on techno-economic characteristics of the technologies; and those who offer a detailed analysis of adopter decisions (for an overview see Rogers, 2003, also Siegel and Rahman, 2011, and Jan, 2012). The approach in this chapter concentrates on the uptake of new technology from international sources. Research scholars have acknowledged that adoption and use of new technologies involves learning, adaptation and the development of capability among technology users (von Hippel, 1986, Bell, 2009) which feeds back to technology providers. Hence, more holistic approaches on technology adoption have been developed. The concept of innovation systems explains the nature of innovation in a systemic way (Freeman, 1995; Lundvall, 1992). It helps us to understand the coevolution of technologies, industries and institutions and describes how technological paradigms are established and how specific technological trajectories develop. Innovation system approaches are based on the idea that the primary resource is knowledge and the primary mechanism is interactive learning (Lundvall, 1988, 2011). The uncertain and public good nature of knowledge and its tacit quality means that technological knowledge cannot be traded like any other merchandise good. It is embedded in national institutions. Insights suggest that innovation systems promote the creation of 
markets and entrepreneurial activities around new technologies by facilitating activities and processes (Hekkert et al., 2007).

The structures of innovation systems have been discussed in a static manner, but the factors and processes which drive innovation were insufficiently acknowledged (Hekkert et al., 2007). The structural factors of innovation systems, as given by Carlsson \& Stankiewicz (1991), Jacobsson \& Johnson (2000), and Vidican et al. (2012) are: actors and networks (stakeholders, i.e. national agencies); institutions (incentives for private sector development, renewable energy law regulating renewable energy production, transmission, marketing); and knowledge and technologies (institutes/networks/knowledge development). The structural factors perform functions inherent to an innovation system. We do not analyse specific actors in further detail but concentrate solely on RET suppliers' perception of system function dynamics.

In general, innovation system functions can be categorised into generation, diffusion and the use of innovation. Further broken down, as suggested by Hekkert et al., (2007), those functions include entrepreneurial activities, development of knowledge, diffusion of knowledge, guidance of research and market regulation, human resource mobilisation and finance, and the creation of capability to embrace the change.

Rather than following a geographical scope of the innovation system (National Innovation System - NIS) nor focusing on one technology (e.g. wind or solar, Technological Innovation System - TIS) we will apply the Sectoral System of Innovation (SSI) approach (Malerba, 2004), which looks at general patterns of knowledge development and innovation that take place at the sector level. The SSI consists of the sectoral innovation system, the sectoral production system and the sectoral distribution and marketing system. The SSI approach emphasises the domestic knowledge base within a specific sector but also acknowledges the fact that country-specific technology trajectories exist, and that they are linked to global inputs and supply chains and demand.

SSI approaches for RET are special since those technologies offer sustainability benefits which are undervalued in the market place. For their development and diffusion they require sustainability-oriented frameworks and policies. Altenburg and Pegels (2012) evoked the notion of sustainability oriented innovation systems (SolS) for such innovation systems (Altenburg and Pegels, 2012). SolS put a high demand on governance as the governments need to disrupt unsustainable technological pathways as well as actively encourage new, alternative technologies to make them commercially viable in the market. The SolS approach gives technological development a strong policydriven nature.

Since the focus of this chapter lies in the analysis of the RET innovation system functions and policy relevant factors that affect the RET sector development, an analysis of the SSI functions is viewed as appropriate. By doing this we will account for the entrepreneurial activity and knowledge development component, the knowledge diffusion element in networks and the market formation and resource mobilisation processes. 
Aspects of SolS are also included through a close examination of the role of government.

Often, new technologies are characterised by higher cost. On the part of potential users there is often limited knowledge of the benefits and little capability to operate and adopt them. This adopter competence, also called absorptive capacity (Cohen \& Levinthal, 1990) is seen as a critical determinant for the success of adoption of new technologies. The concept of absorptive capacity entails the knowledge and skills necessary to adopt a new technology and make use of new technical information (Cohen \& Levinthal, 1990). The absorptive capacity is important for a firm, sector, or country to adopt and also adapt technology. With RET in particular, the skills required for using and changing a new technology are highly diverse. RET are not static hardware technologies but constantly improving in efficiency, durability and cost. The knowledge intensity is therefore high and has a dual character; knowledge of adoption and knowledge of adaptation is required.

The development of technological knowledge for the diffusion of new technologies is especially important in developing countries, as research on innovation and technology diffusion has broadly shown (Ockwell et al., 2008, Ockwell et al., 2009, Murphy, 2001, Nelson and Pack, 1999, Lall, 1992). Capital goods and codified information contained in patents, and also tacit knowledge of firms and individual skills, are required for technological capability and innovation. In conclusion, importing technology is not sufficient for the type of technology adoption which shall positively impact local technological capability improvement. Instead, it hinges on the local firms' absorption capacity for technological knowledge.

Firms need access to a skilled workforce and opportunities to learn from manufacturing and operational and maintenance experience (Bell \& Figueiredo, 2012). Technological learning does not occur on a system level, but on the component level of a technology system (Ferioli et al., 2009). For each component of the value chain, the accumulation of local technological knowledge is crucial for RET adopting countries. As RET are quite complex and global firms have been specialising in certain components of a RET system, the focus for RET adopting countries should be on knowledge sharing throughout the global supply chain (Malerba \& Nelson, 2011). This implies that RET relevant firms in countries which adopt RET, should not concentrate on acquiring access to new technologies, but also ensure that technological learning occurs. Learning and knowledge sharing need to be managed in an interactive setting between producers and users of knowledge, scientists and policymakers (Hall, 2005) across the whole SSI. The conditions needed to use knowledge productively, rather than merely create or acquire knowledge, is a part of innovation capability, besides the hardware related technological knowledge capability. How relevant knowledge of RET is acquired and used in the Kenyan RET innovation system will be discussed in the following section. 


\subsection{Analysis of the RET innovation system functions in Kenya}

We discuss the functions of the RET innovation system in Kenya with regard to their potential to support technological capability and innovation capability. The main activities of key players in the RET sectors are examined from an RET supplier perspective. This is done by using primary data from interviews obtained during field work in Kenya.

\subsubsection{Entrepreneurial activity and knowledge development}

The intensity of technology manufacturing, and the entry of firms/producers in the RET market describes entrepreneurial activity in the country which represents the technological knowledge base.

The sourcing of RET components is an especially suitable indicator for entrepreneurial activity and technology manufacturing capability. The role of RET sourcing from abroad is dominant in Kenya (see Table 11). China and India lead as providers of RET components, and are more important than Germany, United Kingdom, Netherlands and the United States as technology providers.

The majority of the RET suppliers in Kenya offer the technology, training and after sales care (26 companies), which indicates that their entrepreneurial activity is strong in that they do not just sell or install the RET systems. This is especially true for solar technology providers and slightly less so for bioenergy technology providers. It also indicates that solar technology is more complex than bioenergy technology and hence suppliers need to provide stronger downstream services.

Roughly one quarter of RET suppliers state that the technology is fully based on foreign components, while roughly 30\% involve domestic technology to a small degree and another $30 \%$ involve domestic technology to a larger degree. $17 \%$ of RET suppliers responded that the level of domestic components has increased within the last 5 years, while for the coming five years $24 \%$ state that they expect an increase in domestic component sourcing (see Table 11). Since solar technology is more complex compared to bioenergy technology, it is obvious that the solar technology providers source considerably more foreign technology than bioenergy technology providers. The local content of bioenergy technology is much higher. 
Table 11: Development of technology sourcing

\begin{tabular}{|c|c|c|}
\hline Development of RET sourcing & Frequency & Percentage \\
\hline Based on foreign technology only & 10 & 24.4 \\
\hline Involves domestic technology to a small degree & 12 & 29.3 \\
\hline Involves domestic technology to a large degree & 12 & 29.3 \\
\hline Primarily based on domestic technology & 4 & 9.8 \\
\hline No response & 3 & 7.2 \\
\hline Total & 41 & 100 \\
\hline \multicolumn{3}{|l|}{ Source of RETs acquisition } \\
\hline China & 18 & 43.9 \\
\hline India & 4 & 7.8 \\
\hline Dubai & 0 & 0 \\
\hline USA & 3 & 7.3 \\
\hline UK & 0 & 0 \\
\hline Germany & 3 & 7.3 \\
\hline Total & 28 & 66.3 \\
\hline Has the level of domestic component sourcing changed since 2007? & Frequency & Percentage \\
\hline Yes & 7 & 17.1 \\
\hline No & 34 & 82.9 \\
\hline Total & 41 & 100 \\
\hline $\begin{array}{l}\text { Expectation of further increase in domestic sourcing of RET } \\
\text { components in the next five years ( } 2018 \text { ) }\end{array}$ & Frequency & Percentage \\
\hline Yes & 10 & 24.4 \\
\hline No & 31 & 75.6 \\
\hline Total & 41 & 100 \\
\hline Are you supplying only the technology or also other services? & Frequency & \\
\hline We mainly supply the technology & 13 & \\
\hline We supply the technology and help with implementation & 20 & \\
\hline We supply the technology, training, and after sales care & 26 & \\
\hline
\end{tabular}

Source: Analysis of field data, 2013.

RET knowledge development also entails research and development (R\&D) of RET. The degree of research in RET, measured as the percentage of sales spent on product improvement, is being used to indicate whether companies engage in developing their firm internal knowledge of RET.

$27 \%$ of RET suppliers stated that they did not invest in product improvement, another $27 \%$ stated that they do so occasionally, while $46 \%$ engaged in continuous product development (Table 12). More than half of the suppliers invested less than $10 \%$ of their sales on product improvement, while no company invested more than $50 \%$ of their sales on product improvement in the year 2012 (Table 12). Furthermore, a high 
proportion of the suppliers kept their investment on product improvement in the last two years at a constant, while $7.3 \%$ reported having reduced the amount spent on product improvement. This suggests that the suppliers are willing to invest in research and product improvement. It is however necessary to state that further inquiry during the interviews of RET suppliers on the nature of the research for product improvement indicated that their efforts are often only in-house adaptations and fixing of equipment within the firm. The research does not result in any substantially new product and neither does it involve any new process that can be regarded as innovative. There is a tendency for bioenergy technology suppliers to make more effort to improve products than solar technology suppliers. A possible reason for this is that solar technology components are more complex as compared to bioenergy technology components, which therefore can be more easily improved on the basis of existing technological capabilities of the Kenyan RET sector.

Table 12: Commitment by technology providers to improve RET

\begin{tabular}{|c|c|c|}
\hline \multirow[t]{2}{*}{ Research to improve RETs products sold } & \multicolumn{2}{|l|}{ Kenya } \\
\hline & Frequency & Percentage \\
\hline No & 11 & 26.8 \\
\hline Yes, occasionally & 11 & 26.8 \\
\hline Yes, continuously & 19 & 46.4 \\
\hline Total & 41 & 100.0 \\
\hline Percentage of sales spent on product improvement in 2012 & Frequency & Percentage \\
\hline$\leq 10^{*}$ & 16 & 53.3 \\
\hline $11-30$ & 6 & 20.0 \\
\hline $31-50$ & 1 & 3.4 \\
\hline $51-70$ & 0 & 0 \\
\hline$>71$ & 0 & 0 \\
\hline Indecisive & 7 & 23.3 \\
\hline Total & 30 & 100 \\
\hline $\begin{array}{l}\text { Direction of change in the amount spent on product } \\
\text { improvement in last } 2 \text { years (since 2010) }\end{array}$ & Frequency & Percentage \\
\hline Increased & 14 & 34.2 \\
\hline No change & 24 & 58.5 \\
\hline Declined & 3 & 7.3 \\
\hline Total & 41 & 100 \\
\hline
\end{tabular}

Source: Analysis of field data, 2013. * This does not include the value of 0.

A lack of technical competence among potential adopters was only mentioned as a barrier to RET adoption by 7 out of 41 supplier companies. Of these 7, 4 are solar technology providers, 2 are bioenergy technology providers and 1 is a multi-technology 
provider (see in the appendix Table 16). This can be interpreted as demonstrating that for most potential adopters, a lack of technical competence is not a barrier, at least not from the perspective of RET sellers.

Findings suggest that entrepreneurial activity and the knowledge development function in the RET sectors are weakly developed. Although there are a considerable number of technology suppliers in Kenya, the knowledge development capacity is very low at present. RET component sourcing is especially high for solar technology, and RET suppliers project low increase in local content of RET, while limited activity in product improvement and adaptation can be observed. RET knowledge is essentially limited to RET system installations, maintenance and repairs, while manufacturing activity of RET components is absent.

\subsubsection{Knowledge diffusion and networks}

Knowledge diffusion in an SSI typically consists of activities and processes that diffuse information and knowledge about the respective technology (Tigabu et al., 2015). This function captures the presence of knowledge sharing channels and networks among the key actors within the SSI. Technology collaboration among actors is a good measure to investigate whether knowledge on innovative technologies reaches a broader range of actors and thus diffuses the knowledge across the sector. Interaction with other RET suppliers and other stakeholders like universities, technology transfer centres, environmental consultants and environmental organisations has proved to be an important aspect of knowledge diffusion in Kenya (see Table 13). Most companies interacted with universities while the collaboration with customers can be viewed as equally important.

The high interaction between suppliers and users of RET is key for the feedback of information to the supplier. This allows suppliers to adjust their offerings and improve services and contributes to effective use of knowledge.

Another significant aspect is that non-governmental organisations (NGOs) and aid agencies are seen as important entities by RET suppliers: these institutions provide support by increasing the awareness for RET in Kenya, particularly in end users in remote areas of the country. More than $40 \%$ found NGOs and aid agencies crucially helpful for their RET marketing. 
Table 13: Technology collaborations

\begin{tabular}{|c|c|c|c|c|c|c|c|}
\hline \multicolumn{8}{|c|}{$\begin{array}{l}\text { In the last two years, ha } \\
\text { answering with yes)? }\end{array}$} \\
\hline Universities & $\begin{array}{l}\text { Technology } \\
\text { transfer } \\
\text { centres }\end{array}$ & $\begin{array}{l}\text { Environmental } \\
\text { consultants }\end{array}$ & $\begin{array}{l}\text { Technical } \\
\text { institutes }\end{array}$ & $\begin{array}{l}\text { Equipment } \\
\text { suppliers }\end{array}$ & Customers & $\begin{array}{l}\text { Environmental } \\
\text { organisations }\end{array}$ & Competitors \\
\hline 23 & 7 & 11 & 7 & 18 & 21 & 12 & 14 \\
\hline \multicolumn{8}{|c|}{ Are NGOs and aid agencies facilitating RET marketing? } \\
\hline & Crucial & Helpful & $\begin{array}{l}\text { Hardly } \\
\text { helpful }\end{array}$ & $\begin{array}{l}\text { Not } \\
\text { applicable }\end{array}$ & & & \\
\hline $\begin{array}{l}\text { NGOs and } \\
\text { aid agencies }\end{array}$ & $\begin{array}{l}17 \\
(41.5)\end{array}$ & $\begin{array}{l}13 \\
(31.7)\end{array}$ & $\begin{array}{l}5 \\
(12.2)\end{array}$ & $\begin{array}{l}6 \\
(14.6)\end{array}$ & & & \\
\hline
\end{tabular}

Note: Values in parenthesis are in percentages. Source: Analysis of field data, 2013.

The majority of RET suppliers provide technical support for clients in form of training and installation of RET, while technical support is mostly offered by local experts (Table 14). This holds true similarly for solar and bioenergy technology suppliers. The perception was that foreign experts would be completely replaced by local ones within the next 5-10 years. This function is important to diffuse the technological knowledge to end users and ensure that the technology is used professionally.

Table 14: Provision of technical support and training

\begin{tabular}{lcc}
\hline Provision of technical support for clients in the form of & \multicolumn{2}{l}{ Kenya } \\
\cline { 2 - 3 } training and installation & Frequency & Percentage \\
\hline Yes & 33 & 80.5 \\
No & 8 & 19.5 \\
Total & 41 & 100 \\
\hline Technical support done by foreign expert & Frequency & Percentage \\
\hline Yes & 4 & 9.8 \\
No & 37 & 90.2 \\
Total & 41 & 100 \\
\hline
\end{tabular}

Source: Analysis of field data, 2013.

Knowledge linkages between technical centres, researchers and equipment suppliers are well established. But the quality of interaction and knowledge diffusion among those stakeholders cannot be analysed from the survey results. Technology suppliers and end users interact closely when it comes to technology installation and after sales training. This allows the knowledge to being applied effectively and also ensures feedback from end users of technology to RET suppliers. 


\subsubsection{Market formation and resource mobilisation}

Kenya has pioneered the application of policy to promote RET. It became the first country in sub-Saharan Africa to introduce a feed-in tariff in 2008, which guarantees investors grid access and a fixed rate for power generated from renewable energy sources. ${ }^{42}$ Thus, there are clear policy targets which contribute to the market formation of RET in Kenya.

Besides knowledge development and knowledge diffusion, it is of paramount importance that technology use can be triggered by combining it with other enabling factors for diffusion. Resource mobilisation includes activities which are related to organise financial, human and physical resources needed for RET development and promotion (Tigabu et al., 2015). As this chapter concentrates on the technology suppliers' view, we focus on the mobilisation of financial resources, since human and physical resource mobilisation is more an issue for technology manufacturers than for technology suppliers. In developing countries the financial sector is sometimes weakly developed (WEF, 2012). Technology suppliers are a key link between the end user market, the adopters, and technology producers and policymaking entities in a country.

More than $50 \%$ of technology suppliers stated that access to finance is crucial for facilitating the marketing of RET (Table 15). To help end users, $27 \%$ of the RET suppliers provided financial support to their clients (Table 15), for instance by accepting payment in various instalments. Solar technology providers were more supportive than bioenergy technology providers in offering financial advice and flexibility in payment.

73\% of the respondents do not offer any form of financial support either in form of instalment payments, loan or allowing their clients to pay below the normal market rate; probably because of fear of default. A few firms reported having negotiated arrangements with local financial institutions for RET adoption purposes. These appeared to be firms that were more mature and well established in terms of scale of operation, which can be a prerequisite for securing an agreement with a financial institution. It appeared that more firms were interested in doing this but found the contract negotiation with financial institutions too lengthy. $46 \%$ of the RET suppliers offer their customers advice about how to obtain financial means from financial institutions or the government. This shows that there was a great demand for financial advisory services by RET suppliers.

\footnotetext{
${ }^{42}$ Ministry of Energy (2012). Feed-in tariffs policy for wind, biomass, small hydro, geothermal, biogas and solar, 2nd revision, December 2012.
} 
Table 15: Provision of financial support to clients

\begin{tabular}{|c|c|c|c|c|}
\hline \multirow{2}{*}{\multicolumn{3}{|c|}{ Provision of financial support to clients }} & \multicolumn{2}{|l|}{ Kenya } \\
\hline & & & Frequency & Percentage \\
\hline \multicolumn{3}{|l|}{ Yes } & 11 & 26.8 \\
\hline \multicolumn{3}{|l|}{ No } & 30 & 73.2 \\
\hline \multicolumn{3}{|l|}{ Total } & 41 & 100 \\
\hline \multicolumn{3}{|c|}{ Components of the financial support } & Frequency & Percentage \\
\hline \multicolumn{3}{|c|}{ a loan at a normal market price } & 2 & \\
\hline \multicolumn{3}{|c|}{ a loan at a rate below the normal market rate } & 2 & \\
\hline \multicolumn{3}{|c|}{ possibility of payment in various instalments } & 8 & \\
\hline \multicolumn{3}{|c|}{$\begin{array}{l}\text { Do you advise your clients about how to obtain financing from } \\
\text { financial institutions or government? }\end{array}$} & Frequency & Percentage \\
\hline \multicolumn{3}{|l|}{ Yes } & 19 & 46 \\
\hline \multicolumn{3}{|l|}{ No } & 15 & 37 \\
\hline \multicolumn{3}{|l|}{ No answer } & 7 & 17 \\
\hline \multicolumn{3}{|l|}{ Total } & 41 & 100 \\
\hline \multicolumn{5}{|c|}{ How helpful to your sales is access to finance (supplier view)? } \\
\hline \multicolumn{3}{|l|}{ Crucial } & 22 & \\
\hline \multicolumn{3}{|l|}{ Helpful } & 12 & \\
\hline \multicolumn{3}{|l|}{ Not helpful } & 1 & \\
\hline \multirow{2}{*}{$\begin{array}{l}\text { Factors facilitating RETs } \\
\text { marketing }\end{array}$} & Frequen & & & \\
\hline & Crucial & Helpful & Hardly helpful & Not applicable \\
\hline Access to finance & $\begin{array}{l}22 \\
(53.7)\end{array}$ & $\begin{array}{l}12 \\
(29.3)\end{array}$ & $\begin{array}{l}2 \\
(4.9)\end{array}$ & $\begin{array}{c}5 \\
(12.1)\end{array}$ \\
\hline
\end{tabular}

Note: Values in parenthesis are in percentages. Source: Analysis of field data, 2013

According to the majority of the suppliers, access to finance and being able to channel financial sources to their clients is crucial to their sales Thus it can be concluded that the mobilisation of financial sources is very important for the adoption of RET.

\subsection{The way forward: Barriers and the strengthening of a fragmented innovation system}

Technology suppliers are key in developing countries where the technological capability is less developed, since they act as primary facilitator between global suppliers of RET and domestic RET end users.

There are several explicit barriers to RET adoption reported by RET suppliers. Lack of technical knowledge and financial sourcing emerge as important barriers. RET suppliers also raise the issue that there is a strong need to improve the business climate in Kenya, as it affects the availability of financial sources, especially from international financial institutions. Thus there is a great need for technical assistance policies and financial aid 
policies, stated by $87 \%$ of respondents (Table 16), which give technology end users better access to financial sources. To meet this obstacle, RET suppliers offer specific services to reduce shortcomings. The reason for bundling the technology supply with advice on finance or provision of financing solutions is to overcome financing challenges and mobilise financial resources. It alleviates weak financial sector characteristics such as limited knowledge on financial mechanisms and instruments. International donors like the World Bank Group, have supported the Kenyan government and Energy Regulatory Commission (ERC) to set up a guide to renewable energy projects and finance options. This one-stop resource provides information on market tariffs and grid specifications, information on government policies and information on how developers can apply for financing. ${ }^{43}$

Another important barrier, as already mentioned in the context of training and maintenance services offered by suppliers, is that the technological knowledge base of adopters is very low. This especially applies to technology end users, where awareness of new technologies is sometimes very low and technological needs and knowledge to use is weakly developed.

It is also important to note that high import tariffs on RET components were mentioned as a barrier to adoption by $15 \%$ of the RET suppliers (Table 16). It was also reported that interruptions in implementation of tax waivers was an issue as well as bureaucratic delays and poor specification that excluded many RET components from tax exemption. Among RET project developers of large renewable energy projects which several sub-contractor companies participated in, only the developer was able to benefit from tax alleviation (i.e. import duty exemption and VAT waiver), not the producers of intermediate inputs and providers of complementary assets, which suggests that the tax exemption policy may not be sufficiently far reaching. However, in general, Kenyan policy of import duty exemption and VAT waivers are perceived as helpful in reducing barriers to RET adoption.

\footnotetext{
${ }^{43}$ https://www.wbginvestmentclimate.org/advisory-services/private-participation/infrastructure/kenya-launchesrenewable-energy-portal-for-potential-developers.cfm
} 
Table 16: Barriers to RETs adoption according to suppliers/distributors/marketers

\begin{tabular}{|c|c|c|}
\hline \multirow[t]{2}{*}{ Nature of barriers* } & \multicolumn{2}{|l|}{ Kenya } \\
\hline & Frequency & Percentage \\
\hline Government's preference for local equipment & 0 & 0.0 \\
\hline High-tariffs on foreign equipment & 6 & 14.6 \\
\hline Unfavourable business climate/environment for FDI & 10 & 24.4 \\
\hline Lack of technical competence on the part of potential adopters & 7 & 17.1 \\
\hline Language / different culture & 1 & 2.4 \\
\hline $\begin{array}{l}\text { Product offerings from foreign suppliers do not completely fit with } \\
\text { needs of African companies }\end{array}$ & 0 & 0.0 \\
\hline High cost of technology & 0 & 0.0 \\
\hline Benefit derived from subsidies by RETs marketers & Yes & No \\
\hline Import duty exemptions & $24(58.5)$ & $17(41.5)$ \\
\hline VAT exemptions & $8(19.5)$ & $33(80.5)$ \\
\hline Is there a need for technical assistance policies? & Frequency & Percentage \\
\hline Yes & 36 & 87.8 \\
\hline No & 5 & 12.2 \\
\hline Total & 41 & 100 \\
\hline Is there a need for financial aid policies? & Frequency & Percentage \\
\hline Yes & 36 & 87.8 \\
\hline No & 5 & 12.2 \\
\hline Total & 41 & 100 \\
\hline
\end{tabular}

Note: * Multiple responses, values in parenthesis are in percentages. Source: Analysis of field data, 2013.

Transforming weak and fragmented innovation systems requires not only the formal set-up of institutions and the implementation of functions, but also the overcoming of a lack of cooperation and knowledge transmission, as well as targeting weak networking (Žižalová \& Blažek, 2010). It has rarely been discussed in the literature how informal, non-institutionalized functions in the form of additional, non-core business services of private sector actors can contribute to filling the gaps in innovation systems.

Based on our survey it can be observed that RET suppliers offer not only the hardware but often also deliver the installation services of technology, training of technical maintenance staff and after sales services. In many cases, those companies also advise on financing issues and even provide capital for their end user clients.

The bundled offering of services by one actor constitutes a way of providing necessary functions in the SSI, especially when SSI components (organisations, institutions and linkages) are only weakly developed and fragmented. Sharing bundled services, which are provided by one actor within a network, is a way to overcome the challenges of market access caused by technical knowledge shortage and financial gaps that hinder technology adoption. 
The case of the Kenya Tea Development Agency (KTDA) supporting the deployment of small hydropower technology illustrates how the two aspects, technical knowledge shortage and financial constraints, are tackled by one single SSI actor. KTDA provides general services such as finance, insurance, warehousing and power supply to its affiliated tea farms. It set up the subsidiary KTDA Power Ltd. in 2010, which provides funds and consultancy services for power generation projects for its affiliated tea farms throughout Kenya (UNEP, 2013). It also acts as an equity investor in small hydropower projects, which helps to leverage commercial bank loans. KTDA Power Ltd. also sells excess electricity to the Kenya Power and Lighting Company based on a power purchase agreement (Wachira, 2012). KTDA Power Ltd. has acted as loan guarantor facilitating lending from financial institutions and assisted in obtaining credit from multilateral organisations such as the Global Environment Facility (GEF).

It also negotiates grid access agreements and power purchase agreements with the state grid operator, it issues tenders for power projects on behalf of its members and provides an engineering consultancy service. KTDA Power Ltd. helps overcome the weaknesses of an SSI by acting as a knowledge and service broker and at the same time as a network agency between tea farms in Kenya.

All those functions help to overcome the barriers to RET deployment in the tea sector, i.e. lack of technical knowledge and the weak access to financial sources. The role as a shared hub for technical power engineering expertise, and the financial strength of the parent company KTDA to act as a loan guarantor, made the deployment of several small hydropower plants in the Kenyan tea sector possible without the engagement of governmental institutions.

\subsection{Conclusion}

The penetration of solar, wind and bioenergy technology is at very low levels in subSaharan Africa, while at the same time a lack of access to electricity is a severe development challenge. In Kenya, despite considerable potential for renewable energy and the presence of a feed-in tariff, the deployment of RET has been slow. This is in part due to ill-developed innovation systems, which could otherwise facilitate technology adoption more smoothly.

As industry practitioners play an important role in the process of adopting RET, detecting the drivers and barriers of RET adoption from their perspective is of interest for policymakers. This chapter does not focus on the effectiveness of feed-in tariffs in Kenya. It analyses the emergence of the RET innovation system (mainly solar and bioenergy) in Kenya by applying the Sectoral System of Innovation (SSI) approach, which looks at general patterns of knowledge development and innovation that take place at the sectoral level, instead of following a geographical scope of the innovation system ( $\mathrm{Na}$ tional Innovation System - NIS) or focusing on one technology, e.g. wind or solar (Technological Innovation System - TIS), although elements of these have been considered. 
The assessment of the RET innovation system in Kenya is based on a country survey with RET suppliers in Kenya.

The functional analysis of the RET SSI in Kenya reveals that its functions are partially very weak. This is indicated by the high rate of international sourcing of RET components, mainly from China and India, the limited availability of financial resources and technological knowledge among adopters acting as obstacles for technology adoption. The degree of innovation is typically low. Innovative approaches mentioned by respondents consisted of adaptation of foreign RETs using local materials, financing arrangements, resource and the pooling of know-how.

The analysis gives some good indications of how technological capability and overall sectoral functions can be further developed for RET in Kenya. Lack of RET knowledge is revealed as a strong barrier to RET adoption, alongside an unstable business environment and a weak foreign direct investment (FDI) environment, also due to higher risk premiums required for RET project financing. Even though Kenya introduced a feed-in tariff in 2008, there is still a great need for technical assistance policies and financial aid policies which give technology end users better access to knowledge and financial sources.

Our findings support the idea that structural aspects of an innovation system such as actors, networks and institutions should be strengthened by government institutions by providing better access to technology knowledge and financing services for private sector actors. It is specifically important to foster policy capacity to build up the overall system for producing and using knowledge in the private sector, without neglecting international knowledge-sharing networks. Over $90 \%$ of respondents believed that there is need for technical assistance and financial aid policies.

Bundling of various services such as supplying RET, providing financing advice, as well as training of maintenance staff and after-sales services is widely practiced by suppliers as a way to overcome the disadvantages of weakly developed innovation systems.

In conclusion, we suggest that multinational technology collaborations, and technological and financial assistance policies by public institutions, and also the support for industry-driven multi-level, multi-functional entities in the SSI, embedded in global supply chains, should be strengthened to increase RET knowledge development and diffusion. 


\subsection{Appendix}

Figure 18: Sample of RET suppliers/distributors/marketers surveyed in Kenya

\section{Number of companies}

$$
20
$$

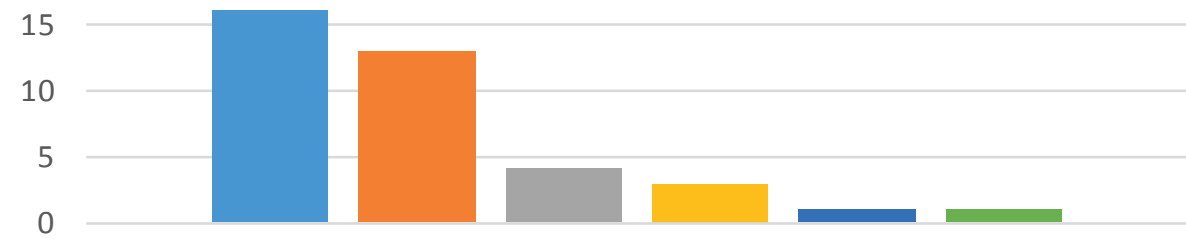

Solar Biomass Multi Wind Hydro Finance Average number of employees

60

50

40

30

20

10

0

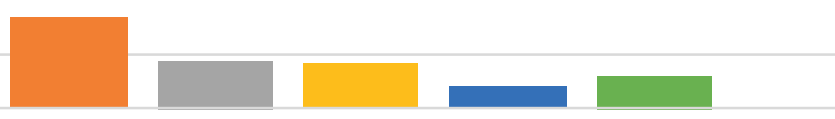

Solar Biomass Multi Wind Hydro $\square$ Finance

Source: Analysis of field data, 2013. 



\section{The adoption of energy efficiency measures by firms in Africa: case studies of cassava processing in Nigeria and maize milling in Kenya ${ }^{44}$}

\footnotetext{
${ }^{44}$ This chapter is based on the publication Ndichu, J., Blohmke, J., Kemp, R., Adeoti, J. \& Obayelu, A. (2015). The adoption of energy efficiency measures by firms in Africa: case studies of cassava processing in Nigeria and maize milling in Kenya, Innovation and Development, 5:2,189-206. This chapter has been co-authored by Jacinta Ndichu (UNU-MERIT), Julian Blohmke (Maastricht University), René Kemp (UNU-MERIT), John Adeoti (NISER), Abiodun Elijah Obayelu (FUNAAB). It is based on research work for the UNIDO project "Diffusion Strategies of Green Technology and Green Industry in Africa. A Study of Renewable Energy Technology Market, and Energy Efficiency Adoption in Cassava and Maize Processing Industries in Kenya and Nigeria" funded by KEEI. We are grateful to the people who provided information and feedback. We are particularly thankful for the helpful comments received from the reviewers and editors of the special issue of Innovation and Development, which very much helped us to improve the paper. My contribution to this chapter consists of supporting the analysis of survey data results and the writing of the sections on literature review, the comparison of our findings with those in the literature on energy efficiency, and discussing the topic of low carbon development in developing countries and policy for low carbon industrial development in Sub-Saharan Africa.
} 



\subsection{Introduction}

So far, renewable energy technology (RET) has been put in the context of climate mitigation technology deployment. Yet, energy efficiency is an important demand-side measure to tackle global warming. This measure's potential is largely untapped in developing countries (Lema et al., 2014). This chapter, similarly to the previous one, looks at the drivers and barriers of energy efficiency technology deployment from the customers' perspective, by concentrating on firms and the momentum for energy efficiency measures coming from within.

As developing countries will need to take on greater responsibilities in the fight against climate change (Kanie et al., 2010), it is legitimate to assess the diffusion of energy efficiency technologies in developing countries in more detail. Data on the drivers and barriers of energy efficiency technology diffusion in Africa is limited, pointing to the need for in-depth research. Our study is exploratory and one of the first to obtain data from companies about the adoption of energy efficiency measures in African countries, namely Nigeria and Kenya. Agro-processing is chosen as the sector of study as agro-processing constitutes an important economic activity in those countries for which energy costs constitute a significant proportion of total costs (between $30 \%$ and $40 \%$ of total production cost according to UNIDO, 2014).

Energy efficiency measures may consist of special measures to reduce energy use or to modernise production equipment. In the case of more modern production technologies, there are often important co-benefits for the adopter (in the form of cost efficiencies, higher production volumes, greater product quality) and for upstream and downstream sectors. Even when the adoption of energy efficiency technologies produces a range of benefits, adoption does not occur automatically and is likely to be predicated on a number of conditions, such as sector-wide policy approaches, national agencies which can fill potential institutional and innovation gaps, and regulations with long-term horizons (Lema et al., 2014; Chaudhary et al., 2012; Sagar, 2013). The present chapter investigates such conditions for the adoption of energy efficiency (EE) measures in the cassava and maize processing industries in Nigeria and Kenya. Special attention will be given to the transfer of foreign technologies and collaborative relationships in the area of learning and innovation, as these are important issues (Altenburg \& Pegels, 2012; Lema et al., 2014).

Analytically, the chapter draws on the literature on innovation systems (Lundvall, 1988, 2011; Malerba, 2002; Adeoti, 2002), the literature about global value chains (Morris et al., 2012; Kaplinsky \& Farooki, 2011) as well as literature on climate change and national low-carbon development pathways (OECD, 2011a; Popp, 2012; Ockwell \& Mallett, 2013; Lema et al., 2014).

In this chapter, local and global aspects of value chains and innovation are brought into the analysis to understand the indigenous and foreign sources of knowledge and technology, the ways in which national policies act as a barrier or facilitator, and the 
need for financial assistance, technology transfer and technical cooperation. The research questions on which the chapter sheds light are: i) what measures have been adopted by companies in the cassava processing and maize milling industries; ii) what are primary motivations for, and barriers to, adoption; iii) are the technology components locally produced or produced abroad, and iv) what solutions are being used to overcome problems encountered? The main purpose of the chapter is to provide an empirical analysis of the drivers of and barriers to the adoption of energy efficiency measures in the sub-Saharan Africa context. ${ }^{45}$

The structure of the chapter is as follows. Section 2 describes the research approach. Section 3 discusses the conceptual framework derived from theoretical perspectives of sectoral systems of innovation, value chain analysis, and emerging literature on low-carbon development pathways for developing countries. Section 4 offers a profile of the two subsectors investigated. Section 5 presents the findings of the empirical analysis and case study illustrations. The final section states the main conclusions and limitations of the study.

\subsection{Research approach}

The chapter is based on original data collection in Nigeria and Kenya about the adoption of EE measures among the cassava processors (in Nigeria) and maize processors (in Kenya). Primary data are of two forms. The first is survey data obtained from cassa$\mathrm{va} / \mathrm{maize}$ processors using a 66 item semi-structured questionnaire. The second is interviews with key informants and case study analysis of selected adopters and potential adopters of energy efficiency technologies. This is supported by secondary data obtained from a review of documents from relevant international and national sources/agencies.

The sample of firms included in the survey analysis consist of 62 cassava processing firms in Nigeria and 40 maize processing firms in Kenya. This chapter presents only two of the case studies in order to deepen the understanding of the survey findings on the factors affecting the adoption of EE measures. Details about the sample and the sampling method are given in the appendix to this chapter.

\subsection{The conceptual framework for studying the adoption of energy efficiency measures in the context of agro-industrial sectors in sub-Saharan Africa}

In the innovation literature, different systems perspectives have been developed for studying innovation processes, the two most important of which are the National System of Innovation (NSI) framework (Freeman, 1995; Lundvall, 1992; Nelson \& Rosenberg, 1993) and Sectoral System of Innovation framework (Malerba \& Nelson, 2012).

\footnotetext{
${ }^{45}$ The findings are based on a study for UNIDO which offers further details and econometric results (UNIDO, 2014).
} 
Applications of those frameworks to the context of developing countries are made by Adeoti (2002), Muchie et al. (2003) and Hall (2005). In the system of innovation approaches firms are at the centre of innovative activities. Yet innovation by firms cannot be understood purely in terms of independent decision-making at the level of the firm, as it depends on complex interactions between a firm and its environment, such as research institutes, suppliers and users (Smith, 2000). The sectoral innovation system is particularly concerned with highlighting characteristics of the environment within which development proceeds that are sector-specific. The national system of innovation looks at broader national features.

Innovation in energy efficiency may be new to the world, new to the sector and new to the company adopting it. The review of industrial energy efficiency by UNIDO (2011) shows that technological solutions already exist for many of the problems in the manufacturing and services sector; and that they just need to be diffused more widely among enterprises, and adapted to local circumstances and conditions. This requires a combination of effective transfer and diffusion mechanisms, along with increased capacity building within enterprises to enable the adoption and adaptation of new technologies. Small and medium enterprises (SMEs) in the manufacturing sector tend to have shortterm priorities, whereas environmental problems and challenges are usually viewed as long-term issues. Motivations for adoption of green technologies are likely to differ across technologies and firms, as are the constraints to adoption (Montalvo, 2002; del Río González, 2005).

There are many possible drivers and many possible barriers to the adoption of energy efficiency measures (Sorrell et al., 2004; Fleiter et al., 2012 and the studies reported therein). Information, access to capital, the characteristics of the production technologies, and incentives for adoption, are hypothesised to be relevant determinants.

A framework and method of analysis has been developed, which allows for deeper insights into aspects of energy efficiency technology adoption by concentrating on technology diffusion media and sources, characterisation of the adopters by size and activity, the potential technology options and finally the barriers and drivers for energy efficiency technology adoption measures, which determine the technology diffusion. The methods used for inquiring into the framework aspects are survey analysis and case analysis. After identifying green technologies and the suppliers, we trace their adoption status, the scale of production activities in which they are employed, the stages of production involved and the type of green technology available for each stage. Then, the factors which facilitate or motivate, and constrain or hinder, adoption are determined with the help of a questionnaire for industry companies and a case study analysis. The framework is a framework for studying adoption decisions in great detail; it is not a framework for studying the dynamics of innovation, which require a different approach (of case histories and innovation patterns). 


\subsection{Cassava processing in Nigeria and maize milling in Kenya}

\subsubsection{Cassava processing in Nigeria}

Cassava is a woody perennial shrub, which grows from 1 meter to 5 meters in height. It is used to produce food products, animal feed, fuel ethanol, and garments. Brought from Brazil, cassava is an important food crop across sub-Saharan Africa and in India, Indonesia and the Philippines. Since it is sensitive to frost and has a growing season of nearly one year, cassava is cultivated almost exclusively in tropical and subtropical regions. It is grown today by millions of small-scale farmers in more than 100 countries (FAO, 2013).

Nigeria is the largest producer of cassava in the world producing about 45 million tonnes of the world's 242 million tonnes in 2009 but accounts for a negligible proportion of global trade in value added due to the uncompetitive nature of its production and weak processing systems (PIND, 2011). Cassava production in Nigeria is increasing at $3 \%$ every year but Nigeria continues to import starch, flour, sweeteners that can be made from cassava. According to the FAO (2013), Nigeria produced $18 \%$ of the world's total cassava production of about 250 million tonnes, Thailand 10\%, Indonesia 9\%, Brazil $8 \%$, Congo $5 \%$, and other countries $50 \%$.

Due to the Nigerian Government's effort to promote a $20 \%$ inclusion of High Quality Cassava Flour (HQCF) in confectioneries as a major component of the Agricultural Transformation Agenda (ATA), it is expected that cassava production will continue to rise in Nigeria. There is also a strong growth prospect for cassava production elsewhere in Africa, particularly in Ghana, Angola, Mozambique, Malawi and Rwanda. This is based on governmental efforts to promote greater national food security in response to the 2008 global food price surge. In Nigeria, the cassava transformation seeks to create a new generation of cassava farmers, oriented towards commercial production and farming as a business, and to link them up to reliable demand, either from processors or a guaranteed minimum price scheme from the government. Under the current Agricultural Transformation Agenda in Nigeria, a Cassava Market and Trade Development Corporation (CMTDC) was recently established as the primary vehicle for implementation of value-added chain activities. The primary activity of the CMTDC is market development, including advocacy with potential users of cassava-based products and policymakers, to ensure reliable demand.

\subsubsection{Maize milling in Kenya}

Maize is Kenya's most important food crop, with its products being consumed by the entire population. Globally, maize serves as a source of animal feed, biofuel feedstock 
and as an input for industrial products in developed countries. In Sub-Saharan Africa it is mainly used for human and animal food consumption ${ }^{46}$.

The maize sector in Kenya is highly concentrated with a few large producers, traders and processors ${ }^{47}$. $20 \%$ of the farmers are responsible for the bulk of the maize marketed and of these under $3 \%$ are responsible for up to $50 \%$ of total maize traded in Ken$\mathrm{ya}^{48}$. In processing, four major milling companies process and distribute $80 \%$ of all maize produce in the country ${ }^{49}$.

There are between 120-150 registered commercial maize processors in Kenya. These processors include small posho millers who use simple and low cost technologies, larger millers who use the more capital intensive and larger scale roller mill technology, and animal feed and cooking oil manufacturers. Maize processing results in whole and refined maize meal, processed sugars (dextrose and glucose syrup), starch, cornflakes, bran, maize cake, confectionery flour and edible oil. Processors also sell their byproducts to food manufacturers, breweries, pharmaceuticals and other industries. Installed capacities of processors in all categories vary, with posho millers handling between one and two $90 \mathrm{~kg}$ bags of maize ${ }^{50}$, medium-sized millers having installed capacity of 10-80 bags, and large ones between 1000-6700 bags per day ${ }^{51}$.

\subsection{Empirical results}

\subsubsection{Findings from the survey}

In this section we present the findings from the survey analysis. The sample of 102 companies is relatively small, owing to the fact that each company had to be visited during the survey. Whilst laborious, it provided the opportunity to ask questions for clarification. The sample consisted of 62 cassava processing companies in Nigeria and 40 maize millers in Kenya. In terms of employment, the Kenyan companies were larger than the Nigerian ones but smaller in terms of sales. The average number of workers in the maize milling firms is 70 and for the cassava processors is 13. The mean value of sales turnover in 2012 was NGN 5.6 million (USD 35,748). Average sales of the Kenyan maize millers was KES 1.8 million (USD 21,062) in 2012. Most firms experienced high levels of growth in the last 3 years. The average annual increase in sales in the last three years was $31.85 \%$ in Nigeria and $29.23 \%$ in Kenya, driven to a large extent by population growth, urbanisation and rising income levels. The growth figures suggest that that

\footnotetext{
${ }^{46}$ www.cgiar.org.

${ }^{47}$ Four major milling companies handle $80 \%$ of all produce processed in the country (Kirimi et al., 2011). There are also reports of major millers who have recently bought up smaller millers (Jayne et al., 2006) 
cassava and maize processing firms in the sample are generally doing well. Energy costs and energy consumption was higher in the Nigerian companies, because of the need for heating. Most companies were established after 2000. In Nigeria and Kenya, $14.5 \%$ and 45.5\% were established before the year 2000; $69.4 \%$ and $42.5 \%$ established between 2000 and 2010; and 14.5\% and 10\% established between 2011 and 2012. The average capacity utilisation for the sample of cassava processing firms was $63.65 \%$ in Nigeria and $65.08 \%$ for the maize millers in Kenya, which is an indication that the firms are generally in good operation conditions.

\section{Energy efficiency measures adopted}

Figure 19 shows the distribution of energy efficiency measures adopted by the respondent firms. The predominant energy efficiency (EE) measures adopted are good housekeeping (adopted by $59.7 \%$ and $52.5 \%$ of the respondents in Nigeria and Kenya respectively), followed by having better process control (adopted by $53.2 \%$ and $42.5 \%$ of the respondents in Nigeria and Kenya), technological change or involving acquisition of new equipment (adopted by $43.5 \%$ of the respondents in Nigeria), and equipment modification (adopted by $37.5 \%$ of the respondents in Kenya). The differences reflect variability in quality of grid electricity and energy needs: cassava processing requires a great deal of heating. The adoption of energy-saving measures resulted in energy reductions of $28.9 \%$ and $16.8 \%$ in the cassava and maize milling sectors in Nigeria and Kenya.

Figure 19: Overview of energy efficiency measures adopted

No response

Product diversification

Production of useful by-products

On-site reuse and recovery of heat

Acquisition of new equipment

Equipment modification

Better process control

Substitute energy carrier

Good house keeping

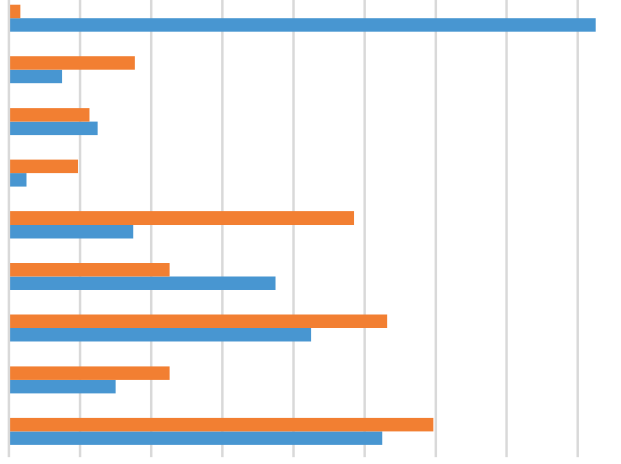

$\begin{array}{llllllllll}0 & 10 & 20 & 30 & 40 & 50 & 60 & 70 & 80 & 90\end{array}$ 


\section{Sources of technologies}

Figure 20 presents the sources of technology of the firms in the survey sample. In the cassava processing industry the technology was mostly domestic, in the maize processing industry it was mostly foreign. $74 \%$ of cassava firms use completely locally fabricated production equipment, $13 \%$ combine both local and foreign equipment and 9.5\% use foreign technology equipment. Of the maize processing firms, $45 \%$ use foreign technology equipment mainly from China. $17.5 \%$ of the technologies are locally fabricated. Technologies were imported from developing countries and developed countries, with China, India and Germany being the most important foreign suppliers of EE equipment.

Figure 20: Origin of energy efficiency technologies

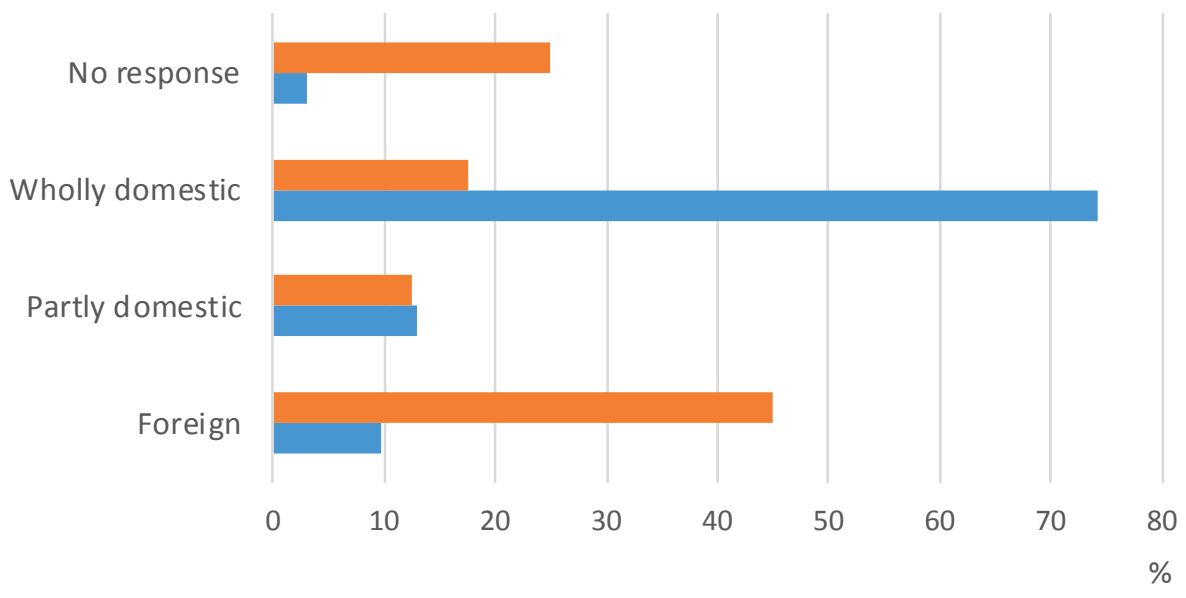

Kenya Nigeria

Source: Analysis of field data, 2013.

The results show a strong reliance on foreign technologies, especially in Kenya.

The important role of domestic technology in Nigeria, where $75 \%$ of the cassava processors use local technology, is due to the long history of relying on local knowledge for cassava processing and domestic fabrication of cassava processing equipment. It also has to do with Nigeria being the world's largest producer of cassava and the research activities in agricultural engineering departments in Nigerian universities and the Nigerian Centre for Agricultural Mechanization in Ilorin. For maize milling in Kenya, global sourcing of technology is critical due to the relative absence of accumulated domestic knowledge on maize processing.

In the study, we observed that suppliers often provide a package of services as a way to overcome the limits of a weakly developed innovation system. Examples of services are training, maintenance, repair, advice on obtaining funds, and flexibility in 
terms of payment schedules. In the technology transfer process to developing countries, the training of local people constitutes a very important aspect (Hassan, 1997). Our findings about the bundling of services (packages) are given in Table 17, showing that compared to maize millers, the cassava processing firms received a fuller package of bundled services from suppliers.

Table 17: Sources and components of energy efficiency packages

\begin{tabular}{|c|c|c|c|c|}
\hline \multirow{2}{*}{$\begin{array}{l}\text { Offered an entire EE project package consisting } \\
\text { of training, equipment, financing, maintenance } \\
\text { and repair }\end{array}$} & \multicolumn{2}{|l|}{ Nigeria } & \multicolumn{2}{|l|}{ Kenya } \\
\hline & Frequency & Percentage & Frequency & Percentage \\
\hline Yes & 42 & 68 & 14 & 35 \\
\hline No & 20 & 32 & 26 & 65 \\
\hline Components of EE project & Frequency & Percentage & Frequency & Percentage \\
\hline Training & 41 & 66 & 14 & 35 \\
\hline Financing & 15 & 24 & 2 & 5 \\
\hline Maintenance & 21 & 35 & 11 & 27 \\
\hline Repair & 17 & 27 & 8 & 20 \\
\hline $\begin{array}{l}\text { Employee trained by someone else on EE } \\
\text { project }\end{array}$ & Frequency & Percentage & Frequency & Percentage \\
\hline Yes & 46 & 74 & 18 & 45 \\
\hline No & 14 & 23 & 24 & 60 \\
\hline $\begin{array}{l}\text { Support from donors and government agencies } \\
\text { for EE project }\end{array}$ & Frequency & Percentage & Frequency & Percentage \\
\hline Yes & 28 & 46 & 0 & 0 \\
\hline No & 34 & 54 & 32 & 80 \\
\hline
\end{tabular}

Source: Analysis of field data, 2013.

A larger percentage (66.1\%) of the cassava processing firms has their employee trained by someone else for the EE project. From the interviews conducted, these trainers include the EE equipment providers, Fadama programme staff, RTEP/IFAD staff, and friends in the same business. 54.1\% of the firms stated they have not received any support from donors or government agencies for the EE project, which shows that the majority of the project is being pursued without external support.

$45 \%$ of maize processing firms reported having received training as part of the EE project. $27.5 \%$ of the whole sample received training from equipment distributors. A few firms reported having received training from other consulting firms. Through the interviews, we learned that some of the world's leading distributors of maize milling machinery and electrical engineering technologies have localised representation in Kenya and are therefore able to offer technical support to firms with resources.

Our findings are in line with the reality that Nigeria's agricultural sector has for many decades engaged in local equipment fabrication, with government taking the lead by 
using institutions of learning. The component of wholly domestic technologies applied to EE projects in Nigeria was $77.2 \%$ while in Kenya it was $17.5 \%$. Kenya's technology sourcing that was wholly foreign was $45 \%$ and partially domestic $12.5 \%$. Maize millers' considerable reliance on consultants for technical expertise, who are largely licensed distributors from developed countries, demonstrates the importance of trade as a vehicle for technology adoption. The training is bundled with other services such as financial advice and products, maintenance and repair. The bundling of services is a "market solution" to finance and technical skills problems.

\section{Organisations involved}

As shown in Figure 21, in terms of the organisations involved in successful EE projects, equipment suppliers are the main external actor for EE technology adoption. For cassava processing firms, government agencies were an important source of knowledge, whereas for maize millers consultants are relatively important. This difference could be related to the product offerings received, which are narrower in the case of Kenya (involving less training and financing). Universities and public research institutes are revealed as not important for EE technology adoption. This is an important finding that conforms with other research (e.g., Adeoti et al., 2010; Kruss et al., 2012), demonstrating that interactions between firms and universities/public research institutes are not a significant sources of short-term innovation in Africa. This does not necessarily mean that universities are unimportant for economic development in developing countries. They are revealed as being a necessary element for long-term achievements (Lall \& Pietrobelli, 2002). Government agencies were an important source of information for the cassava processors in Nigeria whereas they were an unimportant source of knowledge for maize millers in Kenya. 
Figure 21: Organisations involved in successful energy efficiency projects

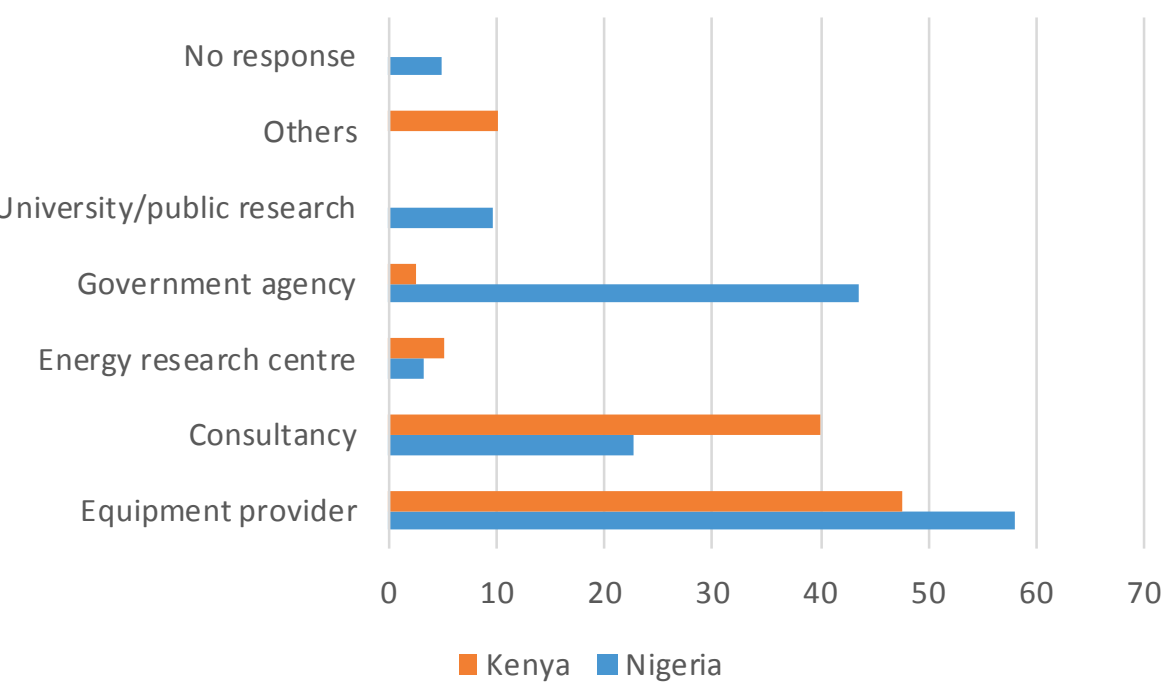

Source: Analysis of field data, 2013.

From the results in Table 18, consultants and other external advisors were important for the projects to go ahead. In Nigeria 40 out of 60 companies considered their involvement necessary or very necessary. For 13 companies out of 60 , consultants and external advisors were not necessary. We obtain similar findings for Kenya.

Table 18: Importance of consultancy /external advisors for energy efficiency project success

\begin{tabular}{lllll}
\hline Necessity of consultancy / external & Nigeria & & Kenya & \\
\cline { 2 - 5 } advisors for EE project success & Frequency & Percentage & Frequency & Percentage \\
\hline Not necessary & 13 & 21 & 4 & 10 \\
Very necessary & 20 & 32 & 16 & 40 \\
Necessary & 20 & 32 & 12 & 30 \\
Undecided & 09 & 15 & 8 & 20 \\
\hline Services provided & Frequency & Percentage & Frequency & Percentage \\
\hline Assist in equipment acquisition only & 3 & 7.5 & 0 & 0 \\
Supply and installation of equipment & 6 & 15 & 7 & 25 \\
Introduction of modern technology; & 17 & 42.5 & 9 & 32.1 \\
advisory services/capacity building & & & & 10.7 \\
Equipment acquisition and training & 14 & 35 & 3 & 14.3 \\
Energy audit & 0 & 0 & 4 & 17.9 \\
Equipment modifications & 0 & 0 & 5 & \\
\hline
\end{tabular}

Source: Analysis of field data, 2013. 
The most important consultancy services observed was the introduction of modern technology and advisory services/capacity building for processing firms' personnel. One striking difference between Nigeria and Kenya is the absence of the provision of energy audits by consultants in Nigeria.

\section{Informal learning}

The study also revealed something very interesting in terms of informal learning mechanisms. In the 102 cases investigated as shown in Figure 22, the majority of the adopters had visited other adopters prior to adoption. Such visits were less frequent in the maize milling sector in Kenya than in the cassava processing industry in Nigeria. In Kenya, only $22.5 \%$ of firms reported having visited another firm prior to adopting EE measures. Stiff competition and suspicion among firms within the sector may explain the reliance on advice from firms outside the maize business (consultants and equipment suppliers). What this shows is that the EE technology adoption among the research sample firms relies in an important way on informal contacts, something which is known but has not been established in a quantitative way in the literature so far. This suggests that the sectoral innovation system, particularly in the cassava processing industry, benefits from informal learning mechanisms.

Figure 22: Learning about energy efficiency measures through visits of previous adopters

Visit by other companies to learn about the firm's experience with a particular EE

Visit a company which had adopted the innovation prior to the decision to adopt

$$
\text { Maize processing firms } \begin{array}{ccc}
0 & 20 & 40 \\
& &
\end{array}
$$

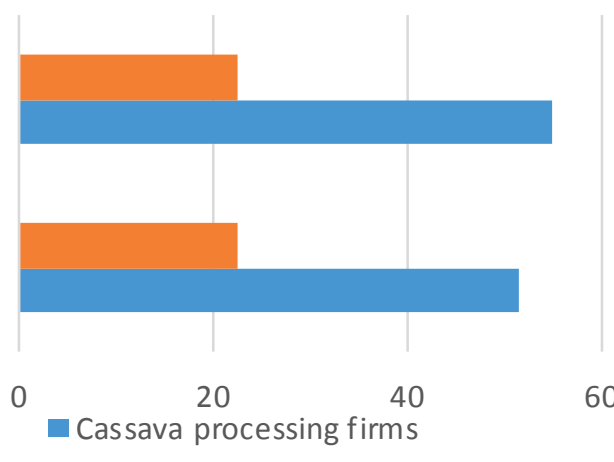

Source: Analysis of field data, 2013

\section{Financing}

Financing is mostly done through the firm's own capital (average of 68 and $81 \%$ in Nigeria and Kenya respectively). The World Bank/GEF, informal sources such as family and friends, and formal sources like commercial banks, are other notable sources of capital for financing EE measures in Nigeria, but less so in the maize processing in Kenya. Nearly half of all firms contacted in Kenya (45\%) financed their implemented energy measures using 100\% own capital. 15\% used own capital proportions of between 20 - 
$60 \%$ while the remaining $40 \%$ did not respond. Interestingly, only $5 \%$ of firms supplemented own capital with bank loans, while the rest used other sources including cooperatives and private networks. This reflects the high cost of financing in the country and stringent requirements for assets to act as security for loans, deterring enterprises from obtaining credit.

\section{Drivers and facilitating factors}

Table 19 presents the survey results for factors affecting the adoption of EE measures. According to the respondents, the most important drivers/facilitating factors for adoption are in-house knowledge and technical expertise and the desire to save costs in both sectors. Support from development actors is revealed to be more important for cassava processing firms. Support received from donor agencies and government is found to be equal in both countries with $45.9 \%$ of the companies receiving such support. Energy regulatory requirements and environmental regulations, such as energy audits, codes and standards, are influential only to a certain extent. These findings suggest that the regulations are not implemented efficiently or their design is insufficient (see also Oyedepo, 2012).

Table 19: Factors affecting the adoption of energy efficiency measures

\begin{tabular}{|c|c|c|c|c|}
\hline \multirow[t]{2}{*}{ Facilitating factors* } & \multicolumn{2}{|l|}{ Nigeria } & \multicolumn{2}{|l|}{ Kenya } \\
\hline & Frequency & Percentage & Frequency & Percentage \\
\hline In-house knowledge about energy management & 55 & 88 & 26 & 65 \\
\hline Technical expertise locally available & 54 & 87 & 12 & 30 \\
\hline Need for cost savings & 51 & 82 & 32 & 80 \\
\hline Requirement by parent company & 3 & 5 & 1 & 2 \\
\hline Energy regulatory requirement & 2 & 3 & 3 & 7 \\
\hline Environmental regulation & 14 & 23 & 1 & 2 \\
\hline Government incentives for EE measures & 9 & 14 & 1 & 2 \\
\hline EE measure adoption by other firms & 16 & 26 & 2 & 5 \\
\hline Advocacy or campaign by environmental NGOs & 2 & 2 & 1 & 2 \\
\hline Support from development partners & 21 & 34 & 2 & 5 \\
\hline Restraining factors* & Frequency & Percentage & Frequency & Percentage \\
\hline High cost of financing & 50 & 81 & 20 & 50 \\
\hline Uncertainty about EE project & 19 & 31 & 4 & 10 \\
\hline Lack of technical capability & 13 & 21 & 5 & 12 \\
\hline Lack of information on appropriate EE measure & 35 & 56 & 8 & 20 \\
\hline $\begin{array}{l}\text { Available EE measures are too complex for our } \\
\text { company }\end{array}$ & 8 & 13 & 0 & 0 \\
\hline Lack of support or government incentive & 38 & 61 & 4 & 10 \\
\hline
\end{tabular}

Note: * Multiple responses. Source: Analysis of field data, 2013. 
Co-benefits played an important role in the adoption decisions. In Kenya, co-benefits were equally important as the cost savings from energy efficiency for $55 \%$ of the maize millers. In $23 \%$ of the cases they were the primary reason for the energy efficiency investment. For cassava firms in Nigeria, co-benefits were important too: $53 \%$ of the companies said they were equally important as cost savings, for $40 \%$ they were the primary reason for adoption (Table 20).

Table 20: The importance of co-benefits

\begin{tabular}{lll}
\hline How important were the co-benefits? & $\begin{array}{l}\text { Frequency for maize } \\
\text { millers in Kenya }\end{array}$ & $\begin{array}{l}\text { Frequency for cassava } \\
\text { processors in Nigeria }\end{array}$ \\
\hline $\begin{array}{l}\text { They were equally important as the cost savings from reduced } \\
\text { energy use }\end{array}$ & 17 & 23 \\
They were of secondary importance & 5 & 30 \\
They were the primary reason for doing the project & 7 & 4 \\
Other & 2 & 57 \\
N/A & 10 & 5 \\
Total & 40 & 62 \\
\hline
\end{tabular}

Source: Analysis of field data, 2013.

\section{Barriers}

About $81 \%$ of respondents claimed that the initial set-up costs are the main barrier to the adoption of EE measures; about $61 \%$ claimed that the lack of support or government incentives were a restraining factor, while lack of information on appropriate EE measures was mentioned by $56.5 \%$ of respondents as an obstacle to EE adoption. As in Nigeria, the high cost of finance was the main deterrent factor in Kenya, cited by $50 \%$ of the firms interviewed. Although Kenyan firms rarely borrow from banks, as observed earlier, high costs imply that the firms have to accumulate savings in order to implement EE projects. Lack of information on what the appropriate technologies or measures would be was another deterrent mentioned by $20 \%$ of firms. Other factors preventing the adoption of EE measures, albeit to a lesser extent, include uncertainty of EE projects, lack of government incentives and poor technical capabilities.

\subsubsection{Case study illustrations}

To further the understanding of the survey findings, we present two cases of companies who have adopted energy efficiency measures. The cases indicate the multitude of factors at play and type of solutions adopted. In the first case (Rewaju Foods Limited) we will see that energy efficiency is coupled with energy generation issues. In the second case (Unga Limited), ICT is used to achieve energy efficiency gains with training carried out by a local electrical engineering firm, which is a part of a big multinational corporation. 


\section{Case 1: Rewaju Foods Limited}

Rewaju Foods Limited is a gari (granulated product from cassava) processing firm that began operation in February 2010. It is located in Osun State Agricultural farm settlement site, Oke-Osun, Osogbo, Osun State, Nigeria. The firm has 2 permanent workers as of 2012, with about 15 temporary staff. It has a branch factory at Ifon Osun, Osun State with 2 permanent staff and 12 temporary workers. In addition, the firm has an ad-hoc certified auditor to assess their finance at regular intervals. Although the firm has the facility to process 90 tonnes of cassava per day, it processes 2.6 tonnes of cassava per day at the time of this study. Cassava tubers are procured from farmers in the community and the neighbouring villages, while the product is marketed in Osogbo and Lagos.

Some energy efficiency improvement measures adopted by the firm are:

- A biogas facility set up as an alternative source of energy in July 2012. The facility uses animal dung and other waste materials regularly dumped near the firm's site by livestock (cattle, poultry and piggery) farmers.

- A battery-operated kernel technology serving as an alternative power generation using palm kernel nuts as a replacement for firewood, which they found to be cheaper relative to firewood. The percentage of energy saved through this technology varies with quantity of cassava to be processed to gari. On average, the firm saved $25 \%$ of total budget in production of 5 tonnes.

- A chimney constructed in a section where gari is fried, to prevent smoke during frying. This increases the efficiency and quantity of gari fried in a short period of time.

- As a means of reducing loss of input and the firm products, the firm adapts certain measures such as measuring cassava tuber before and after peeling, grating and frying. Through this method the firm is able to obtain $1 \mathrm{~kg}$ of gari from every $4 \mathrm{~kg}$ of cassava processed. The method also helps identify the quality of the cassava that is being processed through determination the water content.

The total cost of the installed biogas facility was about NGN 220,000 (USD 1,300), and the facility was installed by a researcher from Obafemi Awolowo University, Ile-Ife, Osun State, Nigeria. This technology has helped the firm to reduce the cost of production by $60 \%$ by decreasing the cost of electricity bills and the cost of firewood in the first year of operation. The firm was motivated to install this biogas equipment as a result of the following factors:

- Availability of inputs: cassava peels, water obtained during dewatering of cassava (recycled into the storex), poultry faeces, cow dung and pig faeces are readily available at little or no cost to the firm.

- Need for reduction in the cost of firewood.

- Reduction in production time: considerable time is usually lost during production when trying to regulate the amount of heat generated by firewood during frying. 
- Environmental concerns: environmental pollution is reduced since waste could be used to generate power at no cost to the firm.

- Quest for alternative source of power (more reliable than the grid and less expensive than the generator using petrol/diesel).

- Health of workers and increased worker productivity: the relatively smokeless biogas facility operation reduces the health risks associated with the production and thus helps increase efficiency/workers' productivity.

- Job creation and economic empowerment: the establishment of biogas facility by the firm had led to increased employment by the company, raising the standing and economic power of the firm.

An important facilitating factor was the availability of local knowledge about the biogas facility. Researchers from the Obafemi Awolowo University trained the staff of Rewaju Foods on the functions and on how to operate the biogas facility. In the adoption of the biogas installation, the firm had to overcome the following difficulties:

- Inadequate construction of the facility by the manufacturer (the inlet of the facility is too small for easy flow of animal dung).

- Cultural challenges: pig dung contains a higher percentage of methane gas than any other animal dung. It is a religious taboo among Muslims to be in close proximity of pigs or pork products. Some of the workers are Muslims and cannot get involved in pig dung collection.

- The high initial cost of construction and the need for a more knowledgeable engineer who can construct an effective industrial biogas facility.

\section{Case 2: Unga}

Established in 1909, Unga Limited is the oldest maize milling enterprise in Kenya. It has operations in Uganda, Tanzania, Rwanda, DR Congo and South Sudan. It is the largest animal feeds manufacturer in East Africa. Its maize milling plant in Nairobi has a capacity of 4000 tonnes per day and key products are maize flour, bran and germ. Monthly electricity consumption costs in the last six months ranged between USD 58,000 to USD 70,000 for Unga Limited's maize milling plant and USD 17,900 to USD 21,000 for the animal products plants.

The firm had in the past used the services of energy specialists to conduct energy audits. In addition to regular system maintenance and housekeeping measures, Unga Ltd had various projects lined up to improve energy use and overall efficiency of the plant. The first was conducting a feasibility study for the removal of conventional light bulbs and replacement with LED technology. Findings revealed that this measure would save the firm USD 3,500 per month only at the maize milling plant. Having realised that the majority of mechanical engineers at Unga Ltd. lacked electrical knowledge, five engineers were being trained in the use of electrical controls for motorised systems. Training enabled them to operate programmable logic controllers (PLCs), which the firm 
was in the process of procuring at the time of the survey. PLCs enable processing plants to automatically switch off and on sections based on sensor recognition mechanism.

Different energy efficiency measures were introduced in the animal feeds manufacturing section of Unga Ltd. Here, the company embarked on lagging all their boilers to avoid boiler steam wastage, and leakages from the compressors were sealed. Technical staff received training from private energy consultants to ensure continuous and effective management. The exercise yielded a boiler performance of 28.8 litre/hour, which is within the range recommended by the Kenyan Association of Manufacturers' (KAM) energy audit agency, and a 30\% reduction of the heavy diesel used to power the boiler.

Prior to coming into contact with KAM and the private energy consultancy company, the firm had attempted to reduce energy consumption at its plant, but a lack of technical knowledge of in-house staff meant the project could not be established. A visit to another firm in the textile sector that had successfully managed to curb its energy loss convinced them that the energy efficiency measures would be beneficial.

Training was carried out by a local electrical engineering firm, International Energy Technik (IET). IET has representation in Eastern African countries and supplies, installs, maintains and trains for multinational electrical technology firms such as Siemens, and Motorola. With more than 5 years of experience in the region, IET conducts short courses training engineers from the region and enabling them to use technology from outside the countries more effectively. This way IET bridges the knowledge transfer gap between technology suppliers and manufacturing industry in the region.

\subsection{Conclusions}

In Africa, the agricultural and agri-business sectors constitute an important part of the economy. Since energy efficiency measures in those sectors can greatly contribute to low-carbon development we empirically investigated the adoption of EE technologies in the two agro-industrial sectors, cassava processing in Nigeria and maize milling in Kenya.

The contribution of environmental regulation and EE policy to EE technology adoption is revealed as being rather weak. In Kenya, environmental regulation was a facilitating factor for $2.5 \%$ of the companies, and government incentives were a facilitating factor for $2.5 \%$ of the companies interviewed. The most important facilitating policy factor for maize millers in Kenya was energy regulatory requirements. For Nigeria, government policies were more important, with $22.6 \%$ of the companies mentioning environmental regulation as a facilitating factor. Government incentives were a facilitating factor for $14.5 \%$ of the cassava processing firms, which is not high given that $45.9 \%$ of the companies had received support, but considerably above the number for Kenya. When asked if all support measures were helpful, 53.2\% of the respondents in Nigeria said they were not. A deeper analysis than we were able to do in this study is needed to uncover the way in which the measures were not helpful. 
In both of the sectors studied (cassava processing in Nigeria and maize milling in Kenya), adoption of EE technologies is driven primarily by the desire to reduce costs. It is facilitated by in-house knowledge and locally available technical expertise. The use of consultancy and external advisors is considered necessary by the majority of the respondents. In the cassava sector, informal learning through company visits was found to be important for firms to adopt technologies. Over $50 \%$ of the companies who had adopted an energy saving measure said that they visited a company who adopted the innovation prior deciding to adopt it themselves. In the cassava processing sector, there is evidence that equipment is quite often bundled with training, finance, repair and maintenance as a solution to problems with skills. The financial help consisted of advice and instalment payments. In both countries, the high costs of finance constituted a big problem. In Kenya, nearly half of the maize millers financed the energy saving measures with own money. Our results highlight the role of global sourcing of EE technologies in developing countries. They confirm the importance of strategic technology collaborations between international and domestic private sector players in an environment where an innovation system's functions are underdeveloped and users' needs sometimes unmet, in line with Newell et al. (2013); Byrne et al. (2014). Our results illustrate that innovation occurs on the basis of a combination of local and global knowledge and technology. The study also established that there is considerable interest among companies in both Nigeria and Kenya to engage in technical cooperation with foreign companies and research institutes. Such cooperation can assume many forms, such as the education of African students and training of workers, joint research programmes and exchange programmes, technological transfers based on African technology solutions which are upgraded and non-African technologies that are adapted to the African context. Technical cooperation should, however, go beyond the transfer of technology and include issues of creating an enabling environment for technological acquisition, finance, education and training. Our findings are in line with a study for Tanzania that found that local management of energy services can take place when local actors receive sufficient technical and managerial training (Ilskog et al., 2005) and that skilled, local actors are crucial in successfully implementing foreign energy related technologies (Lema et al., 2014). It seems, according to our findings, that there is a greater reliance on external advice and informal knowledge exchange than in developed countries, but many of the barriers to the adoption of EE measures by SMEs are the same: high costs of investment, worries about discontinuities in production and lack of information on $\mathrm{EE}$ measures (Fleiter et al., 2012). 


\subsection{Appendix}

Table 21: Basic characteristics of the respondent firms

\begin{tabular}{|c|c|c|c|c|}
\hline \multirow[t]{2}{*}{ Number of employees } & \multicolumn{2}{|l|}{ Nigeria } & \multicolumn{2}{|l|}{ Kenya } \\
\hline & Frequency & Percentage & Frequency & Percentage \\
\hline $2-10$ & 39 & 63 & 15 & 37 \\
\hline $11-20$ & 13 & 21 & 6 & 15 \\
\hline$>20$ & 9 & 14 & 17 & 42 \\
\hline No response & 1 & 2 & 2 & 5 \\
\hline Average, Minimum , Maximum & \multicolumn{2}{|c|}{$13,2,53$} & \multicolumn{2}{|c|}{$70,1,400$} \\
\hline Time of establishment & Frequency & Percentage & Frequency & Percentage \\
\hline Before the year 2000 & 9 & 14 & 17 & 42 \\
\hline $2000-2010$ & 43 & 69 & 17 & 42 \\
\hline 2011-2012 & 9 & 14 & 4 & 10 \\
\hline No response & 1 & 2 & 2 & 5 \\
\hline Total & 62 & 100 & 40 & 100 \\
\hline Average capacity utilisation of firms & \multicolumn{2}{|c|}{63.65} & \multicolumn{2}{|c|}{65.08} \\
\hline $\begin{array}{l}\text { Firm's sales turnover in } 2012 \text { (in million Naira } \\
\text { for Nigeria and Ksh for Kenya) }\end{array}$ & Frequency & Percentage & Frequency & Percentage \\
\hline$\leq 0.5$ & 23 & 37 & 7 & 17 \\
\hline $0.51-1$ & 11 & 18 & 1 & 2 \\
\hline $1.1-1.5$ & 4 & 5 & 1 & 2 \\
\hline $1.6-2$ & 2 & 3 & 1 & 2 \\
\hline $2.1-2.5$ & 2 & 3 & 0 & 0 \\
\hline $2.6-3$ & 3 & 5 & 0 & 0 \\
\hline$>3$ & 8 & 13 & 6 & 15 \\
\hline No response & 9 & 14 & 24 & 60 \\
\hline $\begin{array}{l}\text { Average annual increase in sales in the last } \\
\text { three years (in percentage) }\end{array}$ & Frequency & Percentage & Frequency & Percentage \\
\hline$<5$ & 6 & 10 & 4 & 5 \\
\hline $6-10$ & 8 & 13 & 2 & 2 \\
\hline $11-20$ & 11 & 18 & 11 & 27 \\
\hline $21-30$ & 7 & 11 & 4 & 1 \\
\hline $31-40$ & 5 & 8 & 1 & 2 \\
\hline $41-50$ & 7 & 11 & 1 & 2 \\
\hline$>50$ & 9 & 14 & 0 & 0 \\
\hline No response & 9 & 14 & 17 & 5 \\
\hline Average & \multicolumn{2}{|c|}{31.85} & \multicolumn{2}{|c|}{29.23} \\
\hline
\end{tabular}




\begin{tabular}{lcccc}
\hline $\begin{array}{l}\text { Average annual decrease in sales in the last } \\
\text { three years (in percentage) }\end{array}$ & Frequency & Percentage & Frequency & Percentage \\
\hline$<5$ & 1 & 3 & 1 & 2 \\
$6-10$ & 0 & 0 & 0 & 0 \\
$11-20$ & 2 & 3 & 1 & 2 \\
$21-30$ & 2 & 3 & 3 & 7 \\
$31-40$ & 0 & 0 & 3 & 7 \\
$41-50$ & 2 & 3 & 0 & 0 \\
$>50$ & 1 & 3 & 31 & 77 \\
No response & 54 & 87 & & 34 \\
Average & & 31 & & 7 \\
\hline
\end{tabular}

Source: Analysis of field data, 2013.

\section{Sampling method}

A multi-stage sampling technique was used to select the respondents (cassava processors in Nigeria and maize processors in Kenya).

In the first stage, Nigeria in West Africa and Kenya in East Africa were purposively selected as countries characterised by weak environmental policy regimes and weak national innovation systems. In the second stage in Nigeria, the Southwest region comprising Ogun, Ondo, Oyo, Osun, Lagos, and Ekiti States was purposively selected for the survey study for cost reasons. In this part of the country reside a major cassava production belt and nearly half of Nigeria's industrial production activities. In the third stage, three states (Ogun, Osun and Oyo) were also purposively selected based on the prevalence of cassava producers and processors (processing firms) as well as relevant research institutions (like the IITA, University of Agriculture) in these areas (IITA, 2004). In the fourth stage, the research sample was selected based on the sample frame compiled from the list of cassava processing firms obtained from cassava processing groups available in each of the selected state with the assistance of state agricultural development programme (ADP), Cassava: Adding Value for Africa (C:AVA) Project; and Agricultural Media Resources and Extension Centre (AMREC) of the Federal University of Agriculture, Abeokuta (FUNNAB). This was complemented by a snowballing sampling technique as some of the firms listed in the sampling frame were found to be no longer in operation. In all, a total number of 62 cassava processing firms (17 in Ogun, 22 in Osun and 23 in Oyo) actively involved in cassava processing were sampled and interviewed.

For Kenya, firms in maize processing were identified first through desk research involving an extensive literature search. A section of the milling firms were identified through a study that had been conducted in 2009 while the rest were obtained through ordinary internet search. Maize millers are mostly concentrated in big cities such as Nairobi and Mombasa. For cost reasons, the majority of millers interviewed were based in Nairobi and its suburbs, while the rest were based in Thika, Nanyuki, Nakuru, Eldoret and Mombasa. This gives a reasonably good geographical distribution of milling firms in 
the country. Firms visited ranged from the largest in the country to one-man operated posho mills in poor residential areas. Both geographical distribution and mix of firm size in the sample give a good representation of the national maize sector.

For the case study approach employed in the study, six firms were purposively selected. The selected firms were revisited, observed, and engaged in a more detailed interview. 


\section{Regional and sectoral economic impacts of an integrated renewable energy transition across the Mediterranean in Europe, the Middle East and North Africa ${ }^{52}$}

\footnotetext{
${ }^{52}$ This chapter is based on Calzadilla, A., Wiebelt, M., Blohmke, J., Klepper, G. (2013). Desert Power 2050: Regional and sectoral impacts of renewable electricity production in Europe, the Middle East and North Africa. Kiel Working Paper No. 1891, Kiel Institute for the World Economy, Kiel. It has been co-authored by Alvaro Calzadilla (IfW Kiel), Manfred Wiebelt (IfW Kiel), Julian Blohmke (Maastricht University), Gernot Klepper (IfW Kiel). Financial support and access to data on power systems and technology cost through Dii is greatly acknowledged. My contribution to this chapter consists of drafting the overall chapter outline and setting up the research project as well as the writing of the introduction, the literature review and parts of the modelling results interpretation. I proposed scenario assumptions for comparative scenario analysis. I researched CSP, PV, Wind technology cost vectors, which were added to the CGE framework model by researchers at IfW. I also formulated the build-up pathways, which was then used by IfW researchers as the exogenously given technology capacity expansion in the CGE model. I supported the interpretation of the CGE modelling output results.
} 



\subsection{Introduction}

This chapter sheds light on the economic effects of climate mitigation technology deployment and tries to unravel positive arguments which could help facilitate climate mitigation technology deployment. In the discussion of potential economic benefits of climate mitigation technology deployment it is important to note that the negative external effects of $\mathrm{CO}_{2}$ emissions, from burning fossil fuels for power production, could limit economic growth (Withagen \& Smulders, 2012). The power sector constitutes 41\% of global $\mathrm{CO}_{2}$ emissions (IEA, 2012a), while the world is not on track to realise the 2020 interim $\mathrm{CO}_{2}$ emission reduction targets (IEA, 2012b). Achieving a concentration of 450 parts per million (ppm), and even below, in the atmosphere seems to be necessary to adapt to the impacts of climate change (Solomon et al., 2007). Such climate mitigation targets require a global reduction of $\mathrm{CO}_{2}$ emissions by 2050 between $50 \%$ and $80 \%$ in developed countries (Metz et al., 2007). In order to meet these policy goals a significant reduction of $\mathrm{CO}_{2}$ emissions from the power sector is necessary (IPCC, 2011; OECD, 2011b). ${ }^{53}$ Thus renewable energy technologies (RET) deserve a special focus in the debate over climate change mitigation.

By picking a visionary plan to decarbonise the neighbouring Mediterranean countries' power systems, we assess the potential benefits of renewable energy deployment across a whole region on a macroeconomic level. The EU has set ambitious carbon mitigation targets coupled with renewable energy targets, while in the Middle East and North Africa (MENA) countries to the south of the Mediterranean, renewable energy policy frameworks have evolved rapidly in recent years (REN21, 2013b). Governments in MENA, searching for means to satisfy rising energy demand and diversify their economies, find RET deployment an attractive option (OECD, 2013). Both regions, the EU and MENA region, have embarked on a transition pathway towards RET. Studies suggest that an interconnected power system between MENA and the EU could be highly beneficial from an overall power system cost perspective, as the renewable energy resources in MENA could come at much lower cost compared to those in the EU (German Aerospace Center, 2005; Dii, 2012; Ummel \& Wheeler, 2008). For example, the solar energy received by the earth in one hour could supply electricity for the entire globe for one year (Lewis \& Nocera, 2006). Put differently, 1\% of the area of the Sahara desert covered by solar thermal power plants would be enough to meet the world's annual electricity consumption (German Aerospace Center, 2005). This abundant, unlimited and clean energy can be tapped to supply a large part of the world with sustainable power. Concepts like Desertec or Gobitec have been developed as a consequence of those

\footnotetext{
${ }^{53}$ The global energy supply has not become significantly cleaner in the last two decades, as evidenced by the fact that the amount of $\mathrm{CO}_{2}$ emitted for each unit of energy supplied has decreased by less than $1 \%$ since 1990 (IEA, 2013). Coal-fired power generation rose by nearly $6 \%$ between 2010 and 2012 globally and continues to grow faster than non-fossil energy sources on an absolute basis.
} 
massive energy resource potentials in desert areas. Those concepts envision the exchange of electricity via large interconnectors across borders and continents ${ }^{54}$.

Realising those infrastructure visions might render win-win situations by delivering on climate mitigation and economic development. Such situations underpin the search for facilitation factors for a climate mitigation technology transition (Cooper \& Sovacool, 2013). Investments in RET in the MENA region up to 2020 could be five times higher than the cumulative investments in conventional electricity generation technologies in the last decade (Jablonski et al., 2012). This exemplifies the magnitude of the importance of RET in terms of the role that it could play in the coming years. Energy access, particularly to electricity, is crucial for economic development and poverty reduction; it is required for industrial development and a core requirement to improve competitiveness (Bartels, 2007). The choice of power resource and how to generate electricity, from fossil fuel sources or renewable energy sources, can have a significant influence on the competitiveness of an economy. For example, in a country with good solar and wind conditions, which is also dependent on fossil fuel imports, it can be economical to setup RET instead of investing into conventional, fossil fuel based power plants. Yet, many countries suffer from following a high carbon path dependency and technology lock-in, due to the long life time of energy technologies (Unruh, 2000). Especially in fossil-fuel dependent MENA countries, oil importers and oil exporters ought to better understand how major shifts in the energy system, as against business-asusual growth pathways, can be realised to mitigate climate change.

Trade of electricity can be beneficial for regions which are less favourably equipped with renewable energy potential and large-scale transmission systems with high-voltage transmission technologies are seen as an important feature for sustainable energy systems (Hirschhausen, 2010, p 182). Such electricity trade frameworks have been discussed at ministerial level by institutions like the Union for the Mediterranean (UfM), which promotes the Mediterranean Solar Plan (MSP) to create new renewable energy power production capacity in the Mediterranean basin and the setup of regulatory frameworks for cross-border trade of electricity (UfM, 2008; Trieb et al., 2012). Strong partnerships of this kind between MENA countries and the EU are crucial for the benefit of countries on both sides of the Mediterranean. MENA has vast renewable energy resources, both in terms of solar and wind, while the EU could be an import destination for electricity, and can provide technology and finance for such infrastructure projects.

The MENA region saw dynamic development in the last couple of years with regard to renewable energy capacity installations. Since 2013, all 21 MENA countries have set renewable energy targets while in 2007 it was only 5 countries in the region (REN21,

\footnotetext{
${ }^{54}$ The Desertec concept describes the generation of sustainable power in areas where renewable sources of energy are most abundant. This also contributes to combat climate change, ensure a reliable energy supply and promote security and development (online resources, www.desertec.org). The Gobitec concept aims to produce energy in the Gobi desert in Mongolia and China which is brought via high-voltage lines to the industrial centres in Korea, Japan and Eastern China (online resources, www.gobitec.org).
} 
2013b, p 4). If those renewable energy targets were realised $107 \mathrm{GW}$ of renewable energy capacity would be installed in the MENA region. Saudi Arabia alone would bring online $54 \mathrm{GW}$ of renewable energy by 2032. The success of energy transitions also depends on the timing (Fouquet and Pearson, 2012). The political transition in the MENA region, in combination with the setting of renewable energy targets across countries, could be a promising environment for a low-carbon transition in the MENA region.

Such ambitious infrastructure plans towards current renewable energy targets in the MENA region would definitively have a great economic impact on the MENA region. Hundreds of wind and solar power plants need to be constructed, requiring the mobilisation of huge economic resources which may compete with uses in other sectors of the MENA economies. The MENA region is endowed with solar and wind potentials. In economic growth theory this factor is referred to as land or natural resources; its availability is one of the crucial factors for economic growth (Collier \& Venables, 2012). Yet, according to Collier and Venables, other growth factors like capital, skills and governance capacity, are not sufficiently available in the MENA region to enable a transition to sustainable growth pathways in the Southern Mediterranean. Another barrier to growth in the MENA countries is the low rate of diversification in the economies, sometimes weak service sectors, dependency on natural resource exports and low level of integration (World Bank, 2012). Those are factors which need to be considered and alleviated in the design of low-carbon growth pathways, but they are not focus of this chapter on potential economic benefits of a low carbon transition in the MENA region.

The purpose of this chapter is to evaluate the economic impact of a transition towards RET in the EU and in MENA by using various technology deployment scenarios and different international climate policy assumptions. In particular, we assess the potential economic costs and benefits for the EU and MENA region, identifying the economic impacts across both regions. Our work attempts to address, in particular, the technology deployment pathways of energy sectors with regard to CPS, PV and wind power based on other energy studies which conducted detailed power system modelling on an hourly basis for the year 2050 towards an EU and MENA wide renewable energy transition and system integration (Dii, 2012). Further, trade of electricity across the Mediterranean basin between various trade partners is added in our economic and trade modelling work.

\subsection{An EUMENA renewable energy vision towards 2050}

With a special focus on Europe ${ }^{55}$ and MENA, ambitious power system integration plans across the Mediterranean, based on RET deployment, have been backed by policymakers aiming to provide clean energy from MENA's deserts to the entire region, as well as exporting electricity to Europe (UfM, 2008). Potential technology deployment pathways

\footnotetext{
${ }^{55}$ In the following, Europe also includes Norway, Turkey and Switzerland.
} 
were assessed by the industry up to the year 2050 (Dii, 2012). ${ }^{56}$ A future power system almost fully based on solar and wind energy in MENA is technically feasible. A paradigm shift from today's little interconnected fossil fuel-based power systems to an integrated, renewable energy based system is feasible. Power generation from deserts could enable MENA countries to supply their own energy needs reliably by tapping the abundant solar and wind resources in the light of a massive increase in electricity demand until 2050.

Different scenarios in which MENA and Europe pursue electricity generation in a renewable energy system but independently of each other and without the possibility to trade electricity have been compared to a scenario where the power system in MENA and Europe are interconnected and the possibility to trade electricity is given (Dii, 2012).

In fact, only 3\% of the total electricity produced across MENA in the year 2050 is expected to be based on conventional technologies (Figure 23, upper graph). This requires a rapid development in the mid- and long-term of solar and wind power plants (Figure 23, middle graph). This is expected to be dominated by wind technologies (53\%), since their levelised cost of electricity is lower compared to CSP and PV technologies. Solar technologies are expected to contribute around 44\% (Dii, 2012). The lower cost of wind technologies, combined with the higher potential of wind along the costal lines in North Africa, favour wind technologies in the energy mix of Morocco, Egypt, Algeria and Libya. Conversely, high solar irradiation in the Middle East enables solar technologies to play a dominant role in Saudi Arabia. This would require the installation of around 1 terawatt (TW) of renewable power capacity across the MENA region, which is equivalent to today's installed capacity in Europe. Most of the electricity produced would cover the growing energy demand in MENA countries, and up to $20 \%$ would be exported to Europe.

The average system cost for EU and MENA can be reduced from 65€/MWh in the reference scenario to $61 € / M W h$ in the connected scenario (Dii, 2012). This implies around $€ 33$ billion cost savings per year (Dii, 2012). European countries benefit from importing low-cost renewable energy from MENA while costs in MENA countries remain essentially flat when more electricity is produced for exporting to Europe.

Solar and wind technologies in MENA are not only expected to replace conventional power plants, they will also meet the increasing electricity demand in the region (annual growth between 6-8\%) and cover part of the electricity demand in Europe. Compared to current numbers, power generation in MENA countries is expected to triple by 2050 to meet their own demand and to quadruple when exports to Europe are considered. Countries inside MENA develop differently according to their geographical and natural conditions. Morocco, Algeria and Libya will become main power producers within the MENA region, generating five times more power than they consume.

\footnotetext{
${ }^{56}$ This chapter uses findings from the power system modelling of the Desertec vision conducted in Dii, 2012.
} 
Figure 23: Electricity production, installed capacity and investment in solar and wind energy in MENA
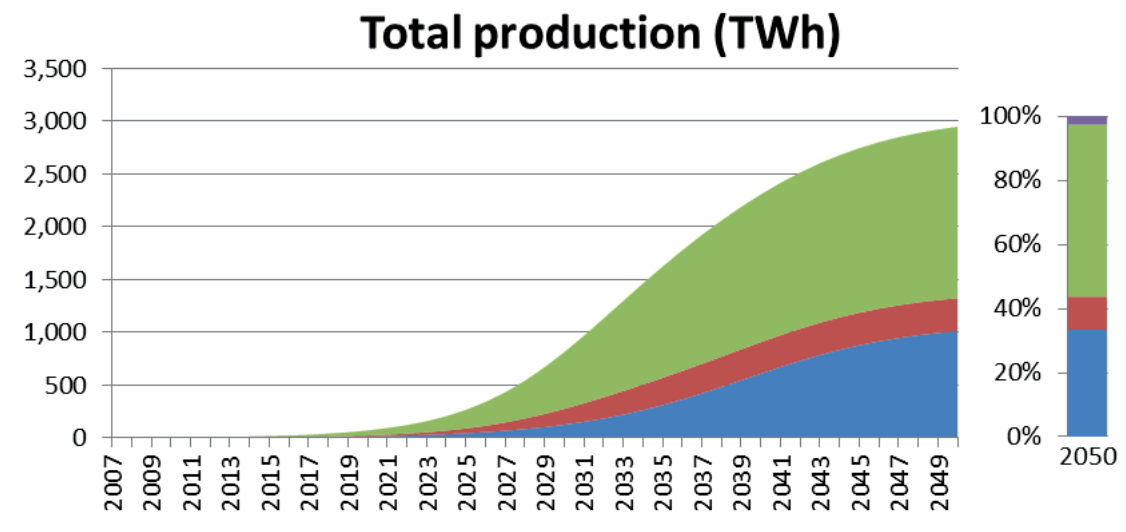

$\square$ MENA CSP $\square$ MENAPV $\square$ MENA WIND $\square$ MENA ELYN

\section{Installed capacity (GW)}

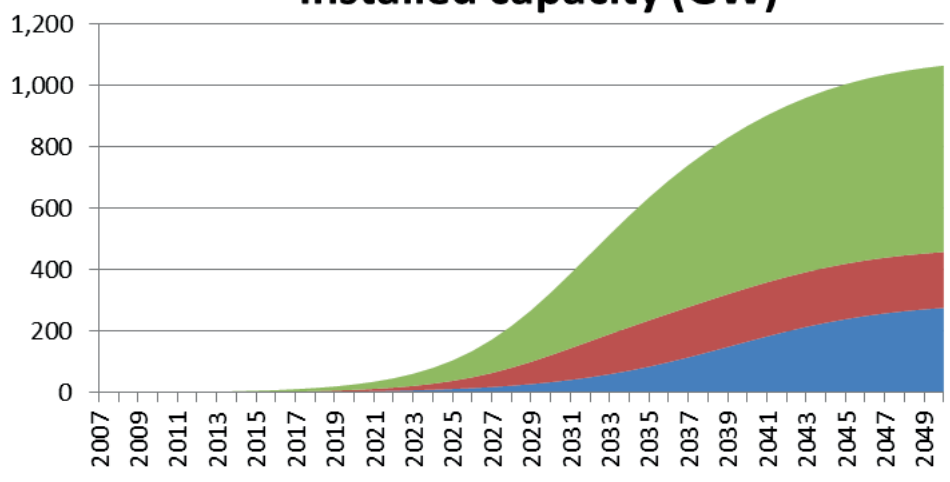

MENA CSP $\square$ MENAPV $\square$ MENA WIND

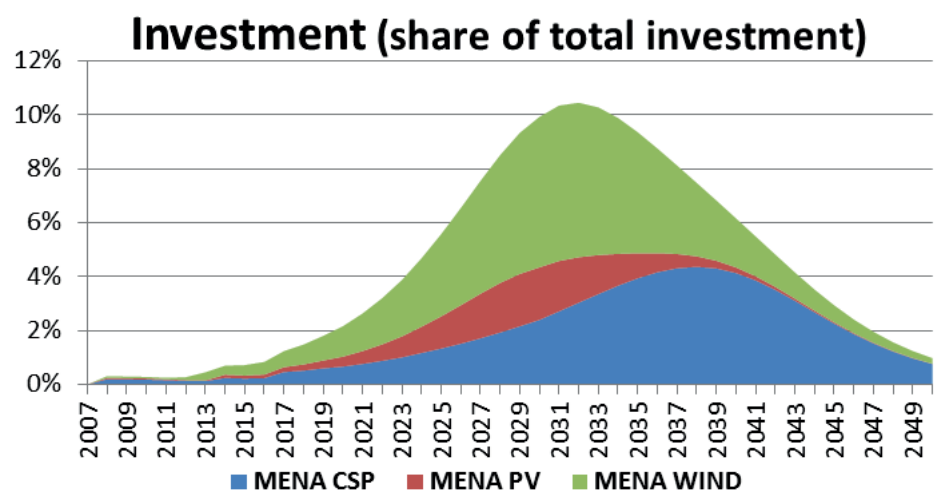

Note: $\mathrm{CSP}=$ concentrating solar power, $\mathrm{PV}=$ photovoltaic, ELYN = electricity generation from conventional sources (fossil fuels, hydroelectric, nuclear, geothermal, tide, wave, biomass and waste).

Source: Own calculations based on Dii, 2012. Total investment according to a current policy scenario (DART model). 
The renewable energy development in the EU is guided by the low-carbon economy framework set in the European Commission's Energy Roadmap 2050, which set the target to reducing greenhouse gas emissions in the energy sector to $80-95 \%$ below 1990 levels by 2050 (European Commission, 2011). Thus, by 2050 more than two-thirds of the electricity produced in Europe will come from solar and wind power plants (Dii, 2012). Wind energy will play a crucial role in Europe, providing more than half of the total electricity produced (Figure 24, upper graph). This implies a gradual substitution of solar and wind technologies for fossil fuel based technologies. In fact, to meet these requirements, the current European installed capacity of solar and wind electricity generation needs to grow 20 times by 2050 when power markets are not connected in Europe and MENA, and up to 15 times in the case of interconnection (Figure 24, middle graph).

Figure 24: Electricity production, installed capacity and investment in solar and wind energy in Europe
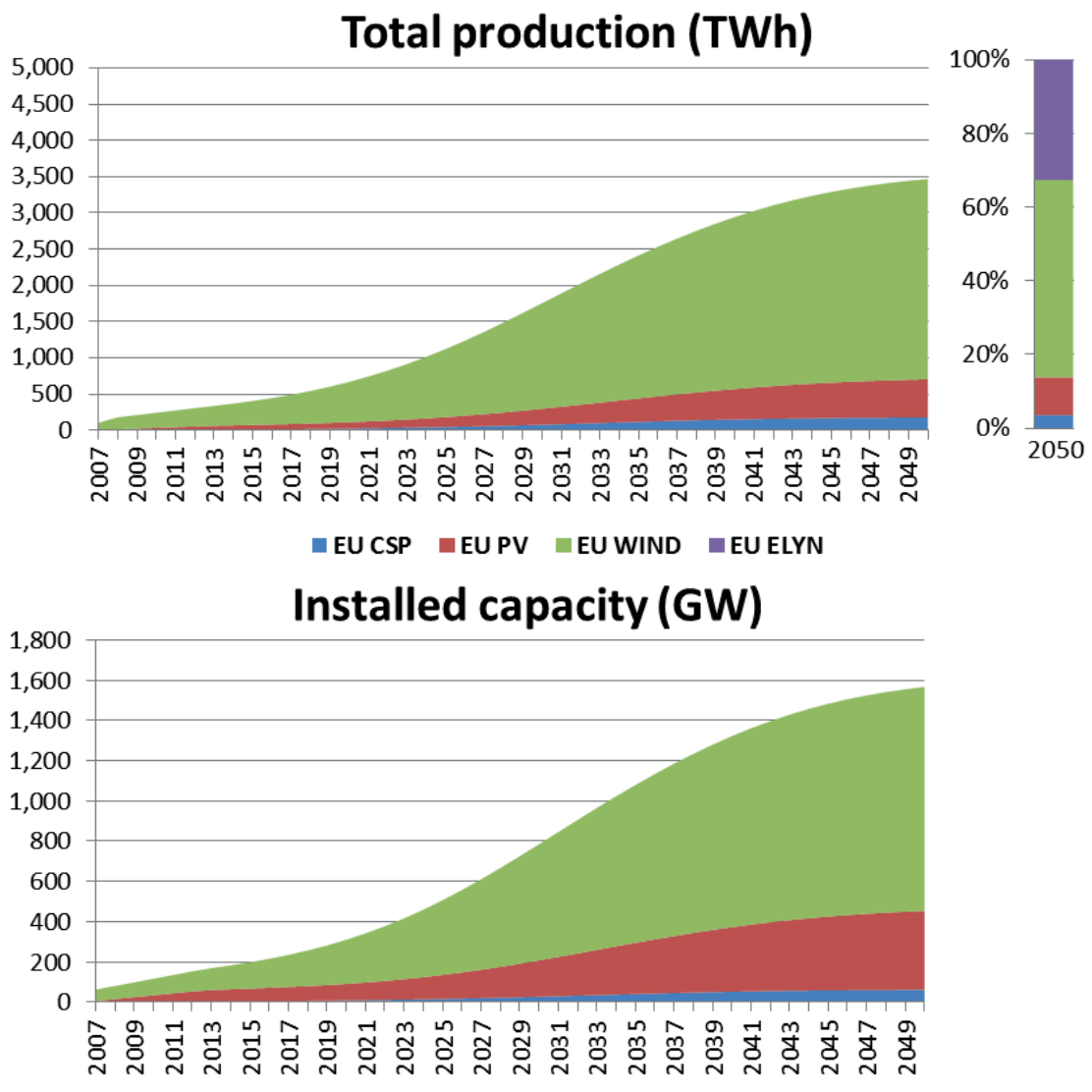

$\square$ EU CSP EUPV $\square$ EUWIND 


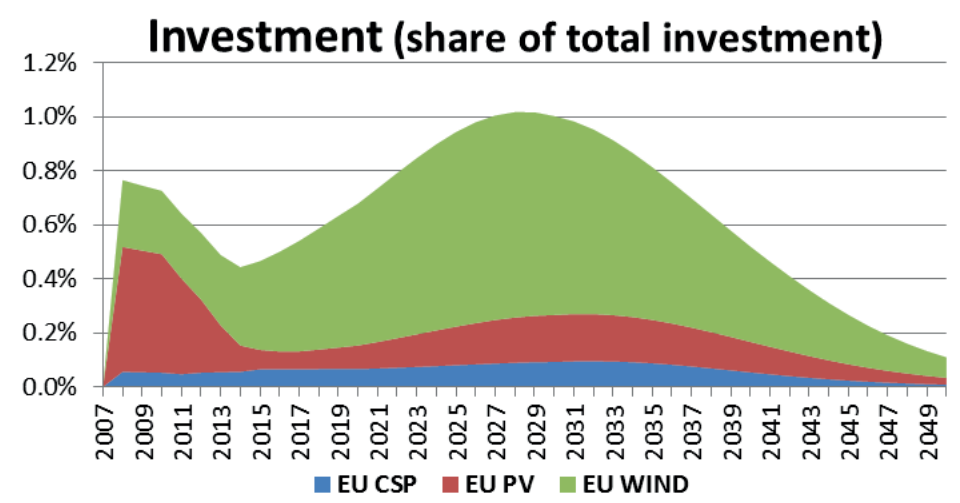

Note: $\mathrm{CSP}=$ concentrating solar power, $\mathrm{PV}=$ photovoltaic, $\mathrm{ELYN}=$ electricity generation from conventional sources (fossil fuels, hydroelectric, nuclear, geothermal, tide, wave, biomass and waste).

Source: Own calculations based on Dii, 2012. Total investment according to a current policy scenario (DART model).

The decarbonisation of the power sector in the EU and MENA has several challenges. First, it implies that huge amounts of resources must be allocated to the installation of solar and wind generation capacity. In MENA the annual investment grows gradually up to more than $10 \%$ of the total investment in the region (Figure 23, lower graph). In Europe, even if the required installed capacity of solar and wind power plants is $50 \%$ higher, it represents a maximum $1 \%$ of total investment in the region (Figure 24, lower graph). The investment peak for PV technologies in the early years was mainly driven by Germany's promotion of PV installations with high feed-in tariffs through the National Renewable Energy Law and respective National Renewable Energy Action Plans (NREAP). As shown further below, the financing mechanisms for renewable energy investments, and their impact on other sectors of the economy, are crucial in terms of the extent to which the countries can benefit from the build-up of renewable electricity installations.

Another challenge is related to the submarine transmission lines across the Mediterranean to connect EU and MENA countries. While technically feasible, the construction of high voltage direct current (HVDC) power lines will increase the cost of electricity supply and the consumer electricity price in the EU. An additional 130 billion Euros in grid investments are necessary for an interconnected system in the year 2050 (Dii, 2012). Furthermore, the cost of electricity produced in MENA for export to Europe would increase from 4.3 to 5.8 Euro cents/kWh (in the year 2050) when transmission costs and costs of transmission losses are taken into account.

Detailed power-system cost optimisation of envisioned energy mixes are useful to inform the infrastructure planning but lack analysis of the effects on the overall economic system (Dii, 2012). Thus, we will study the power system transition from a broad perspective including not only the relevant energy sectors but also other sectors of the 
economy. We also address the transition from an international perspective to capture the economic interactions across regions and sectors.

\subsection{Assumptions and quantitative model}

Studies have modelled the energy demand and supply for the EU and MENA up to 2030 by applying large-scale energy-economic models on an annual resolution (Fragkos et al., 2012). ${ }^{57}$ Those studies do not take into account renewable energy potentials based on spatial renewable energy potential analysis, nor do they analyse the different demand patterns over the day/year for the respective countries. Rather, their assessment of technology deployment pathways is cost driven, while geo-spatial renewable energy potentials are neglected. Nevertheless, for power demand, as well as power supply, those hourly changes in conditions for demand and supply vary substantially on a country level. Energy system models have been used for disaggregated technology sectors, including also CSP, PV and Wind, and have also taken into account fluctuations in the supply and demand of power generation (Haller et al., 2012). However, they are hampered by low temporal resolution which leads to the neglect of fluctuations on short time scales, as only 49 "characteristic" time slices are used to represent demand and supply match. Energy-economy models that simplify inter-continental electricity trade among a small amount of world regions in a static general equilibrium model have been built (Bauer et al., 2008), or they over-simplify time and space resolution in such models by not taking into account intermittence in their energy module (Massetti et al., 2013).

We use an economy-wide modelling approach. To evaluate the economic impact of renewable electricity development in MENA and Europe, the Dynamic Applied Regional Trade $(D A R T)^{58}$ model has been extended to explicitly account for CSP, PV and wind electricity production (for a detailed description of power sector expansion, see 6.7 and 7.2). Thus, the DART model assesses the direct and indirect effects of annual investments into the power sector up to the year 2050. Moreover, its dynamic structure is appropriate to evaluate differences during the transition period to a decarbonised power sector.

The DART model uses power sector infrastructure investment figures based on exogenous power system calculations, due to the fact that CGE models cannot model electricity production in that spatial and temporal detail. Power system figures for 2050 have been used, based on PowerACE model output which optimises the construction and dispatch of power plants, storage facilities, transmission grids between countries and renewables generation technologies through linear optimisation in the year $2050 .{ }^{59}$

\footnotetext{
${ }^{57}$ MEDPRO uses results of the E3M-Lab model MENA-EDS, which is a recursive dynamic model which takes into account exogenous inputs like macroeconomic, demographic and sectoral activity projections.

${ }^{58}$ A short description of the DART model and the main changes in its data and structure for the current analysis is presented in the appendix to this chapter.

${ }^{59}$ The PowerACE software has been developed at the Fraunhofer Institute for Systems and Innovation Re-
} 
Based on detailed data for the potential of renewable energy generation technologies and hourly generation profiles, the electricity system is optimised during all 8760 hours of the year for each country in the year 2050. This means that demand in every country has to be met every hour of the year by the selected technology mix for the year 2050 to produce an ideal, cost-effective power supply. An S-shaped interpolation of power system build-up between the start year and 2050 has been applied, based on technology diffusion theory (Hoefnagels et al., 2011). Our limitation is that we have not modelled the intermediate steps for every year between today and the year 2050. Thus, our exogenously generated technology deployment curves, an interpolation between today and 2050, represent a little bit of delay in some technology deployments.

Even if solar and wind conditions are ideal in the desert regions of MENA, solar and wind power production are in many cases currently still more expensive than fossil fuel based technologies, and requires subsidies to be competitive in MENA and EU electricity markets. Based on current projects and using the levelised cost of electricity (LCOE) $)^{60}$, only onshore wind technologies are cost competitive with fossil fuel based technologies (IRENA, 2013).

At present, subsidies are needed for renewables to compete with fossil fuel based technologies. The LCOE shows that only wind technologies in MENA are cost competitive with conventional technologies ${ }^{61}$ (Figure 25). Electricity from wind energy in Morocco could be produced as cheaply as 3.5 Euro cents per kilowatt hour (kWh). On the other hand, electricity produced from PV in Germany is 5 times more expensive (18 Euro cents per kWh). The combination of more than 10 years of PV promotion in Germany and its high LCOE results in about 100 billion Euros in subsidies (Frondel et al., 2012). Only about $16 \%$ of this burden has already been paid, the rest will be paid over the next two decades, as feed-in tariffs in Germany are legally guaranteed for 20 years. It is clear that the viability of a transition towards renewable energy in EUMENA depends to a large degree on the development of the LCOE of the three renewable electricity technologies over the next years.

\footnotetext{
search, (Dii, 2012).

${ }^{60}$ A clear identification of the cost for each technology is not always possible because it depends on specific regional conditions such as resource availability and local cost structure. The levelised cost of electricity allows a comparison of different power generation technologies, by neglecting project finance specifics. It is the ratio between the sum of cost of electricity generation (sum of installation costs and lifetime operation and maintenance costs) and the sum of electricity generated by the system over its operational lifetime.

${ }^{61}$ Conventional technologies in this study include fossil fuels, hydroelectric, nuclear, geothermal, tide, wave, biomass and waste.
} 
Figure 25: Range of LCOE for different technologies in MENA and Europe ( $€ / \mathrm{kWh}), 2010$

\section{Range of LCOE in MENA}

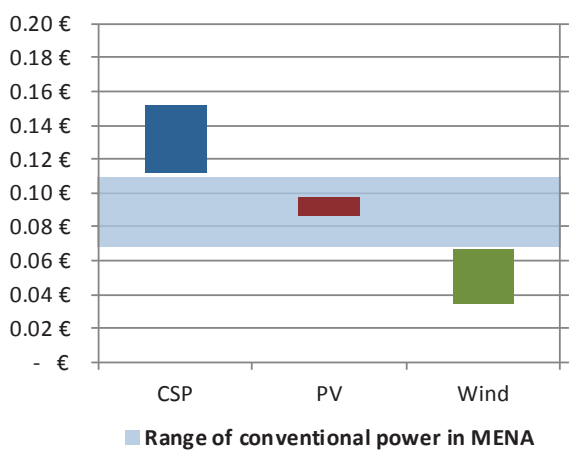

\section{Range of LCOE in Europe}

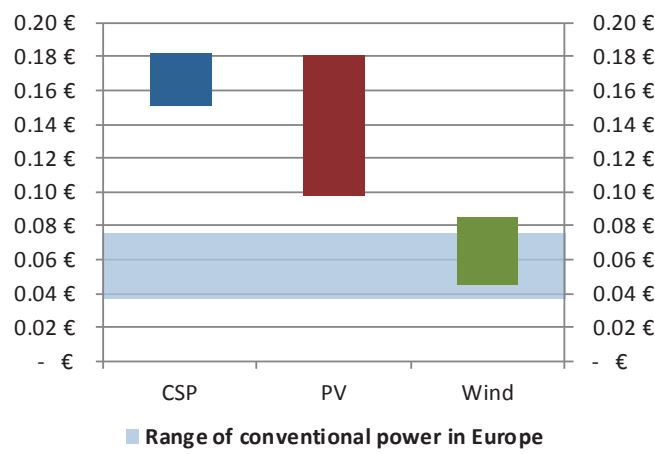

Note: CSP = concentrating solar power, PV = photovoltaic, ELYN = electricity generation from conventional sources (fossil fuels, hydroelectric, nuclear, geothermal, tide, wave, biomass and waste).

Source: Own calculations based on Dii (2012).

LCOE are determined to a great extent by the technology cost. In the last few years, the cost of producing renewable power has fallen drastically. For example, in two years the prices of PV modules from China have fallen by more than 65\% (IRENA, 2013). The LCOE for CSP and wind technology are also declining and there is still substantial potential for cost reductions in all three renewable energy technologies (IRENA, 2013). The cost projections for solar and wind technologies include learning curves which reflect these significant cost reductions in the short- and medium-term (Dii, 2012). Expert opinion and technology analyses were taken into account for the development of cost reduction rates (Dii, 2012). Those cost reduction rates were then applied for each projected global doubling of the installed capacity of technology. Cost reductions for solar technologies of around $50 \%$ are expected by 2025 and for onshore wind technology to a lesser extent to $20 \%$ by 2030 , as wind technology is already well developed and cost competitive.

Another aspect which hugely influences the competitiveness of RET compared to fossil fuel based power production is the inputs over the lifetime of power plant operation, namely fossil fuel prices. We use fossil fuel price assumptions similar to the World Economic Outlook by the International Energy Agency (IEA, 2012).

The CGE analysis is based on the GTAP 8 dataset, which reproduces the global economy as of the year 2007. We focus on 6 MENA countries/regions (Egypt, Morocco, Tunisia, Saudi Arabia, Rest of North Africa and Rest of Western Asia), 9 European countries/regions (Germany, France, Italy, Spain, UK, Switzerland, Norway, Turkey and the Rest of EU27) and the rest of the world is aggregated in 2 broad regions (BRIC plus and Rest of OECD). 


\subsection{Scenarios}

We assess the economic viability of possible renewable energy transition pathways in several scenarios. They incorporate two dimensions: unilateral actions in MENA and the EU versus a regional cooperation, and a scenario without international climate policy versus a scenario of global climate protection. Thus, we can define four scenarios associated to these two dimensions (see Figure 26). ${ }^{62}$ The self-financing scenario reflects a situation where both regions aim to independently decarbonise their power sectors and use national resources to invest in solar and wind power plants. The EUMENA financing scenario incorporates a capital transfer mechanism by which all regions support the MENA countries by financing $70 \%$ of their investment costs (the external financing in the rest of Western Asia is only 30\%). We assume that the regional contribution is set according to the regional GDP. In both scenarios there is no agreement on controlling greenhouse gas emissions, hence fossil fuel prices are at a level that does not include the external cost of emissions.

Figure 26: Schematic representation of the policy scenarios and reference

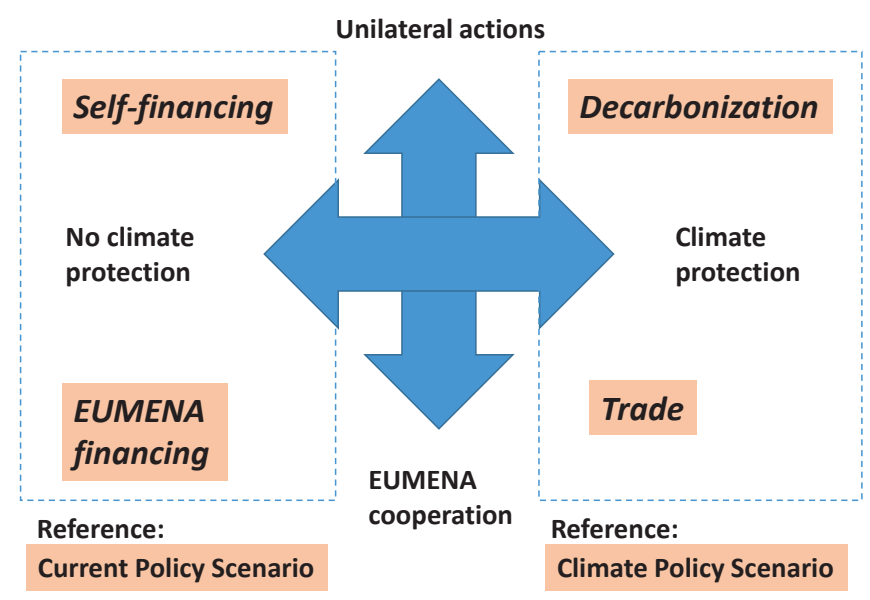

Source: Own illustration.

The scenarios with climate protection are based on the assumption that a contraction and convergence ${ }^{63}$ strategy is followed which is intended to reduce greenhouse gas

\footnotetext{
${ }^{62}$ All scenarios incorporate the investment and production strategies for renewable electricity production as in Dii, 2012.

${ }^{63}$ The contraction and convergence strategy consists of reducing overall emissions of greenhouse gases to a safe level (contraction) where the global emissions are reduced because every country brings emissions per capita to a level which is equal for all countries (convergence). Emissions are constrained in the CGE model and reach a reduction of $-40 \%$ in global $\mathrm{CO}_{2}$ emissions relative to 1990 levels in 2050 . This constraint is achieved by means of a carbon price.
} 
emissions and limit climate change to roughly 2 degrees by the end of this century. For the climate protection scenarios we assume a global reduction of carbon dioxide emissions by 30\% relative to 1990 levels until 2050. Emissions will start to fall by 2015 and will continue in a linear fashion until 2050. Thus, the decarbonised scenario assesses the investment program of a EUMENA wide transition to RET under the assumption that all world regions support the MENA countries to finance their investment costs and there is no electricity trade between the EU and MENA. All this happens in the contraction and convergence scenario, i.e. fossil fuel prices rise considerably in order to limit $\mathrm{CO}_{2}$ emissions. The trade scenario includes the electricity trade between MENA and Europe and the financial support for MENA investments as in the EUMENA financing scenario, but again in a world of global climate policy.

All policy scenarios mentioned above are evaluated by comparing them to a reference scenario. Here we use two reference scenarios. The "current policy scenario" represents a business as usual situation where only current policies are taken into account for future economic trends. The economic development behind the current policy scenario is set to be in accordance with OECD projections. No climate policy is assumed.

The "climate policy scenario" includes the contraction and convergence strategy as a climate policy. Thus it represents a world with climate protection policies in place.

\subsection{Results: Economic impacts of renewable energy transition}

First, in a world without climate mitigation policy, the unilateral decarbonisation of the EUMENA region faces low fossil fuels prices which in turn require substantial subsidies for the RET. Compared to a business as usual situation, the overall costs of the transition to a decarbonised power sector in MENA and Europe, when both regions act independently, leads to a decrease in real income ${ }^{64}$. On average, real income decreases by up to $5 \%$ in MENA and $3 \%$ in Europe (Figure 27, blue lines) depending on the amount of renewable electricity produced and the investment that is drawn from the overall macroeconomic investment budget. The real income effects vary strongly between the different countries as shown in the shaded area of Figure 27. The major drivers of these differences are the total amount of solar and wind power, as well as their composition. The more CSP and PV technologies are introduced, the higher is the need to subsidise electricity production, since those technologies are initially more expensive than electricity produced from wind power.

The EUMENA financing scenario takes into account that the build-up of the renewable energy infrastructure in the MENA region requires a very large volume of investment, especially when it is compared to the overall investment that is available within

\footnotetext{
${ }^{64}$ We use welfare as a measure of real income. Welfare in DART is defined as the Hicksian equivalent variation. That is, the change in regional household income to obtain the new level of utility at initial prices and expenditure.
} 
the region. The losses in real income are less marked in MENA when international support is received (Figure 27, red lines). In fact, as $70 \%$ of the cost of the transition in MENA is financed by international sources, the domestic investment is not drawn from other domestic sectors as much as in the self-financing case and the foreign capital promotes economic growth that partially offsets real income losses caused by subsidies. For European countries, the financing mechanism implies a slightly larger decrease in real income (Figure 27), because in addition to finance their own renewable energy transition, they provide financial support for the transition in MENA.

In fact, several MENA countries already experience real income gains. The members of the EU, on the other hand, experience only a small change if the EU participates in financing MENA investment. In Europe, strong differences occur as real income losses vary between less than $1 \%$ and $12 \%$ in the 2040 s. Real income losses are particularly large in Turkey, which is expected to have the largest installed capacity of RET, due to particularly high electricity demand assumptions (see Dii, 2012).

Figure 27: Changes in real income under a current policy background (percentage change with respect to the current policy scenario)
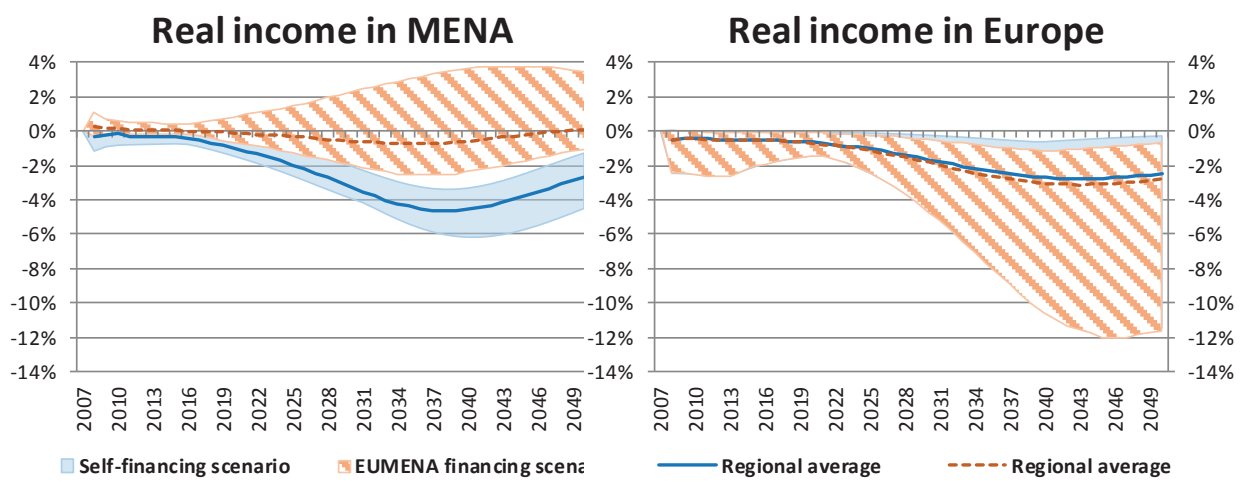

Source: DART model results.

Even with fast cost reduction of the RET as shown in Figure 4, substantial subsidies are required in MENA and Europe to support the production of electricity from renewable energy sources. Figure 28 shows that subsidies increase gradually up to 3.5\% of GDP in MENA and $1.5 \%$ in Europe. These levels of subsidies are associated with production levels that satisfy only domestic demand. When the power systems in MENA and Europe are interconnected, subsidies are larger in MENA and smaller in Europe, because electricity production in MENA increases substantially to cover parts of the European power market. Again, the most important driver of these subsidies is the lack of an international climate policy and hence the lack of a sufficiently high carbon price that should be added to the market price of fossil fuels. 
Figure 28: Total subsidies in solar and wind electricity production (share of GDP)

Subsidies in MENA

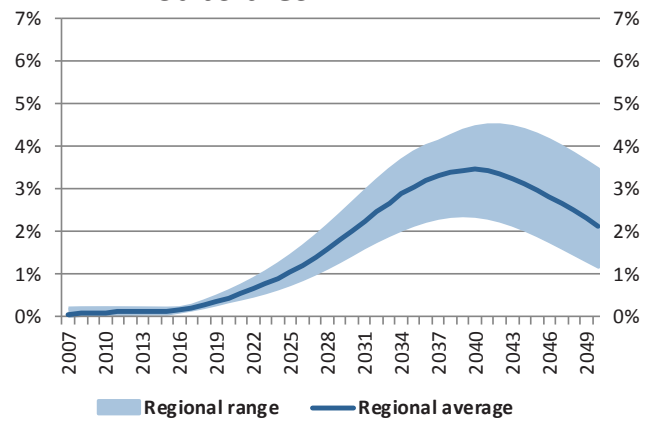

Subsidies in Europe

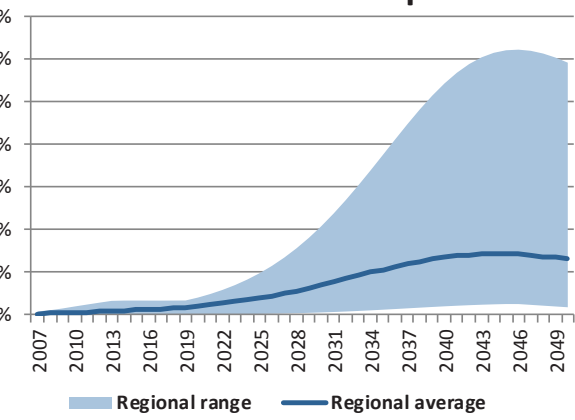

Source: DART model results (Self-financing scenario).

The mechanism of foreign direct investment through which a large part of the expansion of renewable energy infrastructure is financed implies that the MENA countries receive up to $1.6 \%$ of the total investment in the economy (Figure 29, left chart). The sources of these net capital transfers are not only Europe but also the rest of the world. As the investment is substantially larger in MENA if its power system is integrated across the Mediterranean region, the capital transfers to MENA countries go up to 3.3\% of the total investment of the MENA region (Figure 29, right chart).

Figure 29: Net capital transfers

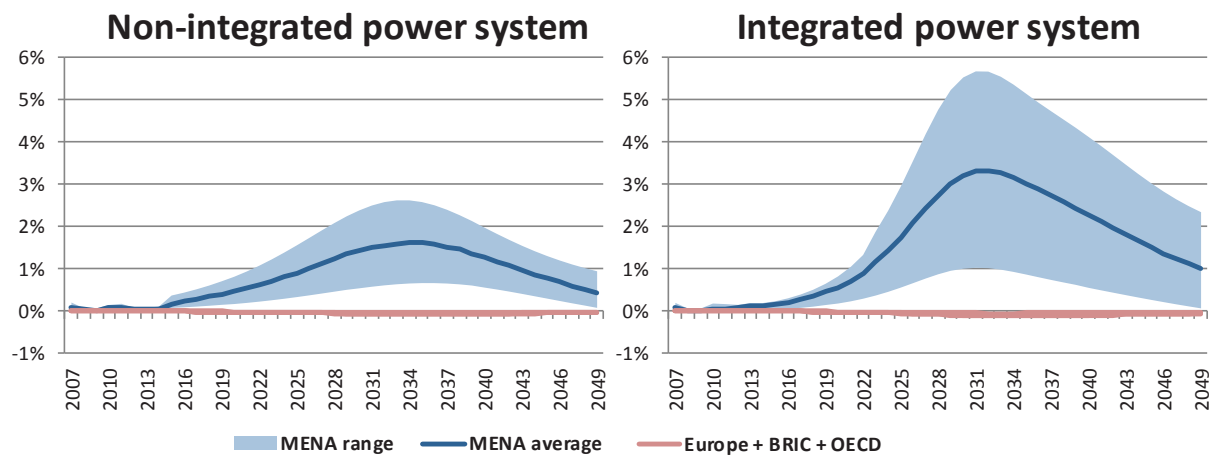

Note: Net capital transfer as share of total investment. Source: DART model results. Total investment according to the current policy scenario.

The scenarios presented so far contain no international climate policy framework. As a consequence, the conversion of the power sector in the Europe and the MENA countries towards a complete decarbonisation takes place in a world economy where unilateral climate mitigation suffers from carbon leakage and a loss in competitiveness of the energy intensive sectors. In addition, the relatively low fossil fuel prices make it neces- 
sary to subsidise renewable electricity to a much larger extent than would be the case if a carbon price were added to fossil fuels. The results of the simulations change significantly if the transition towards RET in EUMENA is assessed against a scenario with an international agreement of the reduction of $\mathrm{CO}_{2}$ emissions.

In the decarbonised scenario fossil fuels prices rise steadily and fast because of the limits on $\mathrm{CO}_{2}$ emissions (see on $\mathrm{CO}_{2}$ limits, 6.7). As a consequence, real income in MENA remains unchanged during the first two decades of the transition and increases afterwards by up to $2.5 \%$ (Figure 30 , blue lines). In Europe, the average decrease in real income is comparable to the case without climate action. However, the decrease in real income is very small in most European countries.

Figure 30: Changes in real income under a climate policy background (percentage change with respect to the climate policy scenario)
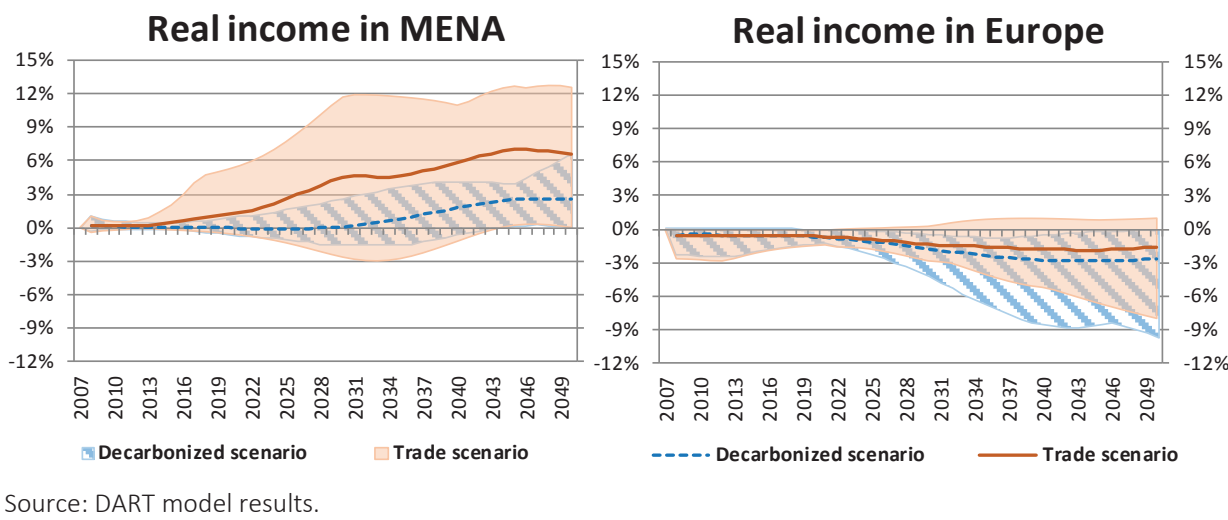

Source: DART model results.

The impact of a renewable energy transition becomes even more positive if the power systems of both regions are interconnected. Given the ideal conditions for solar and wind energy production in MENA and the falling cost of especially PV panels, both MENA and Europe benefit from trading electricity from renewable energy sources. On average, real income in the MENA countries increase by up to $7 \%$ under the trade scenario (Figure 30, red lines); some countries such as Morocco, Tunisia, Algeria and Libya experience income increases of up to $12 \%$. In Europe, importing electricity from MENA slightly reduces the real income losses to around $2 \%$ in the 2040 s. The climate policy scenario indicates that the real income gain in most MENA countries comes more from the reduced need to subsidise solar and wind power, rather than from their comparative advantage in renewable electricity vis-à-vis Europe due to better wind and solar conditions. 


\subsection{Conclusions}

The idea behind an integration of the power systems across the Mediterranean is relatively straightforward as it is based on the principle of comparative advantage: produce renewable energy in areas with relatively abundant natural resource endowments and export it to regions with high electricity demand. However, to bring this idea into practice is very ambitious and challenging. To pursue the 2 degree climate target, a power system in EUMENA almost entirely based on wind and solar technologies would be required. According to the scenarios we analysed, the electricity produced in MENA will not only cover the growing electricity demand in MENA countries, it will also be exported to cover part of the European electricity market.

Achieving this EUMENA energy vision requires substantial economic resources. MENA countries may require annual investments that would grow up to more than $10 \%$ of the total investment in the region, acknowledging that in many cases wind and solar power production are currently still more expensive than fossil fuel based technologies.

Therefore, the extent of the overall costs and benefits for both regions, and particularly for individual countries, depend on the type of strategy adopted to finance the expansion of the power system infrastructure, and the expected development of the LCOE for the different technologies. In fact, without foreign investment MENA countries need to finance the build-up of the renewable infrastructure with their own resources, which restricts investment (and growth) in other energy and non-energy sectors. Likewise, the LCOE of renewable energy relative to conventional electricity production is highly influenced by the international energy price framework, which in turn strongly depends on the global climate policy architecture. Without a climate policy to control greenhouse gas emissions, fossil fuel prices are low because they do not include the external cost of emissions. Thus, higher subsidies for renewable energy are required.

In a world without climate mitigation the decarbonisation of the power sector in the EUMENA countries leads to real income losses in both regions. Indeed, with low fossil fuel prices substantial subsidies are required to make renewable electricity costcompetitive with conventional power generation. For some MENA countries the situation is somewhat better if the renewable energy infrastructure in MENA is financed through foreign direct investment. However, even with international financial support the effect on real income is on average still negative for MENA.

The results change significantly if the renewable energy transition is assessed against a scenario with an international agreement of the reduction of $\mathrm{CO}_{2}$ emissions. In fact, with a climate policy in effect, fossil fuel prices rise steadily and quickly because of the limits on emissions. This reduces the need to subsidise renewable technologies and thus lowers the cost of the transition towards a renewable energy system. Real income in MENA remains constant during the first two decades and increases afterwards. In Europe, the decrease in real income is small in most countries. The results are even 
more positive if the power systems of both regions are interconnected. Trading electricity benefits both regions, MENA and Europe.

The viability of a transition towards renewable energy in MENA depends to a great extent on the international climate policy. Gains in real income in most MENA countries depend more on the reduced need to subsidise solar and wind power in a global climate policy scenario than from their comparative advantage in renewable electricity vis-à-vis Europe due to better wind speed and solar irradiation conditions.

Future research could definitely close the gap by modelling electricity transmission infrastructure in detail, along with renewable energy sector expansion by also taking into account energy storage infrastructure and reserve capacity. Since bioenergy and hydro-power are not applicable in the MENA region, those technologies should definitely be included in the electricity sector of the CGE model, if studies are undertaken for other world regions.

Cross-country renewable energy infrastructure visions are promoted primarily for their environmental attributes, yet policymakers are embracing such plans also because of their perceived strength as engines for industrialisation and economic growth. Yet, the right policy frameworks and pricing mechanisms, i.e. of competing technologies, need to be designed carefully. Only then can the broader economic benefits from RET deployment be attained.

\subsection{Appendix: The renewable energy version of the DART model}

The DART model, developed at the Kiel Institute for the World Economy, is a multisectoral, multi-regional dynamic computable general equilibrium model of the world economy. It has been designed primarily for the analysis of international climate policies. The model is based on microeconomic theory. In each region, the economy is modelled as a competitive economy with flexible prices and market clearing conditions. Agents represented in the model are consumers, who maximise utility, producers, who maximise profits and regional governments. The regions are connected via bilateral trade flows.

The dynamic framework of DART is recursively-dynamic, meaning that the evolution of the economies over time is described by a sequence of single-period static equilibria connected through capital accumulation, changes in labour supply and sector-specific technical progress. Technical progress is exogenously set by total factor productivity rates, while the balance between labour and capital is unaffected. The economic structure of DART is fully specified for each region and covers production, investment and final consumption by consumers and the government. Policy instruments in DART are taxes, subsidies, or quantity constraints in factor markets, product markets, and in international trade. The model results show relative changes to a reference scenario that also needs to be defined. 
Although renewable electricity capacity and generation has substantially increased in the last years, its share in the energy mix is still modest or non-existent in most of the countries. To model the energy transition, we split the electricity sector to include CSP, PV, wind, and conventional technologies. For countries currently producing electricity from renewable sources, we use statistical information from the International Energy Agency. For countries without renewable power production, we assume that a small amount of solar and wind electricity is generated by a standard power plant running at the minimum capacity. ${ }^{65}$

The production technology of solar and wind power plants is defined according to Dii (2013) and it is assumed to be identical for all countries.

We have analysed the cost structure of CSP, PV and wind technology and allocated intermediate inputs for the investment in, and the generation of electricity from those three technologies according to the technology specifics. We also include cost learning curves for each technology over time, which are exogenously given in our model and depend on the cumulative world installed capacity over time (see explanation in Chapter 6). Those learning curves reflect the decrease in investment per unit of capital (technology) over time.

There is not enough information to model grid operation independently; therefore we use the same assumption as the original electricity sector in GTAP. That is, each electricity sector accounts for electricity generation, collection and distribution. In addition to the 4 electricity sectors, DART models 4 energy sectors (coal, oil, gas and petroleum products) which help us to represent the complete interaction of different energy sources on the global energy market. DART also includes 16 different sectors in agriculture, industry and service to capture production synergies during the construction and operation phase. See Table 22 for the regional, sectoral and factoral aggregation used in DART.

\footnotetext{
${ }^{65}$ This assumption does not distort the energy mix because a small production is added for solar and wind technologies. It also allows us to model future development of solar and wind power production in countries where production is currently inexistent.
} 
Table 22: Regional, sectoral and factoral aggregation in DART

\begin{tabular}{|c|c|c|c|}
\hline \multicolumn{2}{|c|}{17 Regions } & \multicolumn{2}{|c|}{24 Sectors } \\
\hline DEU & Germany & AGR & Agricultural and food products \\
\hline FRA & France & $\mathrm{COL}$ & Coal \\
\hline ITA & Italy & CRU & Oil \\
\hline ESP & Spain & GAS & Gas \\
\hline GBR & United Kingdom & MIN & Minerals and mineral products \\
\hline $\mathrm{CHE}$ & Switzerland & TEX & Textiles leather paper \\
\hline NOR & Norway & OIL & Petroleum coal products \\
\hline TUR & Turkey & CRP & Chemical rubber plastic products \\
\hline XEU & Rest of EU27 & MET & Metals and metal products \\
\hline EGY & Egypt & VEH & Motor vehicles and transport equipment \\
\hline MAR & Morocco & ELE & Electronic equipment \\
\hline TUN & Tunisia & MAC & Machinery and other equipment \\
\hline XNF & Rest of North Africa & OTS & Other services \\
\hline SAU & Saudi Arabia & CSP & Concentrating solar power \\
\hline XWS & Rest of Western Asia & PV & Photovoltaic \\
\hline BRIC & BRIC plus & WIND & Wind \\
\hline \multirow[t]{2}{*}{ OECD } & Rest of OECD & ELYN & Electricity from conventional sources \\
\hline & & WTR & Water \\
\hline \multicolumn{2}{|c|}{5 Factors of Production } & CON & Construction \\
\hline LND & Land & TRN & Transport \\
\hline UnSkLab & Unskilled labour & $\mathrm{CMN}$ & Communication services \\
\hline SkLab & Skilled labour & FIS & Financial services \\
\hline CAP & Capital & ISR & Insurance \\
\hline RES & Natural Resources & BUS & Business services \\
\hline
\end{tabular}

In the current policy scenario, renewable electricity production in DART is mainly driven by fossil fuel prices and competitiveness. High fossil fuel prices make the production of electricity from conventional sources expensive, incentivising the production of electricity from renewable sources. Competitiveness, on the other hand, is determined by the LCOE and the learning curve. High LCOE and poor reduction costs are directly linked to production subsidies in the model, which makes its production unattractive.

The electricity produced by each type of power plant is sold to domestic markets and part of it could also be exported. The distribution to intermediate demand, and final demand, of renewable electricity is assumed to be similar to the conventional electricity. Therefore, we use a high elasticity of substitution between CSP, PV, wind, and conventional electricity, characterising a highly homogeneous good. 



\section{Harnessing the sun and wind for economic development? An economy-wide assessment for Egypt ${ }^{66}$}

\footnotetext{
${ }^{66}$ This chapter is based on Al-Riffai, P., J. Blohmke, C. Breisinger, M. Wiebelt (2015). Harnessing the sun and the wind for economic development? An economy wide assessment for Egypt. Sustainability 2015, 7(6), 77147740. Previously, it has also been published as an Economic Research Forum Working Paper Series, WP 851, Cairo, October 2014. It has been co-authored by Perrihan Al-Riffai (IFPRI), Julian Blohmke (Maastricht University), Clemens Breisinger (IFPRI), Manfred Wiebelt (IfW Kiel).

My contribution to this chapter was the introductory section about the energy situation in Egypt, about the renewable energy potentials in Egypt, the literature review as well as recommendations. I researched the technology vectors which were included into the CGE model for Egypt by IFPRI and IfW. I combined the national renewable energy build-up targets for the year 2020 with technology cost for all renewable energy technologies and built investment trajectories.
} 



\subsection{Introduction}

Energy-related global carbon emissions are largely driven by the increasing volume derived from within developing countries, including many Arab countries like Egypt (IEA, 2012a). ${ }^{67}$ Thus, we chose to assess the economic effects of a climate mitigation technology shift also on a more detailed country level in Egypt, by assessing its renewable energy policy plans until 2020.

Similarly to Chapter 6 , this chapter concentrates on the analysis of the potential positive strategic and economic effects induced by the deployment of renewable energy technologies (RET) on a country level. It emphasises the economic assessment of Egypt's renewable energy policy targets up to 2020, as set by the Government of Egypt. Egypt is the second largest industrialised country on the African continent, it has one of the highest rates of electricity demand growth and one of the largest government budgets reserved for subsidising fossil fuel based energy supply (Vidican, 2012). The removal of energy subsidies is important for the long-term success of Egypt's lowcarbon transition (GIZ, 2011) and its reduction has just begun. Egypt is also leader in terms of installed renewable energy capacity in the Middle East and North Africa (MENA) region (REN21, 2013b). Due to its dynamic renewable energy up-scale in the past, newly announced feed-in tariffs, and its current political situation, studying the economic benefits of a low-carbon transition in Egypt could provide interesting insights. The innovation systems environment in Egypt, with regard to renewable energies, is evolving, yet it is weaker when compared, for example, to Morocco (Vidican, 2012; Hawila et al., 2014). Egypt lacks organisational and institutional capacities and the coordination among existing government bodies is weak (Vidican, 2012).

The early and broad diffusion of RET would not only slow down the increase of global carbon emissions but also allow economies to "leapfrog" over the use of conventional energy resources like oil, coal, or gas toward production technologies reliant on more climate friendly power (Popp, 2011; Watson \& Sauter, 2011). Diversifying electricity generation through RET may be particularly important in light of potentially rising future energy costs and geopolitical risks related to mineral resources and especially energy security, thus it could be the right strategy for Egypt. In addition, renewable energies may create jobs and thus foster economic development. To date, several studies have compared the job creation effects of RET deployment with conventional power generation (see Rutovitz \& Atherton, 2009; Lehr, 2012). The general picture shows that on a per-megawatt basis there are more jobs being created in solar and wind technology deployment than in conventional power technology. Finally, there may be other associ-

\footnotetext{
${ }^{67}$ This led to the occurrence, for the first time in history, of developing countries surpassing transition and industrialized countries in aggregate $\mathrm{CO}_{2}$ emissions from the energy sector (IEA, 2012a). The net installations (that is, annual new power capacity installations without repowering) have been slightly larger for RET compared to conventional technology at the end of 2012 (REN21, 2013a, p. 23).
} 
ated socio-economic benefits, including the protection of resources, the reduction of air pollution, and improved health outcomes.

One of the main criticisms of renewable energies is that they are often not cost competitive and thus have to be subsidised. However, production costs for wind turbines and solar panels have decreased and, depending on location and the relevant opportunity costs for conventional energy, energy production from RET can be profitable (REN21, 2013a). As a result, several emerging economies are stepping up efforts in RET deployment (IEA, 2013). China, one such example, has been strengthening its renewables policies and targets since 2012; other countries, including several Arab countries, have developed renewable energy strategies and show considerable potential for achieving them (OECD, 2012). However, for renewable energy based development to work, challenges such as the lack of transparency, political uncertainty, and regional economic disparities, need to be resolved in order to attract and retain investors (OECD, 2012).

Egypt is one of the Arab countries that laid out ambitious plans for developing RET. In fact, one of the reasons for developing RET is the hope that it will help promote economic growth and job creation. This is particularly important since recent political events have slowed down economic growth prospects and increased unemployment and poverty (AfDB, 2013; Breisinger et al., 2013). Poverty has increased by nearly $50 \%$ in the past 15 years from a low of 16.7\% (9.9 million people) in 1996 to 21.6\% in 2009 and $25.2 \%$ (21 million) in 2011. ${ }^{68}$ Moreover, although poverty remained highest in rural areas, the period 2009-2011 saw the fastest rate of increase in urban areas, where poverty grew by nearly $40 \%$.

\subsubsection{Energy sector status quo}

Energy production and use has been growing rapidly in Egypt over the past years. Oil and natural gas are the most important natural resources in Egypt's natural assets (AfDB, 2013). Gas production reached 2.17 trillion cubic feet (tcf) in 2011. Despite this strong growth in gas production, the existing capacity is still insufficient to meet export and domestic demand.

The oil sector presents a similar picture. Even though Egypt continuously discovers more reserves, which increased from 3.7 billion barrels in 2010 to 4.4 billion barrels in 2012 , it produced only 815,000 barrels per day (2011). At the same time, domestic oil consumption has grown to about the same amount as oil production in 2011 (EIA, 2013).

Egypt's current installed capacity for electricity generation consists of $88 \%$ fossilfuel-based technologies and 12\% RET, of which $83 \%$ is hydropower (RCREEE, 2012). Since all major hydropower sites have been developed there is little potential to expand

\footnotetext{
${ }^{68}$ A large share of poor and non-poor people clusters around the poverty line, which can partially explain the rapid rate of increase of people moving into poverty in recent years.
} 
electricity production from hydropower (AfDB, 2012). In places where 99\% of households have access to the electricity system, the peak load growth rate averaged $7.5 \%$ per year from 2005 to 2010 (AfDB, 2012; Ibrahim, 2012). In order to satisfy demand increase, the power sector expanded its installed capacity to roughly 25,000 megawatts by the end of 2010. Those efforts were insufficient to fully meet high and rising demand, however, and have led to widespread electricity shortages across the country (AfDB, 2012). Natural gas has traditionally comprised nearly $100 \%$ of conventional supply but dropped to roughly $80 \%$ in 2010 because of insufficient supply of gas (AfDB, 2012). Heavy fuel oil has been burned to compensate for the gas shortage in the power sector.

The contradiction of high natural resource wealth on the one side and insufficient supply to domestic markets on the other can be explained by the highly distorting subsidy scheme. Egypt's energy consumption has been growing faster than consumption rates in comparable economies (EBRD, 2012). For example, Egypt's consumption of natural gas grew by more than $15 \%$ in 2011 -even though the economy was in a contraction phase. This is due to the fact that oil producers are required to sell to national consumers at a price well below world market level. As a result of providing cheap oil and gas to domestic industries and households the government lost around USD 1 billion per year in 2010.

Simultaneously, it has become more difficult to maintain fossil-fuel-extraction margins since newly discovered reserves are increasingly expensive to access. Energy subsidies amounted to $11.9 \%$ of gross domestic product (GDP), while one-third of those subsidies were spent to subsidise electricity generation (EBRD, 2012).

In 2014 Egypt introduced energy subsidy cuts (IISD, 2015). Due to the political instability they had been in the pipeline over 5 years and resulted in a steep reduction of energy subsidies from USD 20bn in fiscal year 2013/2014 to USD 14bn in 2014/2015 while electricity subsidies were halved, from USD 3.8bn to USD $1.8 \mathrm{bn}$. The government states that the reform of energy subsidies will play an important role of the necessary fiscal adjustment and enable more investments in the power sector in the future.

\subsubsection{Potential for renewables}

Due to the limited availability of fossil fuels in the power sector and the increasing cost of electricity supply, the government's interest in the diversification of the energy mix has been evolving rapidly over the past few years. Egypt has favourable solar irradiation and appropriate wind conditions - the prerequisites to producing electricity from renewable sources. The country has large deserts that are sparsely populated and thus, in principle, both solar and wind technologies have potential for widespread application. The annual direct normal solar irradiance ranges from 2,000 kilowatt hours per square meter $\left(\mathrm{kWh} / \mathrm{m}^{2}\right)$ to $3,200 \mathrm{kWh} / \mathrm{m}^{2}$ across the country, with a steady daily profile of approximately 9-11 hours of sunlight (AfDB, 2012). Wind conditions are also favourable 
in the Gulf of Suez, reaching wind speeds of 7-8 meters per second. The lower cost of wind technologies compared to solar technology, due to relatively high wind speed potentials, especially in the western part of the Gulf of Suez (Ibrahim, 2012) favour the deployment of wind technologies in Egypt's energy mix.

The estimated LCOE of Egyptian power generation from existing power plants (including hydro, natural gas, and fuel oil) is at USD 0.11/kWh. Those of onshore wind energy generation are at USD 0.06/kWh, utility scale solar photovoltaic (PV) at USD $0.11 / \mathrm{kWh}$, and concentrated solar power (CSP) costs USD 0.16/kWh (Dii, 2013). The LCOE calculation takes into account country-specific solar irradiation and wind speed figures affecting the LCOE on country level.

This illustrates that wind technology specifically is competitive with conventional power generation technologies in Egypt. The figures we use (Dii, 2013) are in that range and also confirm that wind technology is competitive with conventional power, unlike PV and CSP.

\subsubsection{Egypt's Renewable Energy Strategy}

In response to the existing opportunities and challenges due to energy shortages in the energy sector, the Egyptian Supreme Council of Energy has approved a strategy that aims to increase the share of renewable energy to $20 \%$ of electricity overall by 2020 , with $12 \%$ coming from solar and wind technologies and $8 \%$ from hydropower (REN21, 2013a). ${ }^{69}$ Specifically, Egypt's wind target is set at roughly 7,200 megawatts until 2020 and is clearly prioritised due to its lower cost compared to solar technologies (REN21, 2013a). Solar development targets are less pronounced and not as ambitious with a solar PV target at 220 megawatts by 2020 and 1,100 megawatts of CSP. Egypt announced further a 2027 target of 2,800 MW of CSP and 700 MW of PV (REN21, 2013a). The lower solar PV target is also due to the fact that solar technology is more expensive relative to wind technology.

Following the Egyptian Economic Development Conference (EEDC) in 2015 the Egyptian government announced that it will also include the production of power from coal and nuclear power into its energy sector strategy by 12.5 GW and 4 GW respectively (JICA, 2015). ${ }^{70}$

Achieving these targets will require swift mid-term development of solar and wind power plants. In order to meet this requirement, the current installed capacity of wind electricity generation needs to grow by 13 times, PV by 15 times, and CSP by 55 times (RCREEE, 2012).

\footnotetext{
${ }^{69}$ The development of wind technology was initiated in 1996 when the New \& Renewable Energy Authority (NREA) was formed. A series of large-scale grid-connected wind projects have been implemented with a total installed capacity of about 550 megawatts in 2010 (AfDB, 2012).

${ }^{70}$ Those coal and nuclear plans have not been taken into account in the CGE model of this chapter.
} 
The process by which to achieve these targets is in two parts (Vidican, 2012; Amer, 2009). First, a competitive bidding process for projects shall be organised, leading to long-term power purchase agreements (PPA) of 20 to 25 years. Second, there shall be feed-in tariffs (FiT) determined based on the results of the bidding process. The FiT intend to support small and medium developers with capacities of up to $50 \mathrm{MW}$ was announced in 2014 and being effective as of 2015 (EBRD, 2015). The NREA has also increased efforts to incentivise private sector engagement in the emerging renewable energy sector. Proposed measures include favourable permits and land-use agreements for renewable energy project developers, custom-duty exemptions, local content awards in tendering processes, and power generation licenses from the national utility company.

Solar and wind technologies in Egypt are not only expected to contribute to fuel savings and $\mathrm{CO}_{2}$ reductions but also to meet the increasing electricity demand in the country (annual growth rate of peak load averaged between 2005 and 2010 at $7.5 \%$ per annum; AfDB, 2012) and may cover part of the electricity demand in Europe, as proposed, for example, by the Desertec vision. ${ }^{71}$

In the following sections, we will investigate how these proposed renewable energy plans and the Egyptian power sector's shift toward RET will impact the country's overall economic development and welfare situation.

The objective of this chapter is to assess how RET can support economic development in Egypt and thus also provide lessons for other countries. In order to provide answers to these questions, the remainder of the chapter is structured as follows. Section 2 describes the methods used. Section 3 presents the results of our modelling analysis. Section 4 provides a discussion of the results and Section 5 concludes and gives policy implications.

\subsection{Methods: Modelling the economy-wide effects of investing in renewable energy}

\subsubsection{The database: A renewable-energy-focused Social Accounting Matrix}

The basis for our assessment of renewable energy investments in Egypt is a social accounting matrix (SAM) we developed. The SAM represents the structure of the Egyptian economy and importantly describes the linkages between various renewable energy sectors, other sectors of the economy, institutions, and other countries (through trade). ${ }^{72}$ The SAM is based on the latest published supply and use tables compiled by

\footnotetext{
${ }^{71}$ The Desertec vision aims to generate sustainable power from the sites where renewable sources of energy are most abundant and export electricity to regions like Europe with high electricity demand. Besides advantageous wind and solar conditions, also production factors such as land and labour are available at large scale. This also contributes to combatting climate change, ensuring a reliable energy supply, and promoting security and development (see www.desertec.org for online resources).

${ }^{72}$ An aggregated macro-SAM can be found in the appendix.
} 
the Central Agency for Public Mobilization and Statistics (CAPMAS, 2013a) for 2008/09 and is complemented with data from the Household Income, Expenditure, and Consumption Survey for the same year (CAPMAS, 2013b) as well as data on the economically active population in 2007 (ILO, 2013). The SAM includes production, intermediate use, final demands, sectoral capital earnings, and sectoral expenditures on wages and salaries, as well as the distribution of factor income to households and the redistribution of income between the private and public sector. Key aspects of the Egyptian economy in 2008 will be discussed below.

The input-output data compiled by CAPMAS (2013a) do not include statistics on renewable electricity supply technologies; instead, the electricity sector in the benchmark data is an aggregate of existing renewable and conventional technologies. We therefore calculated the input requirements for the renewable electricity technologies based on additional data sources, allowing us to disaggregate the aggregate electricity sector into renewable and conventional subcomponents, as in Desertec Industrial Initiative (Dii, 2013) and Calzadilla et al. (2013). We conduct the disaggregation using data from an industry survey conducted by Dii that describes cost and technological characteristics of PV, CSP, and wind electricity generation technologies (see Table 23 and Table 24). The industry survey among industry experts analysed each technology's investment cost structure on a component level and also the operational and maintenance cost structure for each technology. The technology complexity of CSP, PV and wind technology is represented in the model by the import shares of the respective domestic intermediate import sectors. The additional RET sectors stimulate production of intermediate inputs. The sectors producing intermediate inputs themselves have an inherent import share, which cause an increase in renewable energy induced import to a certain extent.

To generate cost shares for renewable equipment manufacturing, we calculated the weighted cost for each technology from the input-output data using the components in Table 23 as weights. The technology equipment manufacturing and the electricity generation phase of the technology, consuming further capital, are two separate groups of vectors. This allows us to compile input cost shares for each technology and to separate the aggregate electricity generation sector into conventional and renewable subsectors. The input cost shares for all electricity-generating technologies are given in Table 25. 
Table 23: Production cost estimates for renewable equipment manufacturing (EUR/kW)

\begin{tabular}{lccc}
\hline & PV & CSP & WIND \\
\hline Minerals and mineral products & & 464 & \\
Rubber, plastic products & 150 & 579 & 289 \\
Metals and metal products & 810 & 678 & \\
Electronic equipment & 260 & 355 & 459 \\
Machinery and other equipment & & 919 & 224 \\
Vehicles and transport equipment & 90 & & 79 \\
Construction & & 583 & 15 \\
Other transport & 150 & 215 & 134 \\
Business services & 1460 & 997 & 1200 \\
Total & & 4790 & \\
\hline
\end{tabular}

Source: Dii (2013).

Table 24: Production cost estimates for renewable electricity generation (EUR/kW)

\begin{tabular}{lccc}
\hline & PV & CSP & WIND \\
Electronic equipment & 7.5 & & 10.8 \\
Machinery and other equipment & 4.2 & 21.7 & \\
Water & & 3.8 & 3.2 \\
Business services & 0.7 & 8.1 & 3.2 \\
Insurance & 5.0 & 26.6 & 3.6 \\
Labor remuneration & 21.0 & 32.6 & 84.0 \\
Capital rental & 102.2 & 335.3 & 3.20 \\
Land rental & 1.60 & 0.20 & 108.0 \\
Total & 142.2 & 428.3 & \\
\hline
\end{tabular}

Source: Dii (2013).

Table 25: Benchmark cost shares for renewable equipment manufacturing, all other manufacturing, and electricity generation

\begin{tabular}{|c|c|c|c|c|c|c|c|c|}
\hline & \multicolumn{4}{|c|}{ Equipment manufacturing } & \multicolumn{4}{|c|}{ Electricity generation } \\
\hline & PV & CSP & WIND & Other manu. & PV & CSP & WIND & Conventional \\
\hline Intermediates & 0.65 & 0.56 & 0.65 & 0.69 & 0.12 & 0.14 & 0.16 & 0.55 \\
\hline Energy & & & & & & & & 0.10 \\
\hline primary education & 0.05 & 0.06 & 0.05 & 0.03 & 0.09 & 0.05 & 0.02 & 0.09 \\
\hline secondary education & 0.02 & 0.02 & 0.02 & 0.01 & 0.04 & 0.02 & 0.01 & 0.04 \\
\hline tertiary education & 0.01 & 0.01 & 0.01 & 0.01 & 0.01 & 0.01 & 0.00 & 0.01 \\
\hline Capital & 0.28 & 0.35 & 0.27 & 0.25 & 0.72 & 0.78 & 0.78 & 0.21 \\
\hline Land & 0.00 & 0.00 & 0.00 & 0.00 & 0.01 & 0.00 & 0.03 & 0.00 \\
\hline Total & 1.00 & 1.00 & 1.00 & 1.00 & 1.00 & 1.00 & 1.00 & 1.00 \\
\hline
\end{tabular}

Source: Author's calculations. 
Overall, the key differences between renewable and conventional electricity technologies are that the RET are more capital intensive and less energy intensive than the conventional electricity generating technology. Renewable energy technologies are also somewhat less labour intensive and require significantly less intermediate inputs. Moreover, our data suggest that the renewable equipment manufacturing sectors, especially CSP, have a higher proportion of value added compared to the broader manufacturing sector. Yet, most of the value added that will be generated in the renewable sectors is capital income on foreign direct investment (FDI) that will be repatriated to foreign owners of the capital stock.

\subsubsection{The model: A Dynamic Computable General Equilibrium Model}

To assess the potential impacts of alternative renewable investment schemes for Egypt, we build a multi-sector dynamic computable general equilibrium (DCGE) model. The Egyptian economy is modelled as a competitive economy with flexible prices and market conditions. Agents represented in the model are consumers, who maximise utility; producers, who maximise profits; and the government. Egypt is connected with the rest of the world via bilateral trade flows, remittances, and other transfers.

To reflect the fact that investments in wind turbines and solar panels take place over a longer period of time, the analytical framework is recursively dynamic-which means that the evolution of the economy over time is described by a sequence of single-period static equilibria connected through capital accumulation, changes in factor supply, and sector-specific technical progress. The economic structure, including energy production from renewables, is fully specified and covers production, investment, and final consumption by consumers and the government. Policy instruments are taxes, subsidies, or quantity constraints in factor markets, product markets, and international trade. The model results show relative changes to a reference scenario that also needs to be defined.

Producers of renewable energy and those of other goods and services (including 1 agricultural sector, 23 industrial sectors, and 2 service sectors) are assumed to operate at constant returns to scale in a perfect competitive environment, and so make zero profits (see Table 26). For all sectors, except renewable energy producers, the production function consists of a constant-elasticity-of-substitution (CES) aggregate of capital and labour (and land in agriculture and renewables) nested within a Leontief aggregate of all other inputs (that is, intermediate demand is determined by fixed technology coefficients, or Leontief demand). For renewable energy producers, we support the entire capital-labour-land nest within the fixed factor FDI, which is determined exogenously by foreign investors.

We model separate domestic manufacturing sectors that produce capital equipment for renewable energy generation (for example, wind turbine blades, nacelles, solar panel and inverter manufacturers). Producers of renewable energy will choose to pur- 
chase outputs from these manufacturing sectors, rather than purchasing imported renewable energy capital goods. Profit maximisation implies that factor payments equal average production revenues. Labour, capital, and land are fixed, implying full employment and inter-sectoral mobility, except for capital and land, which are assumed to be immobile across sectors. New capital from past investment is allocated to sectors according to profit rate differentials under a "putty-clay" specification. This means that once capital stocks have been invested it is difficult to transfer them to other uses. The same holds true for land in agriculture and in renewable electricity sectors. This means that as renewable electricity sectors expand, they generate additional demand for labour, which then affects economy-wide wages and production in other sectors by increasing labour competition. Based on the 2008/09 Household Income, Expenditure and Consumption Survey (HIECS), labour markets are segmented across three skill groups: (1) low-skilled workers with primary education; (2) semi-skilled workers with secondary education; and (3) skilled workers who have completed tertiary schooling.

Factor incomes are distributed to households using fixed income shares on households' initial factor endowments. Incomes are then saved (based on marginal propensities to save) or spent on consumption (according to marginal budget shares). Household savings and foreign capital inflows are collected in a national savings pool and used to finance investment demand (meaning a savings-driven investment closure). Finally, prices equilibrate product markets so that demand for each commodity equals supply. The model therefore links production patterns to household factor incomes through changes in factor employment and returns.

Households maximise a Cobb-Douglas utility function so that budget shares are constant. Households are disaggregated across rural/urban and by per capita expenditure quintiles, giving a total of 10 representative households in the full DCGE model. Households pay taxes to the government based on fixed direct and indirect tax rates. Tax revenues finance exogenous recurrent spending and transfers to households, resulting in an endogenous fiscal deficit. Finally, the model includes a simple consumption-side micro simulation module where each respondent in HIECS is linked to their corresponding representative household in the DCGE model. Changes in commodity prices and each household group's consumption spending are passed down from the DCGE model to the survey respondents, where their total per capita consumption and poverty measures are recalculated.

International trade is captured by allowing production and consumption to shift imperfectly between domestic and foreign markets, depending on the relative prices of imports, exports, and domestic goods (inclusive of relevant sales, trade taxes, and subsidies). This specification captures differences in domestic and foreign products and allows for observed two-way trade. However, Egypt is still considered a small economy, such that world prices are fixed and the real exchange rate (that is, price index of tradable to non-tradable goods) adjusts to maintain a fixed current account balance. 
Renewable electricity expansion is assumed to be driven entirely by FDI, and all profits generated in the renewable sectors are remitted abroad. The decision to invest is thus resolved exogenously by foreign investors FDI in the renewables electricity and manufacturing sectors will expand renewables' capital stock. This expansion in resources will cause renewables' growth rate to increase in all renewable energy scenarios. Renewable energy producers must, however, compete with other sectors for intermediate inputs and labour resources. In the DCGE model, we assume full employment, which means that total labour supplies are fixed and increasing labour demand raises workers' wages, thereby leading to a reallocation of workers from non-renewables to renewables sectors. Ultimately, the trade-offs from renewables production will generally be smaller than the gains from new investments in the renewables industry. As a result, national GDP growth rates will increase in most renewable energy scenarios. Moreover, we assume that all renewable electricity is exported, while at the same time coverage of national demand is ensured.

We initially create the renewable electricity and renewable equipment manufacturing sectors representing their current capacities (see next section), then smoothly increase renewable energy production over the period 2008-2020, reflecting the likely gradual expansion of the industry. The wind target in Egypt is set to 7,200 megawatts by 2020 and is clearly prioritised for its lower cost compared to solar technologies (REN21, 2013a). Solar development targets are less pronounced and not that ambitious, with a solar PV target at 220 megawatts by 2020 and 1,100 megawatts of concentrated solar power.

The Egypt DCGE model is first run forward using the 2008-2020 period, assuming no expansion in renewable electricity production. This produces a reference scenario against which to assess Egypt's renewables strategy. For this, we first calibrate the Egypt DCGE model to track observed trends in key demographic and macroeconomic indicators. Population growth and growth of unskilled, medium-skilled, and high-skilled labour are all set at 2\% per year during 2008-2020. We exclude an expansion of agricultural land to capture rising population density in rural areas. In order to achieve recently observed growth rates in GDP, total factor productivity growth is set to $0.5 \%$ for agriculture and $1.6 \%$ for industry per year during the simulation period. Thus, the baseline scenario also captures the recent poor performance of the Egyptian economy. Then in the renewables simulations we expand the size of the renewable electricity and renewable equipment subsectors to produce the above mentioned target values.

When interpreting these results, it is important to keep several well-known weaknesses of DCGE models in mind. While none of the following limitations of the model presented in this chapter is likely to alter the key messages, it is important to highlight them. First, like any other model, the DCGE is very data intensive. While it is a major strength of this type of model to reconcile data from different sources, such as balance of payments data, national accounts and household surveys, it is also perhaps their major weakness. Second, the assumption of full employment and flexible wages in 
Egypt can be justified by the fact that producing renewable energy equipment and operating renewable energy plants require specific skills, which unemployed people may not have. Thus hiring people to support renewable energy driven growth will have to be done from the existing workforce.

\subsection{Results and discussion: Potential impacts of investing in renewable energy projects}

\subsubsection{Renewables in the economy-wide context}

Table 26 shows the structure of the Egyptian economy in 2008, which is the initial starting point for the model. Given our focus on renewable energy, employment generation, and poverty reduction, we are interested in how Egypt's renewable energy strategy affects the amount of income earned by each household and how it is earned. The SAM provides the information needed to answer both questions. The former is what is referred to as the functional distribution of income - the returns to factors - and the latter is the size distribution of income - how the factor returns are distributed (and redistributed) among households and the government and the rest of the world.

Agriculture generates only 13\% of Egypt's gross domestic product but more than $30 \%$ of total employment. Most farmers are smallholders with low education levels; more than $17 \%$ of total low-skilled labour income is generated in agriculture. However, Egypt as a whole relies on imported food, which accounts for $14 \%$ of total imports and $18 \%$ of all processed food in the country.

The Egyptian economy is dominated by mining (including oil, petroleum, and petroleum processing) and private services (including tourism and Suez Canal services). Mining does not, however, generate much employment, and most non-farm workers in the country are employed in private and public services and construction. Incomes in many of these non-farm sectors are only slightly higher than those in agriculture, due in part to low education levels and shortage of skilled labour in the country. Indeed, $85 \%$ of skilled labour income is generated in the public sector. Energy is a small sector and renewable energy is still in its infancy, making up only a tiny share of total value added and employment in 2008. 


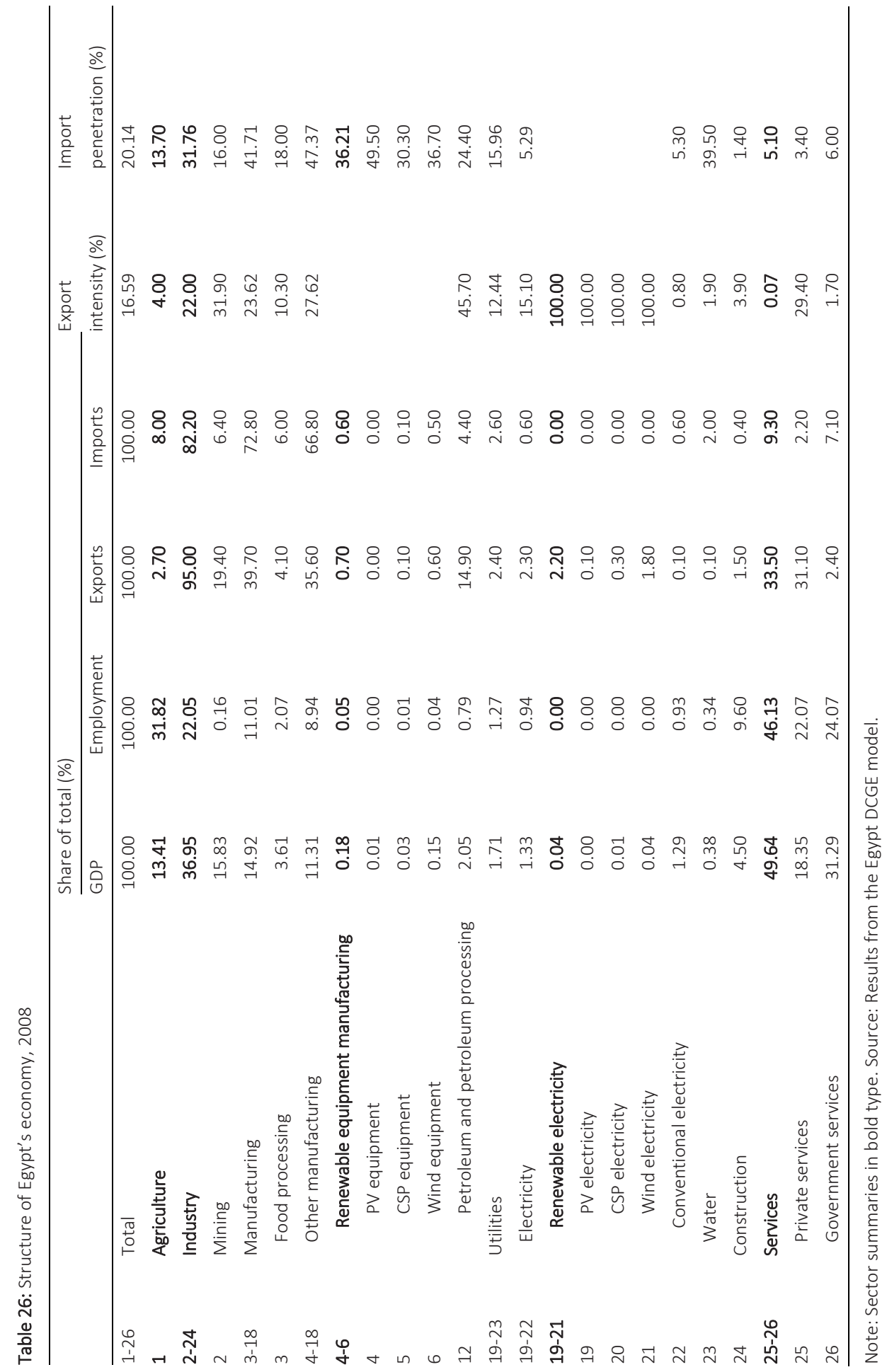




\subsubsection{Renewable energy scenarios}

We assess the Egyptian renewable energy strategy in several scenarios (Table 27). All scenarios incorporate Egypt's investment and production plans for renewable electricity production by 2020, both for specific technologies (labelled "PV," "CSP," and "WIND") or for the combined investment into all technologies (labelled "COMB"). For combined scenarios, this involves a permanent 34\% increase in FDI inflow to the renewable energy sector. This increase is equivalent to just under 1\% of baseline GDP and 5\% of baseline investment but total investment in renewables reaches 10\% of total investment in 2020.

In all scenarios we assume that all renewable electricity is exported while additional domestic demand for electricity is satisfied by domestic and import supply of conventional electricity, which is a perfect substitute to renewable sources. COMB1 (and PV, CSP, and WIND) examines a scenario without climate policy, where renewable electricity can only be exported at prices of conventional electricity. Given low fossil fuels prices, this requires substantial subsidies to CSP technology and to a less extent to PV technology (Table 27). COMB2 assumes that climate change mitigation policies raise conventional electricity prices to a level that covers CSP production costs. Finally COMB3 assumes that, additionally, the Egyptian government reduces fuel subsidies by $10 \%$ as a complimentary measure to renewables policy. Consequent changes in the domestic budget balance, which follows from climate change mitigation policy and fuel policy balance, are accommodated through adjustments in investment, thus implying a redistribution of income from fuel consumers to investors.

Table 27: Scenarios for Renewable Energy development in Egypt by 2020

\begin{tabular}{|c|c|c|c|c|}
\hline Scenario & $\begin{array}{l}\text { Capacity build-up, } \\
\text { MW }\end{array}$ & $\begin{array}{l}\text { Total FDI/ baseline } \\
\text { investment, \% }\end{array}$ & $\begin{array}{l}\text { Reference electricity } \\
\text { price }\end{array}$ & Subsidy rate $\%$ \\
\hline COMB1 & $585-8,420$ & 4.80 & fuels unit cost & PV: 18.8\%; CSP 75.1\% \\
\hline PV & $15-220$ & 0.85 & fuels unit cost & $18.80 \%$ \\
\hline CSP & $20-1,100$ & 2.22 & fuels unit cost & $75.10 \%$ \\
\hline WIND & $550-7,200$ & 3.23 & fuels unit cost & - \\
\hline COMB2 & $585-8,420$ & 4.80 & converges to & - \\
\hline COMB3 & $585-8,420$ & 4.80 & CSP unit cost & fuels excise subsidy: $-10 \%$ \\
\hline
\end{tabular}

\subsubsection{Impacts on economic growth and employment}

The renewables simulations reflect the case, where FDI and land are allocated to the renewables sectors according to Egypt's renewable energy strategy. This implies that the electricity generating capacity of PV will increase from 15 megawatts in 2008 to 220 megawatts in 2020 and that of CSP and WIND from 20 to 1,100 megawatts and from 550 to 7,200 megawatts, respectively. We assume that the solar and wind parks will be located on brown field sites or other sites, where there is no other valuable land use - meaning that renewable energy plants will not displace any agricultural land being cultivated. 


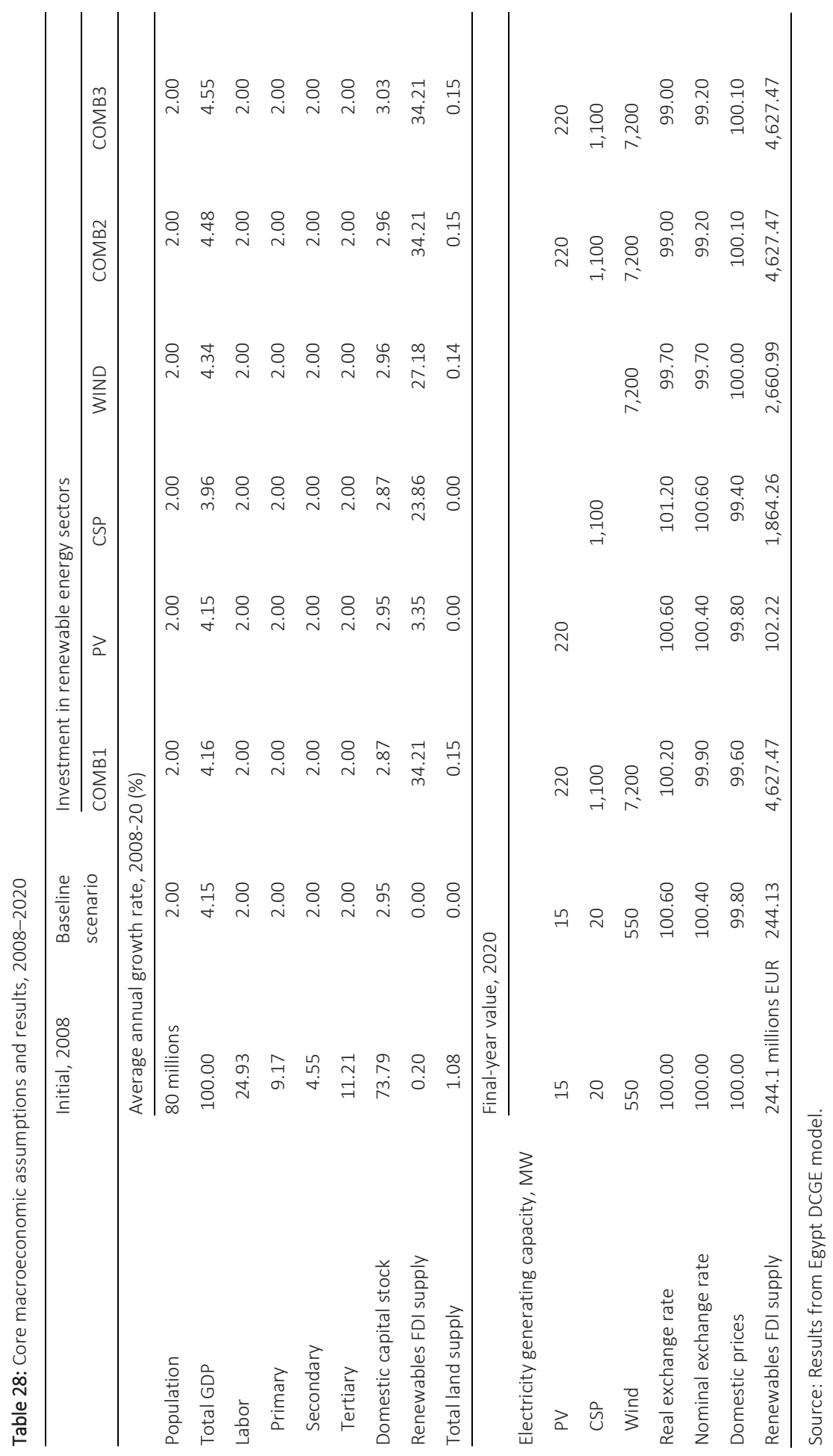


In the scenario without climate policy (COMB1), the Egyptian economy adopts low fossil fuel prices that require substantial subsidies to the renewable electricity sector, especially CSP electricity production, in order for them to be competitive with conventional energy. Our results show that total subsidies for PV and CSP increase gradually to up to $2.5 \%$ of GDP. Compared to the baseline scenario without renewable investment, the transition to a decarbonised power sector in Egypt leads to real income gains in the renewable energy sector (Table 29) as a result of FDI inflow to the renewable energy sector. However, these real income gains are dampened by a decrease in domestic fixed investment (Table 28) and real income losses in other sectors and the overall impact of the renewable energy strategy on growth across the Egyptian economy for that scenario would be quite low; overall growth would be just 0.01 percentage points above baseline growth (Table 28). The reduction of domestic fixed investment is mostly felt in the construction sector, where the growth rate is one percentage point lower than in the baseline and largely results from the subsidies to CSP technology (see column 4 in Table 29), while the impact of subsidies to PV technology (column 5) is quite low, given PV's small share in the renewable energy investment plan.

Our findings suggest that the massive scaling up of renewable energy may negatively affect other sectors in two key ways. First, the expansion of PV and especially CSP technologies and the accompanying rise in subsidy payments to these sectors imply that an increasing amount of investment is drawn from the overall macroeconomic investment budget. Thus demand for investment goods is reduced, and this is mostly felt in the construction sector. Second, export sectors are negatively affected through appreciation of the exchange rate, if all renewable energy is exported (see Table 29). This is because in our simulations the renewable energy sector eventually accounts for almost $25 \%$ of total merchandise export earnings by 2020. Since we assume that the current account balance is fixed in foreign currency, the increase in exports causes the real exchange rate to appreciate relative to the baseline scenario (see Table 28). This reduces the competitiveness of traditional export sectors, such as textiles, chemicals, electrical and nonelectrical machinery, and private services (tourism and Suez Canal services); exports and production of these sectors therefore decline. Yet, it is important to note that the focus of this chapter is to show how Egypt's RE strategy, and the FDI used to finance this strategy, is strengthening local income at macroeconomic, sectoral, functional and household levels.

In the isolated PV and CSP scenarios, the demand effects clearly dominate. For example, the number of workers employed in construction falls to 438,000 and 6,000 workers in the CSP and PV scenarios, respectively (Table 30). By contrast, the number of workers used in construction increases by 21,000 in the WIND scenario, the expansion of wind energy does not require additional subsidies and therefore does not lead to a crowding-out of domestic fixed investment. Moreover, workers are reallocated from trade-oriented agriculture and private services to the renewable energy sectors as a result of the real appreciation. In the COMB1 scenario, which replicates Egypt's renewable energy strategy, both effects are at work and lead to a restructuring of the economy toward manufacturing services while the construction sector contracts. 


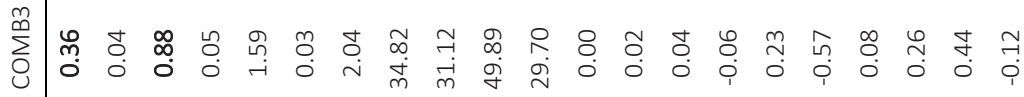

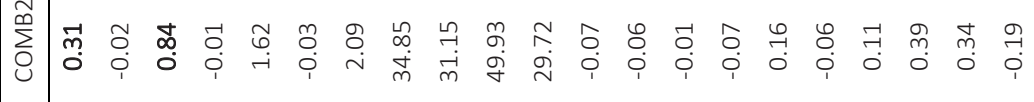

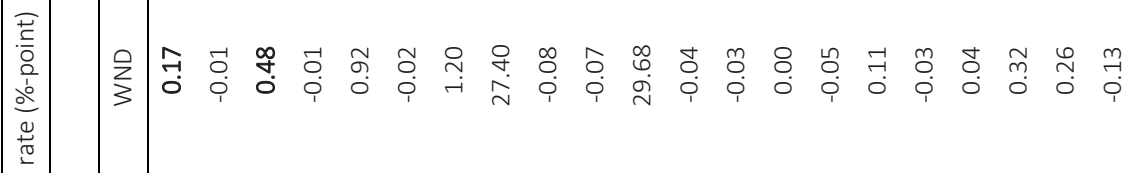

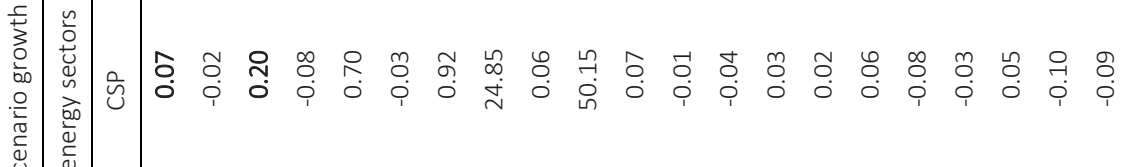

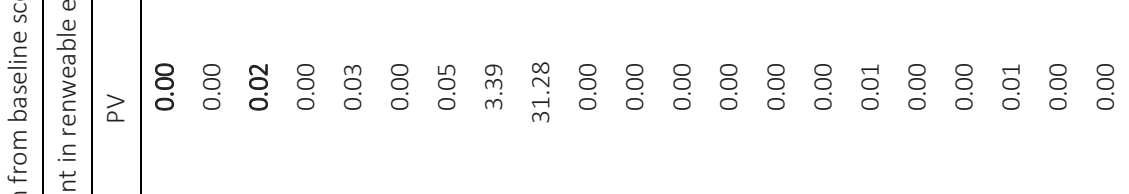

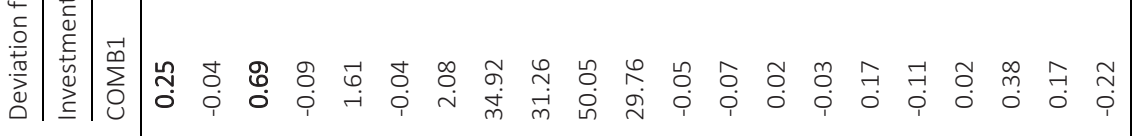

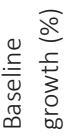

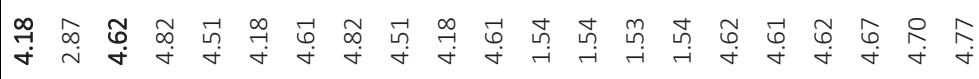

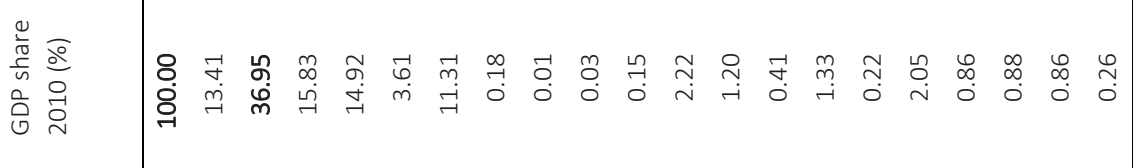

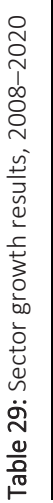
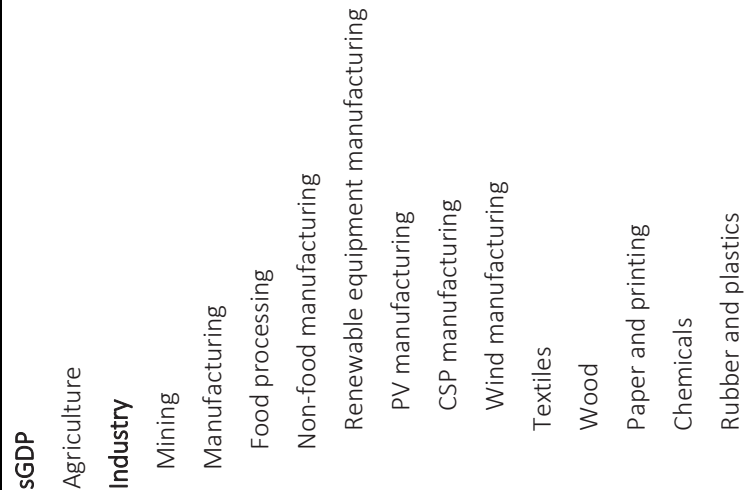

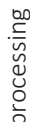

苍

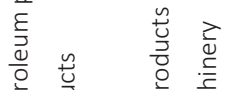




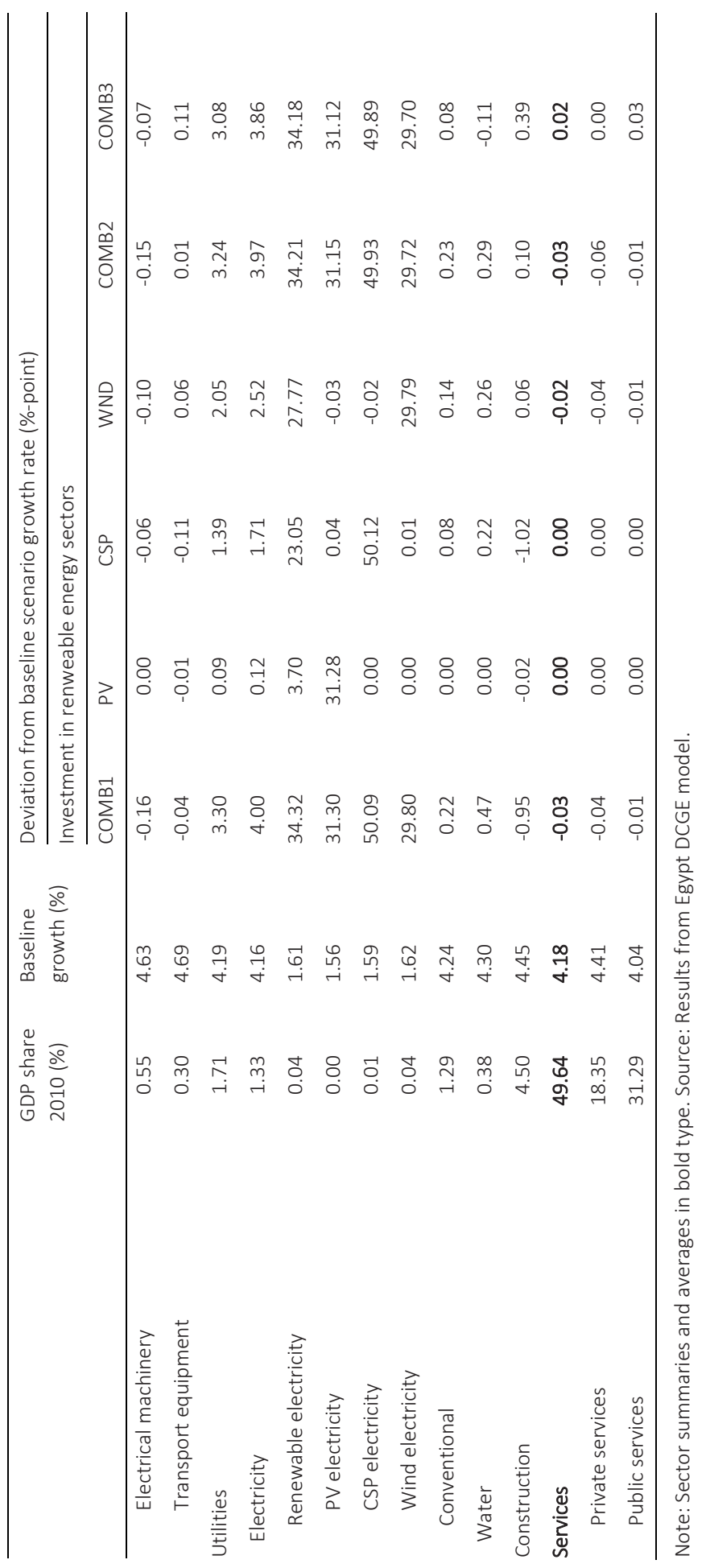


Scenarios COMB2 and COMB3 assume that prices for fossil fuels rise swiftly and steadily because of limits on $\mathrm{CO}_{2}$ emissions, thereby leading to a convergence of renewable and conventional electricity production costs. The reduced need to subsidise solar power implies that the competitiveness of traditional export sectors, such as textiles, chemicals, electrical and non-electrical machinery, and private services (tourism and Suez Canal services), and these exports decline. Agricultural production and food processing decrease despite rising domestic income since the appreciation of the real exchange rate also reduces the competitiveness of domestic import-competing sectors. Ultimately, the trade-offs from renewable energy production are smaller than the gains from new investments in the renewable energy sector. As a result, national GDP growth rates increase in all renewable energy scenarios, though these increases vary depending on the volume of investment and whether the renewable energy strategy is somehow flanked by additional measures.

Scenario COMB3 assumes that the renewable energy strategy is supported by a $10 \%$ reduction of fuel subsidies. Lower fuel subsidies have no direct impact on the renewable energy sectors, but exhibit significant indirect effects: by raising input costs to almost all sectors, they lead to a higher real appreciation. Moreover, lower government subsidies imply a reduction of the public deficit and an increase in investment, both of which lead to higher growth in the COMB3 scenario compared to COMB1 and COMB2.

Generally, the more profitable the renewable electricity production technology is, the larger its impact on national economic growth. Thus, the scenario with the largest positive gains in total GDP is WIND, which is the most profitable renewable electricity technology (see Table 29).

Table 30 reports impacts on employment. The number of jobs created in the renewable energy sector varies greatly across scenarios. The last three columns show the labour requirements to build up and operate a 100 megawatt solar or wind park. Generally, CSP is the most labour-intensive technology followed by PV and WIND. For all technologies, the number of workers used to produce renewable electricity is much smaller than the number of workers used to build up a renewable energy park. For example, one individual operation and maintenance worker in electricity production is needed for every 26 equipment manufacturing workers in the PV sector. The labour intensity of renewable electricity production is higher. Finally, CSP generation is also highly labour-intensive. In fact, the large amount of capital required to produce CSP equipment makes it the most labour-intensive option overall.

Low investments in PV and low labour-intensity mean that only 7,700 manufacturing jobs are created in the PV scenario. Conversely, CSP equipment manufacturing employs 74,000 additional workers to produce renewable equipment in the CSP scenario. Wind equipment manufacturing is less labour-intensive than CSP and PV, however; the significant investment pays off and generates the most jobs.

Renewable electricity generation creates relatively few jobs, with almost all employment effects from renewable investment coming from equipment manufacturing. 
Moreover, unlike those in equipment manufacturing, jobs in electricity plants are largely reserved for semi-skilled and skilled workers; most of these workers must be sourced from other manufacturing subsectors as the renewable electricity sector grows. Lower skilled labourers mainly come from agriculture and services. Enhancing a renewable electricity industry in Egypt will therefore create new job opportunities for some sectors but will also impose significant adjustment costs on others, especially those in export agriculture and services. 


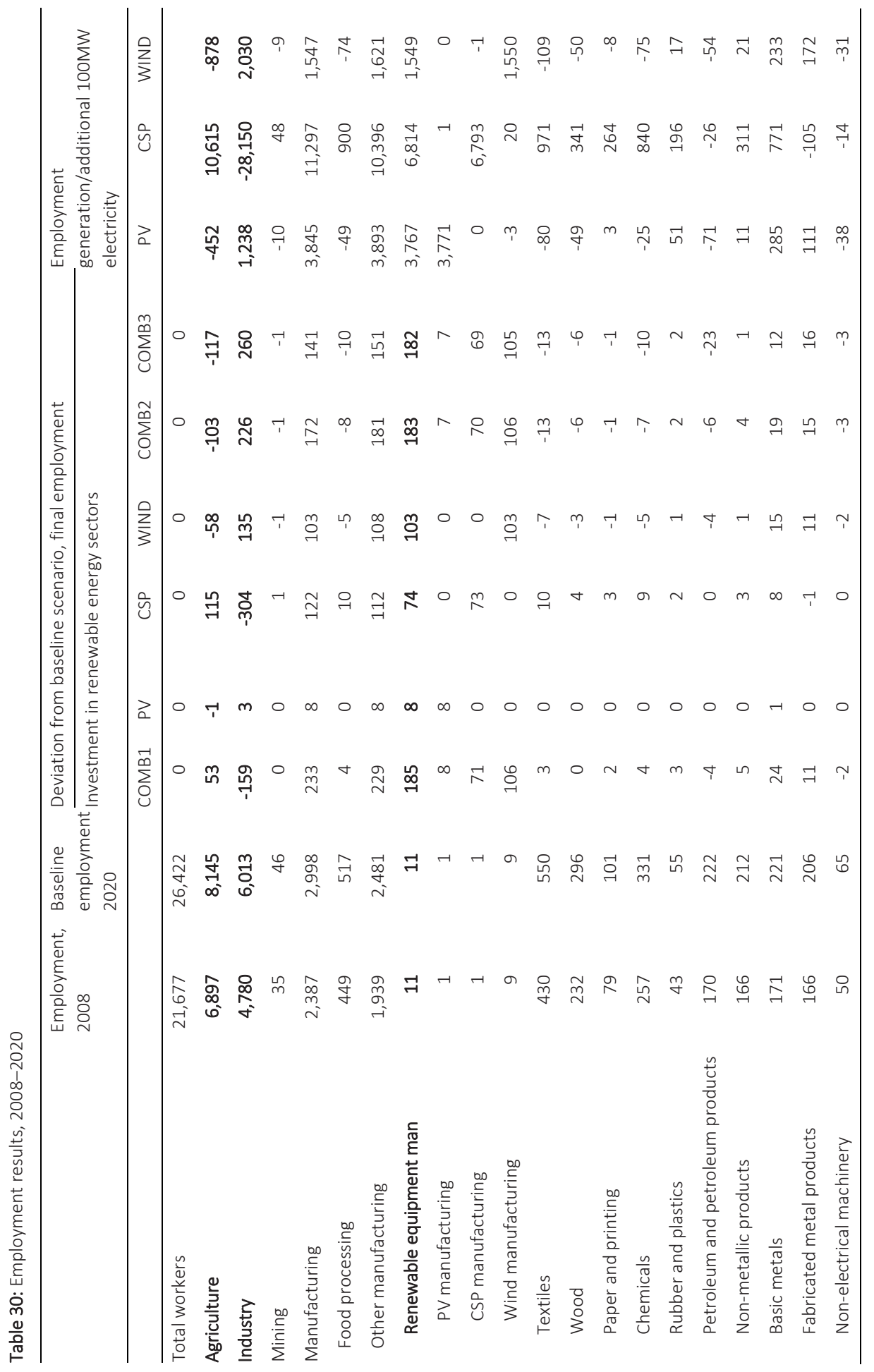




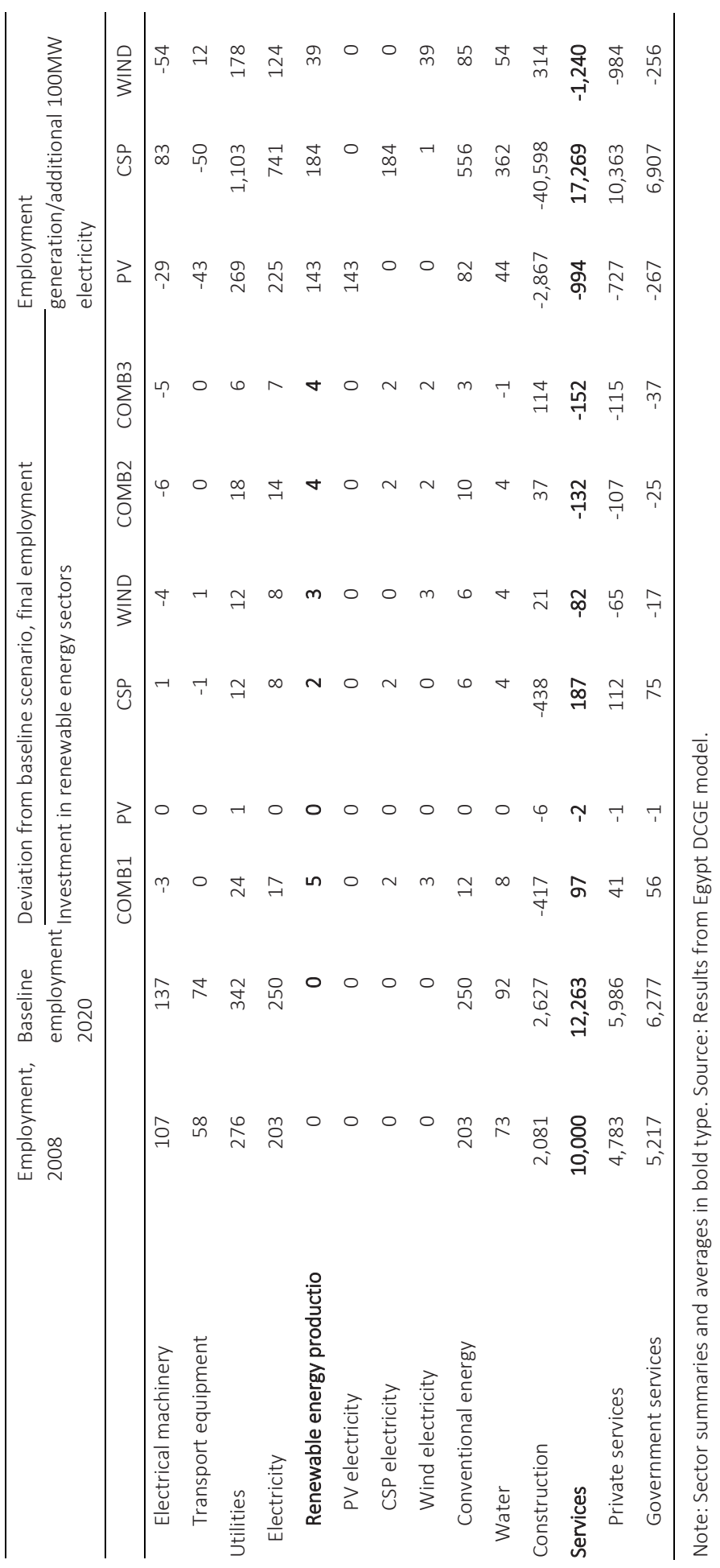




\subsubsection{Impacts on household incomes and poverty}

Investments in renewables increase national GDP and factor returns, causing household incomes to rise. Although this is true in all renewables scenarios, there are significant differences in the distributional impacts across household groups. Table 31 reports changes in households' equivalent variation, which is a welfare measure that controls for changes in prices. All rural quintiles benefit from the expansion of renewable energy production in Egypt. Furthermore, lower-income households actually see the most benefit because they receive a larger share of their income from labour, which has become relatively scarce as a result of the renewables expansion.

Urban households also benefit from an increase in the economy-wide returns to labour and capital and from the higher overall level of economic growth in the country. It is typically the middle of the urban income distribution that benefits the most, owing to the fact that these quintiles rely more heavily on labour wages for their incomes. Moreover, these households are typically endowed with semi-skilled and high-skilled labour, which is used fairly intensively in the renewable equipment manufacturing sectors (for example, as operators and technicians).

Table 31: Household per capita equivalent variation results, 2008-2020

\begin{tabular}{|c|c|c|c|c|c|c|c|c|}
\hline & \multirow{3}{*}{$\begin{array}{l}\text { Per-capita } \\
\text { consumption, } \\
2008 \text { (LE) }\end{array}$} & \multirow{3}{*}{$\begin{array}{l}\text { Baseline } \\
\text { growth (\%) }\end{array}$} & \multicolumn{6}{|c|}{ Deviation from baseline scenario growth rate (\%-point) } \\
\hline & & & \multicolumn{6}{|c|}{ Investment in renewable energy sectors } \\
\hline & & & COMB1 & PV & $\mathrm{CSP}$ & WIND & COMB2 & COMB3 \\
\hline Rural & $2,879.2$ & & & & & & & \\
\hline Quintile 1 & $2,207.5$ & 2.02 & 0.03 & 0.00 & -0.11 & 0.14 & 0.27 & 0.32 \\
\hline Quintile 2 & $2,443.1$ & 2.51 & 0.06 & 0.00 & -0.12 & 0.18 & 0.33 & 0.39 \\
\hline Quintile 3 & $2,648.4$ & 2.53 & 0.00 & 0.00 & -0.12 & 0.12 & 0.23 & 0.27 \\
\hline Quintile 4 & $2,925.3$ & 2.73 & -0.03 & 0.00 & -0.13 & 0.10 & 0.18 & 0.21 \\
\hline Quintile 5 & $3,591.0$ & 2.77 & -0.04 & 0.00 & -0.12 & 0.08 & 0.14 & 0.17 \\
\hline Urban & $4,715.3$ & & & & & & & \\
\hline Quintile 1 & 2,778.9 & 2.13 & -0.04 & 0.00 & -0.12 & 0.08 & 0.14 & 0.17 \\
\hline Quintile 2 & $3,144.2$ & 2.47 & -0.04 & 0.00 & -0.11 & 0.07 & 0.12 & 0.14 \\
\hline Quintile 3 & $3,701.6$ & 2.59 & -0.05 & 0.00 & -0.12 & 0.07 & 0.14 & 0.16 \\
\hline Quintile 4 & 4,496.1 & 2.69 & -0.04 & 0.00 & -0.12 & 0.08 & 0.14 & 0.16 \\
\hline Quintile 5 & $8,356.4$ & 2.76 & -0.06 & 0.00 & -0.11 & 0.05 & 0.10 & 0.11 \\
\hline
\end{tabular}

Source: Results from Egypt DCGE model.

Figure 31 shows the national distributional effects of the renewables strategy on households' equivalent variation. PV receives only a tiny share of the total investment volume of Egypt's renewable strategy and therefore generates very little additional value added in the economy, so its effects on household welfare are small. CSP and 
WIND are far more beneficial for households. Moreover, the welfare gains are evenly distributed across lower expenditure quintiles. Clearly, only if the renewables strategy is combined with a reduction of fuel subsidies will the strategy lead to significant improvements in income distribution. Lower-income households benefit the most from the expansion of overall activity in COMB3.

Figure 31: Change in per capita equivalent variation from baseline scenario by quintile, $2010-2020$

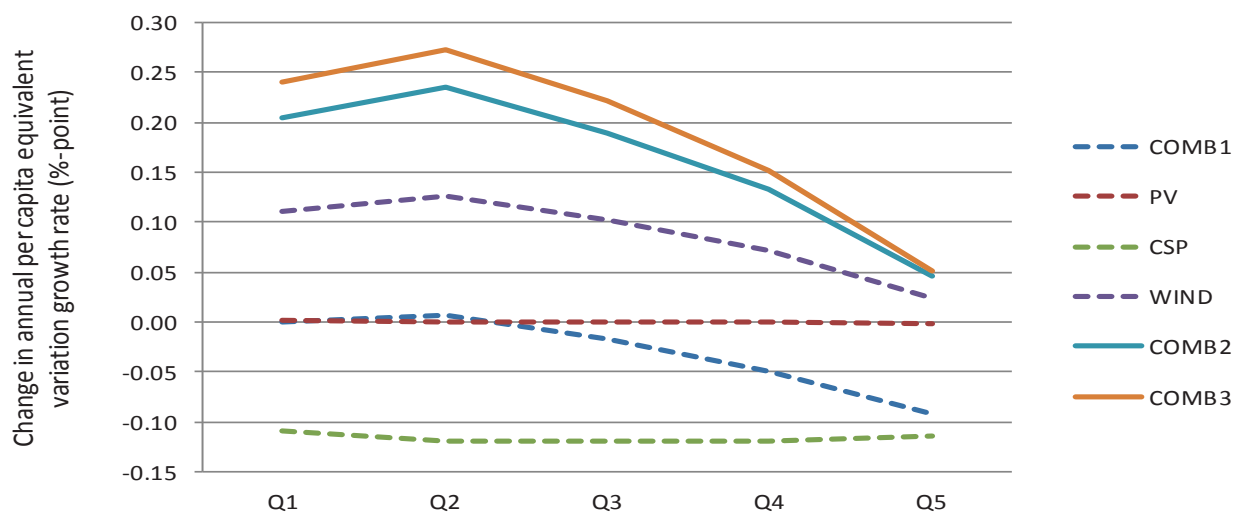

Note: Equivalent variation is a measure of household welfare that controls for changes in commodity prices. Source: Results from Egypt DCGE model and microsimulation model.

Table 32 reports changes in national and regional poverty rates for the various renewable scenarios. The headcount rate - which measures the share of the population below the poverty line - declines the most under the renewable energy cum fuel sector liberalisation scenario (COMB3). There is almost no poverty reduction, however, in the unilateral Egyptian renewables strategy (COMB1). Yet, if undertaken within a global climate protection system (COMB2) and combined with a reduction of fuel subsidies (COMB3), prices for conventional electricity and higher public investment in Egypt will benefit poor households, which earn most of their income from the provision of low-skilled labour to construction and the production of consumer nondurables, including food and agricultural products. 
Table 32: Poverty results, $2008-2020$

\begin{tabular}{|c|c|c|c|c|c|c|c|c|}
\hline & \multicolumn{2}{|c|}{ Poverty rate, Baseline } & \multirow{2}{*}{\multicolumn{6}{|c|}{$\frac{\text { Deviation from final baseline scenario poverty rate (\%age point) }}{\text { Investment in renewable energy sectors }}$}} \\
\hline & \multirow[t]{2}{*}{ 2008(\%) } & \multirow{2}{*}{$\begin{array}{l}\text { poverty, } \\
2020(\%)\end{array}$} & & & & & & \\
\hline & & & COMB1 & PV & CSP & WIND & COMB2 & COMB3 \\
\hline Headcount (PO) & 21.8 & 12.2 & 0.0 & 0.0 & 0.3 & -0.3 & -0.5 & -0.7 \\
\hline RURAL & 29.9 & 17.1 & -0.1 & 0.0 & 0.3 & -0.5 & -0.9 & -1.1 \\
\hline URBAN & 10.4 & 5.3 & 0.1 & 0.0 & 0.2 & -0.1 & -0.1 & -0.2 \\
\hline Gap (P1) & 4.5 & 2.3 & 0.0 & 0.0 & 0.1 & -0.1 & -0.2 & -0.2 \\
\hline RURAL & 6.2 & 3.2 & 0.0 & 0.0 & 0.1 & -0.1 & -0.3 & -0.3 \\
\hline URBAN & 2.0 & 1.0 & 0.0 & 0.0 & 0.0 & 0.0 & -0.1 & -0.1 \\
\hline Squared gap (P2) & 1.4 & 0.7 & 0.0 & 0.0 & 0.0 & -0.1 & -0.1 & -0.1 \\
\hline RURAL & 2.0 & 0.9 & 0.0 & 0.0 & 0.1 & 0.0 & -0.1 & -0.1 \\
\hline URBAN & 0.6 & 0.3 & 0.0 & 0.0 & 0.0 & 0.0 & 0.0 & 0.0 \\
\hline
\end{tabular}

Source: Results from Egypt DCGE model and microsimulation model.

\subsection{Conclusion}

The renewable energy CGE model for Egypt is new. It allows the assessment of potential economic benefits of a low-carbon energy transition in Egypt in detail by comparing different technology pathways, in a country where energy security is a major issue and renewable energy resources are abundant.

Investments in renewable energy can be beneficial for economic growth, employment, and the poor. However, the quantity and quality of those benefits depend on the natural conditions, opportunity costs of conventional energy, structure of the economy and institutional capacity to implement energy sector reform.

While the recent political transition has put many initiatives on hold, we suggest that, under certain conditions, fostering the renewable energy strategy may be a promising way to provide an urgently needed impetus for the ailing economy. More specifically, the evidence-based results of our research lend themselves to the following recommendations.

Egypt should focus on the generation of wind power. Not only is wind power the sole renewable energy source which is competitive without subsidies, but also it is among the most favourable for economic growth, employment, and poverty reduction.

An export-led renewable energy strategy can threaten some of the positive effects through exchange rate appreciation. Results suggest that if all renewable energy planned under the Egyptian strategy is exported, these may compose up to $20 \%$ of all exports by 2020. Given the related appreciation of the real exchange rate and potential loss of jobs in other export sectors, it is advisable to consume a significant amount of additional energy domestically. Yet, it is important to mention that the FDI inflows, which finance the additional renewable energy production infrastructure, lead to an 
increase in domestic capital stock, which leaves the country with an expansion of domestic sectors as well. The results show how Egypt's RE strategy, and the FDI used to finance this strategy, is strengthening local income at macroeconomic, sectoral, functional and household level.

The implementation of the renewables strategy should be accompanied by a reduction of energy subsidies. Energy subsidies distort markets and render most of the renewable energies uncompetitive; they also contribute to Egypt's high budget deficit. Reducing energy subsidies would not only lower the deficit but also support the development of renewable energies.

While investments in renewable energy have positive growth and employment effects, their impact on the poor is modest. Thus, if poverty reduction is the main policy goal, other policies that support broader-based growth and targeted social safety nets are probably more appropriate. However, switching to a renewable energy system could be beneficial from an economic perspective, which provides the necessary justification for facilitating large scale renewable energy infrastructure investments.

Finally, it is important to stress that the implementation of a renewable energy strategy can be very challenging and complex in terms of industrialisation of the relevant sectors. For example, wind turbines and solar panels designed for a European climate may not function well in Egypt's desert region, where temperatures are higher and the sandy environment is a concern. Adapting and developing new technologies is a challenge for the industry. If these potential caveats are carefully assessed, however, sun and wind have the potential to support economic development.

Further research on assessing economic benefits could be done by using a similar CGE model set-up with a focus on different countries and by applying different technology pathways. Also, additional RET could be explicitly added, such as bioenergy or hydro-power. 


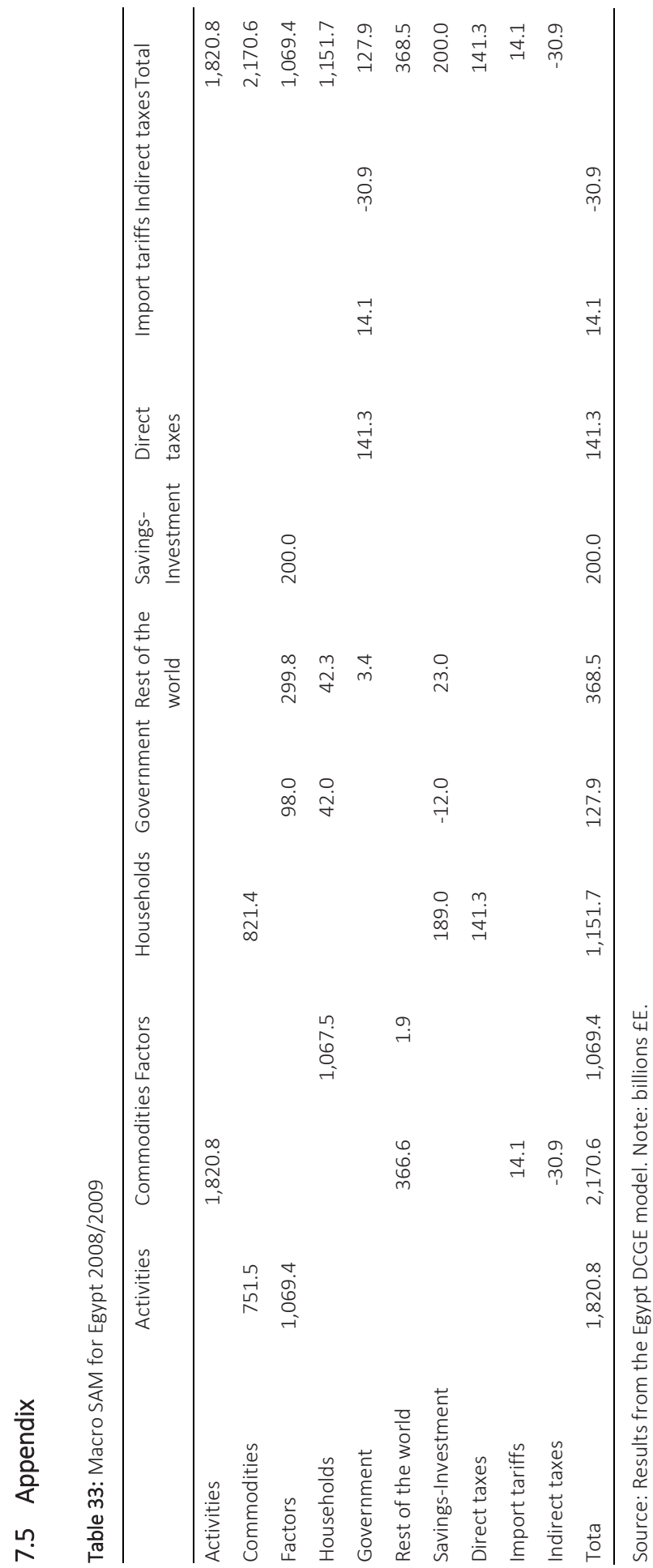


CHAPTER 8

References 
Adeoti, J. O. (2002). Building Technological Capability in the Less Developed Countries: The Role of a National System of Innovation. Science and Public Policy, Vol. 29, No.2, pp.95-104.

Adeoti, J. O., Odekunle, S. O. \& Adeyinka, F. M. (2010). Tackling Innovation Deficit: An Analysis of UniversityFirm Interaction in Nigeria. Evergreen Publishers, Ibadan, Nigeria.

AfDB (2012). Clean Energy Development in Egypt. African Development Bank, Tunis, Tunisia.

AfDB (2013). African Economic Outlook: Egypt. African Development Bank, Tunis, Tunisia.

Altenburg, T., \& Pegels, A. (2012). Sustainability-oriented innovation systems - managing the green transformation. Innovation and Development, Vol. 2, No. 1, 5-22.

Amer, H. (2009). Renewable Energy Strategy for 2020 and Regulatory Framework: Egyptian Electric Regulatory and Consumer Protection Agency. Global Workshop on Grid Connected Renewable Energy, Washington, DC.

Baker, L., Newell, P., \& Phillips, J. (2014). The Political Economy of Energy Transitions: The Case of South Africa. New Political Economy, 19:6, 791-818.

Bartels, F. L. (2007). Energy, industry modernization and poverty reduction: a review and analysis of current policy thinking. Research and Statistics Branch Staff Working Paper 06/2007, UNIDO, Vienna, 2007.

Barua, P., Tawney, L., \& Weischer, L. (2012). Delivering on the Green Economy: The role of policy in developing successful domestic solar and wind industries. Washington, DC: World Resources Institute.

Bauer, N., Edenhofer, O., Jakob, M., Ludig, S., \& Lüken, M. (2008). Electricity Trade among World Regions. Trade Theoretic Foundation of Energy-Economy Models. Potsdam Institute for Climate Impact Research (PIK), Germany, November 2008.

Bell, M. (1990). Continuing industrialisation, climate change and international technology transfer. Brighton: University of Sussex; 1990.

Bell, M. (1997). Technology transfer to transition countries: are there lessons from the experience of the postwar industrializing countries? In Dyker, D. A. (editor). The Technology of Transition: Science and Technology Policies for Transition Countries. Central European University Press, Budapest.

Bell, M. (2009). Innovation capabilities and directions of development. STEPS Working Paper 33, STEPS Centre, Brighton, 2009.

Bell, M. (2012). International Technology Transfer, Innovation Capabilities and Sustainable Directions of Development. In Ockwell, D. and Mallett, A. (eds). Low carbon Technology Transfer: from Rhetoric to Reality. Abingdon: Routledge.

Bell, M., \& Figueiredo, P. (2012). Innovation capability building and learning mechanisms in latecomer firms: recent empirical contributions and implications for research. Canadian Journal of Development Studies, Vol. 33(1): 14-40.

Bell, M., \& Pavitt, K. (1996). The Development of Technological Capabilities. In Haque, I., Bell, M., Dahlman, C., Lall, S., Pavitt, K. (eds.). Trade, Technology, and International Competitiveness. The World Bank, Washington, DC.

Bouma, J., Bulte, E., \& van Soest, D. (2008). Trust and cooperation: Social capital and community resource management. Journal of Environmental Economics and Management, 56(2), 155-166.

Breisinger, C., Al-Riffai, P., Ecker, O., Abuismail, R., Waite, J., Abdelwahab, N., Zohery, A., El-Laithy, H., \& Armanious, D. (2013). Tackling Egypt's Rising Food Insecurity in Times of Transition. Joint Country Policy Note. World Food Programme, Country Office Arab Republic of Egypt, and International Food Policy Research Institute, Washington, DC.

Brewer, T. L. (2008). Climate change technology transfer: a new paradigm and policy agenda. Climate Policy 8 , 516-526.

Brunel, C., \& Levinson, A. (2013). Measuring Environmental Regulatory stringency. OECD Trade and Environmental Working Papers, 2013/05, OECD Publishing.

Byrne R., Smith A., Watson J., \& Ockwell, D. (2011). Energy pathways in low-carbon development: from technology transfer to socio-technical transformation. STEPS Working Paper 46. Brighton: STEPS Centre; 2011. 
Byrne, R., Ockwell, D., Urama, K., Ozor, N., Kirumba, E., Ely, A., Becker, S., \& Gollwitzer, L. (2014). Sustainable energy for whom? Governing pro-poor, low carbon pathways to development: Lessons from solar PV in Kenya. STEPS Centre.

Byrne, R., Smith, A., Watson, J., \& Ockwell, D. (2012). Energy pathways in low carbon development: the need to go beyond technology transfer. In Ockwell, D. and Mallett, A. (eds). Low Carbon Technology Transfer: from Rhetoric to Reality. Abingdon: Routledge.

Calzadilla, A., Wiebelt, M., Blohmke, J., \& Klepper, G. (2013). Desert Power 2050: Regional and Sectoral Impacts of Renewable Electricity Production in Europe, the Middle East, and North Africa. Kiel Working Paper 1891. Kiel Institute for the World Economy.

CAPMAS (2013a). Supply and Use Tables for 2008/2009. Mimeo. Cairo, Egypt.

CAPMAS (2013b). Household Income, Expenditure and Consumption Survey, HIECS (2008/2009). Version 1.0 of the licensed data files, provided by the Economic Research Forum (see www.erfdataportal.com/index. php/catalog).

Carlsson, B., \& Stankiewicz, R. (1991). On the nature, function, and composition of Technological Systems. Journal of Evolutionary Economics 1(2): 93-118

CCAP (2011). Nationally Appropriate Mitigation Actions (NAMAs) and the Clean Development Mechanism (CDM). Center for Clean Air Policy, Washington DC, 2011.

Chaudhary, A., Sagar, A., \& Mathur, A. (2012). Innovating for energy efficiency: a perspective from India. Innovation and Development, 2:1, 45-66.

Chow, J., Kopp, R. J., \& Portney, P. R. (2003). Energy Resources and Global Development. Science 203, 15281531.

Cimoli, M., Dosi, G., \& Stiglitz, J. (eds.) (2009). Industrial Policy and Development: The Political Economy of Capabilities Accumulation. Oxford University Press, New York NY

Cohen, B. J. (2014). Advanced Introduction to International Political Economy. Cheltenham and Northampton, Edward Elgar.

Cohen, W. M., \& Levinthal, D. A. (1989). Innovation and learning: the two faces of R\&D. The Economic Journal 99, 569-596.

Cohen, W. M., Levinthal, D. A. (1990). Absorptive capacity: a new perspective on learning and innovation, Adm. Sci. Q. 35 (1) (1990) 128-152.

Collier, P., \& Venables, A. (2012). Greening Africa? Technologies, endowments and the latecomer effect. Energy Economics 34 (2012) S75-S84.

Cooper, C., \& Sovacool, B. (2013). Miracle or mirage? The promise and peril of desert energy part 1. Renewable Energy 50 (2013) 628-636.

Crow, D. A. (2010). Policy Entrepreneurs, Issue Experts, and Water Rights Policy Change in Colorado. Review of Policy Research, 27(3): 299-315.

DECC (2009). UK-India collaborative study on the transfer of low carbon technology: Phase II Final Report. Department of Energy and Climate Change. London, UK.

Dechezleprêtre, A., Glachant, M., \& Ménière, Y. (2008). The Clean Development Mechanism and the International Diffusion of Technologies: An Empirical Study. Energy Policy, Vol. 36, pp 1273-1283.

del Río González, P. (2005) Analysing the factors influencing clean technology adoption: a study of the Spanish pulp and paper industry. Business Strategy and the Environment 14(1): 20-37.

Deuten, J. (2003). Cosmopolitanising Technologies: A Study of Four Emerging Technological Regimes. PhD thesis, University of Twente, Enschede.

Dii (2012). Desert Power 2050: Perspectives on a Sustainable Power System for EUMENA. Dii GmbH, Munich, 2012.

Dii (2013). The Economic Impacts of Desert Power. Socio-economic aspects of an EUMENA renewable energy transition. Dii GmbH, Munich, 2013.

Doranova, A., Costa, I., \& Duysters, G. (2009). Knowledge Base Determinants of Technology Sourcing in the Clean Development Mechanism Projects. UNU-MERIT Working Papers. \#2009-015.

Doranova, A., Costa, I., \& Duysters, G. (2011). Absorptive capacity in technological learning in clean development mechanism projects. UNU-MERIT Working Papers. \#2011-010. 
Dubash, N. K., Raghunandan, D., Sant, G., \& Sreenivas, A. (2013). Indian Climate Change Policy: Exploring a CoBenefits Based Approach. Economic \& Political Weekly XLVIII (22): 47-61.

EBRD (2012). Egypt Country Assessment. European Bank for Reconstruction and Development, 2012 (see www.ebrd.com/downloads/country/technical_assessments/egypt-assess.pdf).

EBRD (2015). How to solve Egypt's energy problems. News. European Bank for Reconstruction and Development, 2015 (see

http://www.ebrd.com/news/2015/how-to-solve-egypts-energy-problems.html).

Economic Consulting Associates (ECA), Ramboll (2012). Technical and Economic Study for Development of Small Scale Grid Connected Renewable Energy in Kenya. Ministry of Energy, Nairobi.

EIA (2013). Egypt: Overview. US Energy Information Administration, Washington, DC.

ESI (2005). 2005 Environmental Sustainability Index, Benchmarking National Environmental Stewardship. The Environmental Performance Measurement Project, Yale University, 2005.

Esty, D., \& Porter, M. (2005). National environmental performance: an empirical analysis of policy results and determinants. Environment and Development Economics 10: 391-434 C. 2005 Cambridge University Press.

European Commission (2011). Energy Roadmap 2050: Communication from the Commission to the European Parliament, the Council, the European Economic and Social Committee and the Committee of the Regions, European Commission, Brussels, 2011.

FAO (2012). Food Outlook: Global market analysis. Global Information and Early Warning System on Food and Agriculture (GIEWS). Food and Agriculture Organization (http://reliefweb.int/sites/reliefweb.int/files/re sources/al993e00.pdf).

FAO (2013). Save and Grow: Cassava. A Guide to Sustainable Production Intensification. Food and Agriculture Organization, 2013.

Ferioli, F., Schoots, K., \& van der Zwaan, B. C. C. (2009). Use and limitations of learning curves for energy technology policy: A component-learning hypothesis. Energy Policy 37, 2525-2535.

Fisher-Vanden K., Jefferson G.H., Ma, J. M., \& Xu, J. (2006). Technology development and energy productivity in China. Energy Econ 2006; 28:690-750.

Fleiter, T., Schleich, J., \& Ravivangpong, P. (2012). Adoption of energy-efficiency measures in SMEs-An empirical analysis based on energy audit data from Germany. Energy Policy 51: 863-875.

Foa, R. (2008). Social Institutions and Human Development. World Bank, (No. 006).

Fouquet, R., \& Pearson, P. (2012). Editorial Past and prospective energy transitions: Insights from history. Energy Policy 50 (2012) 1-7.

Fragkos, P., Kouvaritakis, N., \& Capros, P. (2012), Prospects for Energy Supply and Demand in the Southern Mediterranean, MEDPRO Technical Report No. 22 (interim version), CEPS, Brussels.

Fredriksson, P. G., \& Svensson, J. (2003). Political instability, corruption and policy formation: The case of environmental policy. Journal of Public Economics, 87(7/8), 1383-1405.

Freeman, C. (1995). The 'National System of Innovation' in Historical Perspective. Cambridge Journal of Economics, Vol. 19, pp. 5-24.

Frondel, M., Schmidt, C. M., \& Vance, C. (2012). Germany's Solar Cell Promotion: An Unfolding Disaster. Ruhr Economic Papers N. 353, Bochum, Germany, 2012.

GEA (Global Energy Assessment) (2012). Towards a Sustainable Future. Cambridge University Press: Cambridge, England, UK, and New York, NY, USA.

Geels, F. (2002). Technological transitions as evolutionary reconfiguration processes: a multi-level perspective and a case-study. Research Policy, 31, 1257-74.

GEF (2008). Elaboration of a Strategic Program to Scale Up the Level of Investment in the Transfer of Environmentally Sound Technologies, GEF / C.34 / 5.Rev.1. Global Environment Facility, Washington, DC.

GEF (2010). OPS4: Progress Towards Impact - Fourth Overall Performance Study of the GEF. Global Environment Facility, Washington, DC.

German Aerospace Centre (2005). Concentrating Solar Power for the Mediterranean Region. German Aerospace Centre (DLR), Institute of Technical Thermodynamics, Section Systems Analysis and Technology Assessment, Stuttgart, 2005. 
GIZ (2011). Green Growth Opportunities and Requirements in Egypt. Deutsche Gesellschaft für Internationale Zusammenarbeit (GIZ) GmbH, Eschborn, Germany, 2011.

GIZ (2012). Support for Moroccan Solar Plan. Solar Technologies in Morocco - Industry and Value Chain Assessment. Deutsche Gesellschaft für Internationale Zusammenarbeit (GIZ) GmbH, Eschborn, Germany, 2012.

Government of Kenya (2007). Kenya Vision 2030. The Government of Kenya.

Haenlein, M., \& Kaplan, A. (2004). A Beginner's Guide to Partial Least Square Analysis. Understanding Statistics, 3(4), 283-297, Lawrence Erlbaum Associates, Inc.

Hair, J., Hult, G., Ringle, C., \& Sarstedt, M. (2014). A Primer on Partial Least Squares Structural Equation Modeling (PLS-SEM). SAGE Publications. 2014.

Hall, A. J. (2005). Capacity Development for Agricultural Biotechnology in Developing Countries: An Innovation Systems view of what it is and how to develop it. Journal of International Development, Vol. 19, No.5, pp. 611-630.

Haller, M., Ludig, S., \& Bauer, N. (2012). Decarbonization scenarios for the EU and MENA power system: Considering spatial distribution and short term dynamics of renewable generation. Energy Policy 47, 282-290.

Haščič, I., Johnstone, N., \& Kalamova, M. (2009). Environmental Policy Flexibility, Search and Innovation. Czech Journal of Economics and Finance (Finance a uver), Charles University Prague, Faculty of Social Sciences, vol. 59(5), pages 426-441, December.

Hassan, N. (1997). Successfully transfer HPI proprietary technology. Hydrocarbon Processing 76(2), 91-99.

Hau, E. (2008). Windkraftanlagen. Grundlagen, Technik, Einsatz, Wirtschaftlichkeit. 4. Vollständig neu bearbeitete Auflage. Springer-Verlag Berlin Heidelberg.

Hawila, D., Hossain, A., Kennedy, S., \& Mezher, T. (2014). Renewable energy readiness assessment for North African countries. Renewable and Sustainable Energy Reviews 33 (2014) 128-140.

Hedger, M. (2012). Stagnation or Regeneration. Technology transfer in the United Nations Framework Convention on Climate Change (UNFCCC). In Ockwell, D. and Mallett, A. (eds). Low Carbon Technology Transfer: from Rhetoric to Reality. Abingdon: Routledge.

Hekkert M., Suurs R., Negro S., Kuhlmann S., \& Smits, R. (2007). Functions of innovation systems: A new approach for analysing technological change. Technological Forecasting and Social Change, 74(4):413432

Henseler, J., \& Fassott, G. (2010). Testing Moderating Effects in PLS Path Models: An Illustration of Available Procedures. In Esposito Vinzi, V., Chin, W., Henseler J., Wang, H. (eds.): Handbook of Partial Least Squares: Concepts, Methods and Applications. Berlin, S. 713-735.

Henseler, J., Ringle, C., \& Sinkovics, R. (2009). The use of partial least squares path modelling in international marketing. Advances in International Marketing, Volume 20, 277-319.

Hirschhausen, C. v. (2010). Developing a Supergrid. In Moselle, B., Padilla, J., Schmalensee, R. (eds.). Harnessing Renewable Energy in Electric Power Systems: Theory, Practice, Policy. RFF Press.

Hoefnagels, R., Junginger, M., Panzer, C., Resch, G., \& Held, A. (2011). RE-Shaping. Shaping an effective and efficient European renewable energy market. 2011.

Holzinger, K., Knill, C., \& Arts, B. (eds.) (2008). Environmental Governance in Europe. The Impact of International Institutions and Trade. Cambridge: Cambridge University Press.

Huenteler, J., \& Schmidt, T. (2013). Considering technology characteristics in bottom-up climate governance A framework to inform green growth strategies and technology transfer institutions. Conference paper at Earth System Governance Conference, Tokyo, January 29-31, 2013

Ibrahim, A. (2012). Renewable Energy Sources in the Egyptian Electricity Market: A Review. Renewable and Sustainable Energy Reviews, 16, 2016-2030.

ICTSD (2011). The Climate Technology Mechanism: Issues and Challenges. International Centre for Trade and Sustainable Development (ICTSD), London, UK.

IEA (2009). World Energy Outlook 2009. International Energy Agency, Paris.

IEA (2012). World Energy Outlook 2012. International Energy Agency, Paris.

IEA (2012a). CO Emissions from Fuel Combustion: Highlights 2012. International Energy Agency, Paris. 
IEA (2012b). Energy Technology Perspectives 2012: Pathways to a Clean Energy System. International Energy Agency, Paris.

IEA (2013). Tracking Clean Energy Progress 2013: IEA Input to the Clean Energy Ministerial. International Energy Agency, Paris.

IISD (2015). Recent Developments in Egypt's Fuel Subsidy Reform Process. Research Report by Laura M. James. International Institute for Sustainable Development, April 2015.

ILO (2013). Key Indicators of the Labour Market (KILM 8). International Labour Organisation, Geneva (see www.ilo.org/empelm/what/WCMS_114240/lang--en/index.htm).

Ilskog E., Kjellstroem B., Gullberg M., Katyega, M., \& Chambala, W. (2005). Electrification co-operatives bring new light to rural Tanzania. Energy Policy 33: 1299-1307.

IPCC (2007). Working Group III contribution to the Intergovernmental Panel on Climate Change $4^{\text {th }}$ Assessment Report. Climate Change 2007: Mitigation of Climate Change. Intergovernmental Panel on Climate Change, Geneva.

IPCC (2011). Special Report on Renewable Energy Sources and Climate Change Mitigation. Cambridge, England, UK.

IPCC (2014). Working Group III contribution to the IPCC 5th Assessment Report. Climate Change 2014: Mitigation of Climate Change. Chapter 1. Intergovernmental Panel on Climate Change, Geneva.

IRENA (2013). Renewable Power Generation, Costs in 2012: An Overview. International Renewable Energy Agency, Abu Dhabi, 2013.

ISS (2011). Indices of Social Development. International Institute of Social Studies. Erasmus University Rotterdam, 2011.

Jablonski, S., Tarhini, M., Touati, M., Garcia, D., \& Alario, J. (2012). The Mediterranean Solar Plan: Project proposals for renewable energy in the Mediterranean Partner Countries region. Energy Policy 44 (2012) 291-300.

Jacob, K., \& Volkery, A. (2006). Modelling Capacities for Environmental Policy-making in Global Environmental Politics. In Jänicke, M., Jacob, K. (eds.). Environmental Governance in Global Perspective, New Approaches to Ecological Modernisation. Freie Universität Berlin. FFU Report 01-2006.

Jacobsson, S., \& Johnson, A. (2000). The diffusion of renewable energy technology: An analytical framework and key issues for research. Energy Policy 28(9): 625-640.

Jaenicke, M. (1992). Conditions for Environmental Policy Success: An International Comparison. The Environmentalist, 12: 1, 47-58.

Jaenicke, M. (1997). The Political System's Capacity for Environmental Policy. In Jaenicke, M., Weidner, H. (eds.) (1997). National Environmental Policies: a Comparative Study of Capacity-Building. Springer: Berlin.

Jaenicke, M. (2005). Trend-Setters in Environmental Policy: the Character and Role of Pioneer Countries. European Environment 15, 129-142 (2005).

Jaenicke, M., Kunig, P., \& Stitzel, M. (1999). http://www.hugendubel-marktplatz.de/B\%C3\%BCcher/Angebote/ titel=Lern-\%2Bund\%2BArbeitsbuch\%2BUmweltpolitik .Dietz Verlag, 1999.

Jakob, M., Haller, M., \& Marschinski, R. (2012). Will History Repeat Itself? Economic Convergence and Convergence in Energy Use Patterns. Energy Economics 34, 95-104.

Jan, I. (2012). What makes people adopt improved cookstoves? Empirical evidence from rural northwest Pakistan, Renew. Sust. Energ. Rev. 16 (2012) 3200-3205.

Jayne, T., Zuli, B., \& Nijhoff, J. (2006). Stabilizing Food markets in eastern and Southern Africa. Journal of Food Policy, 31: 328-341.

JCEE (2012). Renewable Energy and Energy Efficiency in Egypt. Joint Committee for Renewable Energy and Energy Efficiency, Cairo, Egypt (accessed 26.3.2016 www.jcee-eg.net/reee.asp?sublinkID=30).

JICA (2015). JICA's Assistance for Electricity Sector. Japan International Cooperation Agency, April 24, 2015.

Kalamova, M., \& Johnstone, N. (2011). Environmental Policy Stringency and Foreign Direct Investment. OECD Environment Working Papers, No. 33, OECD Publishing. 
Kanie, N., Nishimoto, H., Hijioka, Y., \& Kameyama, Y. (2010). Allocation and architecture in climate governance beyond Kyoto: lessons from interdisciplinary research on target setting. International Environmental Agreements: Politics, Law and Economics 10, 299-315.

Kaplinsky, R., \& Farooki, M. (2011). What are the implications for global value chains when the market shifts from the north to the south? International Journal of Technological Learning, Innovation and Development, Vol. 4(1/2/3): 13-38.

Kemp, R. (2001). Opportunities for a green industrial policy from an evolutionary technology perspective. In Binder, M., Janicke, M., Petschow, U. (eds.), Green Industrial Restructuring: International Case Studies and Theoretical Interpretations. Springer, Berlin, pp. 151-170.

Kemp, R., \& Loorbach, D. (2003). Governance for Sustainability Through Transition Management. Paper for Open Meeting of the Human Dimensions of Global Environmental Change Research Community, 2003, Montreal.

Kenya Power (2012). Annual Report and Financial Statements. Financial Year Ended 30 June 2013. Kenya Power and Lighting Co. Ltd.

Kern, F. (2014). What can the sustainability transitions literature learn from international political economy scholarship? Towards a joint research agenda. Science Policy Research Unit. University of Sussex.

Kern, K, Joergens, H., \& Jaenicke, M. (2001). The Diffusion of Environmental Policy Innovations. A Contribution to the Globalisation of Environmental Policy. Discussion Paper FS II 01-302. Social Science Research Centre: Berlin.

Kiplagat, J. K., Wang, R. Z., \& Li, T. X. (2011). Renewable energy in Kenya: Resource potential and status of exploitation. Renewable and Sustainable Energy Reviews 15 (2011) 2960-2973.

Kirimi, L., Sitko, N., Jayne, T., Karin, F., Muyanga, M., Sheahan, M., Flock, J., \& Bor, G. (2011). A farm gate to consumer value chain analysis of Kenya's maize marketing system. Department of Agricultural, Food, and Resource Economics, Michigan University.

Knack, S., \& Keefer, P. (1997). Does Social Capital Have an Economic Payoff? A Cross-Country Investigation. The Quarterly Journal of Economics, 112(4), $1251-1288$.

Kruss, G., Adeoti, J. O., \& Nabudere, D. (2012). Universities and Knowledge-based Development in subSaharan Africa: Comparing University-Firm Interaction in Nigeria, Uganda and South Africa. Journal of Development Studies, Vol. 48, No.4, pp.516-530.

Lall, S. (1992). Technological capabilities and industrialization, World Dev. 20 (2) (1992) 165-186.

Lall, S. (1998). Investment, technology and international competitiveness. In Dunning, J. H., \& Hamdan, K. A. (eds.). The New Globalism and Developing Countries. United Nations University, Tokyo, New York, Paris.

Lall, S., \& Pietrobelli, C. (eds.) (2002). Competitiveness and National Technology Systems: An Introduction. In Failing to Compete. Technology Development and Technology Systems in Africa. Edwar Elgar, 2002.

Layzer, J. (2002). The environmental case: Translating values into policy. Washington, DC: Congressional Quarterly Press.

Legler, H., Krawczyk, O., Rammer, C., Löhlein, H., \& Frietsch, R. (2007). Zur technologischen Leistungsfähigkeit der deutschen Umweltschutzwirtschaft im internationalen Vergleich. In Bundesministerium für Bildung und Forschung (BMBF) (Ed.), Studien zum deutschen Innovationssystem Nr. 20-2007, Berlin.

Lehr, U. (2012). Green Energy for the Arab Spring - Employment from renewable energy and energy efficiency in Tunisia. Ecomod 2012, International Conference on Economic Modeling, Sevilla, Spain.

Lema, A., \& Lema, R. (2013). Technology transfer in the clean development mechanism: Insights from wind power. Global Environmental Change, Vol. 23, pp 301-313.

Lema, R., \& Lema, A. (2012). Technology transfer? The rise of China and India in green technology sectors. Innovation and Development, 2:1, 23-44.

Lema, R., Johnson, B., Andersen, A., Lundvall, B.-Å., \& Chaudhary, A. (2014). Low-Carbon Innovation and Development. Globelics Thematic Review, Aalborg University Press, Aalborg.

Lewis, N., \& Nocera, D. (2006). Powering the planet: chemical challenges in solar energy utilization. Proceedings of the national academy of sciences of the United States of America 10343. PNAS; October, 2006.

Liefferink, D., Arts, B., Kamstra, J., \& Ooijevaar, J. (2009). Leaders and laggards in environmental policy: a quantitative analysis of domestic policy outputs. Journal of European Public Policy, 16:5, 677-700. 
Lockwood, M. (2013). The political economy of low-carbon development. In Urban, F., \& Nordensvard, J., (eds.) Low-carbon development: key issues. Key Issues in Environment and Sustainability. Routledge, Oxford, UK.

Lofgren, H., Lee Harris, R., \& Robinson, S. (2002). A standard computable general equilibrium (CGE) model in GAMS. International Food Policy Research Institute. Washington DC.

Lundvall, B.-Å. (1988). Innovation as an interactive process: From user-producer interaction to the national innovation systems. In G. Dosi, C. Freeman, R.R. Nelson, G. Silverberg, \& Soete, L. (eds). Technology and economic theory. London: Pinter Publishers, 349-369.

Lundvall, B.-Å. (1992). National Systems of Innovation: Towards a Theory of Innovation and Interactive Learning. London: Pinter Publishers. London.

Lundvall, B.-Å. (2011). Notes on innovation systems and economic development. Innovation and Development, 1:1, 25-38.

Lundvall, B.-Å., Joseph, K. J., \& Chaminade, C. (2009). Handbook on Innovation Systems and Developing Countries: Building Domestic Capabilities in a Global Context. Edward Elgar Publishing, Cheltenham, UK and Northampton, MA.

Magnusson, T., Tell, F., \& Watson, J. (2005). From CoPS to mass production? Capabilities and innovation in power generation equipment manufacturing. Industrial and Corporate Change 14, 1-26.

Malerba, F. (2002). Sectoral Systems of Innovation and Production. Research Policy, Vol.31, pp.247-264.

Malerba, F. (2004). Sectoral Systems of Innovation: Concepts, Issues and Analyses of Six Major Sectors in Europe. Cambridge University Press.

Malerba, F., \& Nelson, R. R. (eds.) (2012). Economic Development as a Learning Process: Variation Across Sectoral Systems. Edward Elgar, Cheltenham UK and Northampton, USA.

Malerba, F., \& Nelson, R. R., (2011). Learning and catching up in different sectoral systems: evidence from six industries. Industrial and Corporate Change 20, 1645-1675.

Mallett, A. (2013). Technology cooperation for sustainable energy: a review of pathways. WIREs Energy Environment 2013, 2: 234-250.

Marechal, K., \& Lazaric, N. (2010). Overcoming inertia: insights from evolutionary economics into improved energy and climate policies. Climate Policy 10, 103-119.

Mason, M. (1999). Environmental Democracy. Earthscan Publications Ltd.

Massetti, E., \& Ricci, E. C. (2013). An assessment of the optimal timing and size of investments in concentrated solar power. Energy Econ. 38, 186-203.

McNerney J., \& Farmer J. (2011). Role of design complexity in technology improvement. Proceedings of the National Academy of Sciences (PNAS) 2011:9008-13.

Meadowcroft, J. (2011). Engaging with the politics of sustainability transitions. Environmental Innovation and Societal Transitions 1(1): 70-75.

Metz, B., Davidson, O. R., Martens, J., van Rooijen, S. N. M., \& van Wie McGrory, L. (eds.) (2000). Methodological and Technological Issues in Technology Transfer. IPCC Special Reports on Climate Change, Cambridge University Press, New York.

Metz, B., Davidson, O., Bosch, P., Dave, R., \& Meyer, L. (Eds.) (2007).Climate Change 2007: Mitigation. Contribution of Working Group III to the Fourth Assessment Report of the Intergovernmental Panel on Climate Change. Cambridge University Press, Cambridge, UK.

Ministry of Energy (2012). Feed-in-Tariffs policy for wind, biomass, small hydro, geothermal, biogas and solar, 2nd revision. Government of the Republic of Kenya. December 2012.

Montalvo, C. (2002). Environmental Policy and Technological Innovation. Why Do Firms Adopt or Reject New Technologies? Cheltenham, Northampton, Edward Elgar.

Morris, M., Kaplinsky, R., \& Kaplan, D. (2012). "One thing leads to another"-Commodities, linkages and industrial development. Resources Policy, 37(4): 408-416.

Muchie, M., Gammeltoft, P., \& Lundvall, B.-Å. (2003). Putting Africa First: The making of African Innovation Systems. Aalborg University Press, Aalborg, Denmark.

Murphy, J. T. (2001). Making the energy transition in rural east Africa: is leapfrogging an alternative? Technological. Forecasting and Socical Change, 68 (2) (2001) 173-193. 
Muyanga, M., Jayne, T., Kodhek, G., \& Ariga, J. (2004). Staple Food Consumption Patterns in Urban Kenya: Trends and Policy Implications. Working paper 19. Tegemeo Institute of Agricultural Policy and Development, Egerton University.

Nelson, R. R., \& Rosenberg, N. (1993). Technical Innovation and National Systems. In Nelson, R. R. (ed.), National Innovation Systems. Oxford University Press, New York.

Nelson, R., \& Pack, H. (1999). The Asian Miracle and modern growth theory. The Economic Journal, Vol. 109 (July), pp. 416-36.

Nes, W., \& Nhete, T. (2007). Biogas for Better Life. An African initiative. Report, 2007.

Newell, P., Philips, J., \& Pueyo, A. (2013). The political economy of low carbon energy in Kenya - Climate Compatible Development in Kenya. Political economy briefing. STEPS Centre.

Nitzl, C. (2010). Eine anwenderorientierte Einführung in die Partial Least Square (PLS)-Methode. Arbeitspapier Nr. 21, Industrielles Management, Universität Hamburg. 2010.

Oates, W. E., \& Portney, P. R. (2003). The political economy of environmental policy. In K. G. Mäler \& J. R. Vincent (eds.), Handbook of Environmental Economics, edition 1, volume 1, chapter 8, pages 325-354 Elsevier.

Ockwell, D. G., Ely, A., Mallett, A., Johnson, O., \& Watson, J. (2009). Low-carbon development: the role of local innovative capabilities, STEPS Working Paper 31, STEPS Centre and Sussex Energy Group, SPRU, University of Sussex, Brighton, 2009.

Ockwell, D., \& Mallett, A. (2013). Low carbon innovation and technology transfer. In Urban, F., \& Nordensvard, J. (eds.). Low carbon development: key issues. Key Issues in Environment and Sustainability. Routledge, Oxford, UK.

Ockwell, D., Haum, R., Mallett, A., \& Watson, J. (2010). Intellectual property rights and low carbon technology transfer: Conflicting discourses of diffusion and development. Global Environmental Change, Vol. 20, pp 729-738.

Ockwell, D., Watson, J., MacKerron, G., Pal, P., \& Yamin, F. (2008). Key policy considerations for facilitating low carbon technology transfer to developing countries. Energy Policy 36 (11) (2008) 4104-4115.

OECD (1994). Capacity Development in Environment. Organisation for Economic Co-operation and Development. 1994.

OECD (2011a). Towards Green Growth. Organisation for Economic Co-operation and Development. 2011.

OECD (2011b). OECD Green Growth Studies: Energy. Organisation for Economic Co-operation and Development. 2011.

OECD (2011c). Fostering Innovation for Green Growth. Organisation for Economic Co-operation and Development. 2011.

OECD (2012). Optimising Investment Incentives for Renewable Energy Projects in MENA: A Stocktaking Report. MENA-OECD Task Force on Energy and Infrastructure, Working Paper. Organisation for Economic Co-operation and Development. 2012.

OECD (2013). Renewable Energies in the Middle East and North Africa. Policies to Support Private Investment. Organisation for Economic Co-operation and Development. 2013.

Olsen, K. H. (2007). The Clean Development Mechanism's Contribution to Sustainable Development: A Review of the Literature. Climatic Change 84 (1): 59-73.

Olsen, K. H. (2013). Sustainable Development Impact of NAMAs: An integrated approach to assessment of cobenefits based on experience with the CDM. UNEP Ris $\varnothing$ Centre. Low Carbon Development Working Paper No. 11, November 2013.

Oludhe, C. (2013). Kenya: A Natural Outlook: Geo-Environmental Resources and Hazards. Chapter 10. Developments in Earth Surface Processes. Elsevier, 2013.

Oyedepo, S. O. (2012). Energy Efficiency and Conservation Measures: Tools for Sustainable Energy Development in Nigeria. International Journal of Energy Engineering, Vol. 2, Issue 3, pp 86-98.

Pellegrini, L., \& Gerlagh, R. (2006). Corruption, Democracy, and Environmental Policy: An Empirical Contribution to the Debate. The Journal of Environment Development 2006 15: 332.

PIND (2011). Report on cassava value chain analysis in the Niger Delta. Foundation for partnership initiatives in the Niger Delta. Nigeria. 
Popp, D. (2012). The Role of Technological Change in Green Growth. Policy Research Working Paper 6239, World Bank.

Popp, D., Hascic, I., \& Medhi, N. (2011). Technology and the Diffusion of Renewable Energy. Energy Economics 33 (4), 648-662.

RCREEE (2012). Egypt Renewable Energy Country Profile. Regional Center for Renewable Energy and Energy Efficiency. Cairo, Egypt.

Reinert, E. (2007). How Rich Countries Got Rich and Why Poor Countries Stay Poor. Constable \& Robinson, London.

REN21 (2013a). Renewables 2013 Global Status Report. REN21 Secretariat, Paris.

REN21 (2013b). MENA Renewables Status Report. REN21 Secretariat, Paris.

Ringle, C., Sarstedt, M., \& Mooi, E. (2010). Chapter 2 Response-Based Segmentation Using Finite Mixture Partial Least Squares Theoretical Foundations and an Application to American Customer Satisfaction Index Data. In Stahlbock, R., Crone, S., Lessmann, S. (eds.). Data Mining: Special Issue in Annals of Information Systems. Springer.

Ringle, C., Wende, S., \& Will, S. (2005). SmartPLS 2.0 (M3) Beta, Hamburg 2005, (see http://www.smartpls.de). Rip, A., \& Kemp, R. (1998). Technological change. In Rayner, S. and Malone, E. (eds). Human Choices and Climate Change. Vol. 2: Resources and Technology. Columbus, $\mathrm{OH}$ : Battelle.

Roberts, T., \& Parks, B. (2007). A Climate of Injustice Global Inequality, North-South Politics, and Climate Policy. The MIT Press, Cambridge.

Rodrik, D. (ed.) (2003). In Search of Prosperity: Analytic Narratives on Economic Growth. Princeton University Press.

Rogers, E. (2003). Diffusion of Innovation (Fifth Edition). New York: The Free Press.

Rogers, J., Hansen, R., \& Graham, S. (2011). Innovation in Rural Energy Delivery: Accelerating Energy Access Through SMEs. Report. Navigant Consulting and Soluz USA, Massachusetts, 2011.

Rutovitz, J., \& Atherton, A. (2009). Energy Sector Jobs to 2030: A Global Analysis. Prepared for Greenpeace International by the Institute for Sustainable Futures. University of Technology, Sydney, Australia.

Sabatier, P. A. (1999). Theories of the Policy Process. Westview: Boulder, CO.

Sagar, A. (2013). Organizing for low-carbon innovation in developing countries. Paper presented at the Globelics Seminar on Learning, Innovation and Low-Carbon Development, Copenhagen, Denmark.

Sauter, R., \& Watson, J. (2008). Technology Leapfrogging: A Review of the Evidence. A report for DFID Sussex Energy Group SPRU (Science and Technology Policy Research), University of Sussex, 3rd October 2008.

Schmid, G. (2012). Technology transfer in the Clean Development Mechanism: the role of host country characteristics. Climate Policy, Vol. 12, Issue 6, pp. 722-740.

Schneider M., Holzer A., \& Hoffmann, V. H. (2008). Understanding the CDM's contribution to technology transfer. Energy Policy 2008; 36: 2930-8.

Seres, S. (2007). Analysis of technology transfer in CDM Projects. Prepared for UNFCCC Registration \& Issuance Unit CDM/SDM; 2007.

Siegel, J. R., \& Rahman, A. (2011). The Diffusion of Off-grid Solar Photovoltaic Technology in Rural Bangladesh. Energy, Climate, and Innovation Program (ECI), Centre for International Environment and Resource Policy (CIERP), The Fletcher School, Tufts University, 2011.

Slocum, A., \& Rubin, E. S. (2008). Understanding Radical Technology Innovation and its Application to $\mathrm{CO}_{2}$ Capture R\&D: Interim Report, Volume One - Literature Review, Department of Engineering and Public Policy, Paper 66, Carnegie Mellon University, Pittsburgh, PA. (accessed on 26.3.2016: http://repository.cmu.edu/epp/66).

Smith, A., Voß, J., \& Grin, J. (2010). Innovation studies and sustainability transitions: the allure of the multilevel perspective and its challenges. Research Policy 39 (4), 435-448.

Smith, K. (2000). Innovation as a Systemic Phenomenon: Rethinking the Role of Policy. Enterprise \& Innovation Management Studies, 1 (1), 73-102.

Solomon, S. (ed.) (2007). Report of the Intergovernmental Panel on Climate Change. Cambridge University Press, Cambridge, UK and New York, USA, 996 pp. 
Sorrell, S., O'Malley, E., Schleich, J., \& Scott, S. (2004). The economics of energy efficiency - Barriers to costeffective investment. Cheltenham: Edward Elgar.

Stern, L. N., \& Noble, I. (2008). Achieving low carbon growth for the world. World Bank. World Bank; 2008. (https://openknowledge.worldbank.org/handle/10986/4525).

Stern, N. (2006). Stern Review on the economics of climate change. London: HM Treasury.

Sutter, C., \& Parreno, C. (2007). Does the Current Clean Development Mechanism (CDM) Deliver Its Sustainable Development Claim? An Analysis of Officially Registered CDM Projects. Climatic Change 84 (1): 7590.

Szirmai, A. (2015). Growth and Stagnation: Theories and Experiences. In Szirmai, A. (ed.). Socio-Economic Development. Chapter 3. 2nd edition, Cambridge University Press.

Tews, K. (2005). The diffusion of environmental policy innovations: cornerstones of an analytical framework. European Environment, 15(2), 63-79.

Tigabu, A., Berkhout, F., \& van Beukering, P. (2015). Technology innovation systems and technology diffusion: Adoption of bio-digestion in an emerging innovation system in Rwanda. Technological Forecasting \& Social Change, Vol. 90, 318-330.

Trieb, F., Schillings, C., Pregger, T., \& O’Sullivan, M. (2012). Solar electricity imports from the Middle East and North Africa to Europe. Energy Policy, Volume 42, March 2012, 341-353.

UfM (2008). UfM Summit - Paris Declaration July $13^{\text {th }}$. Union for the Mediterranean Secretariat, 2008.

Ummel, K., \& Wheeler, D. (2008). Desert Power: The Economics of Solar Thermal Electricity For Europe, North Africa, and the Middle East. Working Paper Number 156, December 2008, Center for Global Development.

UNEP (2011). Towards a green economy: pathways to sustainable development and poverty eradication. United Nations Environment Programme, 2011. (http://www.unep.org/greeneconomy).

UNEP (2013). Terminal Evaluation of the UNEP/GEF Project on "Greening the Tea Industry in East Africa". Evaluation Office. United Nations Environment Programme, 2013.

UNFCCC (2008). Report of the Conference of the Parties on its thirteenth session. United Nations Framework Convention on Climate Change (UNFCCC), Bali, Indonesia.

UNFCCC (2010a). Handbook for Conducting Technology Needs Assessment for Climate Change. United Nations Framework Convention on Climate Change (UNFCCC), 2010.

UNFCCC (2010b). The Cancun Agreements: Outcome of the work of the Ad Hoc Working Group on Long-term Cooperative Action under the Convention. Decision 1/CP.16. United Nations Framework Convention on Climate Change (UNFCCC), 2010. (accessed on 26.3.2016: http://unfccc.int/resource/docs/2010/cop16/ eng/07a01.pdf\#page=18).

UNFCCC (2011). Report of the Conference of the Parties on its sixteenth session. Cancun, Mexico. United Nations Framework Convention on Climate Change (UNFCCC), 2011.

UNIDO (2011). Industrial energy efficiency for sustainable wealth creation: Capturing environmental, economic and social dividends. Industrial Development Report 2011, United Nations Industrial Development Organization (UNIDO), Vienna, Austria.

UNIDO (2014). Diffusion Strategy of Green Technology and Green Industry in Africa. A study of Renewable Energy Technology Market and Energy Efficiency Adoption in Maize and Cassava processing Industries in Kenya and Nigeria, a report of UNU-MERIT, UNIDO and KEEI.

Unruh, G. (2000). Understanding carbon lock-in. Energy Policy, 28, 817-3.

Urban, F., \& Nordensvard, J. (2013). Low-carbon development: Origins, concepts and key issues. In Urban, F., \& Nordensvard, J. (eds.). Low-carbon development: key issues. Key Issues in Environment and Sustainability. Routledge, Oxford, UK.

Verbeken, A.-M. (2012). Low-Carbon Technology transfer under the Climate Change Convention. In Ockwell, D. and Mallett, A. (eds). Low Carbon Technology Transfer: from Rhetoric to Reality. Abingdon: Routledge.

Vidican, G. (2012). Building Domestic Capabilities in Renewable Energy. A Case Study of Egypt. Deutsches Institut für Entwicklungspolitik, Bonn, Germany. 
Vidican, G., McElvaney, L., Samulewicz, D., \& Yasser, A. (2012). An empirical examination of the development of a solar innovation system in the United Arab Emirates. Energy for Sustainable Development 16 (2012) 179-188.

Vogel, D. (1986). National Styles of Regulation. Environmental Policy in Great Britain and the United States. Cornell University Press.

Vogel, D. (1997). Trading up and governing across: transnational governance and environmental protection. Journal of European Public Policy, 4:4, 556-571.

von Hippel, E. (1986). Lead users: a source of novel product concepts, Management Science. 32: 791-805.

Wachira, P. (2012). Change Management Practice at Kenya Tea Development Agency (KTDA). School of Business, University of Nairobi. October, 2012.

Walz, R. \& Nowak Delgado, J. (2012) Different routes to technology acquisition and innovation system building? China's and India's wind turbine industries. Innovation and Development, 2:1, 87-109.

Wang-Helmreich, H., Sterk, W., Wehnert, T., \& Arens, C. (2011). Current Developments in Pilot Nationally Appropriate Mitigation Actions of Developing Countries (NAMAs). JIKO Policy Paper 01/2011, August 2011.

Watson, J., \& Sauter, R. (2011). Sustainable Innovation through Leapfrogging: A Review of Evidence. International Journal of Technology and Globalisation 5 (3/4), pp. 170-189.

WEF (2012). The Financial Development Report 2012. Insight Report. World Economic Forum, Geneva, Switzerland.

WEF (2014). Executive Opinion Survey. World Economic Forum, Geneva, Switzerland.

Weiber, R., \& Mühlhaus, D. (2010). Strukturgleichungsmodellierung: Eine anwendungsorientierte Einführung in die Kausalanalyse mit Hilfe von AMOS, SmartPLS und SPSS. Springer, Berlin/Heidelberg 2010.

Withagen, C., \& Smulders, S. (2012). Green Growth. Lessons from Growth Theory. The World Bank Development Research Group. Policy Research Working Paper 6230. The World Bank, Washington, DC.

Wlokas, H., Rennkamp, B., Torres, B., Winkler, M., Boyd, H., Tyler, A., \& Fedorsky, C. (2012). Low carbon development and poverty: Exploring poverty alleviating mitigation action in developing countries. MAPS. Cape Town, Energy Research Centre 1-30.

Wong, K. (2013). Partial Least Squares Structural Equation Modeling (PLS-SEM) Techniques Using SmartPLS. Marketing Bulletin, 2013, 24, Technical Note 1.

World Bank (2010). World Development Report 2010: Development and Climate Change. The World Bank, Washington, DC, 2010.

World Bank (2011). Middle East and North Africa region assessment of the local manufacturing potential for concentrated solar power (CSP) projects: report conducted for the World Bank by Ernst \& Young et Associés, Fraunhofer Institute for Solar Energy Systems. The World Bank, Washington, DC, 2011.

World Bank (2012). Natural Resource Abundance, Growth, and Diversification in the Middle East and North Africa: The Effects of Natural Resources and the Role of Policies. Ndiamé Diop, Daniela Marotta, and Jaime de Melo (eds.). The World Bank, Washington, DC, 2012.

World Bank (2013). Greening Global Value Chains Innovation and the International Diffusion of Technologies and Knowledge. Policy Research Working Paper 6467. The World Bank, Washington, DC, 2013.

World Commission on Environment and Development (1987). Our Common Future. Oxford: Oxford University Press.

Žížalová P., \& Blažek, J. (2010). Biotechnology industry in metropolitan region of Prague: a cluster within a fragmented innovation system? Department of Social Geography and Regional Development, Faculty of Science, Charles University in Prague. 2010. 


\section{CHAPTER 9}

\section{Summary}

Environmental regulation and low-carbon development A study into regulatory determinants, innovation systems and economic outcomes 
It is widely accepted that the consequences of anthropogenic climate change are among the greatest challenges of the future of humankind. Climate change has potentially devastating impacts on human health, agriculture, and water resources as well as ecosystems. Every world region will be affected, particularly least-developed countries, which are least able to adapt to climate change and thus will be affected the most severely.

Human behaviour and its consequences on the climate, the effects of climate change on humans, and potential benefits of mitigating climate change impacts, have been recognised as important areas of inquiry in the academic literature and given high priority in national and global politics. In order to change policies and unlock countries from high-carbon infrastructure pathways, it is important to detect the barriers and obstacles to low-carbon transitions, and develop arguments for a shift to low-carbon growth pathways by thoroughly studying the economic benefits of a transition towards more climate friendly economies.

The present research can be located in the area of political economy and sustainability transition research. It includes conceptual approaches as well as empirical case studies with real world observations to derive implications. Quantitative modelling approaches are used to explore interdependencies between drivers for environmental regulation, as well as the magnitude of economic benefits induced by a clean energy transition. Broad, and also concrete, country-specific analyses are applied.

Analysing the causal structure of environmental regulation drivers is a conceptual, introductory part of the thesis. The analysis of technology transfer mechanisms is undertaken from a technology-specific, component-level viewpoint, by explaining theoretically the missing aspects of economic development oriented technology needs assessments. For the questions on how to facilitate the technology transfer and adoption of renewable energy and energy efficiency technology in developing countries, a conceptual discussion and concrete case studies are provided. Similarly, with regard to the inquiry on economic benefits of a low-carbon transition, a broad, region-wide empirical analysis, as well as a concrete country analysis, is conducted.

Following the introductory Chapter 1, Chapter 2 provides an exploratory assessment of the concept of the drivers for environmentally friendly regulation. Determinants of environmental regulation have been identified in different studies. The chapter takes the analysis of environmental policy determinants one step further by also studying the interaction effects between the determinants and by trying to disentangle the causal structure behind environmental regulation. The work relates to the political economy of environmental regulation and capacity for environmental policy (Jaenicke, 2005). A political economy approach is adequate to study environmental regulation aspects as it puts particular emphasis on the nexus between political and economic actors. The different actors and institutions in the environmental policymaking process are described (Jaenicke, 2005). Further, the dynamic interactions between the different institutions in the policymaking process towards environmental regulation are assessed with the aid of 
an econometric, structural equation model for a data set of 47 countries. The calculation of different path coefficients between institutions and actors allows exploring the theory by using empirical, cross-country data.

Green advocacy and governance capacity emerge as the main structural determinants of environmental regulation quality. Internet access is found to have a positive influence on environmental regulation through green advocacy and governance capacity. The influence of green advocacy and governance capacity on international environmental governance is through national environmental policy and not the other way around, while international environmental governance is influenced by factors outside the scope of this thesis. We also find that green advocacy depends more on the presence of a competitive green industry than on environmental activism, with respect to the influence on environmental policymaking. Statistically, 92\% of the variance of environmental policy output could be explained by our structural model, which is very high for a model incorporating only structural factors.

Chapter 3 comprises an analysis of technology transfer mechanisms of renewable energy technologies (RET) by anchoring the research in the field of innovation systems in developing countries (see Lundvall et al., 2009). Merging climate change mitigation and sustainable development in developing countries is pivotal for a lasting transition towards low-carbon growth pathways. This chapter combines technology transfer and technology-specific aspects with sustainable development objectives.

It investigates to what degree technology transfer mechanisms have acknowledged climate technology-specific properties in its current frameworks and how those fit together with innovation systems in developing countries. Detailed technology complexity aspects, which are the core of the technology transfer and innovation systems discussion in this chapter, are combined with economic development potentials. Climate change policy usually emphasises the different actors and mechanisms, while the subject matter or hardware characteristics itself, in this case the RET concentrated solar power (CSP), solar photovoltaics (PV) and wind, are viewed through the perspective of the innovation systems and climate governance discussion. It is crucial to consider technology characteristics in order to design technology transfer mechanisms which foster technology transfer and at the same time serve the sustainable development aspect of international climate policy.

Local technology needs and socio-technical circumstances are important in order that economic development is induced by technology transfer. Yet, they are not sufficient conditions alone for successful technology transfer which delivers economic development. A strategy for the adoption of technologies, as well as a broadening of the domestic technology manufacturing base, needs to also consider the technology properties themselves in greater detail. The technology transfer process should emphasise the economic developmental purpose as well as the technical properties of technologies. Thus, I propose a detailed assessment of the technology and its potential for being adopted by suggesting that technology complexity assessments should be detailed in a 
way that they can also approximate potential contributions to domestic economic development. I describe how the evaluation of technology complexity and of potential economic development, determined by domestic demand for manufactured goods and services, which could lead to job creation and added value, could be used to inform policymakers and create targeted technology transfer policies.

Chapter 4 offers a case study on the diffusion of renewable energy technologies in Kenya. The research is embedded in technology diffusion theory in an innovation systems approach. It considers policy frameworks and user preferences (as proposed by Lema and Lema, 2012) in conjunction with concrete examples of solar PV, wind and modern bioenergy technology adoption in Kenya. A detailed country survey has been conducted among RET importers and end users in order to discover the barriers and drivers for RET adoption in the country. The focus of the stakeholder survey is the supply and uptake of small-scale solar PV, wind and modern bioenergy technology. The chapter gives insights into the roles of different stakeholders in the technology adoption process in Kenya and highlights the barriers to adoption of the technology. As a result, the theory on technology diffusion is enriched by experiences from survey participants, giving insights into how domestic participants in the technology adoption process circumvent obstacles to technology deployment in the country. Findings on how weak innovation systems institutions can be substituted or bridged by national actors are added to the innovation systems literature.

It is found that the diffusion of renewable energy in Kenya is to a large extent dependent on government policies and regulatory conditions, that the RET sectors are young, that solar and biomass are the biggest two RET markets with solar PV being based on foreign technology and biomass mostly based on domestic technology and know-how. The foreign components of RE technologies are mainly from China and India, which means that they are based on South-South trade. Capabilities for adoption and technology creation in Kenya are revealed to be weak. Obstacles to the adoption of RET are: poor access to finance; an insecure business environment; low levels of foreign direct investment (FDI); and high tariffs. The weak innovation system made suppliers to bundle services of financial help, training, maintenance and repair, which has proven to be quite effective.

Chapter 5 presents an investigation of the uptake of energy efficiency measures in agro-industrial sectors in sub-Saharan Africa in Nigeria and Kenya. The case studies conducted in the cassava and maize processing industries give deeper insights into the analytical approach of energy efficiency technology oriented innovation systems.

The goal of the analysis is to obtain deeper insight into the problems associated with the adoption of energy efficiency measures in the context of weak environmental policy regimes and weak innovation systems. We investigate the responses of African actors and foreign suppliers to such problems. The overall conclusions are: i) that such measures are mainly undertaken for economic reasons (cost-efficiency); ii) that few firms studied in the agro-industries have adopted sophisticated energy savings 
measures and that of those who have, many encountered problems; iii) that there is a great reliance on foreign suppliers of energy efficiency technologies in the case of maize millers, but less so in cassava processing; iv) that informal mechanisms of learning are an important source of learning; and finally $v$ ) that universities and public research institutes are unimportant sources of knowledge. In the cassava sector, complex technologies are commonly supplied as part of a package involving training and financial advice, with an important role for consultants and external advisors.

Chapter 6 provides a quantitative, economic development analysis of the transition to RET in the Middle East and North Africa (MENA) region and the export of electricity from solar and wind power across the Mediterranean to Europe. It applies a quantitative economic modelling framework in order to detect the major macroeconomic developments induced by RET deployment. A computational general equilibrium (CGE) model for the whole world is used, with a special focus on the MENA region, and adjusted for RET. This analysis is characteristic due to its disaggregated assessment of various RET in the model, such as CSP, PV, and wind as well as the exchange of large amounts of electricity between geographical regions. With regard to RET deployment trajectories, exogenous, renewable energy potential data are utilised. These are based on spatial and hourly renewable energy potential analysis for the MENA region. Other studies use only annual data (see Fragkos et al., 2012, Haller et al., 2012).

Different climate policy scenarios are compared with a baseline, business as usual scenario in order to discuss relative changes in levels of economic development until 2050. Findings of this analysis provide insights on the relative economic benefits for the MENA region if it were to embark on a low-carbon growth pathway and facilitate the exchange of electricity across the Mediterranean.

In some world regions the transition to RET has been framed in ambitious crosscountry cooperative visions, like in the MENA region. It aims at providing electricity from renewable energy sources from MENA's desert regions to the entire MENA region as well as exporting electricity to Europe. According to other power system studies an integrated EUMENA power system based on more than $90 \%$ renewables is technically feasible and economically viable. We use a global general equilibrium model to evaluate the economic effects of a clean energy transition across the Mediterranean from a broader perspective, including not only the energy system but also the repercussions in other sectors of the economies. The results show that the extent of the wider economic costs and benefits for both regions depend on the type of strategy adopted to finance the build-up of the power plants and the expected development of the cost of the different technologies. Furthermore, the viability of a transition towards renewable energy depends to a great extent on the international climate policy.

Chapter 7 examines the economic benefits of a renewable energy transition in Egypt. While Chapter 6 gives an overview of potential macroeconomic development trajectories in the MENA region until the year 2050, Chapter 7 provides a detailed economic development assessment of Egypt. An Egypt-specific CGE model is used and 
expanded by CSP, PV and wind technology. With regard to income distribution changes, and the poverty alleviation potential of RET diffusion up to the year 2020, this chapter provides insights into the economic aspects of RET deployment by assessing the renewable energy strategy of the Government of Egypt. The CGE model used in this chapter differentiates five types of households and tests different technology build-up trajectories. The economic effects of realising domestic renewable energy targets are calculated and compared with a business as usual scenario.

The recent political transition in Egypt has put much-needed policy reforms on hold. This chapter suggests that under certain conditions, fostering the national renewable energy strategy may be a promising way of giving an ailing economy an urgently needed boost by transforming its national renewable energy targets into reality. Based on the literature and results of the CGE model, we recommend that Egypt should focus especially on the generation of wind power. At least part of the newly produced energy should be channelled to the domestic market to ease existing supply constraints and to avoid excessive exchange rate appreciation. In addition, to maximise the benefits of renewable energy sources, the renewable energy strategy should be accompanied by a reduction of energy subsidies, which has already begun. 
CHAPTER 10

\section{Valorisation}




\section{Relevance and target groups}

The research results are relevant in several ways. They add to existing insights into environmental policymaking, technology transfer and renewable energy based economic development in qualitative and quantitative ways.

First, they provide insights into the mechanisms behind environmental policymaking and try to prove political economy theory. The drivers of environmental regulation and influences on national level have rarely been studied in the past. The research provides important information for policymakers as well as civil society and the private sector industry.

Policymakers can retrieve information from the research findings on how different interest groups and institutions interact in the policymaking process with regard to environmental regulation. Civil society can use the information in order to improve their strategic work in lobbying for their interests in the environmental policymaking process. Industry can benefit from the insights with regard to their own lobbying activity, by learning how different institutions and actors behave, and about their own influence in the environmental policymaking process. It also helps them to sharpen their influence and role in the policymaking process. The social relevance is high, as the research results shall improve transparency of the policymaking process, in which industry lobbying is dominant and the balance of powers between stakeholders can be uneven.

Second, the research informs climate policymakers how they could improve climate policy in order to foster economic development in developing countries alongside with the adoption of climate change mitigation technologies. The research detects weaknesses in the design of climate mitigation technology transfer mechanisms with regard to developing countries and provides suggestions on how those mechanisms can be improved and adapted to the needs of developing countries. The purpose of the research is to: i) illustrate that technology transfer must take into account technology specifics on a technology component or technology system level; and ii) demonstrate the potential to add value within an economy by sourcing technology from the domestic industrial sector; while at the same time being country-specific. Those findings could potentially help maximise the economic benefits of RET transfer in developing countries and increase the domestic value added in RET manufacturing sectors in developing countries.

Case study results give insights into the role and importance of technology suppliers within the innovation systems framework of RET deployment in technology adopting countries. Those results are directly applicable for renewable energy policy designs aiming to improve the deployment of RET and overcome institutional shortcomings within the innovation systems of developing countries. Similarly, the interactions of actors and technology, as well as the knowledge transfer routes with regard to energy efficiency technologies, are assessed. It highlights success factors for energy efficiency uptake in developing countries. 
Third, the research gives insights into the potential contribution to economic growth in developing countries that a renewable energy transition could make. This can be used as a reference for developing countries committed to RET diffusion. Green growth pathways are described for the Middle East and North Africa (MENA) region, as well as for Egypt as an example of a country in the midst of a renewable energy transition. Results give promising insights that the transition to RET can be beneficial under certain circumstances. Policymakers and consultants likewise can utilise those insights for the design of renewable energy deployment pathways.

Research results are of interest to policymakers and policy consultants as well as civil society advocates. Policymakers can learn how the different institutions and groups interact in environmental policymaking. Further, policymakers get insights into the potential obstacles and benefits of a transition to RET in their country. Policy consultants can use the assessment of barriers and technology specifics of the clean technology transfer process to advise governments, technology providers and infrastructure project developers alike. Civil society advocates can learn how their interests are channelled in the environmental policymaking process and what the barriers and potential benefits of a renewable energy transition are.

\section{Activities and products}

Insights into the drivers of environmental regulation can help environmental lobby groups and policymakers to increase their influence. It could be applied in lobbying activity and policy advice. The research results on the assessment of technology transfer policies could be used as guidance for consulting and capacity building activities in developing countries. Further, they can aid in the design of national technology adoption policies and spur the diffusion of renewable energy and energy efficiency technologies in developing countries by strengthening various institutions and actors in the technology adoption process.

The insights into the potential for green growth can be used in the renewable energy transformation process in the MENA region and beyond to convince governments, stakeholders and the broader community about the potential economic benefits of a renewable energy transition. Those findings clearly contribute to the public debate about renewable energy based green growth in general and the economic and sustainable transition in the MENA region in particular. Civil society, non-governmental organisations and political stakeholders can make use of the research findings in order to further strengthen the renewable energy and energy efficiency transition in the region and beyond, and gain from a growing market in the region. The economic modelling approaches used in this thesis can be expanded to other world regions and used for consulting purposes or green growth policymaking objectives in different geographical contexts. 
The research results on economic impacts from renewable energy deployment have been presented at the Economic Research Forum (ERF, Cairo) in 2014 and the DIE / PEGNet conference in March 2014.

\section{Innovation}

Results on the drivers of environmental regulation are new in the sense that structural equation modelling has been rarely applied in the political science area. This approach could be used commercially for policy analysis and consulting activities.

The results regarding the technology component complexity assessment in relation to the technology transfer mechanisms are innovative. Component disaggregation is new in the context of technology complexity assessment, technology transfer and global climate policy. As yet, technology transfer mechanisms have not inspected technologies on a component basis. This is recommended when the technology sub-systems can be categorised and differentiated by their degree of technology complexity. Based on this disaggregation approach, country-specific and technology-specific technology transfer and diffusion pathways can be described, and tailored accordingly to be congruent with national, component-specific innovation capabilities.

The work on green growth modelling is innovative as it has been a novelty to disaggregate the electricity sector in a Computable General Equilibrium model by introducing CSP, PV, and Wind technology into the modelling environment and also the trade of electricity between world regions/countries in such a model.

\section{Schedule and implementation}

Currently there are no plans for valorisation of the above mentioned research results and methods. 
CHAPTER 11

Acknowledgement 
Ever since I began studying at university, I have wanted to get grips with how global environmental challenges could be managed. Several people supported me along the way, a journey of valleys and hills, including tough as well as inspiring moments, and I am sincerely indebted to them.

My deepest gratitude is owed to my supervisor René Kemp. I am grateful for your taking on this project as my mentor from the very first day when I was searching for a supervisor for this project. I am indebted to you for tremendous inputs and guidance as well as constructive criticism and immense support. It has been an enormous, invaluable opportunity for me to collaborate with you and having you as my guide and supervisor. Your confidence in my academic work has been crucial for this success.

I am grateful and owe a very special thanks to my co-promoter Manfred Wiebelt. You were a great motivator and collaborator. Your incredible patience and oversight provided a strong and indispensable enabling environment.

Accomplishing the different chapters would have not been possible without the various, incredible and central contributions by Gernot Klepper (IfW), Alvaro Calzadilla (IfW), Clemens Breisinger (IFPRI) and Perrihan Al-Riffai (IFPRI). The great support of Serdar Türkeli (UNU-MERIT), Jacinta Ndichu (UNU-MERIT), John Adeoti (NISER) and Abiodun Elijah Obayelu (FUNAAB) is very much appreciated.

Thank you very much, Annet Grol, for your marvellous assistance and devotion at ICIS. The support you give at all times is hugely appreciated. Your attitude is always very welcoming and comforting.

I am very thankful for the support of my family. My father Robert, my mother Susanne and my brothers Andreas and Christoph as well as my dear Stella always believed in me. 
CHAPTER 12

About the author 
Julian Blohmke was born in Munich, Germany on 24 October 1982. He studied law at Universität Hamburg, specialising in public international and European law, and obtained a Bachelor of Laws degree (LL.B.) in 2006. In parallel, he studied economics and graduated as Diplomvolkswirt from Universität Hamburg in 2008.

Afterwards, he was a research assistant at the Kiel Institute for the World Economy (IfW Kiel), where he conducted research in the area of natural resource management and socio-economic development with a focus on sustainable aquaculture. Subsequently, between 2010 and 2014 he worked in the area of renewable energy technology deployment in the Middle East and North Africa (MENA) region for a multinational industry consortium. The goal was to set up technology deployment strategies for renewable energy technology projects and facilitate cross-border electricity trade across the Mediterranean basin. Besides renewable energy technology he has been working in the area of bio-based chemical technology development and its global deployment. He also spent time working as a short-term consultant for the World Bank in 2010, as a researcher in the research project "Diffusion Strategy of Green Technology and Green Industry in Africa" led by UNU-MERIT and UNIDO and as a renewable energy expert consultant for the African Development Bank in the Scaling-up Renewable Energy Program in Africa. In 2015, he consulted the Ellen MacArthur Foundation and the World Economic Forum in the Project MainStream on closing the loop in plastic recycling and circular economy aspects, focusing on bio-based polymers.

In 2011, he started as a PhD researcher in the PhD Programme in Sustainability Science and Policy (SSP) at the International Centre for Integrated assessment and Sustainable development (ICIS), Faculty of Humanities and Sciences of Maastricht University, a research institute that focuses on interdisciplinary and applied research related to sustainability and integrated assessment of sustainable development. 
